\title{
Isolation and Characterization of Proteins Interacting with Tobacco Transcription Factor TGA2.2
}

\author{
Dissertation \\ zur Erlangung des Doktorgrades der Mathematisch-Naturwissenschaftlichen Fakultäten \\ der Georg-August-Universität zu Göttingen \\ vorgelegt von \\ Ayed Mrief Ayed Al-Abdallat \\ aus Amman, Jordanian
}

Göttingen, 2004 
D7

Referent: Prof. Dr. C. Gatz Korreferent: Prof. Dr. I. Feußner

Tag der mündlichen Prüfung: 


\title{
Isolation and Characterization of Proteins Interacting with Tobacco Transcription Factor TGA2.2
}

\author{
Dissertation \\ Submitted for the acquisition of Doctorate degree in Plant Sciences \\ Albrecht von-Haller Institute for Plant Sciences \\ School of Natural Sciences and Mathematics \\ George August University \\ Göttingen, Germany
}

by Ayed Mrief Ayed Al-Abdallat from Amman, Jordan

Göttingen, 2004 
In the name of Allah, the Compassionate, the Merciful

They are asking you concerning the Spirit. Say: The Spirit is by command of my Lord, and you are not given aught of knowledge but a little. 


\section{Table of Contents}

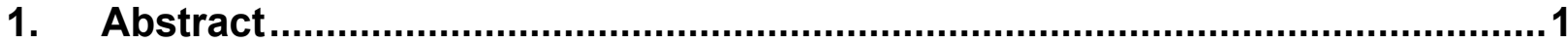

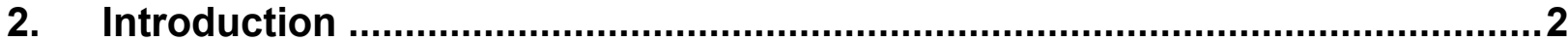

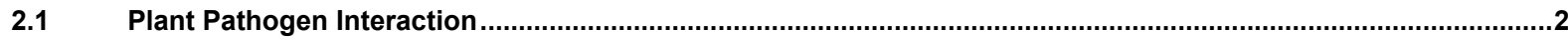

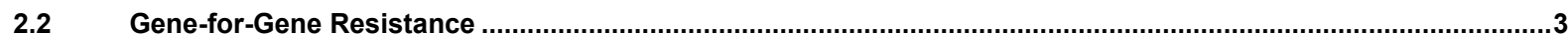

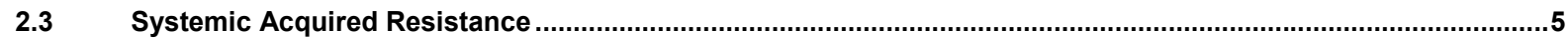

$2.4 \quad$ Other Forms of Plant Resistance

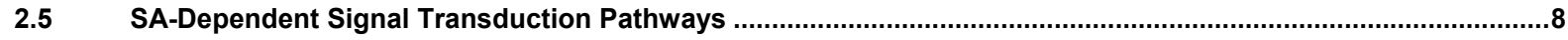

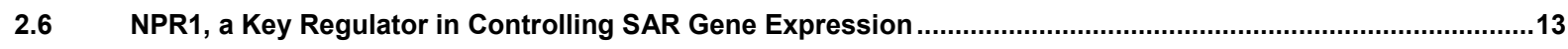

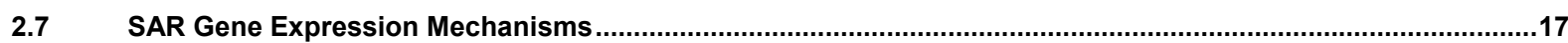

2.8 The As-1 Element and TGA Transcription Factors Regulate SA Mediated Gene Activation ............................18

2.9 Interaction between NPR1 and TGA Transcription Factors Leads to SA-Mediated Gene Activation .................24

2.10 Yeast Hybrid Systems as a Tool to Study Protein Interactions .........................................................................27

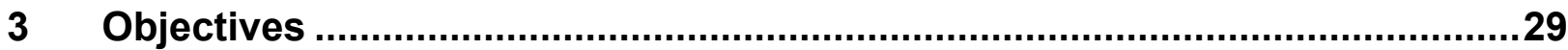

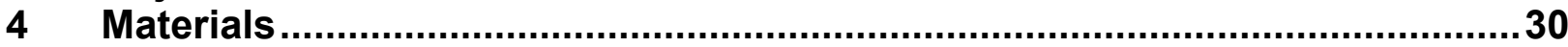

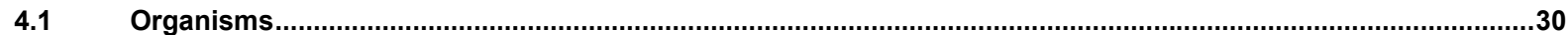

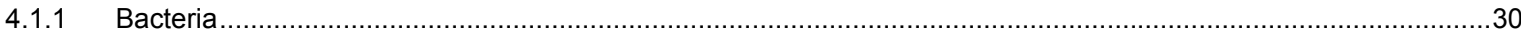

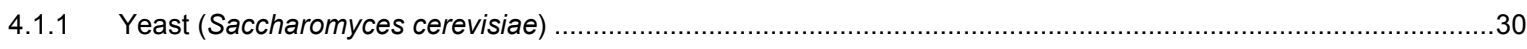

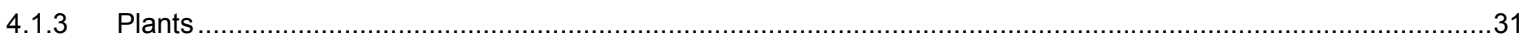

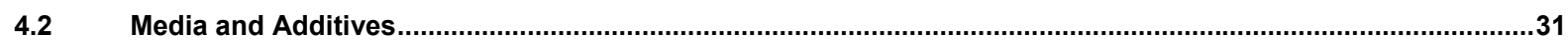

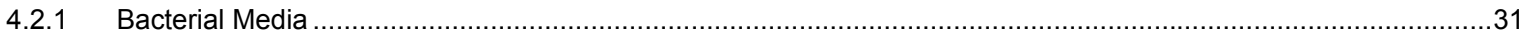

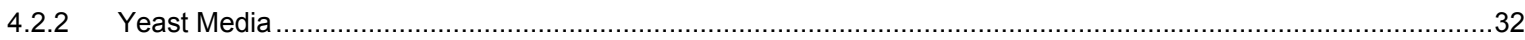

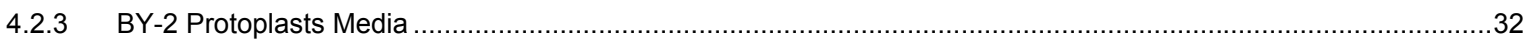

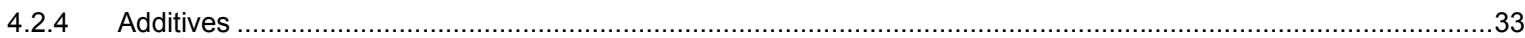

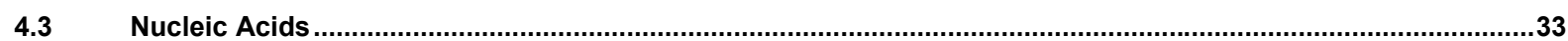

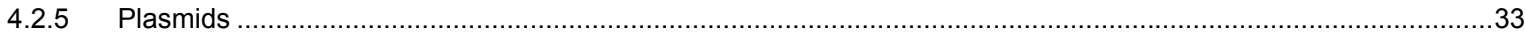

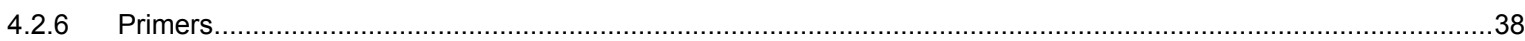

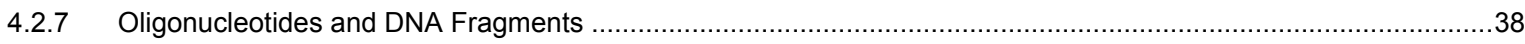

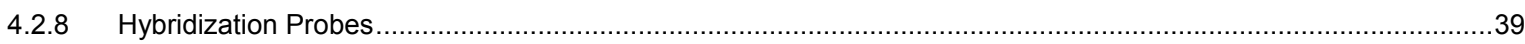

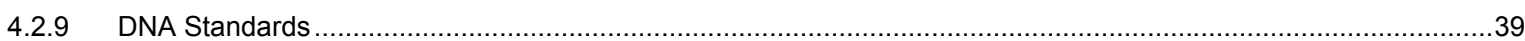

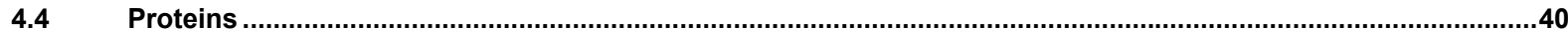

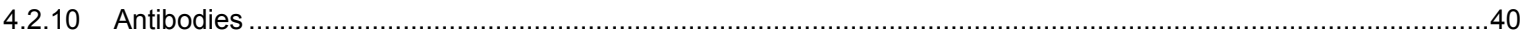

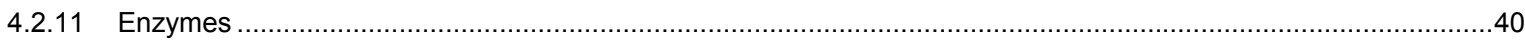

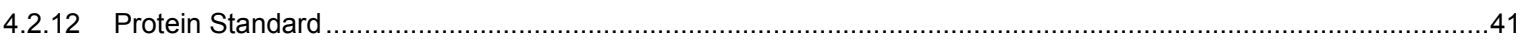

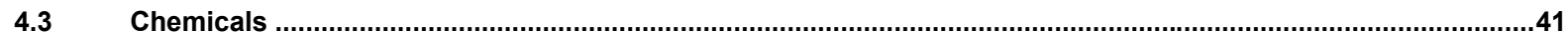

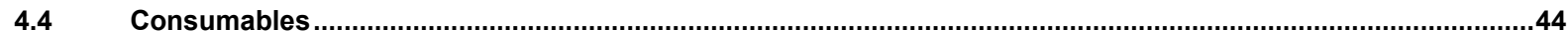

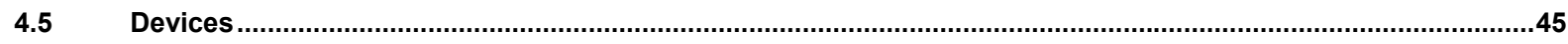

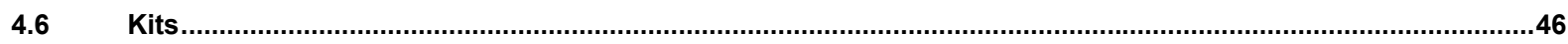

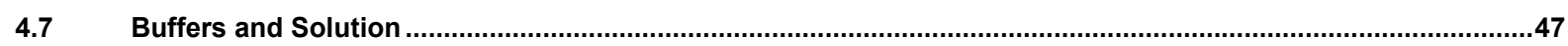

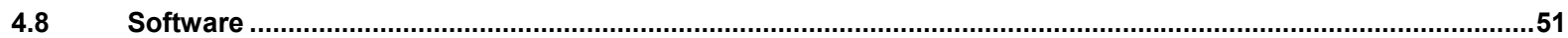

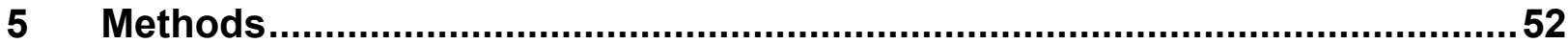

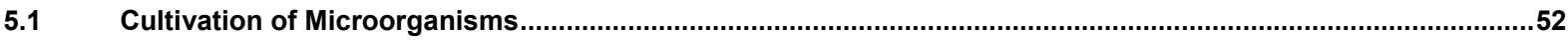

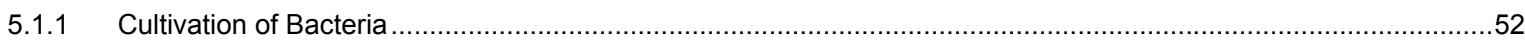

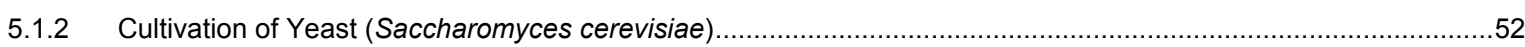

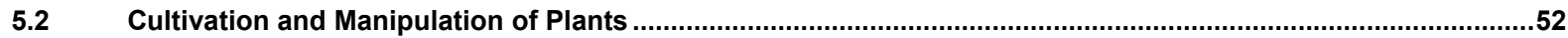

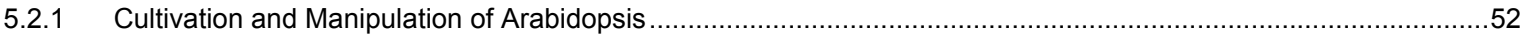




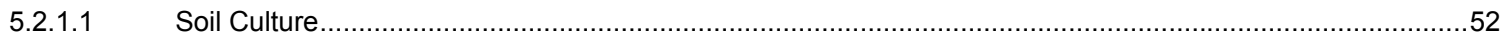

5.2.1.2 The Agrobacterium tumefaciens-Mediated Transformation of Arabidopsis ..............................................53

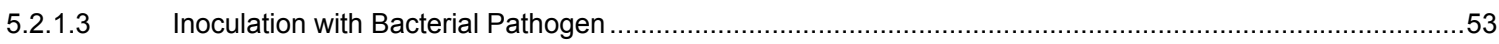

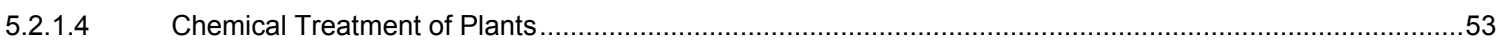

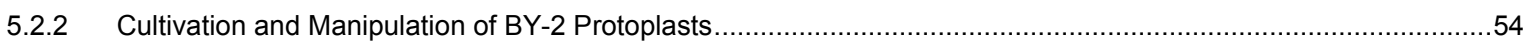

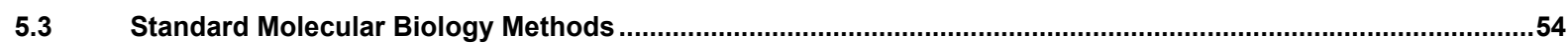

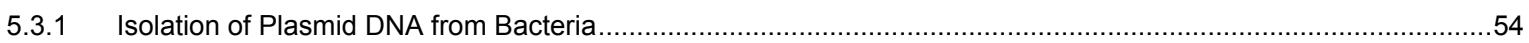

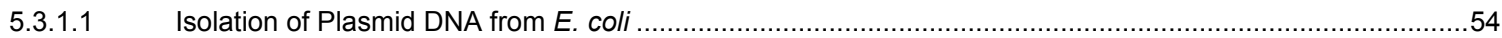

5.3.1.2 Large-scale Preparation of pGAD424/N.t cDNA library Plasmid DNA from E. coli...................................55

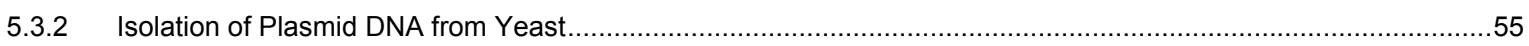

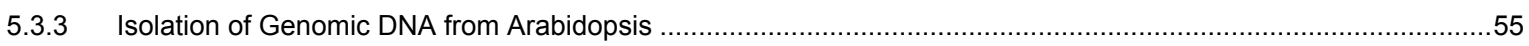

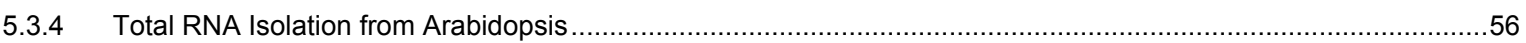

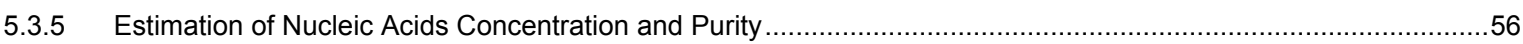

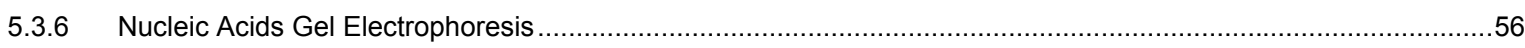

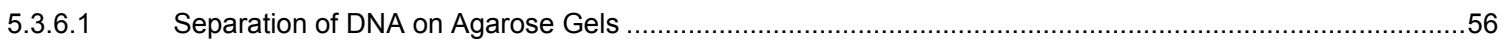

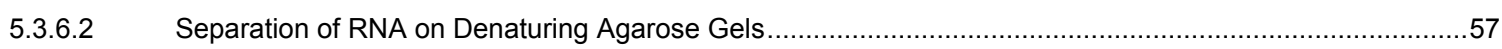

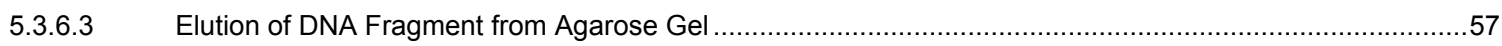

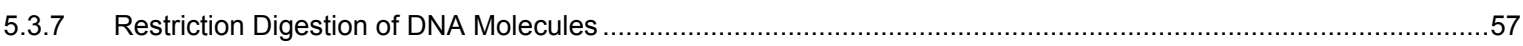

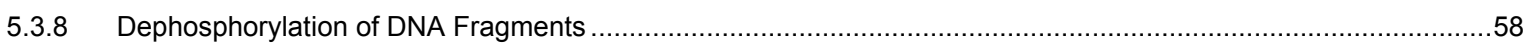

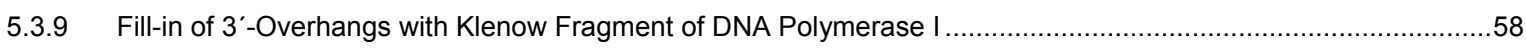

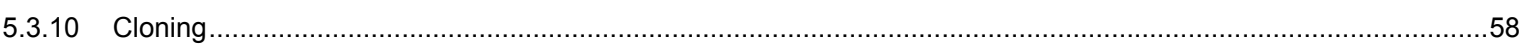

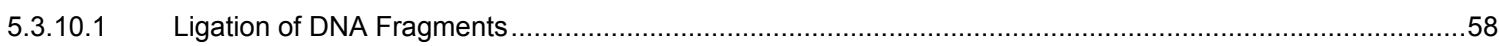

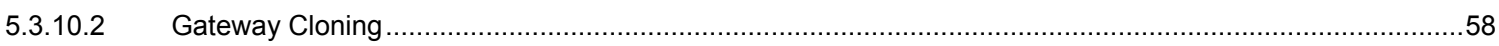

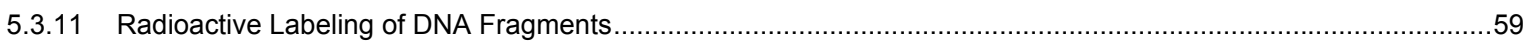

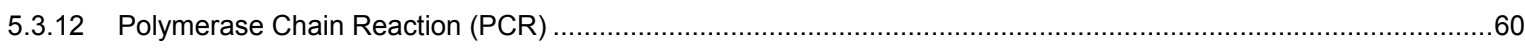

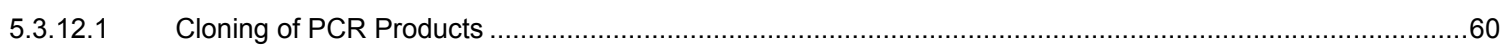

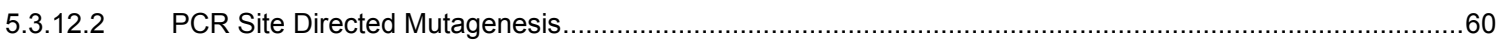

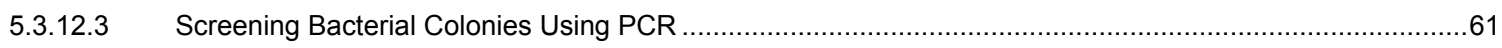

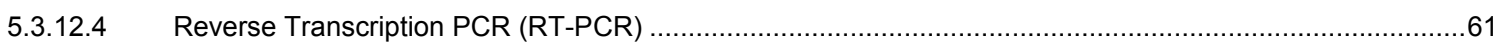

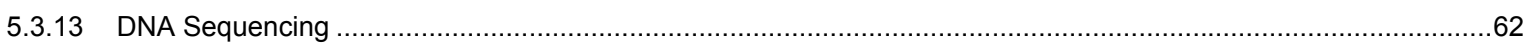

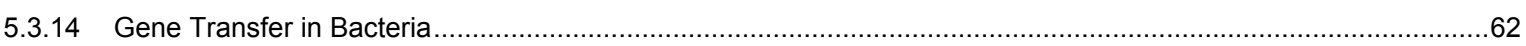

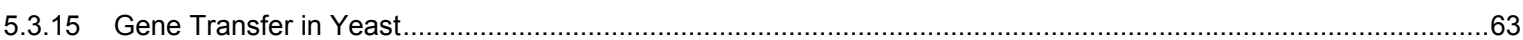

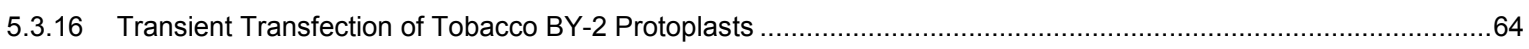

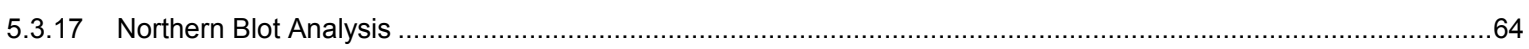

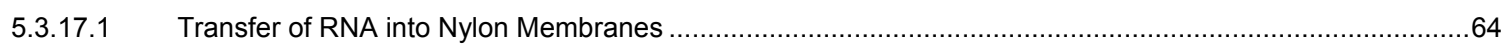

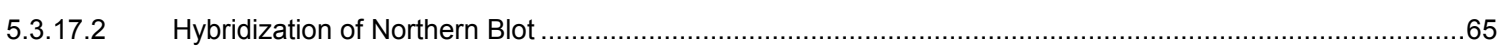

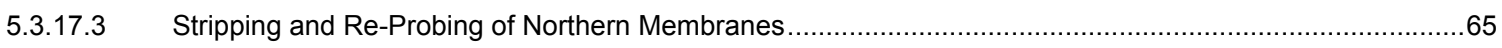

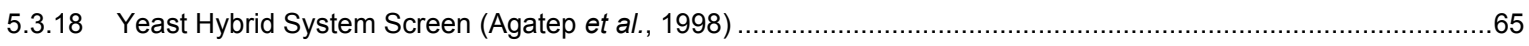

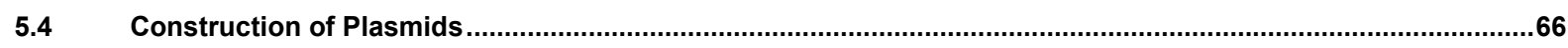

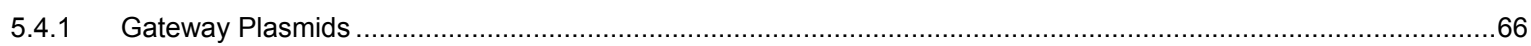

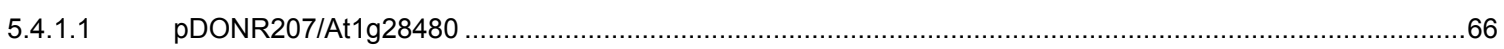

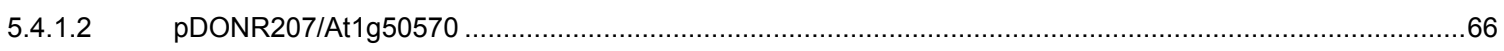

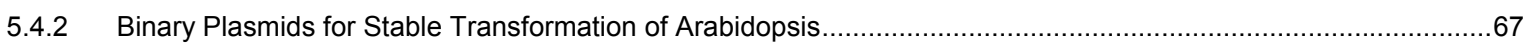

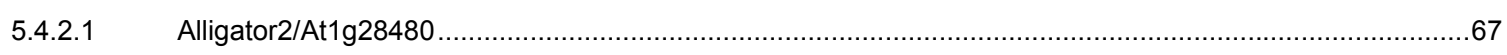

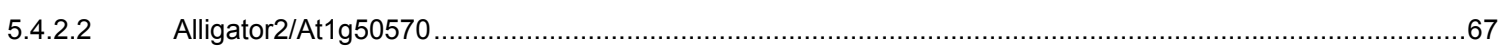

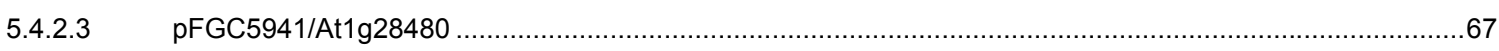

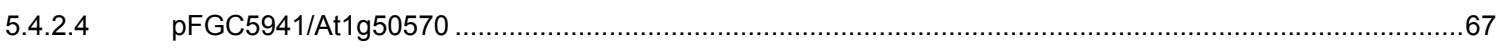




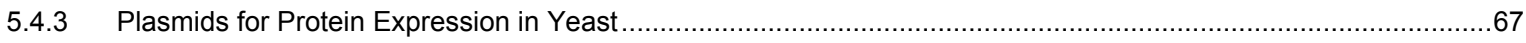

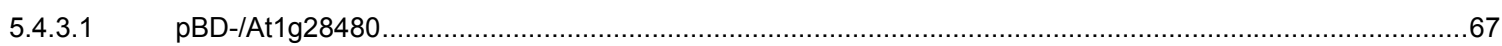

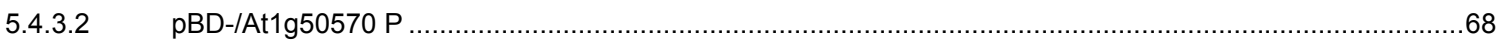

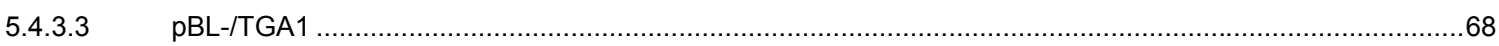

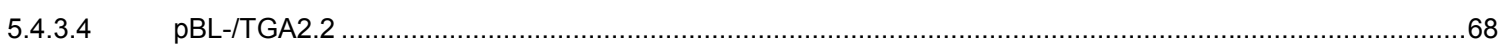

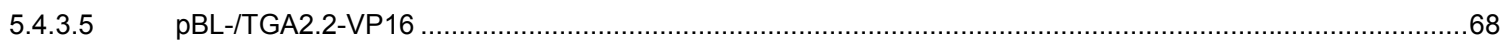

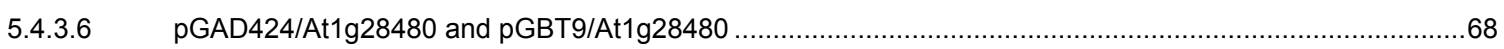

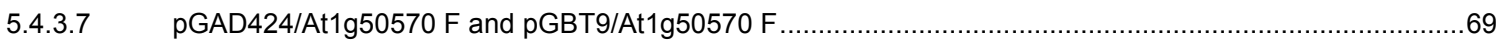

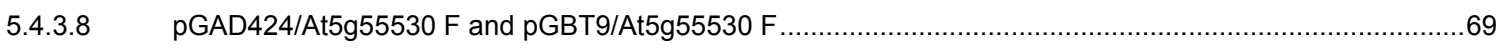

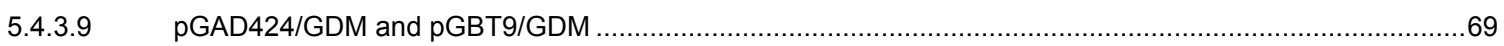

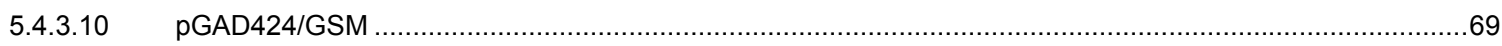

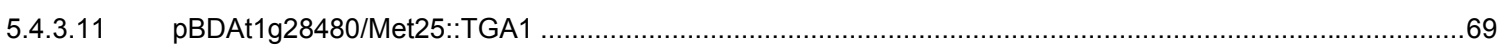

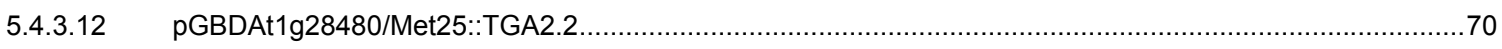

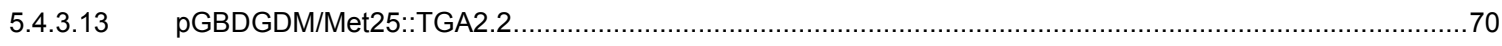

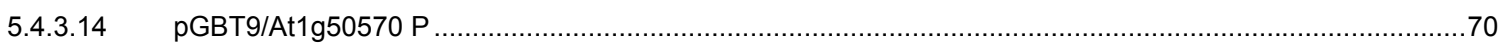

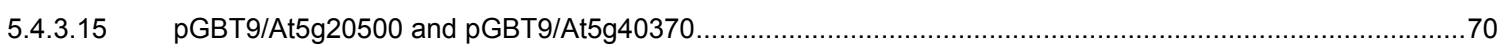

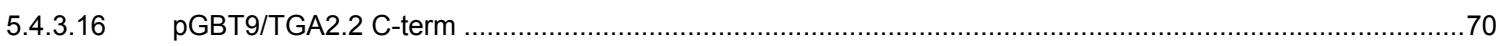

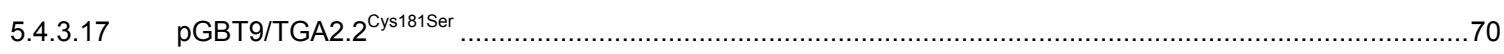

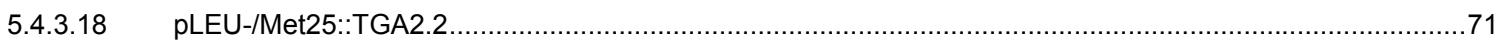

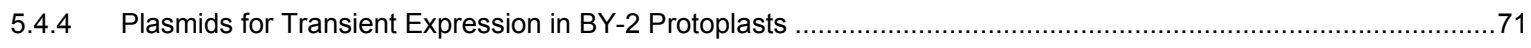

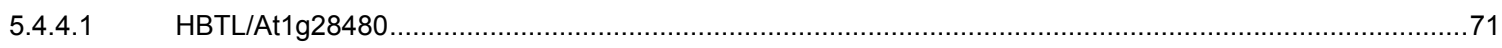

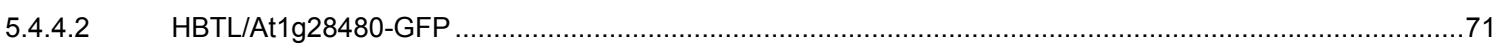

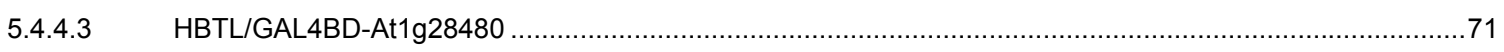

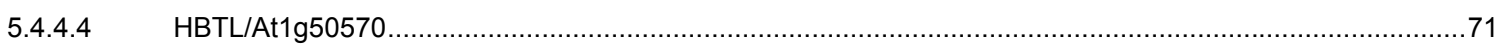

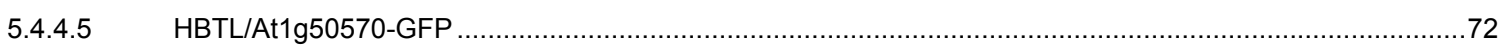

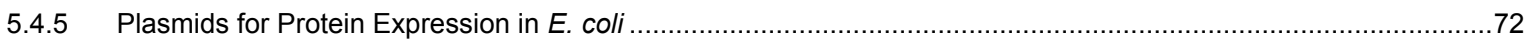

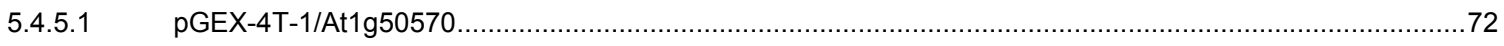

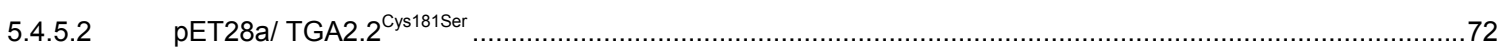

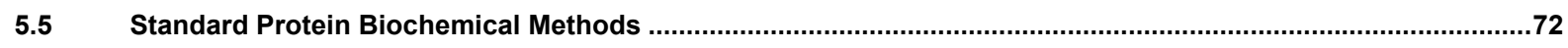

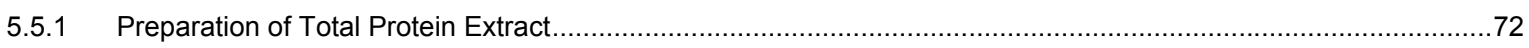

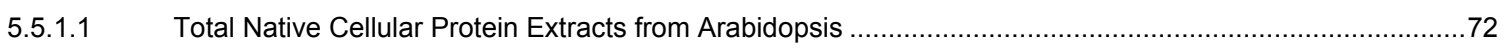

5.5.1.2 Total Native Cellular Protein Extracts from BY-2 Protoplasts .............................................................72

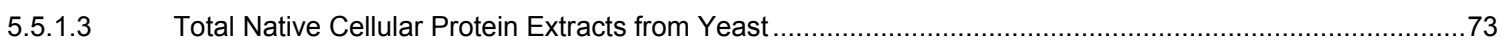

5.5.1.4 Total Denatured Cellular Protein Extracts from Arabidopsis...............................................................73

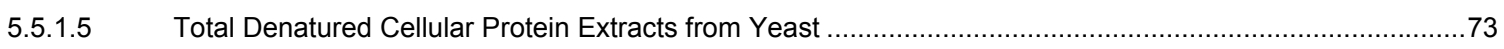

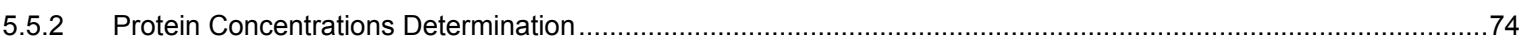

5.5.3 Expression and Purification of Recombinant Proteins in E. coli ....................................................................74

5.5.3.1 Expression and Purification of Recombinant GST Fusion Proteins in E. coli .........................................74

5.5.3.1.1 Screening Recombinants for GST-Fusion Protein Expression in E. coli ..............................................74

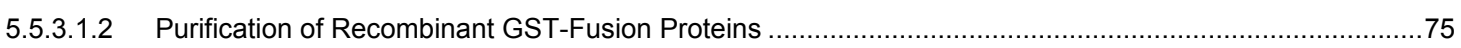

5.5.3.2 Expression and Purification of Recombinant 6x His Fusion Proteins in E. coli...........................................75

5.5.3.2.1 Screening Recombinants for 6x His-Fusion Protein Expression in E. coli..............................................75

5.5.3.2.2 Purification of Recombinant 6x His-Fusion Proteins.............................................................................. 76

5.5.4 Denaturing SDS-Polyacrylamide Gel Electrophoresis (SDS-PAGE) ..........................................................

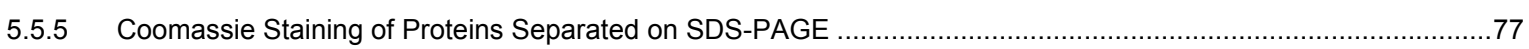

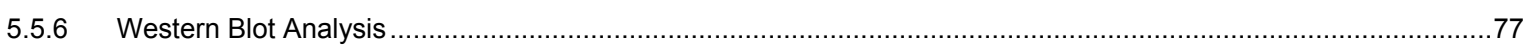

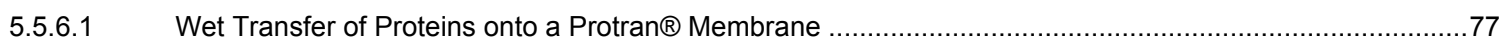


5.5.6.2 Immuno-detection of the Proteins with Specific Antibodies ............................................................

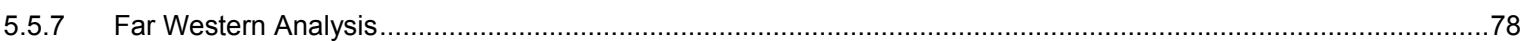

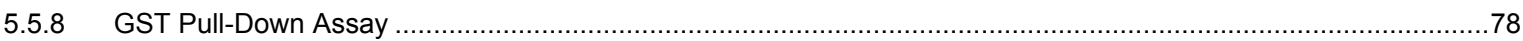

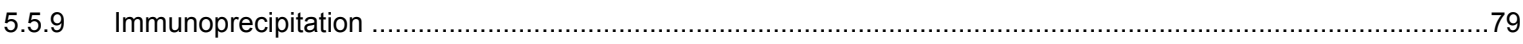

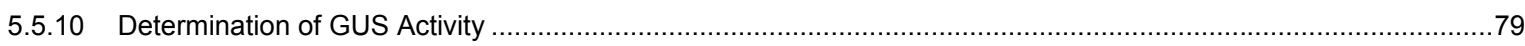

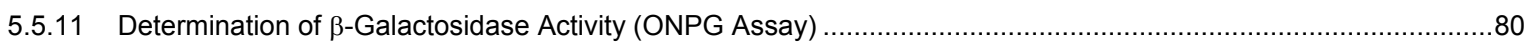

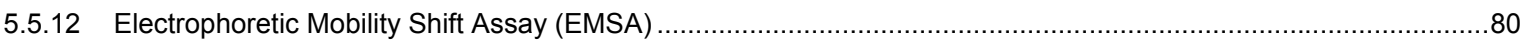

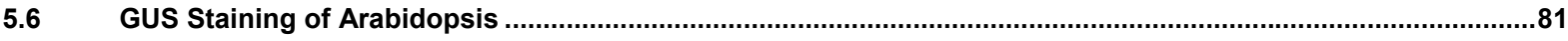

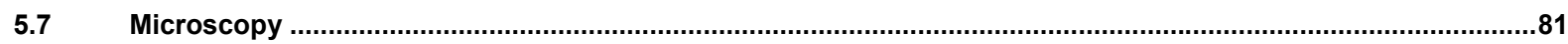

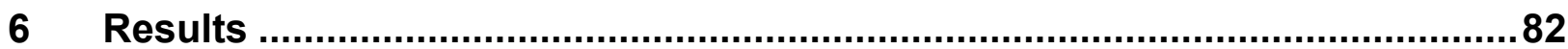

6.1 Establishing the Modified Yeast-One Hybrid System ..........................................................................82

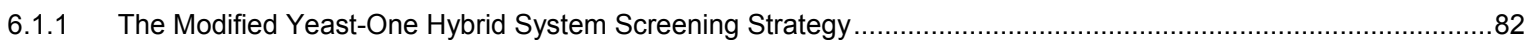

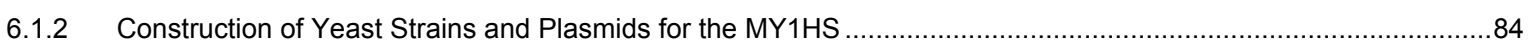

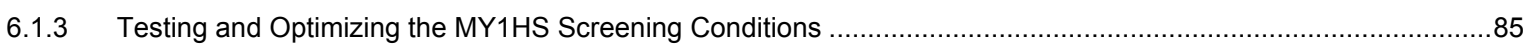

6.2 Isolation of cDNAs Encoding As-1 Binding and TGA2.2-Interacting Proteins Using the MY1HS .....................88

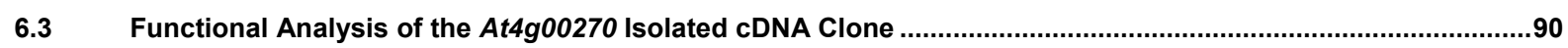

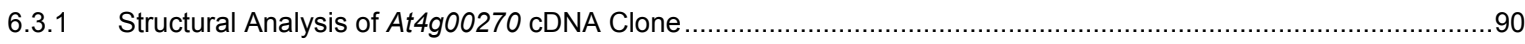

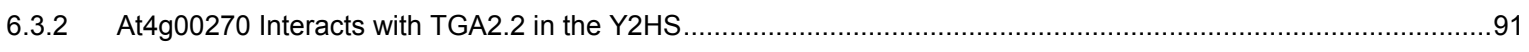

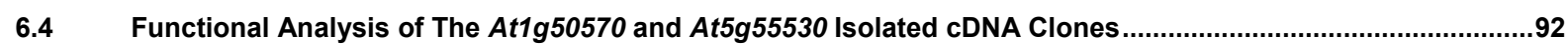

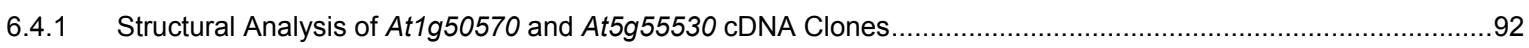

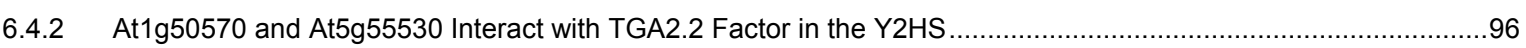

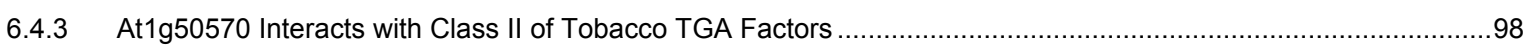

6.4.4 Function of At1g50570 and At5g55530 as Transcription Activators in Yeast................................................99

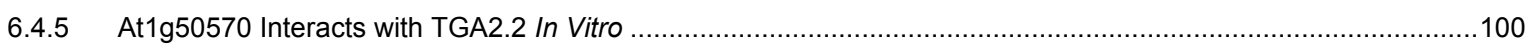

6.4.5.1 GST Pull-down Analysis of At1g50570 and TGA2.2 Interaction ......................................................101

6.4.5.2 Far Western Analysis of At1g50570 and TGA2.2 Interaction ........................................................102

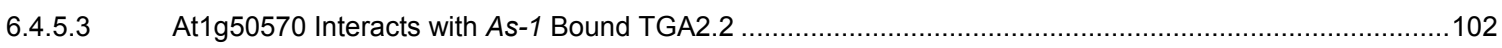

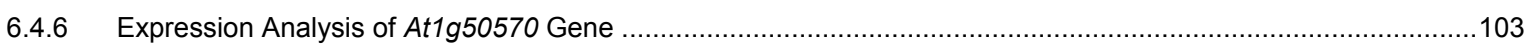

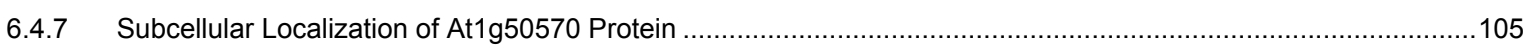

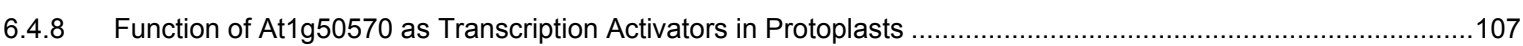

6.4.9 Analysis of the In Vivo Roles of At1g50570 by Generation of At1g50570 Antisense Lines ..............................110

6.4.10 Analysis of the In Vivo Roles of At1g50570 by Generation of At1g50570 Overexpression Lines .......................112

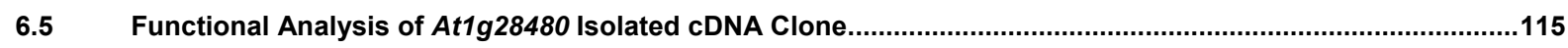

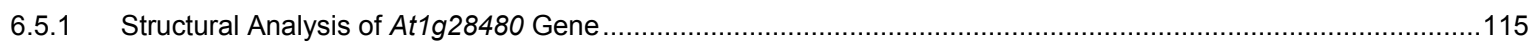

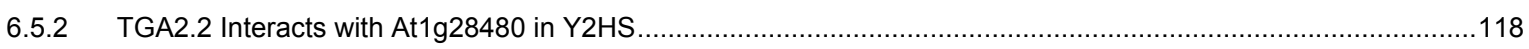

6.5.3 At1g28480 Interacts with All Identified Members of Tobacco TGA Factors ..................................................119

6.5.4 Generation of At1g28480 and TGA2.2 Mutants by Site-directed Mutagenesis ..............................................120

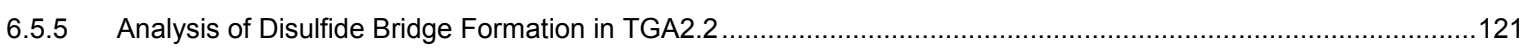

6.5.6 The Interactions of TGA2.2 and At1g28480 Mutants in Yeast ............................................................... 122

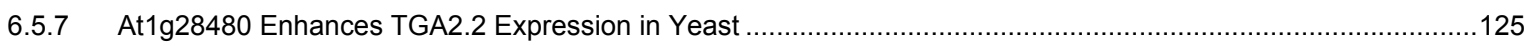

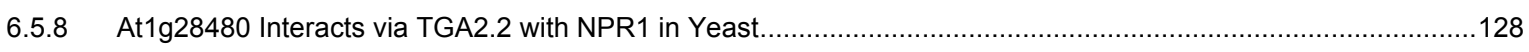

6.5.9 At1g28480 Transactivation Assays in Protoplasts............................................................................... 130

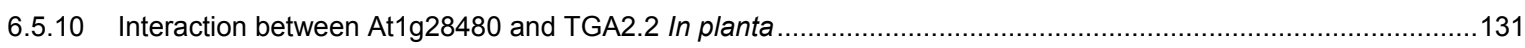

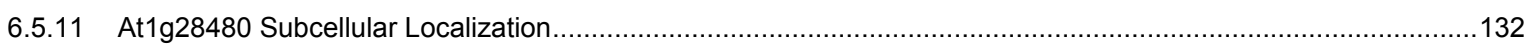

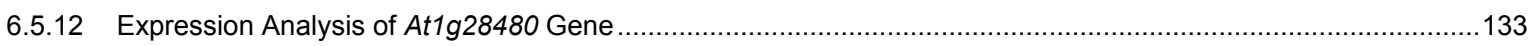

6.5.13 Analysis of the In Vivo Roles of At1g28480 by Generation of At1g28480 Antisense Lines ...............................134

6.5.14 Analysis of the In Vivo Roles of At1g28480 by Generation of At1g28480 Overexpressor lines.........................136 


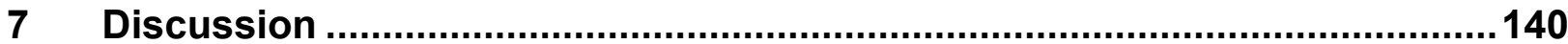

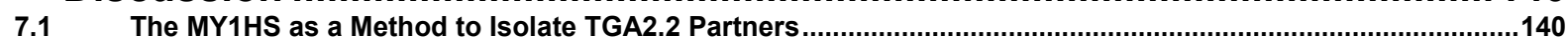

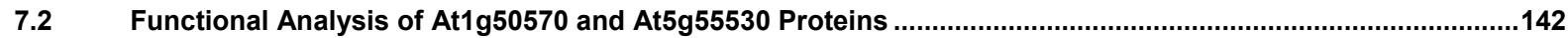

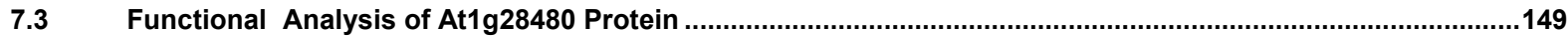

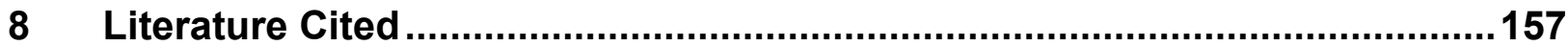

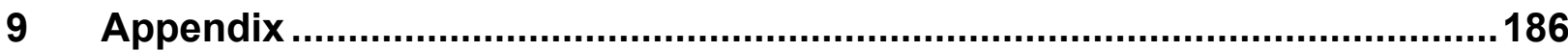

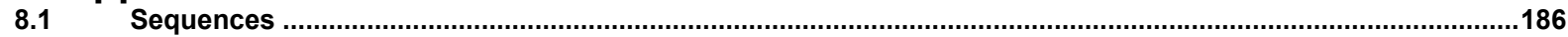

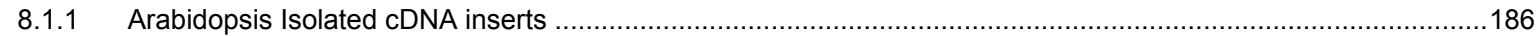

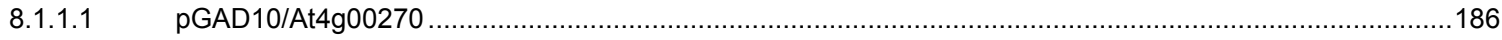

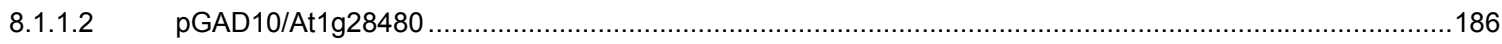

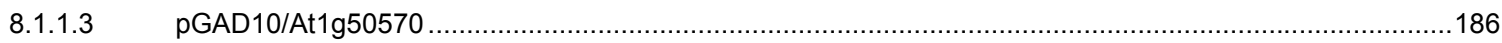

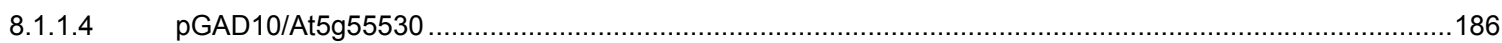

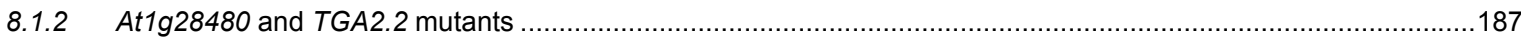

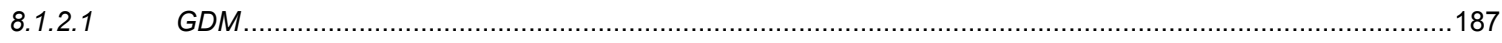

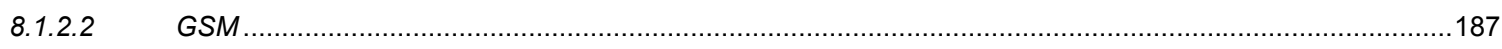

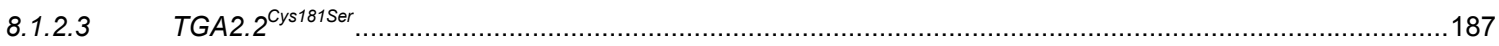

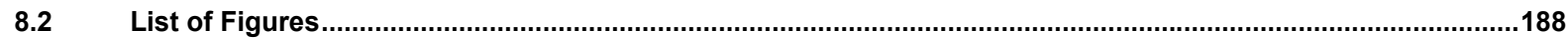

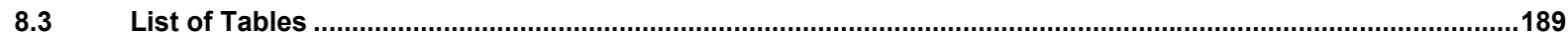

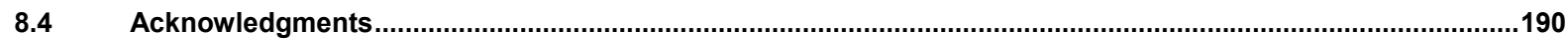

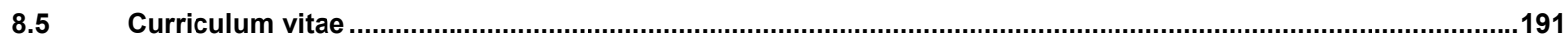




\section{Abstract}

In plants, the as-1 cis-element and its trans-acting factors, known as TGA transcription factors, play an important role in the transcriptional control of salicylic acid- and auxin-inducible gene expression. Previous experiments have established that TGA2.2 is the major component of the nuclear as-1-binding factor (ASF1) and cellular salicylic acid response protein (SARP) that bind to the as-1 element. Using TGA2.2 as bait in a modified yeast hybrid screen, several cDNA TGA2.2-interacting proteins were isolated.

TGA2.2 interacts specifically in yeast and in vitro with two closely related proteins, At1g50570 and At5g55530 that contain a C2 domain in their amino acid sequences. At1g50570 interacts with class-II members of tobacco TGA factors. The At1g50570 and At5g55530 proteins function as transcriptional activators in yeast. At1g50570 protein activated the transcription of the $\beta$-glucuronidase reporter gene driven by the as-1 element in BY-2 protoplasts. At1g50570-green fluorescent protein fusion protein localized mainly to the nuclear envelope and endoplasmic reticulum in BY-2 protoplasts. Expression of the At1g50570 gene was induced in response to pathogen infection. Overexpression or repression of the At1g50570 gene in transgenic Arabidopsis plants did not alter the expression of the $P R-1$ gene under unstressed or salicylic acid -induced conditions. The role of At1g50570-TGA2.2 interaction in as-1-mediated gene activation has yet to be examined.

TGA2.2 interacts specifically with At1g28480, a glutaredoxin protein, which is known to catalyze reductions of disulfides. At1g28480 interacts specifically with all identified members of the tobacco TGA transcription factors. The At1g28480-TGA2.2 interaction was neither affected by oxidative stress conditions nor by site-directed mutagenesis of the TGA2.2 and At1g28480 encoded conserved cysteine residues. At1g28480 enhances indirectly the TGA2.2 dimerization and in vitro DNA binding activity by increasing steady state TGA2.2 protein levels in yeast. The interaction between At1g28480 and TGA2.2 was confirmed in planta by a protoplast two-hybrid system. In addition, At1g28480 interacts via TGA2.2 with NPR1, a key regulator of systemic acquired resistance, in a yeast three-hybrid system. The At1g28480 gene is expressed in Arabidopsis plants in response to SA and pathogen infection. Overexpression or repression of the At1g28480 gene in transgenic Arabidopsis plants did not alter the salicylic acid-inducible gene expression. In contrast, overexpression of the At1g28480 repressed the auxin-induced expression of an as-1::GUS reporter construct in Arabidopsis transgenic plants. These results indicate that At1g28480 protein might function in signal transduction pathways involving TGA transcription factors. 


\section{Introduction}

\subsection{Plant Pathogen Interaction}

During their life span, plants encounter unusual or adverse conditions that have a significant impact on their physiology and development. For instance, plants are constantly exposed to many enemies such as pathogenic microorganisms including fungi, bacteria, nematodes and viruses. Successful pathogen invasion ensues from the disability of the plant to recognize the pathogen. Alternatively, the activated defense mechanism might be ineffective or pathogen virulence factors might suppress host defenses (Hammond-Kosack and Jones, 1996).

When a pathogen invades a host plant there are three main strategies to attack: necrotrophy, biotrophy, or hemibiotrophy (Hammond-Kosack and Jones, 1997). Necrotrophic pathogens have a broad host range and are characterized by killing the host cells first before metabolizing their contents. The biotrophic have a narrow host range and they invade living organisms and exploit their metabolism without killing them. A hemibiotrophic pathogen acts similarly as a biotrophic pathogen but its invasion will lead eventually to host cell death. When a pathogen successfully invades the host and causes disease, the pathogen is said to be virulent, the host to be susceptible and the interaction to be compatible (Glazebrook et al., 1997a). In the contrary, if the host responds by activating defense responses that suppress pathogen colonization, the pathogen is said to be avirulent, the host is resistant and the interaction is incompatible.

Plants show resistance to most pathogens. This phenomenon of general resistance is due to a constitutive arsenal of powerful weapons that can be used against pathogen invasions in a nonspecific manner (Ryals et al., 1996). Plants show other types of resistances, which are inducible (Bent, 1996). For instance, the inducible pathogen resistance, known as race or cultivar specific resistance, is activated upon the recognition of a specific pathogen by the host. 


\subsection{Gene-for-Gene Resistance}

Harold Flor, working with flax and flax rust fungus, proposed a genetic definition for the plant pathogen interactions, known as the gene-for-gene hypothesis (Flor, 1971). Flor postulated that the host resistance occurs, when a particular avirulence gene (Avr gene) product carried by a pathogen is recognized by a particular host resistance gene ( $R$ gene) product, i.e., $R$ gene confers resistance (incompatibility) only against pathogens carrying a correspondent Avr gene and as a consequence the race specific resistance is deployed (Table 2.1; Bent, 1996).

Table 2.1. Types of plant and pathogen genetic interactions in the gene for gene resistance.

\begin{tabular}{cccc} 
& \multicolumn{2}{c}{ Host plant genotype } \\
\cline { 3 - 4 } Pathogen genotype & Avr & Incompatible & \multicolumn{2}{c}{ Compatible } \\
\cline { 2 - 4 } & avr & Compatible & Compatible
\end{tabular}

Several plant $R$ genes have been isolated and were categorized upon their structural motifs into five different classes: class I- intracellular proteins with a nucleotide-binding site (NBS), a leucine-zipper motif and a leucine-rich repeat (LRR) domain and a coiled-coil (CC) domain, class II- intracellular NBS-LRR proteins with a region of similarity to the cytoplasmic domain of mammalian IL-1 receptor and the Drosophila Toll proteins (TIR domain), class III- intracellular protein kinases, class IVproteins with an LRR domain that encodes membrane-bound extracellular proteins and class $\mathrm{V}$ receptor-like kinases with an extracellular LRR domain (Dangl and Jones, 2001; Martin, 1999; Martin et al., 2003; McDowell and Woffenden 2003). The model plant Arabidopsis genome contains around $200 R$ genes that encode proteins with similarity to the nucleotide-binding site and other domains characteristic of many identified plant resistance proteins (Meyers et al., 2003).

The pathogen Avr genes are only present in certain strains of a given pathogen and show little similarity to each other (although myristoylation encoding sites is a 
common motif found in many Avr proteins). In additional to their role as avirulence factors, they are beneficial for the pathogen through their interaction with host virulence targets that are involved in metabolism or in plant defense (Bonas and van den Ackerveken, 1999; Luderer and Joosten, 2001).

The incompatible interaction between the host and pathogen triggers a series of defense responses at the site of infection that includes synthesis of antmicrobial compounds (such as glutathione S-transferases (GSTs), phytoalexins and pathogenesis related (PR) proteins), programmed cell death, production of reactive oxygen species (ROS; Reviewed in: Abel and Hirt, 2004; Lamb and Dixon, 1997), ion fluxes, cell wall fortification, activation of protein kinases and the accumulation of signaling molecules such as salicylic acid (SA), jasmonic acid (JA), ethylene and nitric oxide (Bent, 1996; Cohn et al., 2001; Hammond-Kosack and Jones, 1996).

Gene-for-gene mediated resistance against avirulent necrotizing pathogens triggers a localized programmed cell death around the infection site, a phenomenon known as the Hypersensitive Response (HR) (Figure 2.1; Heath, 2000; Lam et al., 2001; Lamb and Dixon 1997). The HR results in the production of ROS and the formation of lesions around the infection site, which will restrict the spreading of the pathogen into the surrounding tissue.

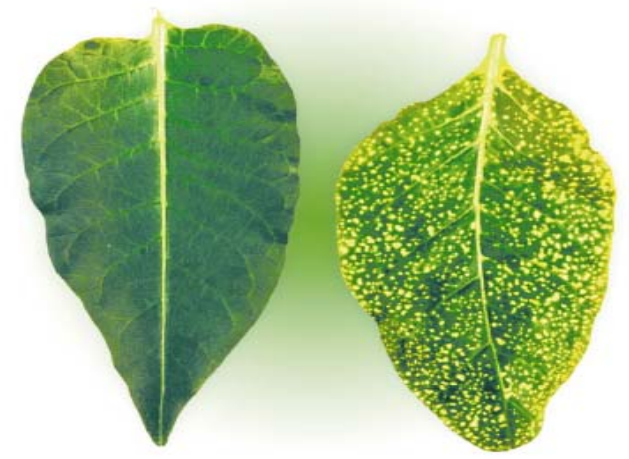

Figure 2.1. A classic HR from tobacco in response to tobacco music virus infection (Lam et al., 2001). 


\subsection{Systemic Acquired Resistance}

Concomitant with the appearance of the HR, an inducible long lasting resistance appears systemically. This resistance, known as the systemic acquired resistance (SAR), is directed to a broad spectrum of different pathogens and is characterized by a reduction in disease symptoms after subsequent pathogen infections (Reviewed in: Durrant and Dong 2004; Ryals et al., 1996; Sticher et al., 1997). The SAR is associated with the local and systemic accumulation of PR proteins and has been well characterized in different plant species (Sticher et al., 1997).

It was postulated that a systemic signal produced at the infection site is translocated to the uninfected tissues (Ross, 1966). White (1979) showed that tobacco treatment with acetyl salicylic acid (aspirin) induced the accumulation of PR proteins and decreased disease symptom development. Van Loon (1983) found that SAR is induced by the synthesis of plant secondary metabolites such as 2,6-dihydroxybenzoic acid, which mimics the action of SA. In support of these findings, increased SA levels were observed in the phloem of tobacco mosaic virus (TMV)-infected tobacco and tobacco necrosis virus infected cucumber plants (Malamy et al., 1990; Métraux et al., 1990). These findings led to the suggestion that SA might be the systemic signal involved in SAR.

Conclusively, the importance of SA in SAR was further documented using Arabidopsis and tobacco transgenic plants expressing the $N a h G$ gene that encodes a Pseudomonas putida salicylate hydroxylase enzyme that converts SA to catechol (Gaffney et al., 1993; Delaney et al., 1994). In NahG plants, SA accumulation is reduced and a subsequent breakdown in SAR occurs. However, recent genetic analysis of Arabidopsis NahG plants demonstrated that the SAR breakdown is not only related to the absence of $S A$, but the NahG expression and the resulting levels of catechol have also a pleotrophic effect on the plant defense response (Heck et al., 2003; van Wees et al., 2003). Based on these observations, many of the results based solely on phenotypes of NahG plants remain to be reconciled. 
SA synthesis in planta is proposed to be as a product of the phenylpropanoid metabolism pathway via the decarboxylation of trans-cinnamic acid to benzoic acid and its subsequent 2-hydroxylation to SA (Figure 2.2; Lee et al., 1995; Shah 2003). In some bacteria species, SA is synthesized from chorismate via isochorismate through two important enzymes: the isochorismate synthase (ICS) and isochorismate pyruvate lyase (IPL) (Serino et al., 1995). Recent studies have shown that the expression of the bacteria ICS and IPL lyase enzymes in plants led to enhanced SA accumulation and conferred disease resistance against pathogens (Mauch et al., 2001; Verberne et al., 2000). Functional analysis of an Arabidopsis gene encoding an ICS revealed that SA is synthesized through the isochorismate pathway in the chloroplast compartment (Figure 2.2; Wildermuth et al., 2001).

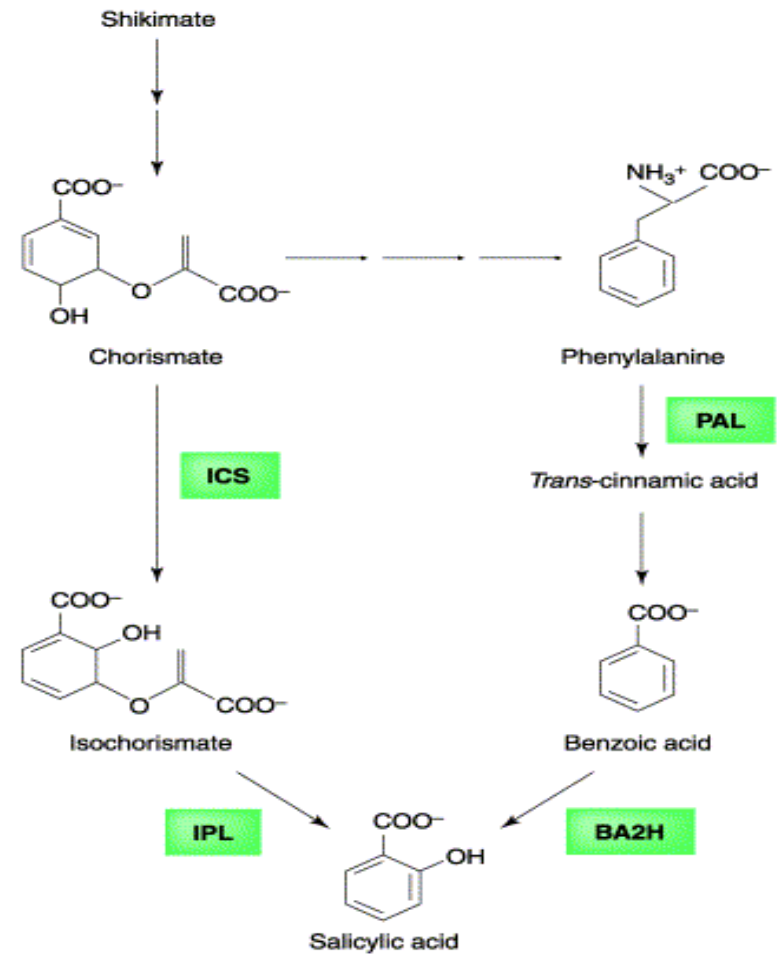

Figure 2.2. Proposed SA biosynthetic pathways in plants (Shah 2003).

Abbreviations: ICS, isochorismate synthase; PAL, phenylalanine ammonia-lyase; $\mathrm{BA} 2 \mathrm{H}$, benzoic acid-2 hydroxylase; IPL, isochorismate pyruvate lyase. 
However, some studies had suggested that SA is not the primary mobile signal. For instance, grafting experiments using transgenic tobacco plants expressing the NahG gene showed that the NahG tobacco rootstocks were capable of delivering a signal that make nontransgenic scions resistant to further pathogen infection (Vernooij et al., 1994). In contrast, other experiments with labeled SA showed that SA was originally synthesized in and exported from the infected leaf (Mölders et al., 1996; Shulaev et al., 1995).

The molecular markers for SAR, the PR genes, were first described in tobacco leaves infected with TMV and were classified as basic or acidic PR forms (Ryals et al., 1996; Ward et al., 1991). An abbreviated definition of PR proteins is: a group of proteins detected and defined as being absent in healthy plants but accumulating in large amounts after pathogen infection (van Loon and van Kammen, 1970). The $P R$ genes are found in different plant species and several cloned genes such as $P R-1, \beta-1,3-$ glucanases (PR-2), chitinasases (PR-3), PR-4 and osmotin (PR-5) showed in vitro antmicrobial activities (Sticher et al., 1997; van Loon and van Strien, 1999). SA induces the expression of many $P R$ genes, for instance, exogenous application of SA or its analogs such as 2,6-dichloroisonicotinic acid (INA) or benzo(I,2,3)thiadiazole-7carbothioic acid S-methyl ester (BTH) induced the expression of many $P R$ genes (Friedrich et al., 1996; Vernooij et al., 1995; Ward et al., 1991).

\subsection{Other Forms of Plant Resistance}

In addition to gene-for-gene resistance and SAR, other plant responses against pathogens were identified. The wound response, which mediates resistance against insect feeding, plays an important role in plant defense against specific fungal pathogens (Diaz et al., 2002; Vijayan et al., 1998). The wound response requires JA and ethylene as signaling molecules and both molecules work synergistically on the induction of many plant resistance genes including the basic form of $P R-1$, osmotin, thionin2.1 and plant defensin1.2 (PDF1.2) (Penninckx et al., 1998; Xu et al., 1994). The PDF1.2 gene from Arabidopsis, which encodes a protein with demonstrated antifungal 
activity, is induced strongly by either pathogen challenge or JA but not by SA (Penninckx et al., 1996).

Nitric oxide, which acts as a signaling molecule in the animal immune responses, exerts signaling properties that regulate the activation of plant defense responses after pathogen attacks (Delledonne et al., 1998; Klessig et al., 2000; Chandok et al., 2003). Nitric oxide induces hypersensitive cell death in soybean and moreover, inhibitors of nitric oxide synthesis compromise Arabidopsis disease resistance against Pseudomonas syringae ( $P$. syringae), promoting disease and bacterial growth (Delledonne et al., 1998).

Another form of plant inducible resistance, known as the induced systemic resistance (ISR), was discovered after the colonization of Arabidopsis roots with the plant growth promoting nonpathogenic rhizobacteria Pseudomonas fluorescens (Pieterse et al., 2002). ISR confers systemic resistance against many pathogens in a SA-independent manner but it requires an intact JA and ethylene pathway (Pieterse et al., 1998).

\subsection{SA-Dependent Signal Transduction Pathways}

To understand the mechanisms through which SA regulates SAR, biochemical approaches were used to define SA binding proteins. The first SA binding protein identified was the SA binding protein 1 (SABP1), a tobacco catalase that converts hydrogen peroxide $\left(\mathrm{H}_{2} \mathrm{O}_{2}\right)$ to $\mathrm{H}_{2} \mathrm{O}$ and $\mathrm{O}_{2}$ (Chen et al., 1993). A second tobacco SAbinding protein (known as SABP2), a lipase, was isolated and showed higher binding specificity for SA and SA analogs (Du and Klessig, 1997; Kumar and Klessig, 2003). The silencing of SABP2 expression suppressed local resistance to TMV, SA induction of $P R-1$ gene expression and SAR development, indicating that SABP2 is a SA receptor that is required for the plant immune response (Kumar and Klessig, 2003). A third SA binding protein, termed SABP3 and identified as a chloroplastic carbonic anhydrase protein, was isolated and the silencing of $S A B P 3$ gene expression in 
tobacco leaves suppressed the HR in a well-known plant pathogen incompatible interaction (Slaymaker et al., 2002).

The SA inhibitory role on SABP1 catalase activity leads to elevate the levels of $\mathrm{H}_{2} \mathrm{O}_{2}$, which is known to induce the expression of PR-1 gene (Klessig et al., 2000). However, many reports questioned this catalase inhibition hypothesis as some findings indicate that $\mathrm{H}_{2} \mathrm{O}_{2}$ might function upstream of $\mathrm{SA}$ rather than downstream (Chamnongpol et al., 1998; Neuenschwander et al., 1995). Another postulated hypothesis for SA mode of action is based on the generation of SA free radicals, which are produced through the SA-mediated inhibition of catalases (Durner and Klessig, 1995).

To analyze the SA-dependent signal transduction pathways controlling the defense responses against pathogens, the Arabidopsis thaliana model plant was used extensively to isolate and characterize genes that are involved in these processes (Reviewed in: Glazebrook et al., 1997a). Arabidopsis plants possess favorable traits for experimental work, such as short life cycle, small size, self-pollination capability, small genome size and its feasibility for molecular and genetic methods (Meyerowitz, 1987).

To elucidate the SAR signaling pathways in Arabidopsis, many genetic screens were conducted to identify genes that are involved in SA synthesis and/or SAR establishment. The correlation of HR and lesion formation with the development of SAR stimulated the search for mutant lines that are able to form spontaneous lesions; such mutant lines were isolated and termed the lesion mimic mutants (Ism) (Reviewed in: Lorrain et al., 2003). The Ism are characterized with constitutive high SA levels and elevated defense gene expression in the absence of pathogen infection, suggesting that these mutants mimic the HR response that might stimulate SAR signaling (Glazebrook, 2001). About $37 \mathrm{Ism}$ were identified in Arabidopsis and were classified into two groups: initiation or propagation mutants. Initiation mutants form lesions of determinate size whereas propagation mutants have uncontrolled lesion size (Lorrain et al., 2003). 
To analysis the function of those mutants regarding SA signaling pathways many crosses between NahG transgenic plants and Ism mutants were conducted. In some crosses, an important role of SA in lesion formation was found, for instance a suppression of spontaneous lesion formation was found when the lesion simulating disease resistance response 6 (Isd6), Isd7 and constitutive expresser of PR 22 (cpr22) mutants were crossed to NahG plants (Weymann et al., 1995; Yoshioka et al., 2001). Other lesion mimic mutants were not affected by the SA absence. For instance, the lesion formation in Isd2, Isd4 and Isd5 mutants was not suppressed in the NahG background (Hunt et al., 1997).

The identification of defense, no death 1 (dnd1) mutant, encoding a cyclic nucleotide-gated ion channel, questioned the assumption that HR development and lesion formation are associated with SAR establishment (Yu et al., 1998). The dnd1 exhibited elevated SA levels and pathogen resistance with an apparent reduced HR formation phenotype (Clough et al., 2000). Other Arabidopsis mutants, such as cpr1 and cpr6, exhibit increased concentrations of SA, constitutive $P R$ gene expression and enhanced resistance to pathogen without any lesion formation (Bowling et al., 1994: Clarke et al., 1998). So caution should be considered dealing with $/ s m$, as they might be evolved from other stresses that might influence indirectly SA accumulation (Dong, 2001).

Besides NahG plants, Arabidopsis mutants that accumulate low SA levels and $P R$ transcripts after pathogen inoculation were isolated. The $S A$ induction-deficient 1 (sid1; also known as enhanced disease susceptibility 5 (eds5) (Rogers and Ausubel, 1997)), sid2 (also known as eds16 (Dewdney et al., 2000)), and eds4 mutants did not accumulate SA after pathogen inoculation and showed enhanced susceptible to pathogens (Gupta et al., 2000; Nawrath and Métraux, 1999). The SID1/EDS5 encodes a protein homologous to members of the multidrug and toxin extrusion (MATE) transporter family (Nawrath et al., 2002). SID1 might be involved in transportation of phenolic compounds transportation involved in SA biosynthesis (Shah, 2003). The SID2 encodes the ICS described above (Wildermuth et al., 2001). SA application 
complemented the sid2 phenotype and restored $P R-1$ expression indicating that SID2 is involved only in SA synthesis (Nawrath and Métraux, 1999).

The EDS1 and phytoalexin deficient 4 (PAD4) Arabidopsis genes, encode lipase-like proteins that can interact physically with each other and act upstream of SA accumulation (Falk et al., 1999; Feys et al., 2001; Jirage, et al., 1999). The pad4 and eds1 mutant plants are compromised in SA synthesis after pathogen infection (Feys et al., 2001; Zhou, et al., 1998). The cpr1, cpr6 and enhanced disease resistance 1 (edr1) mutants with high SA levels, $P R$ gene expression and resistance phenotypes are completely dependent on EDS1 and PAD4 function and their role was placed upstream of SA accumulation (Clarke et al., 2000; Clarke et al., 2001; Frye et al., 2001; Jirage et al., 2001). The high levels of SA, found in the lesion mimic mutant cpr5, were reduced in the eds 1 and pad 4 mutants and completely blocked in the eds 5 mutant, indicating that the SA accumulation does not relay absolutely on EDS1 and PAD4, whereas EDS5 seems to be crucial (Clarke et al., 2000; Clarke et al., 2001; Jirage et al., 2001). The elevated SA levels in the dnd1 mutant were unaffected by PAD4, suggesting the presence of PAD4-independent pathway for SA accumulation, however, a reduction of the dnd 1 enhanced resistance was observed in pad4 plants suggesting that some resistance responses required PAD4 regardless its SA accumulation function (Jirage et al., 2001).

Lipid signaling seems to modulate SA mediated responses in plants. The fact that, SABP2, EDS1 and PAD4 genes encode proteins with lipase domains suggests that a lipid derivative might act as a signal that modulates SA accumulation and function after pathogen infection (Dong, 2001; Kumar and Klessig 2003). The Arabidopsis $\alpha$-dioxygenase enzyme that oxidizes 16 - and $18-C$ fatty acids and results in 2-hydroperoxy fatty acids production was strongly induced after infection with $P$. syringae (de Léon et al., 2002). The levels of hydroperoxy, hydroxy and keto fatty acids were elevated during pathogenesis and especially during the intiation of HR (Rustérucci et al., 1999). Exogenous application of lipid peroxides (the products of lipid peroxidation) induces $P R$ gene expression in tobacco cell cultures (Anderson et al., 
1998). The defective in induced resistance 1 (dir1) mutant is unable to develop SAR or express $P R$ genes, although it has a normal local resistance to pathogens (Maldonado et al., 2002). The wild-type DIR1, which has sequence similarity to lipid transfer proteins (LTP), have a wild-type SA metabolism and a normal response to SA and INA. However, petiole exudate experiments showed that the phloem sap from dir1 is deficient in the SAR mobile signal, while dir1 plants still respond to a signal contained in the sap from wild-type petiole exudates. These data suggest that DIR1 might function in the generation or transmission of a lipid mobile signal that's is involved in SAR establishment.

Using activation tagging, the constitutive disease resistance 1 (CDR1) gene encoding an apoplastic aspartic protease was identified (Xia et al., 2004). The overexpression of CDR1 causes enhanced resistance to virulent $P$. syringae and it seems that CDR1 mediates a peptide derivative signal that is involved in SA accumulation. SA is speculated to generate feedback loops that modulate SA upstream signals components (Shah, 2003). SA could be a part of an amplifying mechanism that lead to the activation of a broad spectrum plant resistance, for instance, the application of SA activates the expression of some R, EDS1, PAD4, EDS5 and SID2 genes.

The involvement of mitogen activated protein kinase (MAPK) cascades in SAR signaling pathways were also described (Reviewed in: Innes, 2001; Zhang and Klessig, 2001). In tobacco, the TMV-infection of tobacco plants that carry the $N$ resistance gene against TMV leads to the activation of two tobacco MAPKs: a SA-induced protein kinase (SIPK) and a wound-induced protein kinase (WIPK) (Zhang and Klessig, 1998). Both proteins are speculated to be positive signaling components acting downstream of SA in both local and systemic defense responses. Strikingly, SIPK protein regulates WIPK gene expression, demonstrating that both proteins are involved in the positive regulation of the same disease resistance-signaling pathway (Liu et al., 2003).

In Arabidopsis, a MAPK gene known as MPK4 negatively regulates SA-mediated defense responses (Petersen et al., 2000). A mutation in MPK4 causes the accumulation of high levels of $S A$, constitutive $P R-1$ expression and enhanced disease 
resistance. The mpk4 phenotype was blocked when it was crossed to the NahG transgenic plants, indicating that MPK4 exerts its function upstream of SA. The EDR1 gene, belongs to the group of Raf-like MAPKKs, has a regulatory function in SA singaling pathways (Frye and Innes, 1998). The EDR1 exerts a negative regulatory function in defense responses as edr1 mutant showed enhanced resistance and had rapid expression of $P R$ genes. The NahG transgene suppresses edr1 phenotype, indicating that EDR1 function upstream of SA accumulation (Frye et al., 2001).

A complete plant MAP kinase cascade that may function downstream of the flagellin receptor involves MEKK1, MKK4/MKK5 and MPK3/MPK6) and WRKY22/ WRKY29 transcription factors was identified using an Arabidopsis leaf cell system (Asai et al., 2002). The BWMK1, a MAPK from rice, can phosphorylate the rice ethyleneresponsive element-binding protein 1 (OsEREBP1) transcription factor, which is known to bind to GCC box located in the promoter region of several PR genes (Cheong et al., 2003).

\subsection{NPR1, a Key Regulator in Controlling SAR Gene Expression}

Several different genetic screens were employed to identify SAR signaling components acting downstream of SA accumulation. A key regulator in controlling $P R$ gene expression and SAR deployment is the non-expressor of PR-1 (NPR1) protein, also known as non-inducible immunity 1 (NIM1) (Cao et al., 1994; Delaney et al., 1995; Glazebrook, et al., 1997b). The Arabidopsis npr1 mutant displays a compromised resistance against avirulent pathogens, non-responsiveness to different SAR-inducing agents (SA, INA), low expression levels of $P R$ genes, hyper-susceptibility to bacterial and fungal infections, hyper-sensitivity to SA (indicating that NPR1 protein is not only required for $S A$ signal transduction but also for a negative feedback regulation mechanism of SA accumulation) and it does not mount an effective SAR (Cao et al., 1994; Cao et al., 1997; Delaney et al., 1995).

The NPR1 gene was cloned and found to encode a novel $65 \mathrm{kDa}$ protein with no obvious biochemical function except the presence of a nuclear localization signal at its 
C-terminus end part and two domains involved in protein-protein interaction, an ankyrin repeat domain located to the central region and a BTB/POZ (broad-complex, tramtrack, and bricà-brac/poxvirus, zinc finger) domain at the $\mathrm{N}$ - terminus end (Cao et al., 1997; Ryals et al., 1997). The presence of protein-protein interaction domains in NPR1 suggests that NPR1 may function as a regulatory protein that might associate with other proteins such as transcription factors (Cao et al., 1997; Ryals et al., 1997). Indeed, screening for NPR1 interacting proteins using the yeast two-hybrid system (Y2HS) identified basic leucine zipper (bZIP) transcription factors from the TGA family (also known as ocs element binding factors (OBFs)) as putative candidates (Després et al., 2000; Zhang et al., 1999; Zhou et al., 2000). The activation sequence-1 (as-1) element, which is the binding site for TGA transcription factors, is present in the PR-1 promoter region and is required for the activation or repression of this gene (Lebel et al., 1998). The significance of NPR1-TGA factors interaction will be discussed in the next sections.

The function of NPR1 and its regulatory role in SAR was further analyzed using both molecular and genetic approaches. NPR1 gene expression is constitutive under normal condition and is slightly induced upon treatment with SAR chemical inducers or after Pernospora parasitica infection (Cao et al., 1997; Ryals et al., 1997; Weigel et al., 2001). The overexpression of the NPR1 gene in Arabidopsis and rice plants enhanced disease resistance to both bacterial and fungal pathogens after treatment with lower does of SAR inducers, i.e., overexpression of NPR1 did not result in constitutive $P R$ gene expression, indicating that the NPR1 protein requires an activation step modulated directly or indirectly by SA, which subsequently will lead to the activation of $P R$ genes. (Cao et al., 1998; Chern et al., 2001; Friedrich et al., 2001).

In a previous study, Kinkema et al. (2000) showed that the bipartite nuclear localization signal found at the C-terminus end of NPR1 mediates its nuclear localization in response to SAR inducers. A functional NPR1-green fluorescent protein (GFP) accumulates in the nucleus in response to SAR inducers (Figure 2.3). 
MS

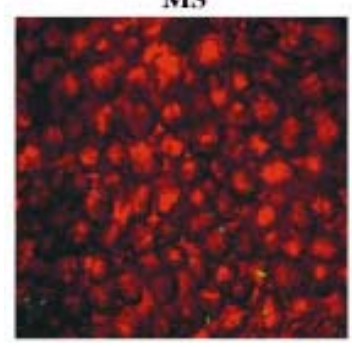

MS-INA

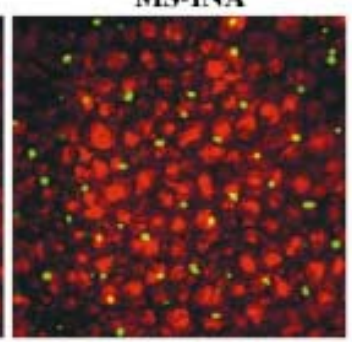

Figure 2.3. Nuclear localization of NPR1-GFP in response to INA induction (Kinkema et al., 2000).

An NPR1 activation step modulated by SA was recently discovered removing some of the ambiguity covering the nature of the SAR signal. The Arabidopsis NPR1 undergoes a conformational change from an inactive oligomer form to the active monomer form as a result of an alerted cellular redox status modulated by SA accumulation during SAR (Mou et al., 2003). SA accumulation seems to prompt a boost of oxidant production at early stage and subsequently the cells will overcompensate this with antioxidants production, converting the oxidizing environment into a reducing one that unhinges NPR1 from an oligomeric complex allowing it to accumulate in the nucleus and to activate gene expression. NPR1 mutants in the cysteine 82 or 216 are constitutively monomeric, nuclear localized and activate $P R$ genes expression.

Additional proteins functioning downstream of NPR1 had been isolated. Screening for suppressors of npr1 phenotype identify the suppressor of npr1-1, inducible 1 (sni1) mutant, which has restored inducible levels of $P R-1$ gene expression and resistance to pathogens, indicating that the wild-type SNI1 gene product, which encodes a novel protein sharing limited homology with the mammalian tumour suppressor retinoblastoma gene product, may function as a negative regulator of SAR (Li et al., 1999). SNI1 is suggested to exert its function through its recruitment to the PR-1 promoter and the interaction with WRKY transcription factors (Durrant and Dong, 2004). In a screen for suppressors of sni1 (ssn), three mutants were identified, ssn1, ssn2, and ssn3, which have alleviated the background PR-1 gene expression of sni1 (Durrant and Dong, 2004 and references therein). It is speculated that the SSN genes are involved in controlling both basal and SA-inducible PR-1 gene expression by 
regulating the same transcription factor(s) that is probably responsible for the background and SA-inducible NPR1-independent $P R$-1 gene expression.

The identification of the detachment 9 (dth9) mutant in Arabidopsis established a novel component in the SAR signalling pathways as the DTH9 gene product appears to act downstream of SA in the development of SAR (Mayda et al., 2000). The expression of $P R$ genes in $d t h 9$ mutant was unaffected although the pathogen resistance was compromised.

Using the Y2HY, three novel genes, NIMIN-1, NIMIN-2 and NIMIN-3 (NIMIN for NIM1-interacting) that encode structurally related proteins interacting physically with NPR1 were identified (Weigel et al., 2001). All NIMIN proteins share a short LXL repeat near the C-terminus that is highly homologous to the ethylene responsive element binding factors (ERF) -associated amphiphilic repression motif found in some ERF transcription factors (Ohta et al., 2001).

Genetic analysis of previously identified mutants acting upstream of SA in the npr1 mutant background and the identification of new mutants acting downstream of SA revealed the presence of a SA-dependent but NPR1-independent resistance pathway (Dong, 2001; Shah, 2003). Crossing the cpr6 mutant to eds5 blocks the enhanced disease resistance against $P$. syringae and Pernospora parasitica, whereas in an npr1 mutant background the resistance to $P$. syringae was only compromised leaving Pernospora parasitica unaffected, hence a SA-dependent but NPR1-independent resistance pathway was postulated (Clarke et al., 1998; Clarke et al., 2000). The existence of such pathway was further supported when the Arabidopsis resistance to turnip crinkle virus conferred by the $H R$ to turnip crinkle virus (HRT) $R$-gene was compromised in the NahG plants but not in the npr1 mutant background (Kachroo et al., 2000).

The identification of mutants that suppress npr1 mutant phenotype uncovered some of the mechanisms mediating the NPR1-independent resistance pathway. For instance, the discovery of suppressor of SAI 2 (ssi2) that encodes a stearoyl-acyl 
carrier protein desaturase (which desaturate stearic acid to oleic acid) in a genetic screen for suppressors of npr1-5 suggests a role for lipid-derived signal in the NPR1independent resistance pathway (Kachroo et al., 2001; Shah et al., 2001). The isolation of suppressor of the fatty-acid-desaturase deficiency 1 (SFD1) that encodes a glycerol3-phosphate dehydrogenase, which is required for the glycerolipid biosynthesis, strengthens those observations as sfd1 suppress the ssi2-conferred NPR1-independent expression of the $P R-1$ gene and resistance to $P$. syringae by lowering the content of the hexadectrienoic acid (16:3), which was elevated in the ssi2 mutant (Nandi et al., 2003).

\subsection{SAR Gene Expression Mechanisms}

An important step in controlling plant defense responses appears to be the transcriptional activation or repression of the defense responsive genes. Up to $20 \%$ of transcriptional changes in the Arabidopsis genome are associated with $R$ genemediated and basal pathogen resistance (Nimchuk et al., 2003).

Studying gene expression changes associated with compatible and incompatible local resistance using large-scale gene expression profiling technologies showed no changes in gene expression patterns between both interactions. However, the Rdependent responses had higher amplitudes and rapid induction kinetics of specific subsets of defense genes compared with the compatible interaction (Maleck et al., 2000; Tao et al., 2003). Strikingly, the expression levels of all genes upregulated during SAR establishment (represented by 132 ESTs) were compromised in the npr1 mutant (Maleck et al., 2000).

Transcriptional regulation of gene expression is largely mediated by the specific recognition of cis-acting promoter elements by trans-acting sequence specific DNAbinding transcription factors. The Arabidopsis genome encodes about 1500 transcription factors that are capable of activating and/or repressing transcription through binding to short specific DNA motifs (Riechmann et al., 2000). In Arabidopsis, a number of families of transcription factors such as ERF, TGAs, Myb, and WRKY 
proteins, each containing a distinct type of DNA binding domain (BD), have been implicated in plant defense responses (Chen et al., 2002; Singh et al., 2002). For instance, ERF proteins are a subfamily of the APETALA2 (AP2)/EREBP transcription factors family that can bind to the GCC box, which is found in several $P R$ genes promoter regions, and involved in ethylene signalling against necrotrophic pathogens (Singh et al., 2002). The ERF1 transcript was induced after Botrytis cinerea infection, and its overexpression in Arabidopsis leads to enhance resistance to Botrytis cinerea and Plectosphaerella cucumerina (Berrocal-Lobo et al., 2002).

WRKY proteins are a class of DNA-binding proteins and comprise 74 members in Arabidopsis that recognize the TTGAC(C/T) W-box elements found in the promoters of a large number of plant defense-related genes such as PR-1 (Eulgem et al., 2000). In the PR-1 gene promoter region, a negative promoter element containing a $W$-box was identified suggesting the involvement of WRKY transcription factors in SAR-related gene expression (Lebel et al., 1998). The expression of NPR1 gene is under the control of WRKY transcription factors (Yu et al., 2001). The overexpression of WRKY70, a SAinducible transcription factor, increases resistance to virulent pathogens and results in constitutive expression of SA-induced pathogenesis-related genes (Li et al., 2004).

The AtWhirly1 (WHY1) protein, a SA inducible single strand DNA binding transcription factor, is required for both SA-dependent disease resistance and SAinducible expression of PR-1 protein (Desveaux et al., 2004).

\subsection{The As-1 Element and TGA Transcription Factors Regulate SA Mediated Gene Activation}

The bZIP transcription factors are a large family of transcription factors in plants with 75 members present in Arabidopsis alone (Figure 2.4; Jakoby et al., 2002). A wellcharacterized class of the bZIP proteins is the TGA family the members of which bind to the as-1 element and regulate the expression of many stress-responsive genes such as PR-1 and GST6 (Chen and Singh, 1999; Lebel et al., 1998). 


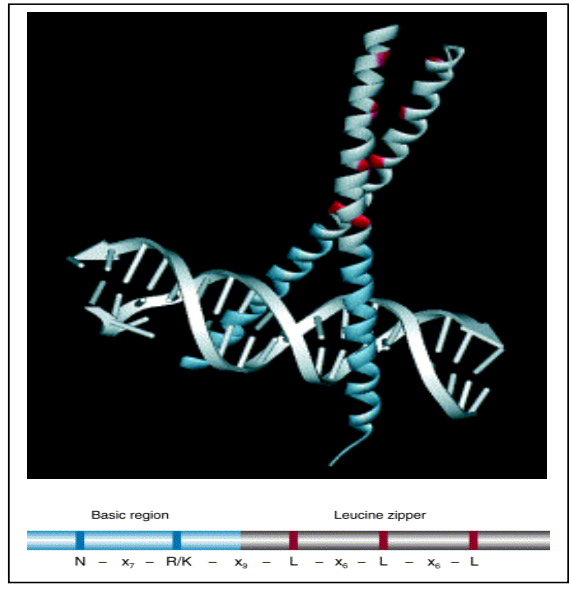

Figure 2.4. Three-dimensional structure of the bZIP domain bound to DNA (Jakoby et al., 2002).

The as-1 element consists of two TGACGTCA imperfect palindrome motifs and was originally identified in the -90 region of the $35 S$ promoter from cauliflower mosaic virus (CaMV) using promoter deletion analysis (Figure 2.5; Lam et al., 1989). In plant leaves, the expression of genes containing as-1 or as-1 like elements in their promoter regions was induced after treatment with SA (Qin et al., 1994) or auxin (Liu and Lam, 1994) or oxidative stress (Garreton et al., 2002).

\section{5' TGACGTAA | ggga| TGACGCAC 3' $3^{\prime}$ ACTGCATT | ccct| GATGCGTG 5'}

Figure 2.5. Sequence of as-1 element from the CaMV promoter.

As-1-like elements are found in promoter regions of genes controlling early defense responses (transiently induced after 1-2 hours after SA or auxin treatment) such as GST6 from Arabidopsis (Chen and Singh, 1999) and in promoter regions of genes controlling late defense responses (long lasting gene induction after 10-12 hours after treatment and closely associated with SAR) such as PR-1 from Arabidopsis (Zhang et al., 1999). Interestingly, the SAR regulatory protein NPR1 controls only late defense genes such as $P R-1$, while the activation of immediate early genes by $S A$ proceeds through an NPR1-independent pathway, indicating that the activation by SA 
of immediate early and late genes occurs by at least two different mechanisms (Uquillas et al., 2004).

Using the electrophoretic mobility shift assay (EMSA), which is used to study the interaction between transcription factors and their DNA target sequences, a nuclear protein complex from tobacco that was able to bind to the as-1 element was identified and was termed the activation sequence factor 1 (ASF1) (Lam et al., 1989). A similar as-1 binding activity was also observed using a total cellular protein extracts from SA treated leaves and was termed the SA response protein (SARP) (Jupin and Chua, 1996).

The first as-1 binding protein was isolated from a tobacco cDNA library using a labeled TGACG-containing DNA probe and was termed TGA1a (Katagiri et al., 1989). Sequence analysis of the TGA1a bZIP transcription factors revealed that it consists of a basic DNA-binding region, a leucine zipper region important for dimer formation, an acidic $\mathrm{N}$-terminus domain for activation, a glutamine-rich with transcriptional activation potential and dimer-stabilizing region in the C-terminus, respectively (Figure 2.6; Katagiri et al., 1992; Neuhaus et al., 1994; Pascuzzi et al., 1998).

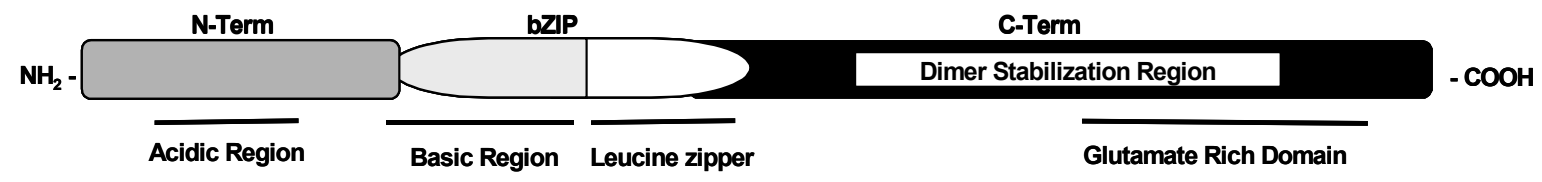

Figure 2.6. Structural features of the TGA1a transcription factor.

Subsequently several proteins homologous to TGA1a had been isolated from different plant species. In Arabidopsis, ten members of this group were described and six were grouped into three classes based on homologies within their amino acid sequences: class I- TGA1 and TGA4, class II- TGA2, TGA5 and TGA6, and class IIITGA3 (Jakoby et al., 2002). In tobacco, five TGA factors have been identified and were grouped according to their homology with the TGA factors from Arabidopsis into three 
classes: class I- TGA1a and PG13, class II- TGA2.1 and TGA2.2 (Niggeweg et al., 2000b) and class IV- TGA10 (Schiermeyer et al., 2003).

Different TGA members are involved in different stress responses such as xenobiotic- or SA-mediated responses. For instance, chromatin immunoprecipitation (ChIP) studies using a cultured cell line showed that tobacco TGA1a binds in vivo to as1 elements found in xenobiotic-responsive promoters but not to as-1 elements found in PR-1 promoters (Johnson et al., 2001a). The Arabidopsis TGA2 protein is only responsive to SA but not to any other biotic or abiotic stress (Fan and Dong, 2002).

As described above, the as-1 element contains two binding motifs that can be occupied with either one or two TGA dimers. Using EMSA, two complexes are identified representing single (lower complex) and double occupation (upper complex) of the as-1 element (Tokuhisa et al., 1990). Heterodimerization and homodimerization between different in vitro translated TGA factors from different classes was observed (Niggeweg et al., 2000b).

Analysis of the ASF1 composition in leaves of Arabidopsis using super-shift assays with specific antibodies revealed that TGA class-II factors contribute significantly to ASF1 activity. About $50 \%$ of the ASF1 activity was related to the TGA2 factor (Lam and Lam, 1995), whereas in tobacco, ASF1 consist of ca. 80\% TGA2.2 and 20\% TGA2.1 (Niggeweg et al., 2000a). These results demonstrate the importance of TGA class-II factors in relation to the SA-inducible gene expression.

The importance of the TGA class-II factors regarding the SA-inducible transcriptional activity from as-1-like elements was further confirmed using transgenic plants overexpressing TGA wild type and/or mutated forms. Transgenic tobacco plant with mutant derivative of the tobacco TGA2.2 that lacks DNA-binding activity had suppressed SA-activated PR-1 and GSTs gene expression (Niggeweg et al., 2000a). However, the overexpression of a dominant-negative Arabidopsis TGA2 mutant in tobacco, which lacks DNA-binding activity and suppresses all as-1-element-binding activity, exhibited heightened induction of $P R$ genes after SA application and pathogen 
challenge (Pontier et al., 2001). In another study, using a trans-dominant approach that targeted just TGA2 in Arabidopsis plants, the expression of $P R-1$ gene following SA treatment was suppressed (Fan and Dong, 2002). Examination of an Arabidopsis triple knockout mutant in the TGA2, TGA5, and TGA6 genes revealed that they are functionally redundant and are essential for both the induction of SAR genes and the negative regulation of the basal PR-1 gene expression (Zhang et al., 2003b). Overexpression of TGA2 sense and antisense transcripts in Arabidopsis did not affect resistance to Peronospora parasitica and $P R-1$ gene expression. However, transgenic plants overexpressing TGA5 displayed enhanced resistance to this pathogen without altering the $P R-1$ expression levels (Kim and Delaney, 2002). Using leaf transfection assays, other TGA factors from Arabidopsis belonging to class-I and class-III had activated reporter gene expression in a SA-dependent manner (Després et al., 2003; Johnson et al., 2003).

The contradiction in these results suggests that the TGA factors can function as both positive and negative regulators of SA-dependent gene expression (Shah, 2003). Indeed, the PR-1 promoter contains two as-1-like elements known as LS5 and LS7 that act as weak silencer element and activator element, respectively (Lebel et al., 1998). This makes it difficult to define the function of any specific TGA factor in relation to $P R$ 1 gene expression mechanism.

Functional analysis of TGA transcription factors revealed that there activity must be regulated in vivo. Consolidation of this assumption is excogitated from the fact that their DNA-binding activity and transactivation potential increase only upon SA induction (Fan and Dong 2002; Jupin and Chua, 1996; Stange et al., 1997). The steady state concentration of TGA factors present in leaf nuclear extracts was not affected after SA induction (Johnson et al., 2003). Transgenic plants encoding a fusion protein between TGA2.2 and the activation domain (AD) of the adenovirus viral particle 16 (VP16) (TGA2.2-VP16) showed higher inducible expression of target genes as compared to wild-type plants, however, transcription was not elevated in the non-induced state, indicating that no constitutive DNA-binding occurs (Lenk, 2001). In conclusion, it seems 
that specific TGA members are sequestered from binding to the as-1 element under non-inducing conditions through unknown mechanisms.

The enhancement of TGA DNA binding after SA treatment was reversed when the total protein extracts were treated with alkaline phosphatase (Jupin and Chua, 1996), while treatment of nuclear protein extracts from non-induced leaves with ATP led to enhance the DNA binding activity to the as-1 element (Stange et al., 1997) hinting that phosphorylation events could play a role in manipulating the DNA binding activities of ASF1/SARP. However, in neither case, direct phosphorylation or dephosphorylation of the TGA factors was shown. In consistence with these results, a nuclear casein kinase 2 protein is speculated to regulate the SA-activated binding of ASF1 to the as-1 sequence (Hidalgo et al., 2001). The DNA binding activity of HBP-1a, a wheat bZIP transcription factor homologous to TGA2, is suggested to be under the control of $\mathrm{Ca}^{2+}$-stimulated phosphorylation events (Meshi et al., 1998).

Treatment of protein extracts from non-induced leaves with formamide and other detergents resulted in stronger binding of ASF1/SARP to the as-1 element. This could be interpreted probably by the dissociation of an inhibitor protein from SARP complex (Jupin and Chua, 1996). A speculative model describing mechanism leading to SAinducible gene expression was based on the presence of a hypothetical repressor protein (named SA-Inhibitor, (SAI)) that associates with SARP under non-inducing hindering TGAs to bind the as-1 element and dissociates after SA induction.

Besides NPR1, the TGA transcription factors were found to interact with other plant proteins. OBP1 (for OBF binding protein 1), a DNA binding protein from Arabidopsis, interacts with TGA factors and enhances their DNA binding activity (Zhang et al., 1995). A TGA1a-interacting protein of apparent molecular size of $120 \mathrm{kDa}$ (p120) which under non-induced conditions hindered the binding of TGA1a to the as-1 element was identified using a coimmunoprecipitation assay with ${ }^{35} \mathrm{~S}$ methionine radio-labeled extracts from tobacco cell suspension culture (Johnson et al., 2001b). Is the p120 identity related to SAI? It's still an open question. 
Besides SA, the as-1 element is also regulated via oxidative stress and it seems that the SA activating effect on the as-1 element seems to be mediated through the production of certain oxidative species (Garreton et al., 2002). TGA1 and TGA3 proteins are regulated in their protein stability during development by a posttranscriptional mechanism that likely involves specific targeting to the proteasome (Pontier et al., 2002).

A conserved spacing of $12 \mathrm{bp}$ between the two centers of the palindromes of the as-1 element was observed in the promoter region of the auxin inducible genes and the 'immediate early' SA inducible genes, whereas the spacing in the 'late' SA inducible genes is less conserved (Krawczyk et al., 2002). TGA-DNA binding was not affected when the two palindromes were not correctly spaced (the as-1 lacked two bp between the two palindromes), whereas a lack in TGA factors transcriptional activity was observed. The tobacco TGA2.1 and TGA1a, but not TGA2.2 (the main factor of the ASF1 and SARP), function as transcriptional activators in yeast, indicating that TGA2.2 might require a post transcriptional modification or to interact with a plant encoded coactivator to exert its function (Niggeweg et al., 2000b).

\subsection{Interaction between NPR1 and TGA Transcription Factors Leads to SA-Mediated Gene Activation}

The ample evidence for the direct physical interactions between NPR1 and the TGA factors and the fact that NPR1-TGA interaction is not constitutive and enhanced by SA, notarize the positive regulatory role of NPR1 in the activation mechanism of SAR genes (Després et al., 2000; Fan and Dong, 2002; Subramaniam et al., 2001; Zhang et al., 1999). Previous studies have indicated that NPR1 interacts with Arabidopsis TGA2, TGA3, TGA5, TGA6, and TGA7 factors in yeast, whereas no interaction with TGA1 and TGA4 could be observed (Zhang et al., 1999; Després et al., 2000; Zhou et al., 2000). The enhancement of the TGA-DNA binding in response to SA requires a functional NPR1 protein as the TGA-DNA binding activity in the npr1 mutant 
background was severely suppressed (Després et al., 2000; Fan and Dong, 2002; Johnson et al., 2003).

In elegant experiments, Fan and Dong (2002) showed that Arabidopsis TGA2 is a transcription activator and is involved in NPR1-mediated SA signaling. They showed that overexpression of a truncated form of TGA2, which lacks DNA binding activity but is able to interact with NPR1, has a dominant-negative effect and confers a phenotype similar to that of the npr1 mutant. A chimeric TGA2 protein, generated by replacing the TGA2 bZIP domain with the Galactose utilization 4 (GAL4) DNA-BD, expressed in transgenic plants harboring a $\beta$-glucuronidase (GUS) reporter construct under the control of GAL4 upstream activation sequence (UAS GAL4), was able to bind to the $U A S^{G A L 4}$ and transactivate reporter gene in an INA- and NPR1-dependent manner.

Using a leaf ChIP assay, Johnson et al. (2003) studied the interactions of Arabidopsis TGA2 and TGA3 with the PR-1 promoter in planta and their results clearly demonstrate that both factors are recruited to this promoter in response to a stimulus induction pathway involving SA and NPR1. Després et al. (2003) suggest doubt regarding TGA class-I no interaction with NPR1 as they showed that TGA1 and TGA4 possess all the structural elements required for the interaction with NPR1. To interact with NPR1, the TGA1 and TGA4 factors should undergo conformational changes that are modulated by SA. SA accumulation leads to the reduction of two critical cysteine residues within the TGA1 and TGA4 that are involving in the formation of intramolecular disulfide bridge that inhibits their interaction with NPR1. Although SA mediates TGA1NPR1 interaction (Després et al., 2003) and TGA3-dependent reporter gene activation (Johnson et al., 2003), the role of TGA class-I and -III factors in SA inducible gene expression is still questionable as Arabidopsis triple knockout mutant in TGA class-II factors was still impaired in SA-inducible $P R-1$ gene expression indicating that TGA class-I and -III could not complement this loss of function phenotypes (Zhang et al., 2003b).

The NIMIN proteins can form a ternary complex with NPR1 and TGA factors in a Yeast Three-Hybrid System (Y3HS), speculating that an interaction between NPR1- 
NIMINs with TGA could take place may be at the as-1 level (Weigel et al., 2001). Indeed overexpression of the NIMIN-1 gene in Arabidopsis suppresses SAR phenotypes and $P R-1$ expression ( $R$. Weigel, unpublished data). The repression effects of NIMIN-1 might be related to the presence of the ERF-associated amphiphilic repression motif.

In conclusion, the signal transduction pathway during SAR will lead to SA accumulation that modulate conformational changes in NPR1 from the inactive oligomer to the active monomer form that enables it to accumulate in the nucleus and activates $P R$-1 gene expression through increasing the affinity of some TGA factors to their DNA binding sites or sequestering some of them from binding and/or probably by replacing the SAI repressor from the SARP/ASF1 complex (Figure 2.7).

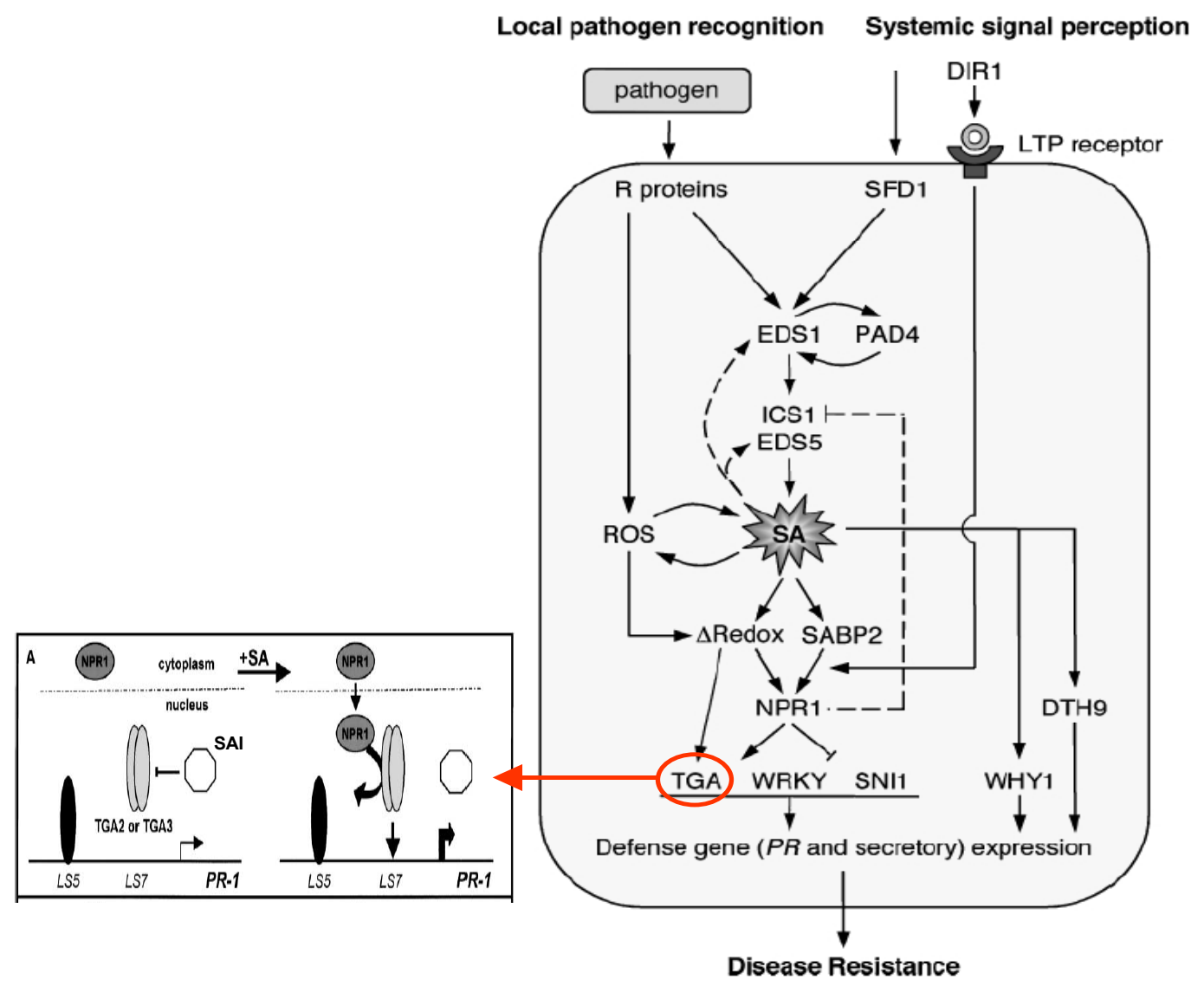

Figure 2.7. Model of PR-1 transcriptional regulation (Durrant and Dong 2004; Johnson et al., 2003). 


\subsection{Yeast Hybrid Systems as a Tool to Study Protein Interactions}

A useful tool for the identification and analysis of protein-protein interactions is the Y2HS. The Y2HS is a sensitive in vivo assay used for the detection of specific protein-protein interactions (Fields and Song, 1989). The Y2HS utilizes two separable modules or domains of a transcription factor: the DNA-BD that mediates binding of the transcription factor to gene promoters by sequence specific DNA recognition and $A D$ that recruits the transcriptional apparatus to the gene for mRNA production (Coates and Hall, 2003).

In the Y2HS, two fusion proteins are generated: the bait protein, which is constructed to have the DNA BD that enables it to bind to its corresponding DNA binding elements found upstream of a reporter gene integrate in the yeast genome, and its potential interacting partner (the fish or prey), which is fused to an AD (Figure 2.8; Fields and Sternglanz, 1994). If the bait protein interacts with the prey protein, the interaction of both proteins will form an intact and functional transcriptional activator, which will lead to reporter gene activation.

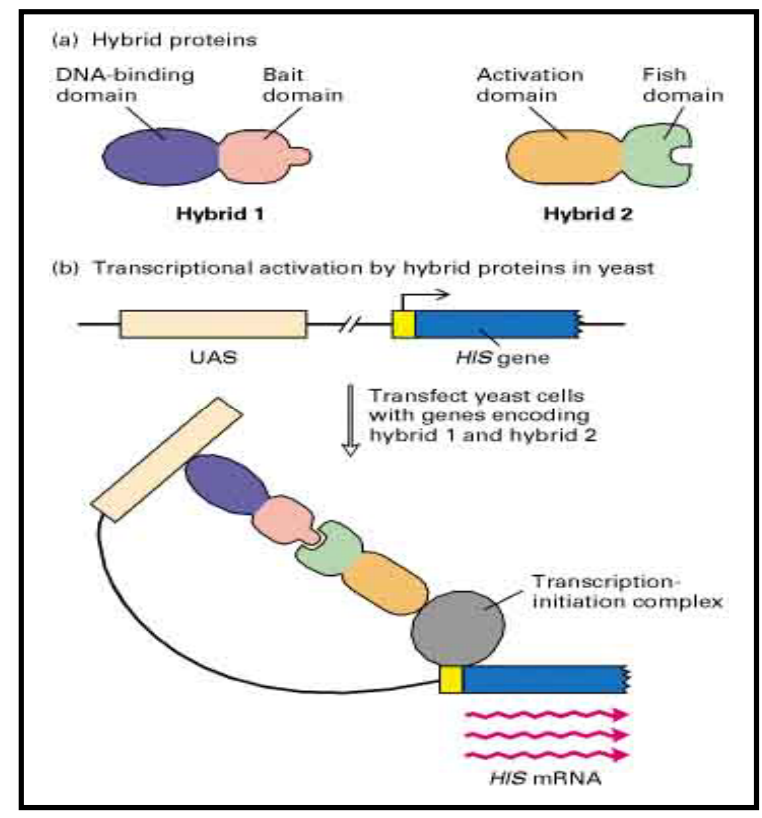

Figure 2.8. Y2HS for detecting proteins that interact. 
In addition to the fusion proteins, plasmids contain selection or marker genes (such as TRP1 and LEU2 that encode enzymes involved in tryptophan and leucine biosynthesis, respectively) that contribute to the cell survival under a particular environment and enable the selection for transfected cells (Fields and Sternglanz, 1994).

There are broad applications of the Y2HS system for the investigation of the protein network of a cell, but the most important use is to identify potential regulatory interacting partners through screening a cDNA library encoding many proteins from a selected organism (Drees, 1999).

In the last few years, several new modifications of $\mathrm{Y} 2 \mathrm{HS}$ have been established recommending the system for several different approaches (Brachmann and Boeke, 1997; Serebriiskii et al., 2001). For instance, the Y3HS was generated involving a third component such as a nucleic acid or a protein and was developed to detect factors mediating the interaction of two proteins (Tirode et al., 1997). The Y3HS makes it possible to investigate ternary protein complex formation by allowing the expression of three proteins together: A DNA-BD fusion, a bridge protein and a DNA-AD fusion protein. The Yeast One Hybrid System (Y1HS) is another derivative from the Y2HS, which is used for isolating of novel genes encoding proteins that bind to a target, cisacting regulatory element (Brachmann and Boeke, 1997).

Limitations in applying the two-hybrid system have been reported by several scientists working with proteins from different organisms (Serebriiskii et al., 2001). A major difficulty in the Y2HS screens is the elimination of false positives. These are clones that cause the activation of reporter genes but not as a result of a specific interaction with the bait (Bartel et al., 1993). 


\section{Objectives}

The evidence presented in the introduction points to a crucial function of TGA transcription factors binding to the as-1 element with respect to immediate early gene expression in response to SA and auxin and with respect to systemic acquired resistance.

As TGA transcription factors are constitutively expressed even in the uninduced cell, their activity has to be regulated at the protein level. Evidence presented by various groups (Jupin and Chua, 1996; Stange et al., 1997) indicates the existence of a protein that interferes with DNA binding capacity of TGA factors. Our data suggest the existence of a co-activator that has to be recruited to TGA factors bound to the as-1 element (Krawczyk et al., 2002).

To isolate putative interacting proteins, a modified yeast one-hybrid system was established using TGA2.2 from tobacco as a bait. We focused on this protein for several reasons:

1. TGA2.2 represents a large fraction of the as-1 binding complex isolated from tobacco nuclear or cellular extracts.

2. Plants overexpressing TGA2.2 showed increased expression of the Nt103 after SA induction.

3. Plants with reduced levels of TGA2.2 show reduced levels of Nt103 after SA and auxin induction.

Here, I describe the identification and characterization of several proteins that interact with the tobacco TGA2.2 factor. Molecular and genetic analysis of TGA2.2 interacting partners will be presented and discussed. I hope the data presented here will help in better understanding of the signaling networks that orchestrate the TGA function in plants and to establish a solid foundation for further work to understand the physiological role for TGA factors in plants. 


\section{$4 \quad$ Materials}

\subsection{Organisms}

\subsubsection{Bacteria}

\begin{tabular}{|c|c|c|}
\hline Bacteria Strain & Description & Reference \\
\hline $\begin{array}{l}\text { Agrobacterium tumefaciens } \\
\text { GV3101 (pMP90) }\end{array}$ & pMP90RK; Rif $^{r}, \mathrm{Gm}^{r}$. & Koncz and Schell, 1986 \\
\hline Escherichia coli BL21 & F-; ompT hsdSB (rB mB) gal dcm. & Studier and Moffat, 1986 \\
\hline Escherichia coli DH5a & $\begin{array}{l}\text { F-; gyrA96 (Nalr), recA1, relA1, endA1, thi-1, hsdR17 } \\
\text { (rk-mk+), glnV44, deoR, D (lacZYA-argF) U169 } \\
\text { p80dD (lacZ) M15]. }\end{array}$ & Hanahan, 1983 \\
\hline Escherichia coli W3110 & $\mathrm{F}^{\prime}$, laclq L8, hsdR-, hsdM+. & Brent and Ptashne, 1981 \\
\hline Escherichia coli XL1Blue & $\begin{array}{l}\mathrm{F}^{\prime}, \text { Tn10 (tetr), proA+B+, laclq, glnV44, recA1, } \\
\text { D(lacZ)M15, relA1, endA1, (Nalr), hsdR17 (rk-mk+) } \\
\text { gyrA96 thi-1. }\end{array}$ & Bullock et al., 1987 \\
\hline $\begin{array}{l}\text { Pseudomonas syringae } \\
\text { pv. maculicola }\end{array}$ & With or without avrRpt2 gene ES4326. & Whalen et al., 1991 \\
\hline
\end{tabular}

\subsubsection{Yeast (Saccharomyces cerevisiae)}

\begin{tabular}{lll} 
Yeast Strain & Description & Reference \\
\hline HF7c & MATa; ura3-52, his3-200, lys2-801, ade2-101, & Clontech \\
& trp1-901, leu2-3, 112, GAL4-542, gal80-538, & \\
LYS 2-GAL1UAS-GAL1TATA-HIS3, URA3-(GAL & \\
& 17mers) 3-Cyc1 TATA-lacZ. & \\
An YM4271-derivative: ura3-52, lys2-801, ade2- & R. Weigel, unpublished \\
YRWH2 & 101, ade5, trp1- 901, leu2-3, 112, tyr1-501, GAL4- & \\
& D512, gal80-D538, ade5::hisG. The HIS3 reporter & \\
& gene is under the control of 3x as-1 elements. & \\
An YM4271-derivative: ura3-52, lys2-801, ade2- & R. Weigel, unpublished \\
& 101, ade5, trp1- 901, leu2-3, 112, tyr1-501, GAL4- & \\
& D512, gal80-D538, ade5::hisG. The Lac-Z reporter & \\
& gene is under the control of 3x as-1 elements.
\end{tabular}




\subsubsection{Plants}

\begin{tabular}{|c|c|c|}
\hline Plant & Description & Reference \\
\hline$-90-G U S$ & $\begin{array}{l}\text { Arabidopsis thaliana Columbia-0 transgenic plant } \\
\text { contains an as-1 element upstream of the uidA } \\
\text { (GUS) reporter gene, } \mathrm{km}^{r} \text {. }\end{array}$ & Redman et al., 2002 \\
\hline At1g28480 antisense & $\begin{array}{l}\text {-90-GUS plant contains pFGC5941/At1g28480 } \\
\text { binary vector with an At1g28480 RNAi cassette } \\
\text { under the control of CaMV } 35 S \text { promoter, } \mathrm{km}^{r} P P T^{r} \text {. }\end{array}$ & This work \\
\hline At1g28480 overexpressors & $\begin{array}{l}\text {-90-GUS plant contains the Alligator2/At1g28480 } \\
\text { plasmid with a } 3 x \text { HA-At1g28480 construct under the } \\
\text { control of } 2 x \text { CaMV } 35 S \text { promoter, strp }{ }^{r} \text {. }\end{array}$ & This work \\
\hline At1g50570 antisense & $\begin{array}{l}\text {-90-GUS plant contains pFGC5941/At1g50570 } \\
\text { binary vector with an At1g50570 RNAi cassette } \\
\text { under the control of } 35 S \text { promoter, } \mathrm{km}^{r} \mathrm{PPT}{ }^{r} \text {. }\end{array}$ & This work \\
\hline At1g50570 overexpressors & $\begin{array}{l}\text {-90-GUS plant contains the Alligator2/At1g50570 } \\
\text { binary vector with a } 3 x \text { HA-At1g50570 construct } \\
\text { under the control of } 2 x \text { CaMV } 35 \text { S promoter, strp }{ }^{r} \text {. }\end{array}$ & This work \\
\hline
\end{tabular}

\subsection{Media and Additives}

\subsubsection{Bacterial Media}

\section{Medium}

Agrobacterium tumefaciens inoculation medium

dYT

King's B

\section{Components and Concentrations}

$50 \mathrm{~g} / \mathrm{l}$ Sucrose

$500 \mu \mathrm{l} / \mathrm{l}$ Silwet L-77

$16 \mathrm{~g} / \mathrm{l}$ Tryptone

$10 \mathrm{~g} / \mathrm{l}$ Yeast Extract

$5 \mathrm{~g} / \mathrm{l} \mathrm{NaCl}$

Adjust $\mathrm{pH}$ to 7.0 with $\mathrm{NaOH}$

$10 \mathrm{~g} / \mathrm{l}$ Proteose-Peptone

$8.6 \mathrm{mM} \mathrm{NaH}_{2} \mathrm{PO}_{4}$

$15 \mathrm{~g} / \mathrm{l}$ Glycerin

Adjust $\mathrm{pH} 7.0$ with $\mathrm{HCl}$

Autoclave

$5 \mathrm{ml}$ of $1 \mathrm{M}$ Magnesium sulfate were added 


\section{Medium}

LB medium

\title{
Components and Concentrations
}

\author{
10 g/l Tryptone \\ $5 \mathrm{~g} / \mathrm{l}$ Yeast Extract \\ $10 \mathrm{~g} / \mathrm{l} \mathrm{NaCl}$ \\ Adjust pH to 7.0 with $\mathrm{NaOH}$ \\ $10 \mathrm{~g} / \mathrm{l}$ Beef Extract \\ $2 \mathrm{~g} / \mathrm{Y}$ Yeast Extract \\ $5 \mathrm{~g} / \mathrm{P}$ Peptone \\ $5 \mathrm{~g} / \mathrm{l}$ Sucrose \\ $2 \mathrm{mM} \mathrm{MgSO}_{4}$ \\ Adjust $\mathrm{pH}$ to 7.0 with $\mathrm{NaOH}$
}

YEB

\subsubsection{Yeast Media}

\section{Medium}

YPD-Medium + adenine

SD-Medium

\section{Components and Concentrations}

20 g/l Tryptone / Peptone

10-20 g Agar (for plates only)

$10 \mathrm{~g} / \mathrm{l}$ Select yeast extract

$20 \mathrm{~g} / \mathrm{l}$ Glucose

$20 \mathrm{mg} / \mathrm{l}$ Adenine

Adjust $\mathrm{pH}$ to 5.8 with $\mathrm{HCl}$

$6.7 \mathrm{~g}$ Yeast nitrogen base without amino acids

10-20 g Agar (for plates only)

$850 \mathrm{ml} \mathrm{H}_{2} \mathrm{O}$

Adjust $\mathrm{pH}$ to 5.8 with $\mathrm{KOH}$, Autoclave

$100 \mathrm{ml}$ of 10x Drop-in Solution

5-30 mM 3-Amino-1,2,4 Triazole (3-AT) was

added when necessary

\subsubsection{BY-2 Protoplasts Media}

\section{Medium}

MS for Bright Yellow-2 (BY-2) protoplast preparations

\section{Components and Concentrations}

\author{
1x MS salts \\ 100 mg/l Myo-inositol \\ $1 \mathrm{mg} / \mathrm{l}$ Thiamine \\ $0.2 \mathrm{mg} / \mathrm{l} 2,4-\mathrm{D}$ \\ $255 \mathrm{mg} / \mathrm{l} \mathrm{KH_{2 } \mathrm { PO } 4}$ \\ $30 \mathrm{~g} / \mathrm{l}$ Sucrose \\ Adjust $\mathrm{pH}$ to 5.0 with $\mathrm{KOH}$
}




\subsubsection{Additives}

Substance

Agar

Ampicillin

Gentamycin

IPTG

500x Histidine

Kanamycin

100x Leucine

Methionine

Rifampicin

Streptomycin

Tetracycline

500x Tryptophan

$X-G a l$
Working concentration

$15-20 \mathrm{~g} / \mathrm{l}$

$100 \mathrm{mg} / \mathrm{l}$

$25 \mathrm{mg} / \mathrm{l}$

$60 \mathrm{mg} / \mathrm{l}$

$1 \mathrm{mg} / \mathrm{l}$

$50 \mathrm{mg} / \mathrm{l}$

$1 \mathrm{mg} / \mathrm{l}$

$1 \mathrm{mM}$

$100 \mathrm{mg} / \mathrm{l}$

$20 \mathrm{mg} / \mathrm{l}$

$10 \mathrm{mg} / \mathrm{l}$

$1 \mathrm{mg} / \mathrm{l}$

$60 \mathrm{mg} / \mathrm{l}$

\section{Stock Solution and Solvent}

$25 \mathrm{mg} / \mathrm{ml} \mathrm{H}_{2} \mathrm{O}$

$23.8 \mathrm{mg} / \mathrm{ml}$ in DMF

$60 \mathrm{mg} / \mathrm{ml}$

$1 \mathrm{~g}$ Histidine in $100 \mathrm{ml} \mathrm{H}_{2} \mathrm{O}$

$50 \mathrm{mg} / \mathrm{ml} \mathrm{H}_{2} \mathrm{O}$

$1 \mathrm{~g}$ Leucine in $100 \mathrm{ml} \mathrm{H}_{2} \mathrm{O}$

$1 \mathrm{M}$ in $\mathrm{H}_{2} \mathrm{O}$

$20 \mathrm{mg} / \mathrm{ml}$ Methanol

$20 \mathrm{mg} / \mathrm{ml}$ in $\mathrm{H}_{2} \mathrm{O}$

$10 \mathrm{mg} / \mathrm{ml}$

$1 \mathrm{~g}$ Tryptophan in $100 \mathrm{ml} \mathrm{H}_{2} \mathrm{O}$

$20 \mathrm{mg} / \mathrm{ml}$ in DMF

\subsection{Nucleic Acids}

\subsubsection{Plasmids}

\section{Plasmid}

Alligator2

Alligator2/At1g28480

Alligator2/At1g50570

as-1-GUS

HBT-2.2VPs

HBT-L

\section{Description}

Gateway binary vector for constitutive expression of a 3x HA tagged protein under the control of $2 x 35$ s promoter; GFP marker gene under the control of At2S3 promoter; strp ${ }^{r}$.

Alligator2 derivative for constitutive expression of a $3 \mathrm{x}$ HA- This work At1g28480 fusion protein; strp ${ }^{r}$.

Alligator2 derivative vector for constitutive expression of a $3 x$ HA-At1g50570 fusion protein; strp ${ }^{r}$.

pUC18 derivative contains the uidA reporter gene coding sequence under the control of the $-90 \mathrm{CaMV} 35 \mathrm{~S}$ promoter; $a m p^{r}$.

HBT derivative contains the TGA2.2-VP16 coding sequence under the control of the chimeric HBT promoter; $a m p^{r}$.

pUC18 derivative contains the chimeric HBT promoter and a Nickolov, 2003 nos termination signal; $a m p^{r}$.

\section{Reference}

http://www.isv.cnrsgif.fr/jg/alligator/ Thurow, 2002 


\begin{tabular}{|c|c|c|}
\hline Plasmid & Description & Reference \\
\hline HBT-L-GFP & $\begin{array}{l}\text { pUC18 derivative contains the coding sequence of a } \\
\text { synthetic and optimized codon-usage GFP (S65T) under the } \\
\text { control of the chimeric HBT promoter and with Nos } \\
\text { termination signal; } a m p^{r} \text {. }\end{array}$ & Nickolov, 2003 \\
\hline HBTL/At1g28480 & $\begin{array}{l}\text { HBT-L derivative contains the } A t 1 g 28480 \text { coding sequence } \\
\text { under the chimeric } H B T \text { promoter; } a m p^{r} \text {. }\end{array}$ & This work \\
\hline HBTL/At1g28480-GFP & $\begin{array}{l}\text { HBT-L-GFP derivative contains the At1g28480-GFP coding } \\
\text { sequence under the control of the chimeric } H B T \text { promoter; } \\
a m p^{r} \text {. }\end{array}$ & This work \\
\hline HBTL/At1g50570 & $\begin{array}{l}\text { HBT-L derivative contains the At1g50570 coding sequence } \\
\text { under the control of the chimeric } H B T \text { promoter; } a m p^{r} \text {. }\end{array}$ & This work \\
\hline HBTL/At1g50570-GFP & $\begin{array}{l}\text { HBT-L-GFP derivative contains the At1g50570-GFP coding } \\
\text { sequence under the control of the chimeric } H B T \text { promoter; } \\
\text { amp }^{r} \text {. }\end{array}$ & This work \\
\hline HBTL/GAL4BD-At1g28480 & $\begin{array}{l}\text { HBT-L derivative contains the GAL4BD-At1g28480 coding } \\
\text { sequence under the control of the chimeric } H B T \text { promoter; } \\
a^{\prime} p^{r} \text {. }\end{array}$ & This work \\
\hline HBTL/NLS-At1g50570-GFP & $\begin{array}{l}\text { HBT-L-GFP derivative contains the NLS-At1g50570-GFP } \\
\text { coding sequence under the control of the chimeric HBT } \\
\text { promoter; } a m p^{r} \text {. }\end{array}$ & This work \\
\hline pBD & $\begin{array}{l}\text { A pBridge derivative, yeast vector for the expression of } \\
\text { GAL4BD-fusion protein under the control of the } A D H 1 \\
\text { promoter and the expression of HA-NLS-fusion protein } \\
\text { under the control of the Met } 25 \text { promoter; TRP } 1 \text {, amp }{ }^{r} \text {. }\end{array}$ & R. Weigel, unpublished \\
\hline pBD-/At1g28480 & $\begin{array}{l}\mathrm{pBD} \text { derivative, contains } H A-N L S-A t 1 g 28480 \text { coding } \\
\text { sequence under the control of the Met25 promoter; TRP } 1 \text {, } \\
a m p^{r} \text {. }\end{array}$ & This work \\
\hline pBD-/At1g50570 P & $\begin{array}{l}\text { pBD derivative, contains the At1g50570 isolated cDNA in- } \\
\text { frame with } H A \text { and } N L S \text { under the control of the Met } 25 \\
\text { promoter; TRP1, amp }{ }^{r} \text {. }\end{array}$ & This work \\
\hline $\mathrm{pBL}$ & $\begin{array}{l}\text { A pBridge derivative, vector for the expression of GAL4BD- } \\
\text { fusion protein under the control of the } A D H 1 \text { promoter and } \\
\text { the expression of proteins under the control of the Met } 25 \\
\text { promoter; TRP1, amp }{ }^{r} \text {. }\end{array}$ & This work \\
\hline pBL-/TGA1 & $\begin{array}{l}\mathrm{pBL} \text { derivative contains the } T G A 1 \text { coding sequence under } \\
\text { the control of the Met } 25 \text { promoter; } T R P 1, a m p^{r} \text {. }\end{array}$ & This work \\
\hline pBL-/TGA2.2 & $\begin{array}{l}\mathrm{pBL} \text { derivative contains the TGA2. } 2 \text { coding sequence under } \\
\text { the control of the Met } 25 \text { promoter; TRP } 1, a m p^{r} \text {. }\end{array}$ & This work \\
\hline
\end{tabular}




\begin{tabular}{|c|c|c|}
\hline Plasmid & Description & Reference \\
\hline pBL-/TGA2.2-VP16 & $\begin{array}{l}\mathrm{pBL} \text { derivative contains the TGA2.2-VP16 coding sequence } \\
\text { under the control of the Met } 25 \text { promoter; TRP1, amp }{ }^{r} \text {. }\end{array}$ & This work \\
\hline pDONR207 & The Gateway donor vector; $\mathrm{Gm}^{r}, \mathrm{Cm}^{r}$. & GIBCOBRL \\
\hline pDONR207/At1g28480 & $\begin{array}{l}\text { pDONER } 207^{\mathrm{TM}} \text { derivative contains the At } 1 \mathrm{~g} 28480 \text { full-length } \\
\text { coding sequence as a gateway construct; } \mathrm{Gm}{ }^{r} \text {. }\end{array}$ & This work \\
\hline pDONR207/At1g50570 & $\begin{array}{l}\text { pDONER } 207^{\mathrm{TM}} \text { derivative contains the } A t 1 \mathrm{~g} 50570 \text { full-length } \\
\text { coding sequence as a gateway construct; } \mathrm{Gm}^{r} \text {. }\end{array}$ & This work \\
\hline pET28a & $\begin{array}{l}\text { Vector for } 6 x \text { His-fusion protein expression under the control } \\
\text { of the IPTG-inducible } T 7 \text { promoter and lac-operator; } \mathrm{km}^{r} \text {. }\end{array}$ & Novagen \\
\hline pET28a/TGA2.2 $2^{\text {Cys181Ser }}$ & $\begin{array}{l}\text { pET28a derivative contains the } 6 x \text { His-TGA2.2 } 2^{\text {Cys } 181 \text { Ser- }} \\
\text { StripTag coding sequence; } \mathrm{km}^{r} \text {. }\end{array}$ & This work \\
\hline pET28a/TGA2.2 & $\begin{array}{l}\text { pET28a derivative contains the } 6 x \text { His-TGA2.2-StripTag } \\
\text { coding sequence; } \mathrm{km}^{r} \text {. }\end{array}$ & R. Weigel, unpublished \\
\hline pFGC5941 & $\begin{array}{l}\text { Gateway binary vector for RNAi constructs under the control } \\
\text { of the } 35 S \text { promoter; } k m^{r}, P P T^{r} \text {. }\end{array}$ & $\begin{array}{l}\text { http://ag.arizona.edu/ch } \\
\text { romatin/fgc5941.html }\end{array}$ \\
\hline pFGC5941/At1g28480 & $\begin{array}{l}\text { pFGC5941 derivative contains an At1g28480 RNAi } \\
\text { construct; } \mathrm{km}^{r}, P P T^{r} \text {. }\end{array}$ & This work \\
\hline pFGC5941/At1g50570 & $\begin{array}{l}\text { pFGC5941 derivative contains an At1g50570 RNAi } \\
\text { construct; } k^{r}{ }^{r}, P P T^{r} \text {. }\end{array}$ & This work \\
\hline pGAD10/A.th cDNA & $\begin{array}{l}\text { pGAD10 derivative contains an Arabidopsis cDNA library in- } \\
\text { frame with } G A L 4 A D \text { coding sequence; } L E U 2, a m p^{r} \text {. }\end{array}$ & Clontech \\
\hline pGAD10/At1g28480 & $\begin{array}{l}\text { pGAD10 derivative contains the At1g28480 isolated cDNA } \\
\text { fused in-frame with } G A L 4 A D ; L E U 2, a m p^{r} \text {. }\end{array}$ & This work \\
\hline pGAD10/At1g50570 P & $\begin{array}{l}\text { pGAD10 derivative contains the At1g50570 isolated cDNA } \\
\text { insert; } L E U 2, a m p^{r} \text {. }\end{array}$ & This work \\
\hline pGAD10/At4g00270 & $\begin{array}{l}\text { pGAD10 derivative contains the } A t 4 g 00270 \text { isolated cDNA } \\
\text { fused in-frame with } G A L 4 A D ; L E U 2, a m p^{r} \text {. }\end{array}$ & This work \\
\hline pGAD10/At5g55530 P & $\begin{array}{l}\text { pGAD10 derivative contains the } A t 5 g 55530 \text { isolated cDNA } \\
\text { in-frame with } G A L 4 A D ; L E U 2, a m p^{r} \text {. }\end{array}$ & This work \\
\hline pGAD424 & $\begin{array}{l}\text { Yeast vector for the expression of GAL4AD-fusion protein } \\
\text { under the control of the } A D H 1 \text { promote; } L E U 2, a m p^{r} \text {. }\end{array}$ & Clontech \\
\hline pGAD424/At1g28480 & $\begin{array}{l}\text { pGAD424 derivative contains the At1g28480 coding } \\
\text { sequence in-frame with } G A L 4 A D ; L E U 2, a m p^{r} \text {. }\end{array}$ & This work \\
\hline pGAD424/At1g50570 F & $\begin{array}{l}\text { pGAD424 derivative contains the At1g50570 coding } \\
\text { sequence in-frame with GAL4AD; LEU2, amp }{ }^{r} \text {. }\end{array}$ & This work \\
\hline
\end{tabular}




\begin{tabular}{|c|c|c|}
\hline Plasmid & Description & Reference \\
\hline pGAD424/At5g55530 F & $\begin{array}{l}\text { pGAD424 derivative contains the At5g55530 coding } \\
\text { sequence in-frame with } G A L 4 A D ; L E U 2, a m p^{r} \text {. }\end{array}$ & This work \\
\hline pGAD424/GDM & $\begin{array}{l}\text { pGAD424 derivative contains the At1g28480 cysteine } \\
\text { double mutant }(G D M) \text { coding sequence in-frame with } \\
\text { GAL4AD; LEU2, } a m p^{r} \text {. }\end{array}$ & This work \\
\hline pGAD424/GSM & $\begin{array}{l}\text { pGAD424 derivative contains the At1g28480 cysteine single } \\
\text { mutant (GSM) coding sequence in-frame with GAL4AD; } \\
\text { LEU2, } a m p^{r} \text {. }\end{array}$ & This work \\
\hline pGAD424/N.t cDNA & $\begin{array}{l}\text { pGAD424 derivative contains an tobacco cDNA library in- } \\
\text { frame with } G A L 4 A D ; L E U 2, a m p^{r} \text {. }\end{array}$ & Strathmann et al., 2001 \\
\hline pGAD424/NPR1 & $\begin{array}{l}\text { pGAD424 derivative contains the NPR1 coding sequence in- } \\
\text { frame with GAL4AD; LEU2, amp }{ }^{r} \text {. }\end{array}$ & R. Weigel, unpublished \\
\hline pGAD424/TGA1a & $\begin{array}{l}\text { pGAD424 derivative contains the } T G A 1 a \text { coding sequence } \\
\text { in-frame with } G A L 4 A D ; L E U 2, a m p^{r} \text {. }\end{array}$ & Thurow, 2002 \\
\hline pGAD424/TGA2.1 & $\begin{array}{l}\text { pGAD424 derivative contains the } T G A 2.1 \text { coding sequence } \\
\text { in-frame with GALAAD; LEU2, } a m p^{r} \text {. }\end{array}$ & Thurow, 2002 \\
\hline pGAD424/TGA2.2 & $\begin{array}{l}\text { pGAD424 derivative contains the } T G A 2.2 \text { coding sequence } \\
\text { in-frame with GALAAD; LEU2, } a m p^{r} \text {. }\end{array}$ & Thurow, 2002 \\
\hline pGAD424/TGA10 & $\begin{array}{l}\text { pGAD424 derivative contains the } T G A 10 \text { coding sequence } \\
\text { in-frame with } G A L 4 A D ; L E U 2, a m p^{r} \text {. }\end{array}$ & This work \\
\hline pBDAt1g28480/Met25::TGA1 & $\begin{array}{l}\mathrm{pBD} \text { derivative contains the } A t 1 g 28480 \text { coding sequence in- } \\
\text { frame with } G A L 4 B D \text { under the control of the } A D H 1 \text { promoter } \\
\text { and the } H A-N L S-T G A 1 \text { coding sequence under the control } \\
\text { of Met } 25 \text { promoter; TRP1, amp }{ }^{r} \text {. }\end{array}$ & This work \\
\hline pBDAt1g28480/Met25::TGA2.2 & $\begin{array}{l}\text { pBD derivative contains the } A t 1 g 28480 \text { coding sequence in- } \\
\text { frame with } G A L 4 B D \text { under the control of the } A D H 1 \text { promoter } \\
\text { and the } T G A 2.2 \text { coding sequence under the control of Met } 25 \\
\text { promoter; TRP1, amp }{ }^{r} \text {. }\end{array}$ & This work \\
\hline pBDGDM/Met25::TGA2.2 & $\begin{array}{l}\text { pBD derivative contains the } G D M \text { coding sequence in-frame } \\
\text { with } G A L 4 B D \text { under the control of the } A D H 1 \text { promoter and } \\
\text { the } H A-N L S-T G A 2.2 \text { coding sequence under the control of } \\
\text { Met } 25 \text { promoter; TRP1, ampr. }\end{array}$ & This work \\
\hline pBDTGA2.2/Met25::At1g28480 & $\begin{array}{l}\text { pBD derivative contains the TGA2.2 coding sequence in- } \\
\text { frame with GAL4BD under the control of the } A D H 1 \text { promoter } \\
\text { and the HA-NLS-At1g28480 coding sequence under the } \\
\text { control of Met } 25 \text { promoter; TRP1, amp }{ }^{r} \text {. }\end{array}$ & This work \\
\hline pGBT9/At1g28480 & $\begin{array}{l}\text { pGBT9 derivative contains the } A t 1 g 28480 \text { coding sequence } \\
\text { in-frame with } G A L 4 B D ; T R P 1, a m p^{r} \text {. }\end{array}$ & This work \\
\hline
\end{tabular}




\begin{tabular}{|c|c|c|}
\hline Plasmid & Description & Reference \\
\hline pGBT9/At1g50570 F & $\begin{array}{l}\text { pGBT9 derivative contains the At1g50570 coding sequence } \\
\text { in-frame with GAL4BD, TRP1 ampr. }\end{array}$ & This work \\
\hline pGBT9/At1g50570 P & $\begin{array}{l}\text { pGBT9 derivative contains the At1g50570 isolated cDNA in- } \\
\text { frame with GAL4BD; TRP1, amp }{ }^{r} \text {. }\end{array}$ & This work \\
\hline pGBT9/At5g20500 & $\begin{array}{l}\text { pGBT9 derivative contains the } A t 5 g 20500 \text { coding sequence } \\
\text { in-frame with } G A L 4 B D, T R P 1 \mathrm{amp}^{r} \text {. }\end{array}$ & This work \\
\hline pGBT9/At5g40370 & $\begin{array}{l}\text { pGBT9 derivative contains the } A t 5 g 40370 \text { coding sequence } \\
\text { in-frame with } G A L 4 B D, T R P 1 \mathrm{amp}^{r} \text {. }\end{array}$ & This work \\
\hline pGBT9/At5g55530 F & $\begin{array}{l}\text { pGBT9 derivative contains the } A t 5 g 55530 \text { coding sequence } \\
\text { in-frame with GAL4BD, TRP1 amp }{ }^{r} \text {. }\end{array}$ & This work \\
\hline pGBT9/GDM & $\begin{array}{l}\text { pGBT9 derivative contains the GDM coding sequence in- } \\
\text { frame with } G A L 4 B D ; T R P 1, a m p^{r} \text {. }\end{array}$ & Thurow, 2002 \\
\hline pGBT9/TGA2 & $\begin{array}{l}\text { pGBT9 derivative contains the } T G A 2 \text { coding sequence in- } \\
\text { frame with } G A L 4 B D ; T R P 1, a m p^{r} \text {. }\end{array}$ & R. Weigel, unpublished \\
\hline pGBT9/TGA2.2 & $\begin{array}{l}\text { pGBT9 derivative contains the TGA2.2 coding sequence in- } \\
\text { frame with GAL4BD; TRP1, } a m p^{r} \text {. }\end{array}$ & Thurow, 2002 \\
\hline pGBT9/TGA2.2 C-term & $\begin{array}{l}\text { pGBT9 derivative contains the TGA2.2 C-terminus coding } \\
\text { sequence in-frame with GAL4AD; TRP1, amp r. }\end{array}$ & This work \\
\hline pGBT9/TGA5 & $\begin{array}{l}\text { pGBT9 derivative contains the TGA5 coding sequence in- } \\
\text { frame with } G A L 4 B D ; T R P 1, a m p^{r} \text {. }\end{array}$ & R. Weigel, unpublished \\
\hline pGBT9/TGA6 & $\begin{array}{l}\text { pGBT9 derivative contains the } T G A 6 \text { coding sequence in- } \\
\text { frame with } G A L 4 B D ; T R P 1, a m p^{r} \text {. }\end{array}$ & R. Weigel, unpublished \\
\hline pGBT9/TGA2.2 $2^{\text {Cys181Ser }}$ & $\begin{array}{l}\text { pGBT9 derivative contains the TGA2. } 2^{\text {Cys } 181 \text { Ser }} \text { coding } \\
\text { sequence in-frame with } G A L 4 B D ; T R P 1, a m p^{r} \text {. }\end{array}$ & This work \\
\hline pGEM-T/At1g28480 & pGEM-T derivative contains At1g28480 PCR product; $a m p^{r}$. & This work \\
\hline pGEM-T/At1g50570 & pGEM-T derivative contains At1g50570 PCR product; $a m p^{r}$. & This work \\
\hline pGEM-T/At5g55530 & pGEM-T derivative contains At5g55530 PCR product; $a m p^{r}$. & This work \\
\hline pGEM-T/GDM & pGEM-T derivative contains GDM PCR product; amp ${ }^{r}$. & This work \\
\hline pGEM-T/GSM & pGEM-T derivative contains GSM PCR product; $a m p^{r}$. & This work \\
\hline pGEX-4T-1 & $\begin{array}{l}\text { Expression vector for GST-protein fusion under the control } \\
\text { of the IPTG-inducible tac promoter; } \mid a l^{q} \text {, } a m p^{r} \text {. }\end{array}$ & Amersham Pharmacia \\
\hline pGEX-4T-1/At1g50570 & $\begin{array}{l}\text { pGEX-4T derivative contains the GST-At1g50570 fusion } \\
\text { protein coding sequence; } a m p^{r} \text {. }\end{array}$ & This work \\
\hline pLEU-/Met25::TGA2.2 & $\begin{array}{l}\text { pGAD424 derivative contains the } T G A 2.2 \text { coding sequence } \\
\text { under the control of Met } 25 \text { promoter; } L E U 2, a m p^{r} \text {. }\end{array}$ & This work \\
\hline
\end{tabular}




\subsubsection{Primers}

Primer

At1g28480 C63 C

At1g28480 C63 N

At1g28480 C60-C63 C

At1g28480 C60-C63 N

At1g28480 gateway bck

At1g28480 gateway fwd

At1g28480 GFP bck

At1g28480 transient bck

At1g28480 transient fwd

At1g50570 full bck

At1g50570 full fwd

At1g50570 GFP bck

At1g50570 gateway bck

At1g50570 gateway fwd

At1g50570 transient bck

At1g50570 transient fwd

At5g55530 full bck

At5g55530 full fwd

Actin18 sense

Actin18 antisense

GAD lower

GAD upper

pBridge seq bck

pBridge seq fwd

TGA2.2 C

TGA2. $2^{\text {Cys } 181 \text { Ser }} \mathrm{C}$

TGA2.2 ${ }^{\text {Cys } 181 \text { Ser } N}$
Sequence $5^{\prime} \rightarrow 3^{\prime}$

AGG ATG TTG CAT GTC TCA TGT GGT GAG G

TCA CCA CAT GAG ACA TGC AAC ATC CTC TC

GGA GAG GAT CTT GCA TGT CTC ATG TGG

TCA CCA CAT GAG ACA TGC AAG ATC CTC TC

GGG GAC CAC TTT GTA CAA GAA AGC TGG GTC ATT AAT TTA CAA TCA CAA CC GGG GAC AAG TTT GTA CAA AAA AGC AGG CTC CAT GCA AGG GAA CGA TTT CTT G GGT ACC CAA CCA CAG AGA GCC CCA ACT TC

CTG CAG TCA CAA CCA CAG AGC CCC AA

GGT ACC ATG CAA GGA ACG GAT TTC TTG

GGA GAT CTT CGC TAC TTC TGA TGC CAA AC

AGA TCT TTA TGG AAT CTC CAC ATT CT

GGT ACC GAA GAA GGC TCT ACT CCC GT

GGG GAC CAC TTT GTA CAA GAA AGC TGG GTC TCG CTA TTC TGA TGC CAA A GGG GAC AAG TTT GTA CAA AAA AGC AGG CTC CAT GAA ATC TCC ACA TTC TGA GCG GCC GCT CAG AAG AAG GCT CTA CTC C

GGT ACC TCT CCA TGG AAT CTC CAC ATT CTG A

AGA TCT CAA ACA TGA TTA GGC AGC AGA AGT TC

AAA GAT CTA CAT GTC TCT TCT GGA TGT GCA AGT TT

AGG TCT CCA TCT CTT GCT CG

GCT GGA TTC GCT GGA GAT GA

GAT GCA CAG TTG AAG TGA ACT TGC GGG G

TTC GAT GAT GAA GAT ACC CCA CCA AAC CC

TCC AAA GAA GCA CCA CCA CCA GTA

TAC AGG GTC GTC AGA TAC ATA

GCG AAT TCC AAC GAG CTC CAC AAC AGG GCA TAT TTA

GAG ATC CTT CTT GTG GCT TGG TGG

CCA AGC CAC AAG AAG GAT CTC

\subsubsection{Oligonucleotides and DNA Fragments}

\section{Oligonucleotide or Fragment}

As-1 element (fragment from pUC18/as-1) pBridge linker (oligonucleotide from MBI)
Sequence $5^{\prime} \rightarrow 3^{\prime}$

nnnnnTGACGTAAgggaTGACGCACnnnnn

CAT ATG GGG GCC ATA CCA TGG GCG AGC TCA CTA GTA GAT C 


\subsubsection{Hybridization Probes}

$\begin{array}{lll}\text { Probe } & \text { Source } & \text { Reference }\end{array}$

At1g28480

A $500 \mathrm{~kb}$ At1g28480 PCR product

This work

At1g50570

An $1130 \mathrm{~kb}$ At1g50570 PCR product

This work

GST6 from Arabidopsis

A 600 bp Sall fragment from pGEM-GST6

Brenner, 2002

$P R-1$ from Arabidopsis

A $500 \mathrm{bp}$ EcoRI fragment from pSK-AtPR1

Brenner, 2002

\subsubsection{DNA Standards}

DNA Standard

$\lambda$ EcoRI, HindIII

Self preparation
Ladder

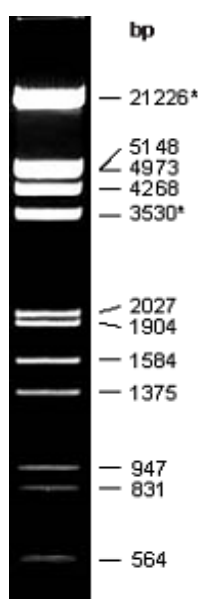

MassRuler ${ }^{\mathrm{TM}}$ DNA Ladder Mix

MBI Fermentas

\begin{tabular}{|c|c|c|}
\hline & $\begin{array}{r}8000 \\
-6000 \\
-5000 \\
-4000\end{array}$ & $\begin{array}{l}160 \\
120 \\
100 \\
60\end{array}$ \\
\hline & -3000 & 60 \\
\hline & -2500 & 50 \\
\hline$=$ & -2000 & 40 \\
\hline 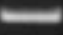 & -1500 & 32 \\
\hline & -1031 & 200 \\
\hline & -500 & 180 \\
\hline & E $_{700}^{000}$ & $\begin{array}{l}160 \\
140\end{array}$ \\
\hline & -600 & 120 \\
\hline & -500 & \\
\hline 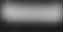 & -400 & 80 \\
\hline 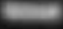 & -300 & 60 \\
\hline$=$ & -200 & \\
\hline$=$ & $=00$ & \\
\hline
\end{tabular}




\subsection{Proteins}

\subsubsection{Antibodies}

\begin{tabular}{|c|c|c|c|}
\hline Antibody & Specificity & Properties & Reference \\
\hline$\alpha$-rabbit lgG & Rabbit immunoglobulin G & Donkey polyclonal & Amersham \\
\hline$\alpha-H A$ & HA-Epitoptag & Rabbit polyclonal & Santa Cruz \\
\hline$\alpha-H i s$ & $6 \mathrm{x}$ His & Rabbit polyclonal & BioScience \\
\hline$\alpha-G S T$ & GST & Rabbit polyclonal & Amersham \\
\hline$\alpha-T G A 2.2 N$-term & $\mathrm{N}$-terminus of TGA2.2 & Rabbit polyclonal & R. Weigel, unpublished \\
\hline
\end{tabular}

\subsubsection{Enzymes}

\section{Enzyme}

Advantage $^{\mathrm{TM}}$ DNA Polymerase Mix

Calf intestine alkaline phosphatase

Cellulase "Onozuka R-10"

DNase (RNase-free)

DNA restriction enzymes type II MBI

Klenow fragment exo

Lyticase

Lysozym

Macerozyme R-10

Pectinase

Pfu DNA-Polymerase

RNase A (DNase-free)

T4 DNA ligase

Taq DNA polymerase

Ribonuclease Inhibitor

\section{Manufacture}

Clontech

MBI Fermentas

Serva

Promega

Fermentas

Gibco BRL

New England Biolabs

MBI Fermentas

Sigma

Serva

Serva

Fluka

Stratagene

MBI Fermentas

MBI Fermentas

MBI Fermentas

MBI Fermentas 


\subsubsection{Protein Standard}

Protein Standard

Prestained Protein Ladder
Manufacture

MBI Fermentas
Ladder

$\mathbf{k D a}$
-180
-130
-100
-70
$\sim 55$
$\sim 45$
-35
-25
-15
-10

\subsection{Chemicals}

\section{Chemical}

$30 \%(\mathrm{w} / \mathrm{v})$ acrylamide: $\mathrm{N}, \mathrm{N}$-methylene-bisacrylamide (37.5:1)

$40 \%(\mathrm{w} / \mathrm{v})$ acrylamide: N,N-methylene-bisacrylamide (19:1)

3-Amino-1,2,4 Triazole (3-AT)

4-Methylumbelliferyl (4-MU)

4-Methylumbelliferyl- $\beta$-D-Glucuronid (4-MUG)

2-[N-morpholino]-ethanesulfonic acid (MES)

3-[N-morpholino]-propanesulfonic acid (MOPS)

[a-32P]-dATP (800 Ci/mmol)

Acetic Acid

Adenine

Agar Bacteriological

Agarose SeaKem LE

Ammonium persulfate (APS)

Ampicillin (Amp)

ß-mercaptoethanol (ß-ME)

Basata ${ }^{\circledR}$

Bicine

Boric acid

Bovine Serum Albumin (BSA)

Bradford reagent
Manufacture

Roth

Roth

Sigma

Sigma

Roth; Duchefa

Sigma

Roth

Hartmann Analytic

Roth

Sigma

GIBCO BRL

Biozym

Biometra

AGS

Roth

AgrEvo

Serva

Serva

Serva

Roth 


\section{Chemical}

Bromphenolblue

Calcium carbonate

Calcium chloride $\left(\mathrm{CaCl}_{2}\right)$

Chloroform

Coomassie brilliant blue R-250

$\mathrm{N}, \mathrm{N}$-dimethylformamide (DMF)

Dimethylsulfoxide (DMSO)

Diamide

Dithiotreitol (DTT)

DNA carrier

DNTPs

Ethylenediaminetetraacetic (EDTA)

Ethanol

Ethidium Bromide (EtBr)

Formaldehyde (37\%)

Formamid

Gentamycin (Gm)

Glacial acetic acid

Glucose

Glutathione

Glycerol

Glycine

Hepes

Histidine

Hydrochloric acid $(\mathrm{HCl})$

Imidazol

Isoamyl alcohol

Isopropanol

Isopropylthiogalactoside (IPTG)

Leucin

Lycine

Kanamycin (Km)

Magnesium acetate

Magnesium Chloride $\left(\mathrm{MgCl}_{2}\right)$

Magnesium sulfat-Heptahydrat $\left(\mathrm{MgSO}_{4} .7 \mathrm{H}_{2} \mathrm{O}\right)$

\section{Manufacture}

Roth

Merck

Merck

Merck

Merck

J.T. Baker Chemicals

Roth

Sigma

Sigma

Sigma

MBI

Roth

Merck

Roth

Roth

Fluka

Duchefa

Merck

Sigma

Sigma

Roth, Merck

Roth

Roth

Sigma

Roth

Sigma

Roth

Roth

BioTech Grade

Sigma

Sigma

Sigma

Merck

AppliChem

AppliChem 


\section{Chemical}

Manitol

Methanol

Methionine

Non-fat dried milk SUCOFIN $®$

o-Nitrophenyle- $\beta$-D-Galactopyranosid (ONPG)

Orange G

Peptone

Phenol

Phenylmethanesulfonyl fluoride (PMSF)

Polydesoxyinosin-desoxycitidine (poly $\mathrm{dl} / \mathrm{dC}$ )

Polyethylene glycol (PEG) diverse

Potassium acetate

Potassium ferricyanide

Potassium ferrocyanide

Potassium chloride $(\mathrm{KCl})$

Potassium glutamate

Lithium acetate

SA

Select Agar

Select Sarcosyl

Selected yeast Extract

Sephadex G-50

SDS (Sodiumlsulfat)

Silwet L77

Sodium acetate

Sodium chloride $(\mathrm{NaCl})$

Sodium hydroxide $(\mathrm{NaOH})$

Sodium carbonate

Sodium citrate

Sodium phosphate, dibasic $\left(\mathrm{Na}_{2} \mathrm{HPO}_{4}\right)$

Sodium phosphate, monobasic $\left(\mathrm{NaH}_{2} \mathrm{PO}_{4}\right)$

Sorbitol

Streptomycin (Strp)

Sucrose

TEMED

\section{Manufacture}

Roth

Roth

Sigma

TSI

Sigma

Sigma

Roth

AppliChem

Fluka

Sigma

Roth, Sigma

Merck

Merck

Merck

Roth

Merck

Sigma

Sigma

Life Technologies

Sigma

GIBCO BRL

Pharmacia

Roth

Sigma

Roth

Roth

Merck

Merck

Merck

Merck

Merck

Sigma

Duchefa

Roth

Roth 


\section{Chemical}

\section{Manufacture}

Tetracycline

Sigma

Tryptophan

Sigma

Tris (hydroxymethyl) aminomethane

Roth

Triton X-100

Roth

Tween $\circledast 20$

Sigma

Tyrosine

Sigma

Uracil

Sigma

Urea

Roth

X-Gluc

Roth

X-ray film developer LX24

Kodak

$X$-ray film fixator AL4

Kodak

Xylenecyanol FF

Roth

Yeast nitrogen base without amino acids

Difco

\subsection{Consumables}

\section{Product}

3MM paper

Aluminum folia

Electroporation cuvettes

Micro Spin ${ }^{\text {TM }}$ G25 Column

Glass material

Glutathione Sepharose 4B

Microscopic slides

Microtiter plates

Nickel Nitrilotriacetic Acid (NiNTA®) Resin

Nylon membranes Hybond-N+

Parafilm® M

Protran $®$ Nitrocellulose Sheets

Single-use plastic ware

Greiner, Biozym

X-ray films Cronex 10T, Cronex 4

\section{Manufacture}

Whatman

Roth

BioRad

Pharmacia

Brand, Schott

Amersham Pharmacia

Roth

Roth

Qiagen

Amersham Pharmacia

American National Can TM

Schleicher BioScience

Sarstedt, Eppendorf

Roth

DuPont 


\subsection{Devices}

\begin{tabular}{|c|c|c|}
\hline Device & Model & Manufacture \\
\hline Autoclave & 3870 ELV & Tuttnauer \\
\hline Automatic pipettes & & Gilson \\
\hline \multirow[t]{2}{*}{ Balance } & SPO51, SAC62 & Scaltec \\
\hline & 1207 MP2 & Sartorius \\
\hline Cold chamber $\left(4{ }^{\circ} \mathrm{C}\right)$ & & ILKA Zell \\
\hline Cooling centrifuge & Sorvall RC 5B Plus & DuPont \\
\hline CytofFluorll plate reader & & PerSpetive \\
\hline Digital camera & Coolpix & Nikon \\
\hline Electroporator & GenePulser II & BioRad \\
\hline Fluorescent microscope & BX 51 & Olympus \\
\hline Gel documentation station & & MWG Biotech \\
\hline Gel electrophoresis chamber, horizontal & & Institute's workshop \\
\hline \multirow[t]{2}{*}{ Gel electrophoresis chamber, vertical } & Joey ${ }^{\text {TM }}$ \#JGC-4 & AGS \\
\hline & V 15-17 & Gibco BRL \\
\hline Handheld radiation monitor & Contamat & Eberline \\
\hline Heating blocks & HB-130 & Unitek \\
\hline Heating shaker & Thermo mixer 5436 & Eppendorf \\
\hline Heating stirrer & RCT basic & IKA Labortechnik \\
\hline Hybridization ovens & & Bachhofer \\
\hline Hybridization shaking water bath & The Belly Dancer® & Stovall \\
\hline Ice machine & AF-20 & Scotman \\
\hline Incubation chambers & & WTC binder Memmert \\
\hline PCR thermocycler & ProGene & Techne \\
\hline Microtiter plate Spectrophotometer & MRX Plate Reader & Dynex \\
\hline MiniCycler & PTC-150 & MJ Research \\
\hline Peristaltic pump & Cyclo1 & Roth \\
\hline $\mathrm{pH}$-meter & HI 9321 & Hanna Instruments \\
\hline Phosphoimager & BAS-1000 & Fuji \\
\hline Photometer & Unikon 720 LC & Kontron \\
\hline \multirow[t]{2}{*}{ Plant growth chambers } & & Weiss Technik \\
\hline & I-37L4VL & Percival Scientific \\
\hline Polyacrylamide Gel Chamber & & AGS \\
\hline RNA-/DNA-calculator & GeneQuant II & Pharmacia \\
\hline Shaker & ST 5 & M. Zipperer GmbH \\
\hline
\end{tabular}




\begin{tabular}{lll} 
Device & Model & Manufacture \\
\hline Scales & A $120 \mathrm{~S}$ & Sartorius Analytic \\
Scanner & ScanJet 4c & Hewlett Packard \\
Sequencing station & ABI PRISM ${ }^{\mathrm{TM}} 310$ & Perkin Elmer \\
Spectrophotometer & Novaspek Biochrom & LKB \\
Sterile benches & Microflow Laminar & Nunc \\
Table-top centrifuges & Biofuge Pico & Heraeus \\
Table-top cooling centrifuges & $5403,5415 \mathrm{R}$ & Eppendorf \\
Ultra-centrifuge & Centricon T-1065 & Kontron \\
Ultra-low freezers $\left(-80^{\circ} \mathrm{C}\right)$ & C54285 & New Brusnwick Scientific \\
Ultra-sound sonicator & SoniPrep 150 & Scientific Instr. \\
UV-transilluminator & FLX 20 M & Vilber Lourmat \\
Vacuum evaporator & SpeedVac L 05 & WKF \\
Vacuum gel dryer & Phero-Temp & Biotec-Fischer \\
Vortex & L46 & Labinco BV \\
Water deionization system & Option 4, Maxima & ELGA \\
Water bath & 1086 & GFL \\
Wet Blotting Apparatus & & Institute's workshop \\
\hline
\end{tabular}

\subsection{Kits}

\section{Kit}

Advantage ${ }^{\mathrm{TM}}$ PCR Enzyme Systems

BigDye $^{\mathrm{TM}}$ Enhanced Terminators (ET) Cycle Sequencing Kit

Enhanced Chemiluminescence Plus ${ }^{\mathrm{TM}}(\mathrm{ECL}+)$ Kit

Gateway ${ }^{\circledR}$ Technology Kit

Invisorb $®$ Spin Plant RNA Mini Kit I

Megaprime. DNA Labeling Systems

pGEM®-T vector system Kit

QIAGEN® QIAfilter ${ }^{\text {TM }}$ Midi-/Maxi- Mega Kits

QIAprep Spin Miniprep® Kit

QIAquick® Gel Extraction Kit

RevertAid $^{\mathrm{TM}}$ Minus First Strand cDNA Synthesis Kit

RNeasy Plant Mini® Kit

\section{Manufacture}

Clontech

Perkin-Elmer

Amersham Biosciences

Invitrogen

Invitek

Amersham Pharmacia

Promega

QIAGEN

QIAGEN

QIAGEN

MBI Fermentas

QIAGEN 


\subsection{Buffers and Solution}

\section{Buffer or Solution}

5x Binding buffer for EMSA

Blocking buffer for Protran $®$ membranes

Blotting buffer for Protran $®$ membrane

Buffer 1 for small-scale plasmid DNA isolation

Buffer 2 for small-scale plasmid DNA isolation

Buffer 3 for small-scale plasmid DNA isolation

Cracking buffer

Church hybridization solution

Coomassie fixing solution

Coomassie staining solution

Coomassie destain solution

10x Drop-in -Leucine -Tryptophan -Histindin solution

\section{Components and Concentrations}

$125 \mathrm{mM}$ Hepes, adjust $\mathrm{pH}$ to 7.5 with $\mathrm{KOH}$

$50 \mathrm{mM} \mathrm{MgCl}_{2}$

$1 \mathrm{mM} \mathrm{CaCl}_{2}$

$50 \%(v / v)$ Glycerol

$5 \mathrm{mM}$ DTT (fresh)

2 mM PMSF (fresh)

1x PBS-T

$5 \%(\mathrm{w} / \mathrm{v})$ Non-fat dried milk

192 mM Glycine

$25 \mathrm{mM}$ Tris

$20 \%(v / v)$ Methanol

$50 \mathrm{mM}$ Tris- $\mathrm{HCl}, \mathrm{pH} 8.0$

$10 \mathrm{mM}$ EDTA

$0.2 \mathrm{M} \mathrm{NaOH}$

$1 \%$ SDS

29.4 g Potassium acetate

$5 \mathrm{ml}$ Glacial acetic acid

$\mathrm{H}_{2} \mathrm{O}$ up to $100 \mathrm{ml}$

$8 \mathrm{M}$ Urea

$5 \% \mathrm{w} / \mathrm{v}$ SDS

$40 \mathrm{mM}$ Tris- $\mathrm{HCl}, \mathrm{pH} 6.8$

$0.1 \mathrm{mM}$ EDTA

$0.4 \mathrm{mg} / \mathrm{ml}$ Bromophenol blue

250 mM Sodium phosphate, $\mathrm{pH} 7.2$

1 mM EDTA, pH 8.0

$7 \%(w / v)$ SDS

$25 \%(v / v)$ Isopropanol

$10 \%(v / v)$ Glacial acetic acid

$0.01 \%(w / v)$ Coomassie brilliant blue G-250

$10 \%(\mathrm{v} / \mathrm{v})$ Glacial acetic acid

$10 \%(v / v)$ Glacial acetic acid

200 mg/l L-Adenine /Hemisulfat

300 mg/l L-Lysine

$300 \mathrm{mg} / \mathrm{l} \mathrm{L-Tyrosine}$ 


\section{Buffer or Solution}

DNA loading buffer

DNA extraction buffer

Denaturation extraction buffer for total protein

Fix prot extraction buffer

Glutathione elution buffer

GUS extraction buffer

GUS staining solution

$\mathrm{H}$ Buffer for total protein extraction from yeast

\section{Components and Concentrations}

\author{
$67 \%(w / v)$ Sucrose \\ 50 mM EDTA pH 8.0 \\ $0.42 \%(w / v)$ Bromphenolblue \\ $0.42 \%(w / v)$ Xylenecyanol \\ $0.42 \%(w / v)$ Orange $G$
}

$0.1 \mathrm{M} \mathrm{NaCl}$

$0.01 \mathrm{M}$ Tris- $\mathrm{HCl}, \mathrm{pH} 7.5$

1 mM EDTA

$1 \%$ SDS

4 M Urea

$16.6 \%$ (v/v) Glycerol

$5 \%(\mathrm{v} / \mathrm{v})$ ß-ME (fresh)

$5 \%(\mathrm{~W} / \mathrm{v})$ SDS

$0.5 \%(w / v)$ Bromphenolblue

$50 \mathrm{mM}$ Hepes, pH 7.5 with $\mathrm{KOH}$

$20 \mathrm{mM} \mathrm{KCl}$

$2.5 \mathrm{mM}$ DTT (fresh)

Protein inhibitors mix

100 mM Glutathione

50 mM Tris- $\mathrm{HCl}, \mathrm{pH} 8.0$

$50 \mathrm{mM}$ Sodium phosphate, $\mathrm{pH} 7.0$

10 mM EDTA

$0.1 \%$ Triton $\mathrm{X}-100$

$0.1 \%$ Sarcosyl

$10 \mathrm{mM}$ ß-ME (fresh)

50 mM Sodium phosphate buffer, $\mathrm{pH} 7.0$

$500 \mu \mathrm{M}$ Potassium ferrocyanide

$500 \mu \mathrm{M}$ Potassium ferricyanide

$2 \mathrm{mM} X$-Gluc

25 mM HEPES, $\mathrm{pH} 7.5$ with $\mathrm{KOH}$

$10 \%$ glycerol

1 mM EDTA

$50 \mathrm{mM} \mathrm{NaCl}$

$5 \mathrm{mM} \mathrm{MgCl}_{2}$

$0.5 \%$ ß-ME

$1 \mathrm{M}$ Potassium glutamate

$250 \mathrm{mM}$ Tris- $\mathrm{HCl}, \mathrm{pH} 7.5$

$100 \mathrm{mM}$ Magnesium acetate

$5 \mathrm{mM}$ ß-ME or DTT

$0.5 \mathrm{mg} / \mathrm{ml} \mathrm{BSA}$ 
Buffer or Solution

10x Klenow buffer

Lac-Z buffer

Ligation buffer

Loading buffer for EMSA

MMM solution for BY-2 protoplast preparations

Nickel nitrilotriacetic acid elution buffer

Nickel Nitrilotriacetic Acid Lysis Buffer

Nickel nitrilotriacetic acid wash buffer

Osmoticum (for BY-2 protoplast preparation)

\section{Components and Concentrations}

500 mM Tris- $\mathrm{HCl}, \mathrm{pH} 8.0$

$50 \mathrm{mM} \mathrm{MgCl}$

$10 \mathrm{mM}$ DTT

$16.1 \mathrm{~g} / \mathrm{l} \mathrm{Na}{ }_{2} \mathrm{HPO}_{4} \cdot 7 \mathrm{H}_{2} \mathrm{O}$

$5.50 \mathrm{~g} / \mathrm{l} \mathrm{NaH} \mathrm{PO}_{4} \cdot \mathrm{H}_{2} \mathrm{O}$

$0.75 \mathrm{~g} / \mathrm{l} \mathrm{KCl}$

$0.246 \mathrm{~g} / \mathrm{l} \mathrm{MgSO}{ }_{4} .7 \mathrm{H}_{2} \mathrm{O}$

Adjust $\mathrm{pH}$ to 7.0 with $\mathrm{KOH}$

$40 \mathrm{mM}$ Tris- $\mathrm{HCl}$

$10 \mathrm{mM} \mathrm{MgCl}_{2}$

$10 \mathrm{mM}$ DTT

$42 \%(v / v) 5 x$ Binding buffer for EMSA

$58 \%(v / v)$ Glycerol

$0.5 \mathrm{mM}$ Manitol

$0.1 \%(w / v)$ MES

$15 \mathrm{M} \mathrm{MgCl}_{2}$

$50 \mathrm{mM} \mathrm{NaH}_{2} \mathrm{PO}_{4}$

$300 \mathrm{mM} \mathrm{NaCl}$

250-1000 mM Imidazole

Adjust $\mathrm{pH}$ to $\mathrm{pH} 8.0$

$50 \mathrm{mM} \mathrm{NaH}_{2} \mathrm{PO}_{4}$

$300 \mathrm{mM} \mathrm{NaCl}$

$10 \mathrm{mM}$ Imidazole

Adjust $\mathrm{pH}$ to 8.0

$50 \mathrm{mM} \mathrm{NaH}_{2} \mathrm{PO}_{4}$

$300 \mathrm{mM} \mathrm{NaCl}$

$20 \mathrm{mM}$ Imidazole

Adjust $\mathrm{pH}$ to 8.0

$10 \mathrm{mM}$ Sodium acetate $\mathrm{pH} 5.8$

$250 \mathrm{mM}$ Manitol

$50 \mathrm{mM} \mathrm{CaCl} 2$

$0.01 \%$ (v/v) ß-ME

$0.5 \%(\mathrm{w} / \mathrm{v}) \mathrm{BSA}$

$68 \mathrm{mM} \mathrm{NaCl}$

$58 \mathrm{mM} \mathrm{Na}_{2} \mathrm{HPO}_{4}$

$17 \mathrm{mM} \mathrm{NaH}_{2} \mathrm{PO}_{4}$

$\mathrm{pH} 7.4(\mathrm{NaOH})$

1x PBS

$0.1 \%(v / v)$ Tween 20 
Buffer or Solution

$\mathrm{PCl}$ mix

PEG solution for BY-2 protoplast preparations

Pseudomonas syringae infection solution

RIPA buffer

3x RNA loading buffer

10x SDS-PAGE running buffer

Solution 2 for BY-2 protoplasts

Solution A for yeast

Solution B for yeast

Solution $\mathrm{C}$ for yeast

\section{Components and Concentrations}

25 volumes Phenol

24 volumes Chloroform

1 volume Isoamylalcohol

$40 \%$ (v/v) PEG-4000

$0.4 \mathrm{M}$ Manitol

$0.1 \mathrm{M}$ Calcium carbonate

Adjust $\mathrm{pH}$ around 8.0-9.0 with $\mathrm{KOH}$

Autoclave, stabilize $\mathrm{pH}$ at 5.0-6.0

$10 \mathrm{mM} \mathrm{MgCl} 2$

$0.01 \%$ Silwet L-77

$150 \mathrm{mM} \mathrm{NaCl}$

10 mM Tris, pH 7.2

$0.1 \%$ SDS

1\% Triton X-100

$1 \%$ Deoxycholate

4 mM EDTA

$50 \%$ Formamid

10\% 10x MOPS

$0.45 \%$ Formaldehyd

$7 \%$ Glycerin

0.5\% Bromphenolblau

25 mM Tris- $\mathrm{HCl}, \mathrm{pH} 8.3$

200 mM Glycine

$0.1 \%(w / v)$ SDS

250 mM Manitol

$250 \mathrm{mM}$ sorbitol

$50 \mathrm{mM} \mathrm{CaCl}_{2}$

$1 \mathrm{mM}$ MES

Adjust $\mathrm{pH}$ to 5.8 with $\mathrm{KOH}$

$10 \mathrm{mM}$ Bicine

$1 \mathrm{M}$ Sorbitol

$3 \%$ Ethylenglycol ( $\mathrm{v} / \mathrm{v})$

$\mathrm{pH} 8.35(\mathrm{KOH})$

$200 \mathrm{mM}$ Bicine

40\% PEG 1000 (w/v)

Adjust $\mathrm{pH}$ to 8.35 with $\mathrm{KOH}$

$10 \mathrm{mM}$ Bicine

$150 \mathrm{mM} \mathrm{NaCl}$

Adjust $\mathrm{pH}$ to 8.35 with $\mathrm{KOH}$ 


\section{Buffer or Solution}

$20 \times$ SSC

20x TAE

$5 \times$ TBE

100x TE

W5 solution for BY-2 protoplast

Wall-digestion solution for BY-2 protoplasts

\section{Components and Concentrations}

$2 \mathrm{M} \mathrm{NaCl}$

0.3 M Sodium citrate

Adjust $\mathrm{pH}$ to 7.0 with $\mathrm{HCl}$

$800 \mathrm{mM}$ Tris

20 mM EDTA

$2.3 \%(v / v)$ Glacial acetic acid

$450 \mathrm{mM}$ Tris

$450 \mathrm{mM}$ Boric acid

1 mM EDTA

Adjust $\mathrm{pH}$ to 8.0

$1 \mathrm{M}$ Tris- $\mathrm{HCl}, \mathrm{pH} 8.0$

$0.1 \mathrm{M}$ EDTA

$154 \mathrm{mM} \mathrm{NaCl}$

$125 \mathrm{mM} \mathrm{CaCl}_{2}$

$5 \mathrm{mM} \mathrm{KCl}$

$5 \mathrm{mM}$ Glucose

Adjust $\mathrm{pH}$ around 5.8-6.0 with $\mathrm{KOH}$

Osmoticum

$1 \%(w / v)$ Cellulase Onozuka R10

$0.5 \%$ (w/v) Macerozyme Onozuka R10

$0.1 \%(w / v)$ Pectinase

\subsection{Software}

Program

Acrobat Reader 6.0

BLAST and Bioinformatics

Color View Soft Imaging System

CorelDRAW

Office

PCBAS® Reader 2.09

PhotoPaint

PhotoShop

TINA® 2.0

\section{Company}

Adobe

NCBI, MIPS, TAIR and TIGER

Olympus

Corel

Microsoft

Raytest GmbH

Corel

Adobe

Raytest $\mathrm{GmbH}$ 


\section{$5 \quad$ Methods}

\subsection{Cultivation of Microorganisms}

\subsubsection{Cultivation of Bacteria}

A single colony of $E$. coli cells was cultured overnight at $37^{\circ} \mathrm{C}$ in LB or dYT liquid or solid media in the presence of selective antibiotics. The liquid culture was grown under continuous shacking at 250 rpm in a $37{ }^{\circ} \mathrm{C}$ shaker, while solid cultures were grown in a $37{ }^{\circ} \mathrm{C}$ incubator. Number of cells in a liquid culture was determined by measuring the Optical Density at $600 \mathrm{~nm}\left(\mathrm{OD}_{600}\right)$. A liquid culture with $\mathrm{OD}_{600}$ equal to 0.1 corresponds to $2 \times 10^{7} \mathrm{E}$. coli cells $/ \mathrm{ml}$.

Agrobacterium tumefaciens cells were grown in YEB solid or liquid media at $28{ }^{\circ} \mathrm{C}$ for two or three days. The GV3101 strain requires the presence of rifampicin and gentamycin antibiotics in the media.

P. syringae pv. maculicola ES4326 cells were grown on King's B medium at $28{ }^{\circ} \mathrm{C}$ for two days. Virulent strain required the presence of streptomycin antibiotic in the media, while the avirulent strain carrying the avrRpt2 gene requires the presence of streptomycin and tetracycline.

\subsubsection{Cultivation of Yeast (Saccharomyces cerevisiae)}

Untransformed yeast cells were grown in YPD rich medium in $30{ }^{\circ} \mathrm{C}$ incubators. The yeast YPD liquid culture needs 16-18 hours to grow, while YPD solid culture needs from 2-5 days. The addition of adenine to YPD was crucial to enhance the growth of yeast strains that contain the ade2-101 mutation (all the strains in this study carry this mutation). Transformed yeast strains were grown on SD drop-in medium (lacks specific nutrients) in order to keep selective pressure on transformed plasmids. The 3amino-1,2,4-triazole (3-AT), a competitive inhibitor of the HIS3 gene product, was added in order to suppress background growth on SD medium lacking Histindin, which is resulted from the autonomous HIS3 gene expression. Cells number of the liquid culture was determined by measuring the $\mathrm{OD}_{600}$. $\mathrm{A}$ liquid culture with $\mathrm{OD}_{600}$ equal to 1 corresponds to $1 \times 10^{6} \mathrm{cells} / \mathrm{ml}$.

\subsection{Cultivation and Manipulation of Plants}

\subsubsection{Cultivation and Manipulation of Arabidopsis}

\subsubsection{Soil Culture}

The Arabidopsis plants were grown in soil (Mini-Tray type) in $6 \mathrm{~cm}$ in diameter and $6 \mathrm{~cm}$ height pots. Soil was autoclaved for 30 minutes at $100{ }^{\circ} \mathrm{C}$ before usage. Before sowing the seeds, pots were 
irrigated with water containing a starter fertilizer and an insectside. Sowed seeds were vernalized at $4{ }^{\circ} \mathrm{C}$ for two days before transferring them to an Arabidopsis growth chamber. The Arabidopsis growth chamber conditions were set at $24 / 18{ }^{\circ} \mathrm{C}$ (day/night temperature), $65-75 \%$ relative humidity, 150 $\mu \mathrm{E} / \mathrm{m}^{2} / \mathrm{S}^{2}$ brightness and 14 hours photoperiod. After one week of germination, seeds were transplanted into new pots with a planting density of four plants/pots, watering of the pots took place once or twice every week. For seeds collection, plants were left to set seeds and then were transferred to greenhouse. The plants were covered with bags and left until completely dried. The seeds were sieved, collected and stored at room temperature.

\subsubsection{The Agrobacterium tumefaciens-Mediated Transformation of Arabidopsis}

The transformation of Arabidopsis was done using the floral dip method (Clough and Bent, 1998). Plants were grown at a density of four plants/pot, and when they reached the primary bolts (at a height of 5 to $10 \mathrm{~cm}$ ) stage, a clipping procedure was conducted. The secondary bolts were allowed to grow until reached about 2-10 cm (with few open flowers). Agrobacterium tumefaciens strain GV3101 (pMP90) carrying the corresponding binary plasmid were grown on $5 \mathrm{ml}$ YEB liquid media supplemented with corresponding antibiotics at $28{ }^{\circ} \mathrm{C}$ for two days under continuous shacking at $250 \mathrm{rpm}$. This starter culture was used to inoculate a $500 \mathrm{ml}$ YEB culture that was allowed to grow overnight. Next day, the cells were harvested by centrifugation for 5 minutes at $5000 \mathrm{rpm}$. The cells pellet was washed twice in water, collected by centrifugation and resuspended in $400 \mathrm{ml}$ infiltration medium to a final $\mathrm{OD}_{600}$ of approximately 2.0 prior to use. For the floral dip procedure, the inoculum was filled in a $500 \mathrm{ml}$ beaker. The pots were inverted into the inoculum such that all aboveground tissues were submerged, and plants were then removed after 30 seconds of gentle agitation. Dipped plants were removed from the beaker, placed in a plastic tray and covered with a tall clear-plastic dome to maintain humidity for two days. Plants were grown for a further 3-5 weeks until siliques were mature and dry. Seeds were harvested as described above.

\subsubsection{Inoculation with Bacterial Pathogen}

P. syringae pv. maculicola ES4326 was grown as described above. Cells were harvested by centrifugation for 5 minutes at $5000 \mathrm{rpm}$ and diluted in a $P$. syringae infection solution to a final $\mathrm{OD}_{600}$ of 0.002. The bacterial suspension was pressure-infiltrated on the abaxial side of 3-4 weeks old leaves using a $1 \mathrm{ml}$ syringe.

\subsubsection{Chemical Treatment of Plants}

For SA treatments, an aqueous solution of $1 \mathrm{mM}$ SA was sprayed directly on the leaves until run off. Leaves were harvested at the indicated time points after treatment, flash frozen in liquid nitrogen and 


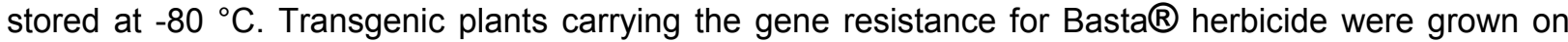
soil. After one week from seeds germination an aqueous solution of $1 \mathrm{mM}$ Basta® was sprayed directly on the seedlings until they were completely wetted. After one week from the treatment the Bastaß resistance plants were transferred to new pots.

For studying the salicylic acid (SA) or auxin (2,4-D) GUS reporter gene-inducible gene expression for the GUS staining of Arabidopsis, plants were grown in soil for 2 weeks. Plants were floated on $20 \mathrm{ml}$ of $20 \mathrm{mM}$ potassium phosphate buffer $\mathrm{pH} 5.8$ and incubated in a climate chamber at $24^{\circ} \mathrm{C}$. The inductions were performed with $1 \mathrm{mM}$ SA or $100 \mu \mathrm{M} 2,4-\mathrm{D}$. The plants were collected after 24 hours and analysed for GUS activity.

\subsubsection{Cultivation and Manipulation of BY-2 Protoplasts}

BY-2 cells suspension culture was grown in a modified MS medium supplemented with $3 \%$ sucrose, $0.9 \mathrm{~g} / \mathrm{l}$ of myo-Inositol and $0.9 \mathrm{~g} / \mathrm{l}$ of thiamine in a $100 \mathrm{ml}$ flask. Cells were cultivated at $26{ }^{\circ} \mathrm{C}$, complete darkness and continuous shacking at $120 \mathrm{rpm}$. Every week a $3 \mathrm{ml}$ culture was transferred to 27 $\mathrm{ml}$ medium for subculturing purpose. The preparation of protoplasts from the BY-2 tobacco suspension cells took place after 3 days of subculturing. $20 \mathrm{ml}$ culture were pelleted using centrifugation at $1440 \mathrm{rpm}$ (soft start option, room temperature and 5 minutes duration were used in all centrifugation steps). The cells were resuspended in $20 \mathrm{ml}$ osmoticum, collected and resuspended in $45 \mathrm{ml}$ wall-digestion solution. The $45 \mathrm{ml}$ volume was divided into 3 plates, which were incubated overnight at $26^{\circ} \mathrm{C}$ in darkness.

\subsection{Standard Molecular Biology Methods}

\subsubsection{Isolation of Plasmid DNA from Bacteria}

\subsubsection{Isolation of Plasmid DNA from E. coli}

Isolation of small amounts of plasmid DNA from $E$. coli for analytical purposes was done using a modification of the alkaline lysis method (Le Gouill et al., 1994). $1.5 \mathrm{ml}$ of E. coli overnight culture were collected by centrifugation at 13000 for 1 minute. The supernatant was removed using a vacuum pump and the cells were resuspended in $100 \mu \mathrm{l}$ of buffer 1 for plasmid DNA isolation. The cell suspension was lysed for 5 minutes on ice using $200 \mu \mathrm{l}$ of buffer 2 for small-scale plasmid DNA isolation. The suspension was neutralized with $150 \mu$ of buffer 3 for small-scale plasmid DNA isolation. The solution was mixed well by inverting 5-6 times and the suspension was centrifuged for 10 minutes at $13000 \mathrm{rpm}$ at room temperature. The aqueous solution $(\sim 450 \mu \mathrm{l})$ was transferred into a new eppendorf tube containing $1 \mathrm{ml}$ of $96 \%(\mathrm{v} / \mathrm{v})$ ethanol. The DNA was left to precipitate for 1 hour at $-20^{\circ} \mathrm{C}$. Plasmid DNA was collected by centrifugation for 10 minutes at $13000 \mathrm{rpm}$ and $4{ }^{\circ} \mathrm{C}$. The pellet was washed with $70 \%(\mathrm{v} / \mathrm{v})$ ethanol and dried for 5 minutes using a speedvac. The DNA was dissolved in $100 \mu \mathrm{l}$ of TE buffer. 
For sequencing and yeast transformation purposes, high-purity plasmid DNA was isolated using QIAprep® Spin Mini kit following the manufacturer's instructions. For the isolation of large amounts of high-purity plasmid DNA, the QIAfilter® Midi-, Maxi- and Mega- kits from QIAGEN were used following the manufacturer's instructions.

\subsubsection{Large-scale Preparation of pGAD424/N.t cDNA library Plasmid DNA from E. coli}

The amplification of the pGAD424/N.t cDNA library plasmid was done following a protocol described by Parchaliuk et al. 1999. In brief, $\sim 1 \times 10^{7}$ of pGAD424/N.t cDNA transformed bacterial cells were grown overnight on large LB media plates. Bacterial cells were harvested by flooding a plate with 10 $\mathrm{ml}$ of $150 \mathrm{mM} \mathrm{NaCl}$ and scarping the colonies from the agar surface using a glass rod, the suspension was dump onto another plate and this step was repeated with another plates using the same suspension. Each $10 \mathrm{ml}$ were used to scarp up to 5 plates. All aliquots of bacteria were mixed together and added to 1 liter LB media and the culture was grown further for 2 hours under continuous shacking. Plasmid DNA was isolated using QIAfilter@ Mega kit from QIAGEN following the manufacturer's instructions.

\subsubsection{Isolation of Plasmid DNA from Yeast}

For plasmid isolation from yeast, a single colony was used to inoculate a $5 \mathrm{ml}$ overnight SD liquid culture (lacking the nutritional marker to keep selective pressure on the plasmid) at $30^{\circ} \mathrm{C}$. Next day, cells were vortexed briefly and a $1.5 \mathrm{ml}$ aliquot was centrifuged for 5 minutes at $13000 \mathrm{rpm}$ to harvest the cells. Pelleted cells were suspended in $30 \mu$ of Lyticase solution, an enzyme that hydrolyzed the $\beta-1,3-$ glucose polymer and facilitate cell wall degradation. The cells suspension was incubated to digest for 1.5 hour at $37{ }^{\circ} \mathrm{C}$. The suspension was used then to isolate the plasmid DNA using the QIAprep® Spin Mini kit following the manufacturer's instructions. The isolated yeast DNA plasmid amount considered low, so plasmids were amplified in E. coli and DNA isolation was done as described above.

\subsubsection{Isolation of Genomic DNA from Arabidopsis}

For Arabidopsis genomic DNA isolation, $100 \mathrm{mg}$ vegetative tissues were ground in liquid nitrogen into fine powder. The powder was resuspended in $1 \mathrm{ml}$ DNA extraction buffer. To the suspension, $1 \mathrm{ml}$ of $\mathrm{PCl}$ mix was added and extraction mixture was vortexed strongly. The mixture was incubated for 5 minutes at room temperature and then centrifuged for 20 minutes at $13000 \mathrm{rpm}$. The upper aqueous supernatant was transferred into new eppendorf tube and the DNA was precipitated by the addition of $300 \mu \mathrm{l}$ of sodium acetate and $1 \mathrm{ml}$ of isopropanol. Genomic DNA was collected by centrifugation for 10 minutes at $13000 \mathrm{rpm}$ and $4{ }^{\circ} \mathrm{C}$. The pellet was washed twice with $70 \%(\mathrm{v} / \mathrm{v})$ ethanol and dried for 5 minutes using a speedvac. The DNA was dissolved in $50 \mu \mathrm{l} \mathrm{TE}$ buffer and stored at $-20^{\circ} \mathrm{C}$. 


\subsubsection{Total RNA Isolation from Arabidopsis}

Tissue samples were collected from treated plants at indicated time points. Samples were flash frozen in liquid nitrogen and the total RNA was isolated using the Invisorb® Spin Plant RNA Mini kit I. In brief, 100-200 mg tissues were grounded in liquid nitrogen and collected in a safe lock eppendorf tube. Grounded tissues were extracted in $900 \mu$ of lysis solution and incubated for 30 minutes in a thermomixer at $25{ }^{\circ} \mathrm{C}$ under continuous shaking. Samples were centrifuged for 1 minute at $13000 \mathrm{rpm}$ and the supernatant was transferred into a prefilter tube and centrifuged for 1 minute at $10000 \mathrm{rpm} .500$ $\mu \mathrm{l}$ of absolute ethanol were added to the filtrate (approximately $800 \mu \mathrm{l}$ ) and the suspension was mixed thoroughly. Approximately $750 \mu \mathrm{l}$ of the mixture were transferred into a RNA binding spin filter placed into a new receiver tube. The mixture was incubated for 1 minute and then centrifuged at $10000 \mathrm{rpm}$ for 1 minute, and this step was repeated with the rest. The RNA binding spin filter was washed once with 500 $\mu \mathrm{l}$ of R1 wash buffer and twice with $600 \mu \mathrm{l}$ of R2 wash buffer. To eliminate any traces of ethanol, a centrifugation at $13000 \mathrm{rpm}$ for three minutes was conducted. To elute RNA, the RNA binding spin filter was transferred into an RNase-free Elution tube and $40 \mu$ of elution buffer $R$ was added. A 5-10 minutes incubation period took place and the RNA was collected by centrifugation for 1 minute at $13000 \mathrm{rpm}$.

\subsubsection{Estimation of Nucleic Acids Concentration and Purity}

The concentration of nucleic acids was estimated by measuring their absorption in a spectrophotometer at a wavelength of $260 \mathrm{~nm}$ (maximum nucleic acid absorption value; due to the $\pi-$ electron systems of the heterocycles of the nucleotides). An $\mathrm{OD}_{260}$ equal to 1 in case of a $1 \mathrm{~cm}$ cuvette corresponds to $50 \mu \mathrm{g} / \mathrm{ml}$ double stranded DNA and to $40 \mu \mathrm{g} / \mathrm{ml}$ RNA. Absorption at $280 \mathrm{~nm}$ (for the presence of aromatic rings from amino acids and phenol compounds) was used to give information about the purity of the DNA or RNA sample, an optimal ratio $\mathrm{OD}_{260} / \mathrm{OD}_{280}$ is in the range of 1.9-2.0 for RNA and 1.8 for DNA. DNA concentrations lower than $100 \mathrm{ng}$ were measured on an agarose gel using the MassRuler ${ }^{\mathrm{TM}}$ DNA Ladder Mix.

\subsubsection{Nucleic Acids Gel Electrophoresis}

\subsubsection{Separation of DNA on Agarose Gels}

DNA samples were mixed with $1 / 10$ volume of 10x DNA loading buffer and then separated on horizontal agarose gels $(10 \times 7 \times 0.3 \mathrm{~cm})$ containing $1 \times$ TAE buffer. The gel was prepared by dissolving Agarose in 1x TAE and the concentration of the gel ranged between 1-2\% depending on the size of the expected DNA fragment, shorter the fragment higher agarose concentration. Electric current of $3 \mathrm{~V} / \mathrm{cm}$ was used for 1-2 hours to run the gel, and the gel was ended depending on the distance between the migrated bands of the dyes present in the DNA loading buffer. Ethidium bromide solution $(0.1 \% \mathrm{w} / \mathrm{v}) \mathrm{was}$ 
used to satin the DNA fragments. The DNA detection was done under UV light. Before exposure to the UV light, the gel was rinsed briefly in $\mathrm{H}_{2} \mathrm{O}$ to reduce background staining. In a gel-documentation station, gels were visualized on a UV-transilluminator and documented. The sizes and amount of the DNA fragments were determined using DNA standards.

\subsubsection{Separation of RNA on Denaturing Agarose Gels}

Total RNA isolated from plants was separated by electrophoresis using denaturing agarose gels. The gel composed of $1.5 \mathrm{~g}$ agarose dissolved in $105 \mathrm{ml} \mathrm{H}_{2} \mathrm{O}$ before adding $15 \mathrm{ml}$ of 10x MEN buffer followed by $22.5 \mathrm{ml}$ of formaldehyde. The agarose mixture was poured into a gel box and left to polymerise for 30 minutes. The polymerised gel was placed into a vertical gel electrophoresis chambers containing 1x MEN buffer. RNA samples, with a concentration range between 7.5-10 ug, were equalized with RNase free water and a defined volume of 3x RNA loading buffer (containing $1 \mu \mathrm{g}$ Ethidium Bromide/sample). Samples were denatured for 10 minutes at $65{ }^{\circ} \mathrm{C}$ and incubated on ice before loading them into the gel. The electrophoresis was run at $300 \mathrm{~V}, 500 \mathrm{~mA}, 12 \mathrm{~W} / \mathrm{gel}$ and $0.20 \mathrm{kVh}$ until the bromphenolblue dye was $2-3 \mathrm{~cm}$ from the end of the gel. The separation of the RNAs was visualized on a UV transilluminator and photographed.

\subsubsection{Elution of DNA Fragment from Agarose Gel}

The elution of DNA fragments from agarose gel was done using the QIAquick® Gel Extraction kit following the manufacturer's instructions. The eluted fragments were verified by electrophoresis as described above.

\subsubsection{Restriction Digestion of DNA Molecules}

The restriction enzymes of endonucleases type II were used to digest a double stranded DNA molecule for analytical and cloning purposes. The enzymes cut the DNA either as $5^{\prime}$ or $3^{\prime}$ "sticky" overhangs or as blunt ends. The digestion reactions were incubated in a buffer system optimized for the used enzyme and in the case of double digestion a universal buffer system was used. The activity of the restriction enzymes was estimated in units $(U)$, where $1 U$ stands for the amount of enzyme cutting completely at optimal conditions $1 \mu \mathrm{g}$ of $\lambda$ DNA for 60 minutes. The minimal amount of enzyme necessary for each restriction was determined according to the following formula:

$$
\begin{aligned}
U_{\min }= & \frac{[b p(\lambda) \cdot \text { recognition sites }(D N A)]}{[\text { Recognition sites }(\lambda) \cdot \text { bp (DNA)] }} \\
& \text { Where bp }(\lambda)=48500
\end{aligned}
$$


The digest reaction mixture was incubated for 2 hours at $37^{\circ} \mathrm{C}$. The digestion was confirmed by running the reaction on agarose gel.

\subsubsection{Dephosphorylation of DNA Fragments}

When a plasmid DNA (used as a vector for cloning a donor DNA fragment) linearized using a single restriction enzyme, a hydrolyization of the $5^{\prime}$-terminal phosphate residue (dephosphorylation) was performed using calf intestine alkaline phosphatase (CIAP) enzyme in order to prevent self-enclosure of the vector in a subsequent ligation reaction. The linearized vector was incubated with the CIAP enzyme for 30 minutes at $37^{\circ} \mathrm{C}$ before DNA separation on agarose gel.

\subsubsection{Fill-in of 3'-Overhangs with Klenow Fragment of DNA Polymerase I}

The E. coli klenow fragment of DNA-Polymerase I has a $5^{\prime}-3^{\prime}$ exonuclease activity. Using the Klenow fragment, it is possible to incorporate nucleotides in a free $3^{\prime} \mathrm{OH}$ group of DNA fragments. A reaction mix used for the filling the $3^{\prime}$ overhangs contains a 10x klenow buffer and $0.25 \mathrm{mM}$ dNTPs mix. The reaction was incubated for 1 hour at $37^{\circ} \mathrm{C}$ and stopped by the precipitation of the DNA fragments.

\subsubsection{Cloning}

\subsubsection{Ligation of DNA Fragments}

The conventional cloning of a DNA fragment into a selected plasmid was performed using the T4-DNA ligase enzyme, which is able to catalyze the formation of a phosphodiesther chemical bond between free 5 '-phosphate and $3^{\prime}-\mathrm{OH}$ groups of double-stranded DNA fragments and vectors. The donor DNA fragment (10x accesses to the vector) was incubated with the vector DNA, $2 \mu$ l of ligation buffer and $1 \mu \mathrm{l}$ of T4-DNA ligase for 2 hours at room temperature. The ligation of DNA fragments with blunt ends was performed in the presence of 5\% (w/v) PEG 4000 with the ligation mix described above.

\subsubsection{Gateway Cloning}

Gateway ${ }^{\circledR}$ Technology is a new universal cloning technology based on the site-specific recombination properties of the bacteriophage lambda. The Gateway® Technology kit provides a rapid and highly efficient way to move DNA sequences into multiple vector systems for functional analysis and protein expression. The first step in this cloning is the amplification of an attB-PCR then the cloning of the attB-PCR product into a pDONR207 plasmid. This cloning step was called the BP recombination reaction and was catalyzed by the BP Clonase enzyme mix. The final product of this reaction is known as the pDONER207/entery clone plasmid. The pDONER207/entery clone plasmid is used for the recombination 
of an entry clone (the attB-PCR product) into a destination vector to create the $\mathrm{pENTR/expression} \mathrm{clone}$ plasmid using the LR Clonase enzyme mix.

The BP recombination reaction contained a $40-100 \mathrm{fmol}$ of the attB-PCR product, $300 \mathrm{ng}$ pDONER207 ${ }^{\mathrm{TM}}$ vector (linearized before use), $4 \mu \mathrm{l}$ x BP Clonase reaction buffer and TE buffer, pH 8.0, up to $16 \mu \mathrm{l}$ before adding $4 \mu \mathrm{l}$ of BP Clonase enzyme mix. The reaction was incubated at $25^{\circ} \mathrm{C}$ for 2 hours. The reaction was concluded by adding $2 \mu \mathrm{l}$ of $2 \mu \mathrm{g} / \mu \mathrm{l}$ of proteinase $\mathrm{K}$ solution and was incubated at $37{ }^{\circ} \mathrm{C}$ for 10 minutes. The reaction mix was used to transform $E$. coli competent cells. The LR recombination reaction was performed similarly except that the PCR product and PDONER207 ${ }^{\mathrm{TM}}$ were replaced by the pDONER207/entery clone (linearized before use) and pDONER207/entery clone plasmid, respectively.

\subsubsection{Radioactive Labeling of DNA Fragments}

The radioactive labelling of DNA fragments for Northern blot analysis was done using the random prime labelling method (Feinberg and Vogelstein, 1982). A reaction mixture composed of $50 \mathrm{ng}$ of purified DNA fragment, $1.4 \mu \mathrm{l}$ random primers and $\mathrm{H}_{2} \mathrm{O}$ up to $33 \mu \mathrm{l}$ were denatured at $95^{\circ} \mathrm{C}$ for 5 minutes and then left to cool down at room temperature. To the denatured mixture, $5 \mu$ of $10 x$ Klenow buffer (MBI Fermentas), $6 \mu \mathrm{l}$ of dNTP-A mix (dCTP, dGTP, dTTP, $500 \mu \mathrm{M}$ each), $5 \mu \mathrm{l}$ of $\left[\alpha^{-32}{ }^{32}\right.$ ]-dATP (800 Ci/mmol) and 1 Unit of klenow exo were added. The reaction mix was incubated for 2 hours at $37^{\circ} \mathrm{C}$. The unlabeled nucleotides and primers were separated from the mixture using a Sephadex G50 gel filtration columns. The columns were prepared from a $1 \mathrm{ml}$ blue pipit tip closed with a filter paper and filled with Sephadex G50. The elution of the radioactive labelled DNA from the Sephadex G50 gel filtration columns was done by centrifugation for 5 minutes at $1500 \mathrm{rpm}$.

The radioactive labeling of DNA fragment for EMSA was done using the following reaction: 3 ug digested DNA (pUC-as-1 plasmid (containing a Bpil cloned as-1 fragment) digested with Bpil restriction enzyme), $2.0 \mu \mathrm{l}$ 10x KGB buffer, $0.8 \mu$ l klenow exo ${ }^{-}, 5.0 \mu \mathrm{l}\left[{ }^{32} \mathrm{P}\right]-\alpha-A T P$ and $\mathrm{H}_{2} \mathrm{O}$ up to $20 \mu \mathrm{l}$. The reaction was incubated for 2 hours at $37^{\circ} \mathrm{C}$. Radioactive labeled DNA was separated from dNTPs by a MicroSpin G25 column (Pharmacia) following the manufacturer's instructions. The eluted sample was mixed with 5 $\mu \mathrm{l}$ of BOX dye and the mixture was applied to a native $5 \%$ polyacrylamide gel. The gel was run for 2 hours at $180 \mathrm{~V}$, and then exposed to an X-ray film for 10 minutes. After the development of the X-ray screen, two bands were detected, where the lower one corresponded to the as-1 fragment. The as-1 fragment was excided from the predicted position and the gel piece was transferred into a new screw-cup tube. The sample was homogenized in $400 \mu \mathrm{l} \mathrm{TE}$ buffer and incubated overnight at $37^{\circ} \mathrm{C}$. Next day the tube was centrifuged at $13000 \mathrm{rpm}$ for 20 minutes and the supernatant was transferred into a new screwcup and was stored at $-20^{\circ} \mathrm{C}$. 


\subsubsection{Polymerase Chain Reaction (PCR)}

Specific DNA fragments were amplified using the polymerase chain reaction (PCR) (Mullis and Faloona, 1987). The reaction started with the denaturation of two strands of a DNA template. The $5^{\circ}$ complementary strands of the denatured DNA was recognized and hybridized with specific primers (annealing). A Taq-polymerase enzyme catalyzes elongation of a newly synthesized chain and the complementary polymerization of nucleotides to the free $3{ }^{\prime}-\mathrm{OH}$ group of the primer. Repeating the previous steps (denaturation, annealing and elongation) for $x$ cycles (usually from 25 to 35 ) will exponentially enrich the reaction with the primer-flanked DNA sequence. In some cases a suitable synthetic restriction sites were incorporated to the $5^{\prime}$-end of the primer for cloning purposes. The PCR reaction was carried out in a $20 \mu \mathrm{l}$ reaction volume with the following constituents: $10-50 \mathrm{ng}$ template DNA, $2 \mu \mathrm{l}$ of 10 pmole sense primer, 10 pmole antisense primer, $0.2 \mathrm{mM}$ dNTPs, $2 \mu \mathrm{l}$ of 10x Taq-buffer, $2 \mathrm{U}$ Taq-polymerase and $\mathrm{H}_{2} \mathrm{O}$ up to $20 \mu \mathrm{l}$. The amplification reaction was done in a PCR thermocycler using the following program:

Initial denaturation

Denaturation

25-35 x Cycle
Annealing

Elongation

Final elongation

\section{4 minutes $94^{\circ} \mathrm{C}$}

1 minutes $94^{\circ} \mathrm{C}$

30 seconds $50-65^{\circ} \mathrm{C}$

1 minute/kb $72{ }^{\circ} \mathrm{C}$

10 minutes $72{ }^{\circ} \mathrm{C}$

\subsubsection{Cloning of PCR Products}

The DNA molecule amplified using the Taq- Polymerase is characterized by the presence of additional deoxyadenosine nucleotides $(\mathrm{dA})$ at the 3 '-end of the PCR product, which is due to the terminal deoxy-nucleotidiltransferase activity nature of the Taq-polymerase enzyme. PCR product with the $3^{\prime}$-dA overhangs can be used to clone a vector having a complementary 3 '-deoxytimidine (dT). For this purpose the $P G E M \otimes-T$ vector system kit (Promega) was used. The ligation reaction was performed following the manufacturer's instructions.

\subsubsection{PCR Site Directed Mutagenesis}

The principle of the PCR site-directed mutagenesis is that a mismatched oligonucleotide is extended and incorporating a "mutation" into a strand of a selected DNA that can be cloned (Ho et al., 1989). In this study, the PCR site-directed mutagenesis was used to create point mutations to help define the role of individual amino acid residues in a protein. 
In this study the point mutation was introduce using the PCR overlap extension method (Figure 5.1). In the overlap extension method two separate PCRs were conducted to amplify two PCR fragments (Figure 5.1; PCR1 and PCR2). Each PCR reaction uses one flanking primer that hybridizes at one end of the target sequence (primers A or D) and one internal primer that hybridizes at the site of the mutation and contains the mismatched nucleotide bases (primers $C$ and $D$ ). Finally, a third PCR was conducted using primers $A$ and $D$ and the generated DNA fragments from PCR1 and PCR2 as template (Figure 5.1; PCR3).

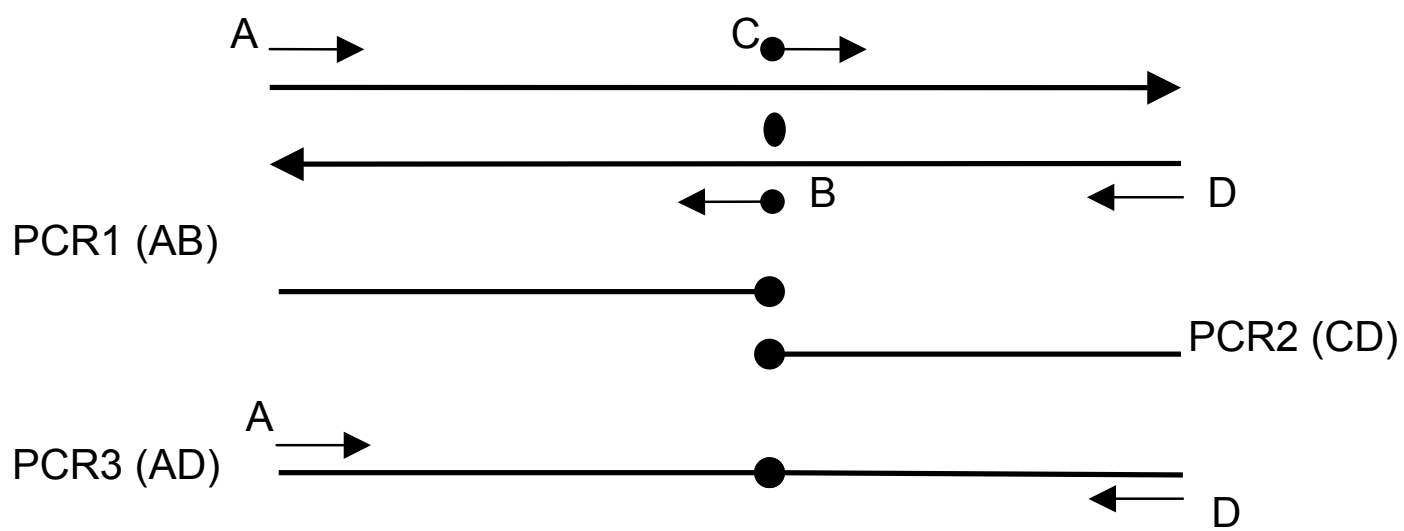

Figure 5.1. Schematic diagram of site directed mutagenesis by overlap extension

\subsubsection{Screening Bacterial Colonies Using PCR}

To verify the presence of a certain DNA molecule in bacterial colonies (E. coli or A. tumefaciens), a PCR reaction was conducted using the cell lysate as a DNA template. Bacteria cells were picked up with yellow tips from a single colony that was grown on master plate. The tip was vortexed in $10 \mu \mathrm{l}$ of $\mathrm{H}_{2} \mathrm{O}$ and the cells suspension was boiled for 5 minutes at $95^{\circ} \mathrm{C}$. The lysate was centrifuged for 5 second to pellet cell debris. A PCR mixture was added to the cell lysate (represents DNA template) and a PCR reaction was run as described above.

\subsubsection{Reverse Transcription PCR (RT-PCR)}

The reverse transcription PCR (RT-PCR) is a technique used for mRNA detection and quantification. The technique consists of two parts: the synthesis of cDNA from RNA by reverse transcription and the amplification of a specific cDNA by PCR. The RT-PCR reaction was conducted using the RevertAid ${ }^{\mathrm{TM}}$ Minus First Strand cDNA Synthesis kit following the manufacturer's instructions. In brief, a reaction mixture containing $500 \mathrm{ng}$ isolated total RNA, $0.2 \mu \mathrm{g} / \mu \mathrm{l}$ random hexamer primers and RNase free $\mathrm{H}_{2} \mathrm{O}$ up to $11 \mu \mathrm{l}$ was prepared. The reaction was incubated for 10 minutes at $70{ }^{\circ} \mathrm{C}$ then chilled on ice. To this mixture $4 \mu \mathrm{l}$ of $5 \mathrm{x}$ Reaction Buffer, 20 units of RNase inhibitor and $2 \mu \mathrm{l}$ of $10 \mathrm{mM}$ 
dNTPs were added and the reaction was incubated for 5 minutes at $25{ }^{\circ} \mathrm{C}$. To the mixture, $1 \mu \mathrm{l}$ of RevertAid $^{\mathrm{TM}} \mathrm{H}$ Minus M-MuLV Reverse Transcriptase enzyme $(200 \mathrm{u} / \mathrm{\mu l})$ was added and the mixture was incubated at $25{ }^{\circ} \mathrm{C}$ for 10 minutes followed by $42{ }^{\circ} \mathrm{C}$ for 60 minutes. Finally, the reaction was heated at $70{ }^{\circ} \mathrm{C}$ for 10 minutes. A PCR reaction using the Advantage ${ }^{\mathrm{TM}}$ PCR Enzyme Systems kit was carried out using $2 \mu$ of the synthesized cDNA reaction.

\subsubsection{DNA Sequencing}

The DNA sequencing was done using the BigDye ${ }^{\mathrm{TM}}$ Terminator Enhanced Terminators Cycle Sequencing kit. The principle of DNA sequencing is based on the chain-termination method (Sanger et al., 1977). In the chain-termination method, dideoxynucleotides (terminators) are incorporated into a newly synthesized complementary chain that will lead to stop its elongation in a PCR reaction. Each of dideoxynucleotides is labeled with a specific fluorescent dyes and the terminated chains can be specifically detected using an ABI Prism 310 Capillary Sequencer. The PCR sequencing reaction was prepared using 300-1000 ng plasmid DNA, 5 pmol primer, $2 \mu \mathrm{l}$ ET sequencing mix and $\mathrm{H}_{2} \mathrm{O}$ up to $10 \mu \mathrm{l}$. The samples were subjected to 25 cycles of: 10 seconds at $95^{\circ} \mathrm{C}, 5$ seconds at $50{ }^{\circ} \mathrm{C}, 4$ minutes at 60 ${ }^{\circ} \mathrm{C}$ in a thermocycler. The DNA product was precipitated using $1 \mu \mathrm{l}$ sodium acetate and $41 \mu \mathrm{l}$ of absolute ethanol and left on ice for 1 hour. The DNA was collected by centrifugation for 15 minutes at $13000 \mathrm{rpm}$. The pellet was washed using $200 \mu \mathrm{l} 70 \%$ ethanol and then centrifuged for 15 minuets at $13000 \mathrm{rpm}$. The pellet was dried at $95{ }^{\circ} \mathrm{C}$ for one minute and resuspended in $20 \mu \mathrm{l}$ of template-suppression reagent (TSR). A denaturation step at $95^{\circ} \mathrm{C}$ for 2 minutes took place and the tube was immediate placed on ice. The reaction was transferred into a special sequencing tube and then loaded on an ABI-Prism ${ }^{\text {TM }} 310$ capillary electrophoresis sequencing station (Perkin- Elmer) for analysis.

\subsubsection{Gene Transfer in Bacteria}

The E. coli and A. tumefaciens have no competence nature, i.e., they are not able to accept naked DNA molecules from the environment. To enable the bacterial cells to take up circular vector DNA they have to be made competent using special treatments. Two transformation methods were used to transform bacteria cells: the heat shock and the electroporation. The heat shock method was used only to transform E. coli chemical competent cells. The transformation procedure was done after Hanahan (1983). In brief, 50-100 $\mu \mathrm{l}$ competent $E$. coli cells were thawed on ice slowly before adding 2-30 $\mu \mathrm{l}$ of plasmid DNA and the mixture was briefly vortexed. The mixture was incubated on ice for 30 minutes. The cells were heat shocked for 90 seconds at $42{ }^{\circ} \mathrm{C}$ and were placed immediately on ice for at least 2 minutes. $1 \mathrm{ml}$ of dYT medium was added to the tube and the suspension was agitated for 1 hour at 37 ${ }^{\circ} \mathrm{C}$. Different volumes of the culture were plated on plates containing LB medium supplemented with antibiotics. The plates were incubated overnight at $37^{\circ} \mathrm{C}$. 
The transformation using electroporation was done for $E$. coli and A. tumefaciens cells after

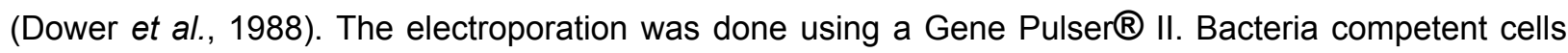
were thawed on ice slowly before adding $2 \mu$ of plasmid DNA. The mixture was transferred into an icecooled electroporation cuvette ( $2 \mathrm{~mm}$ electrode distance). The cuvette was subjected to electroporation at $25 \mu \mathrm{F}, 2.5 \mathrm{kV}, 200 \Omega$. The cells were suspended immediately with $1 \mathrm{ml} \mathrm{dYT} \mathrm{medium} \mathrm{and} \mathrm{incubated} \mathrm{for}$ 1-2 hours at selected temperature depending on the bacteria type. Different volumes of the culture were plated on LB media supplemented with selective solid medium (depending on bacteria type) and incubated at selected temperatures for 1-2 days depending on the bacteria type.

\subsubsection{Gene Transfer in Yeast}

The yeast cells were transformed with plasmid DNA using two different methods. The first method was after Dohmen et al. (1991) and was conducting using yeast competent cells prepared as follows. A $5 \mathrm{ml}$ culture (YPD or SD) inoculated with a single yeast colony and grew overnight at $30{ }^{\circ} \mathrm{C}$. The culture was used to inoculate a $100 \mathrm{ml}$ YPD media. Cells were allowed to grow under continuous shacking at $200 \mathrm{rpm}$ at $30{ }^{\circ} \mathrm{C}$ until an $\mathrm{OD}_{600}$ of 0.6 reached. The cells were collected and washed in 20 $\mathrm{ml}$ of solution A, pelleted at $5000 \mathrm{rpm}$ and resuspended in $5 \mathrm{ml}$ of solution A. $100 \mu \mathrm{l}$ from the suspension were pipetted as aliquots in eppendorf tube and stored at $-80^{\circ} \mathrm{C}$. For the yeast transformation, a mixture consisting from $5 \mu \mathrm{l}$ of DNA carrier $\left(2 \mathrm{mg} / \mathrm{ml}\right.$ ) (denatured at $90^{\circ} \mathrm{C}$ for 5 minutes and cooled on ice) and 1 $\mu \mathrm{g}$ of DNA plasmids were added to the frozen cells. The mixture was incubated for 3 minutes at $37^{\circ} \mathrm{C}$ and the thawed cells were vortexed briefly before adding $1 \mathrm{ml}$ of solution $\mathrm{B}$. the suspension was mixed thoroughly and incubated for 1 hour at $30{ }^{\circ} \mathrm{C}$. Cells were harvested by centrifugation for 10 seconds at $13000 \mathrm{rpm}$, washed with $800 \mu \mathrm{l}$ solution $\mathrm{C}$, collected by centrifugation again, plated on yeast media and grown for $3-4$ days at $30^{\circ} \mathrm{C}$.

The second transformation method used was after Gietz and Woods (2002). About $30 \mu$ of yeast cells (from liquid or solid culture) were resuspended in $1 \mathrm{ml}$ sterile $\mathrm{H}_{2} \mathrm{O}$. The cells were collected by centrifugation and resuspended in $1 \mathrm{ml}$ of $100 \mathrm{mM}$ lithium acetate. The cell suspension was incubated for 5 minutes at $30^{\circ} \mathrm{C}$. The following transformation mixture was added to the cells pellet:

$\begin{array}{rrl}240 & \mu \mathrm{l} & \text { PEG }(50 \% \mathrm{~W} / \mathrm{V}) \\ 36 & \mu \mathrm{l} & \text { 1 M Lithium acetate } \\ 50 & \mu \mathrm{l} & \text { DNA carrier } \\ \mathrm{x} & \mu \mathrm{l} & \text { Plasmid-DNA }(0.1-10 \mu \mathrm{g}) \\ 34-\mathrm{x} & \mu \mathrm{l} & \mathrm{H}_{2} \mathrm{O}\end{array}$


The transformation mixture was vigoursley vortexed for at least 1 minute. The mixture was incubated for 40 minutes at $42{ }^{\circ} \mathrm{C}$. The cells were harvested by centrifugation and the supernatant was removed and the pellet were resuspended in $150 \mu \mathrm{l} \mathrm{H}_{2} \mathrm{O}$ and plated on a proper media.

\subsubsection{Transient Transfection of Tobacco BY-2 Protoplasts}

BY-2 protoplasts for the transient assays were prepared using three days old sub-cultivated BY-2 cells as described above. The cell suspensions dispensed into 3 petri dishes $(\sim 15 \mathrm{ml}$ each) were collected separately in $50 \mathrm{ml}$ tubes by centrifugation (soft start) at $780 \mathrm{rpm}$ for 5 minutes. $10 \mathrm{ml}$ of the supernatant were removed and the protoplasts were resuspended gently in the rest. The protoplasts were washed with $20 \mathrm{ml}$ osmoticum and then collected by centrifugation at $780 \mathrm{rpm}$. The supernatant was removed and the protoplasts were resuspended in the rest. To the protoplasts, $10 \mathrm{ml}$ of W5 solution were added (stepwise application of 1, 2, 3, $4 \mathrm{ml}$ ) and the suspension was mixed gently. The protoplasts were collected and resuspended in the rest of the supernatant. Stepwise application of $5 \mathrm{ml}(1,2,2 \mathrm{ml})$ W5 took place and the protoplasts suspensions from the three tubes were collected in one of them. The tube was incubated at $4{ }^{\circ} \mathrm{C}$ for 1 hour and meanwhile protoplast number was determined. After the incubation, protoplasts were collected and the supernatant were completely removed and the pellet was resuspended in an appropriate volume of MMM solution to a protoplasts density of $2 \times 10^{6}$ protoplasts $/ \mathrm{ml}$.

For the transfection of BY-2 protoplasts, DNA plasmids were added to a defined point in a red cap glass tubes. $300 \mu \mathrm{l}$ protoplasts were pipetted directly to the defined point and the suspension was mixed thoroughly. To the mixture, $300 \mu \mathrm{l}$ of PEG solution were added drop-wisely and the suspension was mixed gently. The samples were incubated for 20 minutes at room temperature. $1 \mathrm{ml}$ of W5 solution was added to stop the reaction and the suspension was mixed gently. A stepwise addition of (2, 3, $4 \mathrm{ml})$ W5 took place and the suspension was gently mixed after each step. The protoplasts were collected, the supernatant was removed and the pellet was resuspended in $700 \mu \mathrm{l}$ of MS sucrose medium. The samples were incubated overnight at $24^{\circ} \mathrm{C}$ in darkness.

\subsubsection{Northern Blot Analysis}

\subsubsection{Transfer of RNA into Nylon Membranes}

After separation of RNA on denaturing agarose gels, a blotting of the gel onto nylon membranes (Hybond $\mathrm{N}^{+}$, Amersham) using the capillary blotting method was conducted. The blot was constructed in a plastic tray filled with $500 \mathrm{ml}$ of $10 x$ SSC buffer. A flat surfaced plastic stand was placed above the buffer level and covered with 2 pre-wetted $30 \times 15 \mathrm{~cm}^{2} 3 \mathrm{MM}$ paper stripes with their ends dipped in the buffer (avoiding air bubbles was considered in all steps). The upper side of the RNA gel $\left(10 \times 15 \mathrm{~cm}^{2}\right)$ was placed downwards to the plastic stand. The areas around the gel were surrounded by plastic foil stripes to prevent any drying-out. A $10 \times 15 \mathrm{~cm}^{2}$ Hybond $\mathrm{N}^{+}$membrane piece, pre-wetted in 10x SSC and 
3 layers of pre-wet $3 \mathrm{MM}$ papers $\left(10 \times 15 \mathrm{~cm}^{2}\right)$ were placed on the lower surface of the gel. A thick layer of paper towels $(10 \mathrm{~cm})$ was placed upon the $3 \mathrm{MM}$ papers and an equally distributed weight of approximately. About $1 \mathrm{~kg}$ weight (thick catalogue, etc.) was placed upon the paper towels. The blotting duration was for at least 14 hours and after that the construction was dismantled and the transfer of RNA on the nylon membrane was controlled under UV light and photographed. The covalent binding of the RNA molecules to the membrane surface was performed by incubation at $80^{\circ} \mathrm{C}$ for 2 hours.

\subsubsection{Hybridization of Northern Blot}

The membrane was wetted with 2x SSC and placed with the RNA-bound sides inwards in a hybridization glass tube and pre-hybridized at $65^{\circ} \mathrm{C}$ in $10 \mathrm{ml}$ of church solution for 1 hour. This step was important to ensure that free non-specific binding sites on the membrane are saturated. $100 \mu$ of DNA carrier were added to the radioactively labeled probe and the mixture was denatured on a boiling water bath for 5 minutes. The probe was immediately transferred to ice and left there for 5 minutes and was then added to the pre-hybridized membrane by pipitting it directly to the church solution in the hybridization tube. The hybridization of the labelled single stranded probe with its complementary RNAs sequences took place overnight at $65^{\circ} \mathrm{C}$ under continuous rotation. Next day, the solution containing the probe was collected in a falcon tube and stored at $-20{ }^{\circ} \mathrm{C}$ for multiple usages. The membrane was subjected to serial washing procedure with buffers containing increasing percentage of SSC (2\%; $1 \%$; $0.5 \% ; 0.1 \%$ - each containing $0.1 \%$ SDS) in order to remove unspecific-bound probe. The washing was concluded when the radioactivity of the membrane was fewer than $30 \mathrm{cpm}$. The membrane was sealed in plastic foil and exposed to an Imager Plate (IP) overnight. The signals were detected with a Bioimager and processed and quantified with the PCBAS® 2.09 and TINA® 2.0 programs. For normalization, signals were compared with the signals from the Ethidium Bromide staining of the RNAs.

\subsubsection{Stripping and Re-Probing of Northern Membranes}

RNA blotted membrane can be reused again for hybridization with other probes. The hybridized probes need to be removed from the membrane. This was achieved by 2 times for 30 minutes washing with $250 \mathrm{ml}$ of a pre-warmed $0.1 \%(\mathrm{w} / \mathrm{v}) \mathrm{SDS}$ at $75^{\circ} \mathrm{C}$ on The Belly Dancer®, Stovall.

\subsubsection{Yeast Hybrid System Screen (Agatep et al., 1998)}

A large single yeast colony transformed with the bait plasmid was used to inoculate a $5 \mathrm{ml} \mathrm{SD}$ tryptophan liquid culture that was allowed to grow at $30^{\circ} \mathrm{C}$ overnight. Next day, cells were vortexed briefly and the culture was poured into $200 \mathrm{ml}$ SD-tryptophan media and left to grow overnight at $30{ }^{\circ} \mathrm{C}$. The cells were vortexed briefly and the culture was poured into $500 \mathrm{ml}$ volume of YPD medium and the cells left to grow for 4 hours at $30{ }^{\circ} \mathrm{C}$ until the $\mathrm{OD}_{600}$ of $1 \mathrm{ml}$ was $>1.5$. The cells were harvested by 
centrifugation at $5000 \mathrm{rpm}$ for 5 minutes. The cells pellet was washed in 1/2 volume of sdd water and was collected again. The cells pellet was resuspended in an appropriate volume of $100 \mathrm{mM}$ lithium acetate. The cells were transferred to an appropriate centrifuge tube and were incubated for 15 minutes at $30{ }^{\circ} \mathrm{C}$. The cells were collected again by centrifugation at $3000 \mathrm{rpm}$ and the supernatant were discarded.

To the cells pellet the following transformation mixture was added:

$\begin{array}{lll}24 & \mathrm{ml} & \text { PEG }(50 \% \mathrm{~W} / \mathrm{V}) \\ 3.6 & \mathrm{ml} & \text { 1 M Lithium acetate } \\ 100 & \mu \mathrm{l} & \text { DNA carrier }(2 \mathrm{mg} / \mathrm{ml}) \\ 100 & \mu \mathrm{l} & \text { Library plasmid DNA } \\ 6.5 & \mathrm{ml} & \mathrm{H}_{2} \mathrm{O}\end{array}$

The transformation mixture was vigoursley vortexed for at least 1 minute and the suspension was incubated for 30 minutes at $30{ }^{\circ} \mathrm{C}$. The cell suspension was incubated at $42{ }^{\circ} \mathrm{C}$ for 60 minutes and the culture tube was inverted several times every 5 minutes to equilibrate the temperature in the tube. The cells were harvested by centrifugation and the pellet was resuspended in $10 \mathrm{ml} \mathrm{H}_{2} \mathrm{O}$. The cells suspension was plated into large plates with SD -tryptophan, leucine and histidine medium, supplemented with $30 \mathrm{mM}$ 3-AT.

\subsection{Construction of Plasmids}

\subsubsection{Gateway Plasmids}

\subsubsection{1 pDONR207/At1g28480}

An At1g28480 attB-PCR was amplified using an Arabidopsis cDNA library with primers designed with site-specific recombination sites. The cloning of attB-At1g28480 PCR product into the pDONR207 vector was done using the gateway $\mathrm{BP}$ recombination reaction following the manufacturer's instructions.

\subsubsection{2 pDONR207/At1g50570}

An At1g50570 attB-PCR was amplified from an Arabidopsis cDNA library with primers designed with site-specific recombination sites. The cloning of attB-At1g50570 PCR product into the pDONR207 vector was done using the gateway BP recombination reaction following the manufacturer's instructions. 


\subsubsection{Binary Plasmids for Stable Transformation of Arabidopsis}

\subsubsection{Alligator2/At1g28480}

A binary plasmid generated for the overexpression of 3x HA-tagged At1g28480 protein in plant. The strong 2x CaMV 35S promoter drove the constitutive expression of 3x HA-At1g28480 construct. The cloning of At1g28480 into the Alligator2 vector was done using the gateway LR recombination reaction following the manufacturer's instructions.

\subsubsection{Alligator2/At1g50570}

A binary plasmid generated for the overexpression of 3x HA-tagged At1g50570 protein in plant. The strong 2x CaMV 35S promoter drove the constitutive expression of 3x HA-At1g50570 construct. The cloning of At1g50570 into the Alligator2 vector was done using the gateway LR recombination reaction following the manufacturer's instructions.

\subsubsection{3 pFGC5941/At1g28480}

A binary plasmid generated for the expression of a RNAi At1g28480 construct in plant in order to reduce the endogenous expression of At1g28480 in plants. The CaMV 35S promoter drove the constitutive expression of the RNAi At1g28480 construct. The cloning of At1g28480 into pFGC5941 was done using the gateway LR recombination reaction following the manufacturer's instructions.

\subsubsection{4 pFGC5941/At1g50570}

A binary plasmid generated for the expression of a RNAi At1g50570 construct in plant in order to reduce the endogenous expression of At1g50570 in plants. The CaMV 35S promoter drove the constitutive expression of the RNAi At1g50570 construct. The cloning of At1g50570 into pFGC5941 was done using the gateway LR recombination reaction following the manufacturer's instructions.

\subsubsection{Plasmids for Protein Expression in Yeast}

\subsubsection{1 pBD-/At1g28480}

The isolated At1g28480 cDNA clone was excised from pGAD10/At1g28480 as $550 \mathrm{bp} \mathrm{Bg/lI}$ fragment and ligated into pBD opened with the same enzymes. The At1g28480 cDNA was under the control of Met25 promoter. 


\subsubsection{2 pBD-/At1g50570 P}

The isolated At1g50570 partial cDNA clone was excised from pGAD10/At1g50570 as 950 bp $B a m H 1$ fragment and ligated into pBD opened with Bg/ll. The At1g50570 cDNA was under the control of Met25 promoter.

\subsubsection{3 pBL-/TGA1}

The TGA1 full-length coding sequence was amplified using PCR from an Arabidopsis cDNA library with primers designed with artificial restriction sites. The PCR product was cloned into PGEM-T vector following the manufacturer's instructions. An $1100 \mathrm{bp} \mathrm{Bg/ll}$ excised fragment from the pGEMT/TGA1 was ligated into $\mathrm{pBL}$ opened with the same enzymes. The TGA1 coding sequence was under the control of Met25 promoter.

\subsubsection{4 pBL-/TGA2.2}

Two-step cloning procedure was employed in order to clone the pBL-/TGA2.2. A pGBT9/TGA2.2 plasmid was digested with $\mathrm{Ncol}$ and $\mathrm{BamHI}$. The digestion produces two fragments: a $800 \mathrm{bp}$, a $\mathrm{Ncol}$ fragment that begins from the TGA2.2 start codon, and a $200 \mathrm{bp}$ that represents a Ncol and BamHI fragment or the rest of TGA2.2 coding sequence. The $200 \mathrm{bp} \mathrm{Ncol}$ and $\mathrm{BamHI}$ fragment was ligated first into $\mathrm{pBL}$ vector opened with $\mathrm{Ncol}$ and $\mathrm{Bg} / \mathrm{ll}$ and the cloning product was termed $\mathrm{pBL} / 200 \mathrm{bpTGA2.2}$. The $800 \mathrm{bp} \mathrm{Ncol}$ fragment was inserted into pBL/200bpTGA2.2 opened with the same enzyme. The TGA2.2 coding sequence was under the control of Met25 promoter.

\subsubsection{5 pBL-/TGA2.2-VP16}

Two-step cloning procedure was employed in order to clone the pBL-/TGA2.2-VP16. A pSK2.2VP16 (Lenk, 2001) plasmid was digested with $\mathrm{Ncol}$ and Spel. The digestion produces two fragments: a $800 \mathrm{bp}$, a Ncol fragment that begins from the TGA2.2 start codon and a $650 \mathrm{bp}$ that represents a $\mathrm{Ncol}$ and $\mathrm{BamHI}$ fragment or the rest of TGA2.2 and the VP16 coding sequences. The 650 bp Ncol and Spel fragment was ligated first into the pBL vector opened with $\mathrm{Ncol}$ and Spel and the cloning product was termed pBL/650bpTGA2.2-VP16. The $800 \mathrm{bp} \mathrm{Ncol}$ fragment was inserted into pBL/650bpTGA2.2-VP16 opened with the same enzyme. The TGA2.2-VP16 coding sequence was under the control of Met25 promoter.

\subsubsection{6 pGAD424/At1g28480 and pGBT9/At1g28480}

The isolated At1g28480 cDNA insert was excised from pGAD10/At1g28480 as $550 \mathrm{bp} \mathrm{Bg/ll}$ fragment and ligated into pGAD424 or pGBT9 opened with BamHI. The At1g28480 cDNA was under the control of $A D H 1$ promoter and fused in-frame to the GALAAD or GAL4BD. 


\subsubsection{7 pGAD424/At1g50570 F and pGBT9/At1g50570 F}

The At1g50570 full-length coding sequence was amplified using PCR from an Arabidopsis cDNA library with primers designed with artificial restriction sites. The PCR product was cloned into pGEM-T vector following the manufacturer's instructions. An $1100 \mathrm{bp} \mathrm{Bg/ll}$ excised fragment from the pGEMT/At1g50570 was ligated into pGAD424 opened with BamHI. The At1g50570 coding sequence was under the control of $A D H 1$ promoter and fused in-frame to the GALAAD or GAL4BD.

\subsubsection{8 pGAD424/At5g55530 F and pGBT9/At5g55530 F}

The At5g55530 full-length coding sequence was amplified using PCR from an Arabidopsis cDNA library with primers designed with artificial restriction sites. The PCR product was cloned into pGEM-T vector following the manufacturer's instructions. A $1450 \mathrm{bp} \mathrm{Bg/ll}$ excised fragment from the pGEMT/At5g55530 was ligated into pGAD424 or pGBT9 opened with BamHI. The At5g55530 coding sequence was under the control of $A D H 1$ promoter and fused in-frame to the GAL4AD or GAL4BD.

\subsubsection{9 pGAD424/GDM and pGBT9/GDM}

The GDM full-length coding sequence (An At1g28480 cysteine double mutant generated by PCR site directed mutagenesis) was amplified using overlap extension PCR method with primers designed with artificial restriction sites and base pair mismatching sequence. The PCR product was cloned into pGEM-T vector following the manufacturer's instructions. A $450 \mathrm{bp} \mathrm{Bg/ll}$ excised fragment from the pGEM-T/GDM was ligated into pGAD424 or pGBT9 opened with BamHI. The GDM coding sequence was under the control of $A D H 1$ promoter and fused in-frame to the GAL4AD.

\subsubsection{0 pGAD424/GSM}

The GSM full-length coding sequence (An At1g28480 cysteine single mutant generated by PCR site directed mutagenesis) was amplified using overlap extension PCR method with primers designed with artificial restriction sites and base pair mismatching sequence. The PCR product was cloned into pGEM-T vector following the manufacturer's instructions. A $450 \mathrm{bp}$ Bg/ll excised fragment from the pGEM-T/GSM was ligated into pGAD424 opened with BamHI. The GSM coding sequence was under the control of $A D H 1$ promoter and fused in-frame to the $G A L 4 A D$.

\subsubsection{1 pBDAt1g28480/Met25::TGA1}

The DNA sequence of the Met25::HA-NLS-TGA1::PGK expression cassette was cut out from the pBL/TGA2.2 plasmid as Stul fragment ( 1950 bp) and ligated into pGBT9/At1g28480 opened with Pvull. 


\subsubsection{2 pGBDAt1g28480/Met25::TGA2.2}

The DNA sequence of the Met25::TGA2.2::PGK expression cassette was cut out from the pBL/TGA2.2 plasmid as Stul fragment ( 1950 bp) and ligated into pGBT9/At1g28480 opened with Pvull.

\subsubsection{3 pGBDGDM/Met25::TGA2.2}

The DNA sequence of the Met25::TGA2.2::PGK expression cassette was cut out from the pBL/TGA2.2 plasmid as Stul fragment ( 1950 bp) and ligated into pGBT9/GDM opened with Pvull.

\subsubsection{4 pGBT9/At1g50570 P}

The isolated At1g50570 cDNA insert was excised from pGAD10/At1g50570 as $950 \mathrm{bp} \mathrm{Bg/ll}$ fragment and ligated into pGBT9 opened with BamHI. The At1g50570 cDNA insert was under the control of $A D H 1$ promoter and fused in-frame to the GALABD.

\subsubsection{5 pGBT9/At5g20500 and pGBT9/At5g40370}

The At5g20500 and At5g40370 full-length coding sequences were amplified using PCR from an Arabidopsis cDNA library with primers designed with artificial restriction sites. The PCR product was cloned into pGEM-T vector following the manufacturer's instructions. A $\sim 400 \mathrm{bp}$ and $500 \mathrm{bp}$ EcoRI excised fragments from the pGEM-T/At5g20500 pGEM-T/At5g40370 were ligated into pGBT9 opened with EcoRI, respectively. The At5g20500 and At5g40370 coding sequences were under the control of $A D H 1$ promoter and fused in-frame to the GAL4BD.

\subsubsection{6 pGBT9/TGA2.2 C-term}

The TGA2.2 C-terminus coding sequence was amplified using PCR method with primers designed with artificial restriction sites. The PCR product was cloned into PGEM-T vector following the manufacturer's instructions. A $735 \mathrm{bp}$ EcoRI and Bgll excised fragment from the pGEM-T/TGA2.2 Cterm was ligated into pGBT9 opened with EcoRI and BamHI. The TGA2.2 C-terminus coding sequence was under the control of $A D H 1$ promoter and fused in-frame to the GALABD.

\subsubsection{7 pGBT9/TGA2.2 $2^{\text {Cys } 181 \text { Ser }}$}

The TGA2.2 $2^{\text {Cys } 181 \text { Ser }}$ full-length coding sequence (A TGA2.2 cysteine single mutant generated by PCR site directed mutagenesis) was amplified using overlap extension PCR method with primers designed with artificial restriction sites and base pair mismatching sequence. The PCR product was cloned into pGEM-T vector following the manufacturer's instructions. A 1000 bp EcoRI and Bg/ll excised fragment from the pGEM-T/TGA2.2 $2^{\text {Cys181Ser }}$ was ligated into pGBT9 opened with EcoRI and BamHI. The $T G A 2.2^{\text {Cys } 181 \text { Ser }}$ coding sequence was under the control of $A D H 1$ promoter and fused in-frame to the GALAAD. 


\subsubsection{8 pLEU-/Met25::TGA2.2}

The DNA sequence of the Met25::TGA2.2::PGK expression cassette was cut out from the pBL/TGA2.2 plasmid as Stul fragment (1950 bp) and ligated into pGAD424 opened with Pvull.

\subsubsection{Plasmids for Transient Expression in BY-2 Protoplasts}

\subsubsection{HBTL/At1g28480}

The At1g28480 full-length coding sequence was amplified using PCR from the At1g28480 isolated cDNA insert with primers designed with artificial restriction sites. The PCR product was cloned into pGEM-T vector following the manufacturer's instructions. A 450 bp Acc651 and Pstl excised fragment from the pGEM-T/At1g28480 was ligated into HBTL opened with Acc651 and Pstl. The At1g28480 coding sequence was under the control of the chimeric HBT promoter.

\subsubsection{HBTL/At1g28480-GFP}

The At1g28480 full-length coding sequence was amplified using PCR from the At1g28480 isolated CDNA insert with primers designed with artificial restriction sites. The PCR product was cloned into pGEM-T vector following the manufacturer's instructions. A 450 bp Acc651 excised fragment from the pGEM-T/At1g28480 was ligated into HBTL-GFP opened with Acc651. The At1g28480 coding sequence was under the control of the chimeric $H B T$ promoter and has a C-terminus in-frame fusion with GFP coding sequence.

\subsubsection{HBTL/GAL4BD-At1g28480}

The GAL4BD-At1g28480 coding sequence was amplified using PCR from the pGAD424/At1g28480 plasmid with primers designed with artificial restriction sites. The PCR product was cloned into pGEM-T vector following the manufacturer's instructions. A 450 bp Acc651 and Pstl excised fragment from the pGEM-T/At1g28480 was ligated into HBTL-GFP opened with Acc651 and Pstl. The At1g28480 coding sequence was under the control of the chimeric HBT.

\subsubsection{HBTL/At1g50570}

The At1g50570 full-length coding sequence was amplified using PCR from the pGEMT/At1g50570 with primers designed with artificial restriction sites. The PCR product was cloned into pGEM-T vector following the manufacturer's instructions. An 1100 bp Acc651 and Notl excised fragment from the pGEM-T/At1g50570 was ligated into HBTL opened with Acc651 and Notl. The At1g50570 coding sequence was under the control of the chimeric $H B T$ promoter. 


\subsubsection{HBTL/At1g50570-GFP}

The At1g50570 full-length coding sequence was amplified using PCR from the pGEMT/At1g50570 with primers designed with artificial restriction sites. The PCR product was cloned into pGEM-T vector following the manufacturer's instructions. An 1100 bp Acc651 excided fragment from the pGEM-T/At1g50570 was ligated into HBTL opened with Acc651. The At1g50570 coding sequence was under the control of the chimeric $H B T$ promoter and has a C-terminus in-frame fusion with GFP coding sequence.

\subsubsection{Plasmids for Protein Expression in E. coli}

\subsubsection{1 pGEX-4T-1/At1g50570}

The At1g50570 full-length coding sequence was excised from pGAD424/At1g50570 F as 1100 bp Bg/ll fragment and ligated into pGEX-4T-1 opened with BamHI. The At1g50570 has a N-terminus inframe fusion with the GST coding sequence and was under the control of the IPTG-inducible TAC promoter.

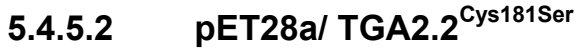

The TGA2. $2^{\text {Cys181Ser }}$ full-length coding sequence was excide from pGBT9/TCM181 as $1100 \mathrm{bp}$ EcoRI and Sacl fragment and ligated into pET28a opened with EcoRI and Sacl. The TGA2.2 $2^{\text {Cys } 181 \text { Ser }}$ has a N-terminus in-frame fusion with the $6 x$ His coding sequence and was under the control of the IPTGinducible $T 7$ promoter.

\subsection{Standard Protein Biochemical Methods}

\subsubsection{Preparation of Total Protein Extract}

\subsubsection{Total Native Cellular Protein Extracts from Arabidopsis}

Total native cellular protein extracts from Arabidopsis were prepared using vegetative tissues. About 50-100 mg leaf material were grinded in liquid nitrogen to fine powder. The powder was collected in eppendorf tube and $300 \mu \mathrm{l}$ of GUS extraction buffer or fix prot extraction buffer were added. The mixtures were homogenized and centrifuged for 20 minutes at $4{ }^{\circ} \mathrm{C}$ and $13000 \mathrm{rpm}$. The supernatant was transferred into a new eppendorf tube and was stored at $-80^{\circ} \mathrm{C}$.

\subsubsection{Total Native Cellular Protein Extracts from BY-2 Protoplasts}

Total native cellular protein extracts from BY-2 protoplasts was used to estimate the GUS activity in a MUG assay. Transfected BY-2 protoplasts were resuspended in $700 \mu$ l of solution 2 for BY-2 protoplasts and the mixture was harvested by centrifugation at $1000 \mathrm{rpm}$ (soft start) for 5 minutes at room 
temperature. About $1 \mathrm{ml}$ of the supernatant was discarded and the protoplasts $(\sim 500 \mu \mathrm{l})$ were transferred into an eppendorf tube. $1 \mathrm{ml}$ of solution 2 for BY-2 protoplasts was added and the mixture was centrifuged for 10 minutes at $5000 \mathrm{rpm}$ at room temperature. The supernatant was aspirated and the pellet was resuspended vigoursley (in order to destroy the protoplasts) in 100-200 $\mu$ GUS extraction buffer. The mixture was dipped in liquid nitrogen and then thawed at $37^{\circ} \mathrm{C}$ and this step was repeated twice. The mixture was centrifuged for 10 minutes at $13000 \mathrm{rpm}$ at $4{ }^{\circ} \mathrm{C}$ and the supernatant was transferred into new tube and stored $-80^{\circ} \mathrm{C}$.

\subsubsection{Total Native Cellular Protein Extracts from Yeast}

For protein extraction, cells from a $50 \mathrm{ml}$ liquid culture grown to an $\mathrm{OD}_{600}$ of 1 were resuspended in $\mathrm{H}$ buffer and lysed by sonication. After addition of $\mathrm{NaCl}$ to $400 \mathrm{mM}$ and Nonidet $\mathrm{P} 40$ to $0.2 \%$ the homogenate was kept on ice for 20 minutes, centrifuged for 15 minutes at $13000 \mathrm{rpm}$ and the supernatant (native protein extract) was stored at $-80^{\circ} \mathrm{C}$.

\subsubsection{Total Denatured Cellular Protein Extracts from Arabidopsis}

The preparation of total denatured cellular protein extracts from Arabidopsis was done using the Urea/SDS extraction method. $100 \mathrm{mg}$ leaf martial was grinded in liquid nitrogen into fine powder. $300 \mu \mathrm{l}$ of denaturation extraction buffer for total protein ( $5 \%$-ME and $0.2 \mathrm{mM} \mathrm{PMSF}$ were added prior to use) were added to the powder in an eppendorf tube and the mixture was homogenized. The mixture was incubated 10 minutes at $65{ }^{\circ} \mathrm{C}$ for 10 minutes under continues shacking. The cell debris and unbroken cells were pelleted in a centrifuge at $13000 \mathrm{rpm}$ and $4{ }^{\circ} \mathrm{C}$ for 10 minutes. About $200 \mu$ of the supernatant were transferred into a new eppendorf tube and stored at $-80^{\circ} \mathrm{C}$.

\subsubsection{Total Denatured Cellular Protein Extracts from Yeast}

The preparation of total cellular protein extracts from yeast was done using the Urea/SDS extraction method. A $5 \mathrm{ml}$ culture was used to inoculate $50 \mathrm{ml}$ YPD medium and the culture was incubate at $30{ }^{\circ} \mathrm{C}$ with continuous shaking $(220-250 \mathrm{rpm})$ until the $\mathrm{OD}_{600}$ for $1 \mathrm{ml}$ reaches $0.4-0.6$. The $\mathrm{OD}_{600}$ unties for the entire culture was calculated by the multiplication of the $\mathrm{OD}_{600}$ with the total culture volume. The culture was poured into a prechilled $100 \mathrm{ml}$ centrifuge tube halfway filled with ice and the tube was placed in a prechilled rotor and centrifuged at $3000 \mathrm{rpm}$ for 5 minutes at $4{ }^{\circ} \mathrm{C}$. The supernatant was removed and the cell pellet was resuspended in $50 \mathrm{ml}$ of ice-cold $\mathrm{H}_{2} \mathrm{O}$. The cells were pelleted by centrifugation at $3000 \mathrm{rpm}$ for 5 minutes at $4{ }^{\circ} \mathrm{C}$. The cells pellet was transferred into new eppendorf tube and immediately frozen in liquid nitrogen. The cells were quickly thawed and resuspended in prewarmed cracking buffer. The cell suspension was transferred to a $1.5-\mathrm{ml}$ safe cap microcentrifuge tube containing $80 \mu \mathrm{l}$ of glass beads/7.5 $\mathrm{OD}_{600}$ units of cells and the samples were heated at $70{ }^{\circ} \mathrm{C}$ for 10 minutes. The 
samples were vortexed vigoursley for 1 minute. The cells debris and unbroken cells were pelleted in a microcentrifuge at $13000 \mathrm{rpm}$ for 5 minutes at $4{ }^{\circ} \mathrm{C}$. The supernatants was transferred to fresh $1.5 \mathrm{ml}$ screw-cap tubes and place on ice or stored at $-20^{\circ} \mathrm{C}$ until use.

\subsubsection{Protein Concentrations Determination}

Protein concentration was estimated by a colorimetric assay after Bradford (1976). The assay was conducted by pipitting equal amounts of protein extract into a microtiter plate containing $200 \mu$ of 5fold diluted Bradford reagent. The $\mathrm{OD}_{595}$ was measured with a MRX plate reader (Dynex). Protein concentrations were calculated with the help of a standard curve derived from different BSA protein amounts $(1 \mu \mathrm{g}, 4 \mu \mathrm{g}, 8 \mu \mathrm{g})$ on the same plate.

\subsubsection{Expression and Purification of Recombinant Proteins in E. coli}

\subsubsection{Expression and Purification of Recombinant GST Fusion Proteins in E. coli}

5.5.3.1.1 Screening Recombinants for GST-Fusion Protein Expression in E. coli

The cloned plasmids for the expression of GST fused protein were transformed into BL21 or W3110 E. coli strains using the electroporation. The pGEX recombinants were screened for fusion protein expression as follows. Several colonies of $E$. coli transformed with the pGEX recombinants were picked and transferred into separate tubes containing $2 \mathrm{ml}$ of $\mathrm{dYT}$ medium. The liquid cultures were grown to an $\mathrm{OD}_{600}$ of $0.6-0.8$ (3-5 hours) with vigorous agitation at $30-37{ }^{\circ} \mathrm{C}$. The fusion protein expression was induced in all cultures, except for one (uninduced control) with $1 \mathrm{mM}$ IPTG. The cultures were incubated for 2 hours with vigorous agitation at $30-37^{\circ} \mathrm{C}$. After 2 hours, $1.5 \mathrm{ml}$ of the culture were harvested in eppendorf tubes by centrifugation for 1 minute at $13000 \mathrm{rpm}$. The cells pellet was resuspended in $300 \mu \mathrm{l}$ of ice-cold 1x PBS supplemented with $1 \mathrm{mM}$ PMSF. The cell suspension was disrupted using an ultra-sound sonicator on ice 6 times for 10 seconds. $10 \mu \mathrm{l}$ of the lysate (crude lysate) were analyzed on SDS gel and stained with Coomassie brilliant blue stain. The positive lysate was centrifuged at $13000 \mathrm{rpm}$ for 10 minutes at $4{ }^{\circ} \mathrm{C}$ and the supernatant (cleared lysate) was transferred into new tube. $10 \mu \mathrm{l}$ of the cleared lysate were saved for SDS gel analysis. To the rest of the cleared lysate and $20 \mu \mathrm{l}$ of $50 \%$ slurry of glutathione sepharose 4B (prepared as described by the manufactured) were added and the tubes were mixed gently for 5 minutes at room temperature. The mixture was washed three times with $100 \mu \mathrm{l}$ of ice-cold 1x PBS and the beads were collected by centrifugation. The supernatant was discarded and the beads were resuspended in $10 \mu \mathrm{l}$ of protein loading buffer. The purified GST fusion protein in positive lysate was analyzed on SDS gel and stained with Coomassie brilliant blue stain. 


\subsection{Purification of Recombinant GST-Fusion Proteins}

For the purification of the GST-fusion proteins, an affinity chromatography on glutathione-coupled sepharose 4B resin (Amersham Pharmacia) was performed according to the manufacturer's instructions. A large-scale bacterial sonicate was prepared as follows. A single colony of $E$. coli cells containing a positive recombinant pGEX plasmid was used to inoculate $100 \mathrm{ml}$ of dYT media and the culture was incubated for $12-15$ hours at $37^{\circ} \mathrm{C}$ with vigorous shaking. The culture was induced with $1 \mathrm{mM}$ IPTG and the incubation continued for an additional 6 hours. The cells were harvested by centrifugation at 5000 rpm for 5 minutes at $4{ }^{\circ} \mathrm{C}$ and the supernatant was discarded. The pellet was completely resuspended in $2.5 \mathrm{ml}$ of ice-cold 1x PBS supplemented with $1 \mathrm{mM}$ PMSF, $0.1 \%$ Tween-20 and 1\% Lysozym. The suspension was incubated on ice for 30 minutes. The suspended cells were disrupted using an ultrasound sonicator on ice 6 times for 10 seconds each. The crude lysate was centrifuged for 10 minutes at $13000 \mathrm{rpm}$ for 10 minutes at $4{ }^{\circ} \mathrm{C}$. The supernatant was transferred to a fresh tube and incubated with $100 \mu \mathrm{l}$ of the $50 \%$ slurry of glutathione sepharose $4 \mathrm{~B}$ and the suspension was mixed gently for 30 minutes at room temperature. The mixture was washed three times with $1 \mathrm{ml}$ of ice-cold 1x PBS and the beads were collected by centrifugation. The supernatant was discarded and the beads were resuspended in $50 \mu \mathrm{l}$ of glutathione elution buffer and incubated for 15 minutes at room temperature. The suspension was centrifuged for 1 minute at $13000 \mathrm{rpm}$ and the supernatant (the eluate) was transferred into a new tube, and the elution step was repeated twice with a yield averaged between $0.5-10 \mu \mathrm{g} / \mu \mathrm{l}$. The eluates were stored at $-20^{\circ} \mathrm{C}$ till use.

\subsubsection{Expression and Purification of Recombinant 6x His Fusion Proteins in E. coli \\ 5.5.3.2.1 Screening Recombinants for 6x His-Fusion Protein Expression in E. coli}

The cloned plasmids for the expression of $6 x$ His-fused protein were transformed into BL21 or W3110 E. coli strains by electroporation. The pET28a recombinants were screened for positive clones. Several colonies of $E$. coli transformed with the $\mathrm{pET}$ recombinants were picked and transferred several into separate tubes containing $2 \mathrm{ml}$ of $\mathrm{dYT}$ medium. The fusion protein expression was induced in all cultures except for one (uninduced control) with $1 \mathrm{mM}$ IPTG. The cultures were incubated for 2 hours with vigorous agitation at $30-37^{\circ} \mathrm{C}$. After 2 hours, $1.5 \mathrm{ml}$ of the culture were harvested in eppendorf tubes by centrifugation for 1 minute at $13000 \mathrm{rpm}$. The cells pellet was resuspended in $300 \mu \mathrm{l}$ of nickel nitrilotriacetic acid lysis buffer. The cell suspension was disrupted using an ultra-sound sonicator on ice 6 times for 10 seconds. $10 \mu \mathrm{l}$ of the lysate (crude lysate) were analyzed on SDS gel and stained with Coomassie brilliant blue stain. The positive lysate was centrifuged at $13000 \mathrm{rpm}$ for 10 minutes at $4{ }^{\circ} \mathrm{C}$ and the supernatant (cleared lysate) was transferred into new tube. $10 \mu \mathrm{l}$ of the cleared lysate were saved for SDS gel analysis. To the rest of the cleared lysate, $20 \mu \mathrm{l}$ of $50 \%$ NiNTA®-matrix resin (prepared as described by the manufactured) were added. The tubes were mixed gently for 5 minutes at room temperature. The mixture was washed three times with nickel nitrilotriacetic acid wash buffer and 
the beads were collected by centrifugation. The supernatant was discarded and the beads were resuspended in $10 \mu \mathrm{l}$ of protein loading buffer. The purified 6x His-fusion protein in positive lysate was analyzed on SDS gel and stained with Coomassie brilliant blue stain.

\subsection{Purification of Recombinant 6x His-Fusion Proteins}

For the purification of the $6 x$ His fusion proteins, an affinity chromatography on NiNTA®-matrix resin (Qiagen) was performed according to the manufacturer's instructions. A large-scale bacterial sonicate was prepared. A single colony of $E$. coli cells containing a positive recombinant $\mathrm{pET}$ plasmid was used to inoculate $100 \mathrm{ml}$ of dYT medium and the culture was incubated for $12-15$ hours at $37{ }^{\circ} \mathrm{C}$ with vigorous shaking. The culture was induced with $1 \mathrm{mM}$ IPTG and the incubation continued for an additional 6 hours. The cells were harvested by centrifugation at $5000 \mathrm{rpm}$ for 5 minutes at $4{ }^{\circ} \mathrm{C}$ and the supernatant was discarded. The pellet was completely resuspended in $5 \mathrm{ml}$ of nickel nitrilotriacetic acid lysis buffer supplemented with $1 \%$ Lysozym and the suspension was incubated on ice for 30 minutes. The suspended cells were disrupted using an ultra-sound sonicator on ice 6 times for 10 seconds each. The crude lysate was centrifuged for 10 minutes at $13000 \mathrm{rpm}$ for 10 minutes at $4{ }^{\circ} \mathrm{C}$. The supernatant was transferred to a fresh tube and incubated with $1 \mathrm{ml}$ of the $50 \%$ NiNTA®-matrix resin and the suspension was mixed gently for 1 hour at $4{ }^{\circ} \mathrm{C}$. The mixture was washed three times with $250 \mu$ of nickel nitrilotriacetic acid wash buffer and the beads were collected by centrifugation. The supernatant was discarded and the beads were resuspended in $250 \mu \mathrm{l}$ Nickel nitrilotriacetic acid elution buffer and incubated for 30 minutes at $4{ }^{\circ} \mathrm{C}$. The suspension was centrifuged for 1 minute at $13000 \mathrm{rpm}$ and the supernatant was transferred into new tube, and the elution step was repeated twice with a yield averaged between $0.5-1 \mu \mathrm{g} / \mu \mathrm{l}$. The eluates were stored at $-20^{\circ} \mathrm{C}$ till use.

\subsubsection{Denaturing SDS-Polyacrylamide Gel Electrophoresis (SDS-PAGE)}

In SDS-Polyacrylamide Gel Electrophoresis (SDS-PAGE), proteins are separated largely on the basis of polypeptide length. The electrophoresis of the protein was done using a discontinuous buffer system, in which a non-restrictive large pore gel, called a stacking gel, is layered on top of a separating gel called a resolving gel (Laemmli, 1970). The recipe for the resolving gel was consisting of: 10-12\% (w/v) acrylamide/bisacrylamide (19:1), $400 \mathrm{mM}$ Tris-HCl pH 8.8, 0.1\% (w/v) SDS, 0.1\% (w/v) TEMED and $0.1 \%(\mathrm{w} / \mathrm{v})$ ammonium persulfate. The stacking gel was consisting of: $4 \%(\mathrm{w} / \mathrm{v})$ acrylamide/bisacrylamide (37.5:1), $125 \mathrm{mM}$ Tris- $\mathrm{HCl} \mathrm{pH}$ 6.8, 0.1\% (w/v) SDS, 0.2\% (w/v) TEMED and $0.1 \%(\mathrm{w} / \mathrm{v})$ ammonium persulfate. The denatured protein extract samples were boiled at $95{ }^{\circ} \mathrm{C}$ for 5 minutes then cooled on ice and loaded into the gel. The native extracted protein samples were mixed with $10 \mu$ of protein loading buffer (in some cases the ß-ME was omitted) and denatured at $95{ }^{\circ} \mathrm{C}$ for 5 minutes, cooled on ice and then loaded on the gel. The electrophoresis was performed at $120 \mathrm{~V}$ in $1 \times$ SDS-PAGE running buffer until 
the bromphenolblue band run out of the gel. $6 \mu$ prestained protein ladder was loaded on each gel for the estimation of the size of the separated proteins.

\subsubsection{Coomassie Staining of Proteins Separated on SDS-PAGE}

The Coomassie Brilliant Blue G-250 dye was used to detect proteins separated on SDS-PAGE (Ausubel et al., 1988). The gels were fixed in a Coomassie fixing solution for 10 minutes under continuous agitation then the fixing solution was removed. The fixed gel was incubated with Coomassie staining solution for at least 2 hours at room temperature. The gel was destained using Coomassie destain solution for 2 hours.

\subsubsection{Western Blot Analysis}

\subsubsection{Wet Transfer of Proteins onto a Protran® Membrane}

The transfer of proteins from the SDS-PAGE gel onto Protran® membranes was performed using the tank electroblotting method. After the electrophoresis, the stacking gel was removed and the resolving gel was wetted with the blotting buffer for Protran $®$ membranes. A blotting sandwich was constructed, in which the gel was placed on three wetted filter papers (similar to gel size). Then a wet Protran $®$ membrane (similar to gel size) was placed above the gel. A second sheet of three moistened

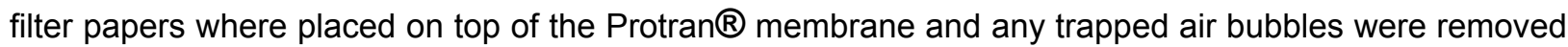
by rolling a pipit on the sandwich. The sandwich was placed between two sponges. The construct was placed between a porous foam plastic sheet on top and a metal sheet to ensure uniform membrane contact with the gel. The assembled cassette was inserted into the blotting apparatus that was filled with 2 liters of blotting buffer for Protran $®$ membranes and the proteins were transferred overnight from the SDS-PAGE gel to the Protran® membrane using a constant electric current of $120 \mathrm{~mA}$.

\subsubsection{Immuno-detection of the Proteins with Specific Antibodies}

The efficiency of the blotting was determined by visualization of the prestained protein ladder on the membrane. The membrane was washed 3 times for 5 minutes in 1x PBS-T buffer. The non-specific protein-binding capacity of the Protran $\circledR$ membrane was blocked by the incubation with $5 \%(\mathrm{w} / \mathrm{v}$ in $1 \mathrm{x}$ PBS-T) non- at dried milk for 2 hours under continuous shacking. The blocked membrane was washed three times for 5 minutes with 1x PBS-T buffer. The membrane was incubated with the primary antibody (diluted appropriately in 5\% (w/v in 1x PBS-T) non-fat dried milk) for 2 hours under continuous gentle agitation. The membrane was washed 3 times for 5 minutes with 1x PBS-T buffer. The membrane was incubated for 2 hours with the secondary antibody (anti-rabbit IgG antibody peroxidase conjugate diluted 
$1: 20000$ in $5 \%(\mathrm{w} / \mathrm{v}$ in $1 \times$ PBS-T). The membrane was washed twice for 5 minutes with $1 \times$ PBS-T followed by 3 times washing for 5 minutes in $1 \times$ PBS buffer. The detection of proteins on the membrane was done using the Enhanced Chemiluminescence Plus ${ }^{\mathrm{TM}}\left(\mathrm{ECL}^{+}\right)$kit (Amersham) following the manufacturer's instructions. The membrane was incubated with the enzyme substrate for 5 minutes at room temperature and the chemiluminescence was detected by an exposition to a Cronex 10T X-ray film (DuPont).

\subsubsection{Far Western Analysis}

Far western blotting is an in vitro method for detecting protein-protein interactions. The protein sample $(1 \mu \mathrm{g})$ was fractionated on an SDS-PAGE gel by electrophoresis as described above. The proteins were transferred from the gels onto a Protran ${ }^{\circledR}$ membrane by electroblotting as described above. The non-specific protein-binding capacity of the Protran $\circledR$ membrane was blocked by the incubation with $5 \%$ ( $\mathrm{w} / \mathrm{v}$ in $1 \mathrm{x}$ PBS-T) non-fat dried milk for 2 hours under continuous agitation. The membrane was washed three times with 1x PBS-T for 5 minutes and then the membrane was incubated for 2 hours with estimated 10 -fold excess $(\sim 10 \mu \mathrm{g})$ of purified $6 \mathrm{x}$ His-fusion proteins. The membrane was washed three times for 5 minutes with 1x PBS-T buffer to risen it, and then the membrane was incubated with the primary antibody (diluted appropriately in 5\% (w/v in 1x PBS-T) non-fat dried milk) for 2 hours under continuous gentle agitation. The membrane was washed 3 times for 5 minutes with 1x PBS-T buffer and then was incubated for 2 hours with the secondary antibody (anti-rabbit IgG-antibodyperoxidase conjugate; diluted 1:20000 in 5\% non-fat dried milk. The detection of proteins on the membrane was done as described above.

\subsubsection{GST Pull-Down Assay}

The GST pull-down assay is used to detect protein-protein interaction in vitro. In this method $1 \mathrm{ml}$ of cleared lysate containing bacterial overexpressed GST fusion proteins was incubated with $1 \mathrm{ml}$ of cleared lysate containing bacterial overexpressing the $6 x$ His-fusion protein for 1 hour at room temperature under continuous agitation. $200 \mu \mathrm{l}$ of $50 \%$ glutathione slurry matrix was added to the mixture and the reaction was incubated for 1 hour at room temperature. The beads were collected by centrifugation (1 minute at $13000 \mathrm{rpm}$ ) and were washed three times with $1 \mathrm{ml}$ of ice-cold $1 \mathrm{x}$ PBS. The beads were collected by centrifugation and the supernatant was discarded. The beads were resuspended in $100 \mu \mathrm{l}$ of glutathione elution buffer and incubated for 15 minutes at room temperature. The suspension was centrifuged for 1 minute at $13000 \mathrm{rpm}$ and the supernatant was transferred into new tube. To the eluate, $400 \mu \mathrm{l}$ of cold methanol, $100 \mu \mathrm{l}$ of cold chloroform and $400 \mu \mathrm{l}$ cold $\mathrm{H}_{2} \mathrm{O}$ were added. The mixture was mixed gently and centrifuged for 1 minute at $13000 \mathrm{rpm}$ for 2 minutes. The aqueous upper phase was carefully discarded and $300 \mu$ of cold methanol were added to the pellet. The proteins 
were then precipitated by centrifugation at maximum speed for 2 minutes. To the dried pellet, $20 \mu \mathrm{l}$ of $1 \mathrm{x}$ PBS were added. A western blot analysis was carried out as described above.

\subsubsection{Immunoprecipitation}

Immunoprecipitation involves the interaction between a protein and its specific antibody, the separation of these immune complexes with proteinA beads, and the subsequent analysis by western blotting. Native protein extract from Arabidopsis leaves $(1 \mathrm{mg}$ ) was thawed on ice before adding $2 \mu \mathrm{l}$ of $\mathrm{HA}$ antibody. The mixture was incubated on ice for 1 hour. A volume of $50 \mu$ of proteinA beads (prepared in $20 \%$ RIPA buffer according to manufacture recommendations) was added to the mixture. The mixture was then incubated for 1 hour at $4{ }^{\circ} \mathrm{C}$ under continuous agitation. The proteinA beads were collected by centrifugation at $13000 \mathrm{rpm}$ for 2 minutes and the supernatant was removed completely by aspiration. The beads were washed three times in $1 \mathrm{ml}$ of $20 \%$ RIPA buffer and the supernatant was discarded. The beads were resuspended in $50 \mu \mathrm{l}$ of loading buffer for proteins. $30 \mu \mathrm{l}$ of Immunoprecipitated eluates were used for western blot analysis as described above.

\subsubsection{Determination of GUS Activity}

The activity of GUS reporter gene was done using a modified GUS assay (Jefferson et al., 1987). The GUS assay allows the quantification of $\beta$-Glucuronidase enzyme activity using Methylumbelliferyl- $\beta$ Glucuronid (4-MUG) as a substrate. The catalectic activity of GUS will convert the 4-MUG substrate into Methylumbelliferon and the fluorescent of Methylumbelliferon can be estimated using a Spectrophotometer for microtiter plate. 5-20 $\mu$ g total protein extract were diluted in $100 \mu$ l GUS extraction buffer in a microtiter plate. The reaction was started by the addition $100 \mu \mathrm{l}$ of $4 \mathrm{mM}$ MUG to the protein extract in a microtiter plate well and the plate was incubated at $37^{\circ} \mathrm{C}$. After 15 minutes incubation (time A) half of the reaction was transferred into new well containing $100 \mu \mathrm{l}$ of $200 \mathrm{mM}$ sodium carbonate (to stop the reaction), the rest of the reaction was run between 45 minutes to 2 hours (time $B$ ). The rest of the reaction was stopped by adding $100 \mu \mathrm{l}$ of $200 \mathrm{mM}$ sodium carbonate. The quantification of Methylumbelliferon fluorescent was done using CytoFluorll plate reader (excitation wavelength $360 \mathrm{~nm}$; emission measurement wavelength $460 \mathrm{~nm}$ ) and 50 pmol Methylumbelliferon was used as standard.

The GUS activity was measured using the following formula:

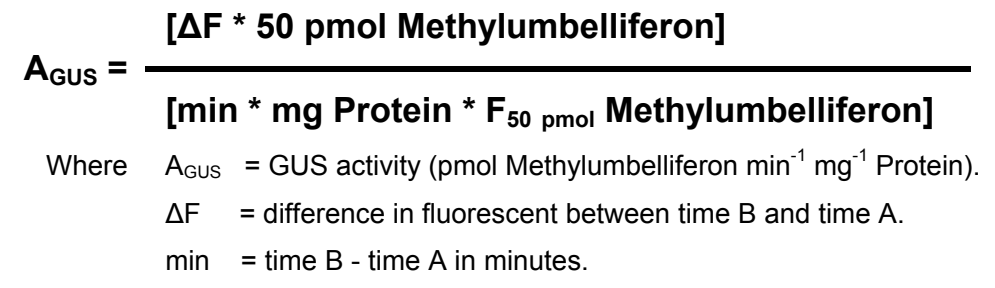




\subsubsection{Determination of $\beta$-Galactosidase Activity (ONPG Assay)}

The activity of $\beta$-Galactosidase reporter gene was done using ONPG (o-Nitrophenyle- $\beta$-DGalactopyranosid) assay. The $\beta$-Gal catalyzed the colorless substrate ONPG into the fluorescent oNitrophenyle substance. $2 \mathrm{ml}$ of yeast culture were grown on selective medium overnight. In the next day, $8 \mathrm{ml}$ of YPD medium were added to the overnight culture and the culture was further incubated for 3-5 hours at $30{ }^{\circ} \mathrm{C}$. After $3-5$ hours $1 \mathrm{ml}$ of the culture was used to record the $\mathrm{OD}_{600}$. When the culture reached an $\mathrm{OD}_{600}$ between $0.5-0.8,1.5 \mathrm{ml}$ of the culture was placed into three $1.5-\mathrm{ml}$ microcentrifuge tubes and the tubes were centrifuged at $13000 \mathrm{rpm}$ for 30 seconds. The supernatant was removed and the cell pellet was resuspended in $1.5 \mathrm{ml}$ of Lac-Z buffer. The cells suspension was centrifuged and the supernatant was removed. The cell pellet was resuspended in $300 \mu \mathrm{L}$ Lac-Z buffer (the concentration factor is $1.5 / 0.3=5$-fold) and $100 \mu \mathrm{l}$ of the cell suspension were transferred into a fresh microcentrifuge tube (safe lock). The tubes were placed into liquid nitrogen until the cells were frozen and then they were allowed to thaw at $42^{\circ} \mathrm{C}$. This step was repeated twice to ensure that the cells have broken.

For the ONPG assay, a blank tube with $100 \mu$ of Lac-Z buffer was set, then $700 \mu$ of Lac-Z buffer (+ $\beta-M E)$ were added to the samples and to the blank tubes. $160 \mu$ of ONPG $(4 \mathrm{mg} / \mathrm{ml}$ in Z buffer) were added immediately to the reaction tubes and the reactions were placed at $30^{\circ} \mathrm{C}$ until a yellow color develops. $400 \mu \mathrm{l}$ of $1 \mathrm{M} \mathrm{Na}_{2} \mathrm{CO}_{3}$ were added to stop the reaction and the elapsed time was recorded in minutes. The reaction tubes were centrifuged for 10 minutes at $13000 \mathrm{rpm}$ to pellet cell debris and the supernatants was carefully transferred into clean cuvettes. The spectrophotometer was adjusted against the blank at $\mathrm{OD}_{420}$ and the $\mathrm{OD}_{420}$ of the reactions was measured relative to the blank.

The $\beta$-Gal activity was measured using the following formula:

$$
\begin{aligned}
& \beta-\mathrm{Gal}_{\mathrm{units}}=\frac{1,000 \times \mathrm{OD}_{420}}{\left(\mathrm{~T} \times \mathrm{V} \times \mathrm{OD}_{600}\right)} \\
& \text { Where } \quad \beta \text {-Gal } \text { units }_{\text {. }} \quad=\beta \text {-Gal activity in units } \\
& \mathrm{T}=\text { Elapsed time (in minutes) of incubation. } \\
& \mathrm{V} \quad=100 \mu \mathrm{l} \times \text { concentration factor. } \\
& \mathrm{OD}_{600} \quad=\mathrm{OD}_{600} \text { of } 1 \mathrm{ml} \text { of culture. }
\end{aligned}
$$

\subsubsection{Electrophoretic Mobility Shift Assay (EMSA)}

The EMSA is a simple and rapid method for detecting DNA-protein interactions that is used widely in the study of sequence-specific DNA binding proteins such as transcription factors. The assay is based on the observation of DNA-protein complexes migration through a native polyacrylamide gel, which is slower than the free DNA migration. The EMSA were performed using a labeled as- 1 fragment. 
The components for the preparation of $5 \%(\mathrm{w} / \mathrm{v})$ non-denaturing gels were $28 \mathrm{ml} \mathrm{H}_{2} \mathrm{O}, 10 \mathrm{ml}$ of $5 x$ TBE buffer, $5.75 \mathrm{ml}$ of $86 \%$ glycerol, $6.25 \mathrm{ml}$ of $40 \%$ acrylamide, $200 \mu \mathrm{l}$ of $15 \%$ APS and $20 \mu \mathrm{l} \mathrm{TEMED.} \mathrm{After}$ gel polymerization, the gel was mounted in an EMSA electrophoresis chamber and was pre-run at $100 \mathrm{~V}$ for 30 minutes. Protein samples were mixed with $6 \mu \mathrm{l}$ of $5 \mathrm{x}$ binding buffer, $3 \mu \mathrm{l}$ of $1 \mu \mathrm{g} / \mu \mathrm{l}$ poly-dldC (a non-specific DNA competitor) in a total volume of $28 \mu \mathrm{l}$ and the mixture was incubated on ice for 10 minutes. $4 \mu \mathrm{l}$ of the radioactively labeled as-1 fragment were added and the samples were incubated for at least 10 minutes at room temperature. For loading of the binding reactions on the gel, $10 \mu$ l of loading buffer were added. The samples were loaded and the gel was run overnight at $4{ }^{\circ} \mathrm{C}$ at $60 \mathrm{~V}$. The next day, the gel was dried under vacuum at $80^{\circ} \mathrm{C}$ for 2 hours. The dried gel was exposed for radiography to a Phospholmager plate overnight.

\subsection{GUS Staining of Arabidopsis}

Two-week-old soil grown plants were stained for GUS activity using a solution containing $2 \mathrm{mM}$ 5-bromo-4-chloro-3-indolyl glucuronide (X-Gluc) in $0.1 \mathrm{M} \mathrm{Na}_{2} \mathrm{HPO}_{4}, \mathrm{pH} 7.0,10 \mathrm{mM}$ EDTA, $0.5 \mathrm{mM}$ potassium ferricyanide/ferrocyanide, and $0.06 \%$ Triton X-100 (Jefferson et al., 1987) at $37^{\circ} \mathrm{C}$ for 16 hours. The samples were cleared of chlorophyll by sequential washing in $70 \%$ ethanol. Microscopy

\subsection{Microscopy}

Transfected BY-2 Protoplasts were mounted in MSF and viewed with a BX 51 fluorescent microscope (Olympus) with filter sets for UV light (excitation filter EF 395-440; beam splitter FT-460; band-pass filter LP-470) and for blue light (excitation filter EF 450-490; beam splitter FT-510; band-pass filter LP-520). Water-immersion objectives with up to 40x magnifications were used for observations. The microscopy was performed using $50 \mu \mathrm{l}$ of protoplast suspension that was pipetted with a clipped yellow tip on a microscopic slide. The slides were covered carefully with a covering glass to avoid any mechanical shearing of the protoplasts. Screening for protoplasts expressing the transfected GFP-fusion

proteins was performed using the blue filter set on a dark background to minimize photo-damages and bleaching of the chromophore of GFP. The photographs were taken with a mounted photo camera at blue and visible light fields. 


\section{Results}

\subsection{Establishing the Modified Yeast-One Hybrid System \\ 6.1.1 The Modified Yeast-One Hybrid System Screening Strategy}

After having shown that TGA2.2 is involved in SA-mediated gene expression, our group addresses the question: how is the activity of TGA2.2 regulated? As no direct posttranscriptional modifications have been detected yet, it is likely that protein-protein interactions mediate the TGA2.2 regulation. For instance, a protein inhibiting DNA binding in the absence of SA was postulated (Jupin and Chua, 1996). As TGA2.2 does not activate transcription in yeast, a coactivator might be recruited. Thus, TGA2.2 may be a good bait to isolate putative regulatory proteins using yeast hybrid systems.

Accordingly, a yeast hybrid system strategy was established based on the Y1HS principles. In the classical Y1HS, a cDNA expression library is constructed that encodes hybrid proteins fused to the C-terminus of an AD. The CDNA expression library is transformed into a yeast strain carrying reporter genes under the control of specific cisacting regulatory elements. Hybrid proteins that can recognize these cis-elements can act as transcriptional activators of the reporter genes. A modified Y1HS (MY1HS) that utilizes TGA2.2 binding to the as-1 element and its disability of reporter gene transactivation was used to screen a cDNA library fused to the end of a transcriptional $A D$ of the yeast GAL4 (GAL4AD) to isolate putative TGA2.2-interacting proteins (Figure $6.1)$.

A parental yeast strain carrying as reporter gene an integrated copy of HIS3 with three-times tandemly repeated as-1 elements upstream of the TATA element was constructed (R. Weigel, unpublished data). The resulting yeast strain, termed YRWH2, transcribes the HIS3 reporter gene at basal levels and is not able to grow on media lacking histidine in the presence of $30 \mathrm{mM}$ 3-AT, a competitive inhibitor of the HIS3 gene product. The YRWH2 yeast cells were transformed with a construct encoding TGA2.2 as a bait protein. The YRWH2 yeast cells harboring TGA2.2 were used to 
screen for TGA2.2 interacting proteins using different types of cDNA libraries prepared from tobacco or Arabidopsis vegetative tissue.

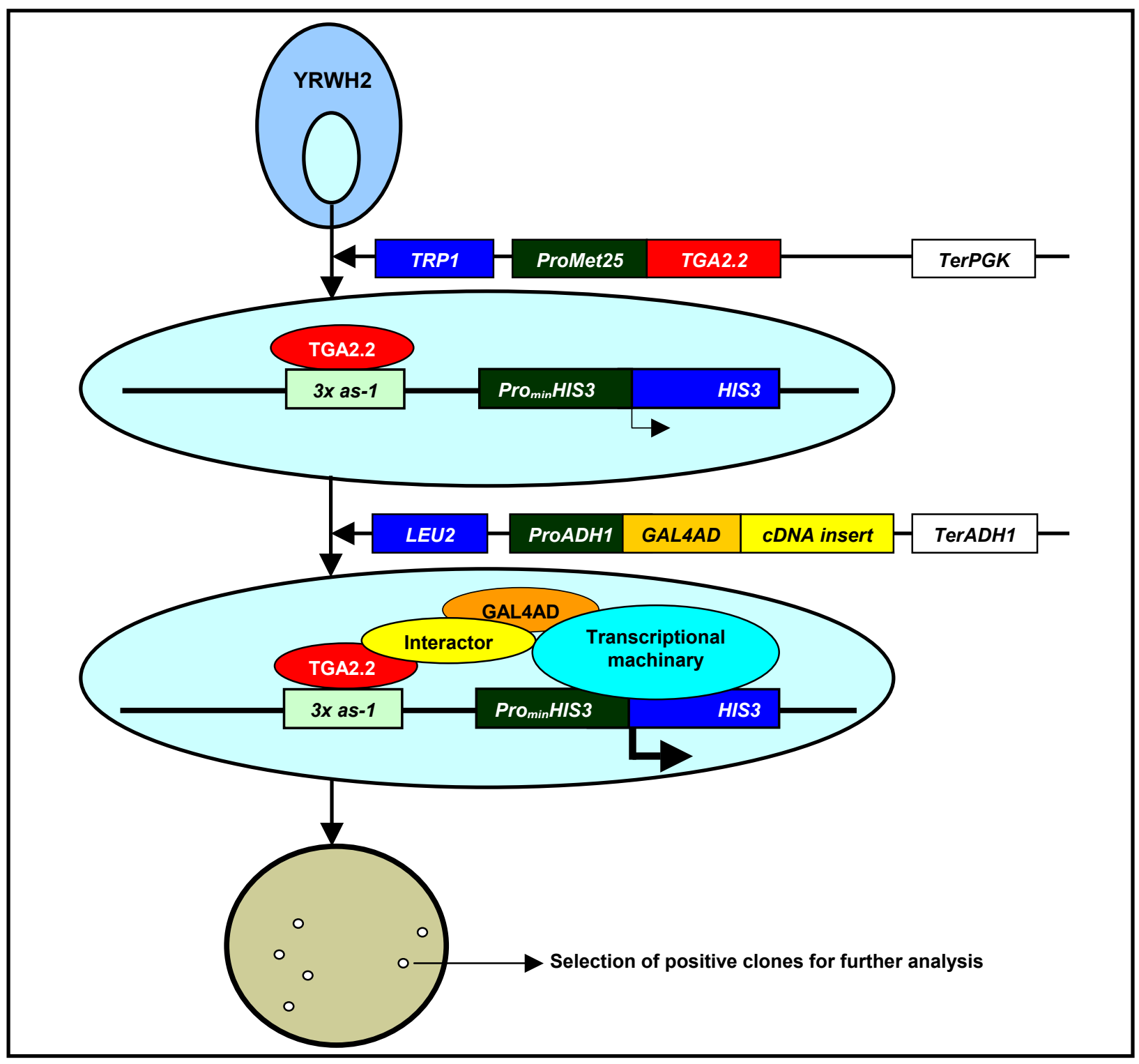

Figure 6.1. Strategy for the isolation of TGA2.2-interacting proteins by selection in yeast.

An expression library of hybrid proteins was transformed into the YRWH2 strain carrying the HIS3 reporter gene under the control of $3 x$ as- 1 element. The TGA2.2 bait protein coding sequences was first transformed into YRWH2. Hybrid proteins fused to the Cterminus of the GAL4AD were used for TGA2.2 interacting proteins screening. Cells grown on SD medium lacking histidine in the presence of $30 \mathrm{mM} 3-\mathrm{AT}$ were considered to be putative positive and selected for further analysis. Pro $\mathrm{min}_{\mathrm{H}} \mathrm{HIS} 3$ indicates the minimal promoter of the HIS3 gene, TerPGK indicates the terminator of the phosphoglycerokinase (PGK) gene, ProADH1 indicates the promoter of the alcohol dehydrogenase1 ( $A D H 1)$ gene, and TerADH1 indicates the terminator of the ADH1 gene. 


\subsubsection{Construction of Yeast Strains and Plasmids for the MY1HS}

The establishment of the MY1HS started with the construction of yeast strains carrying reporter genes under the control of three-times tandemly repeated as-1 elements upstream of a TATA box. In addition to the YRWH2 strain described above, another yeast strain carrying an integrated copy of lac-Z reporter gene with three-times tandemly repeated as-1 elements upstream of the TATA element was constructed ( $R$. Weigel, unpublished data). The resulting yeast strain, termed YRWZ2, was used for ONPG assays. The YRWH2 strain was used to screen cDNA inserts encoding TGA2.2interacting proteins, while YRWZ2 was used to quantify the interactions. The YRWH2 strain transcribes the HIS3 gene at basal levels and was not able to grow on medium lacking histidine in the presence of $30 \mathrm{mM}$ of 3-AT, indicating that the as-1 elements in YRWH2 are transcriptionally inactive.

The TGA2.2 bait protein was expressed in yeast cells using the pBL vector (a pBridge derivative from CLONTECH). TGA2.2 was expressed as a native protein, i.e., TGA2.2 was not fused to any other domains. The pBL-/TGA2.2 plasmid harbors the Met25:: TGA2.2::PGK cassette, which allows the conditional expression of TGA2.2 from the Met25 promoter in response to methionine levels in the yeast medium (Tirode et al., 1997). TGA2.2 expression is repressed in the presence of methionine and it is induced if the methionine is omitted from the media.

Before performing the MY1HS, the binding of the TGA2.2 bait protein to the as-1 element was tested. However, as described above, TGA2.2 does not transactivate reporter genes in yeast (Niggeweg et al., 2000b). To overcome this deficit, the TGA2.2VP16 coding sequence, encoding a TGA2.2 protein fused in-frame to the VP16 AD, was cloned into the $\mathrm{pBL}$ vector under the control of the Met25 promoter. The TGA2.2VP16 plasmid was designated as pBL-/TGA2.2-VP16. The presence of the TRP1 gene as a selectable auxotrophic marker in the $\mathrm{pBL}$ vector allows the selection of transformed yeast cells on SD medium lacking tryptophan. 


\subsubsection{Testing and Optimizing the MY1HS Screening Conditions}

Before embarking on the MY1HS screens for TGA2.2-interacting proteins, several control experiments were conducted to test the MY1HS feasibility, credibility and reliability.

To test the effect of TGA2.2 and TGA2.2-VP16 overexpression or repression on the yeast transformation efficiency, the pBL-/TGA2.2 and pBL-/TGA2.2-VP16 plasmids were transformed into the YRWH2 strain and the transformants were plated on selective SD media lacking tryptophan, supplemented with or without methionine. Surprisingly, when TGA2.2 and TGA2.2-VP16 proteins were overexpressed in the YRWH2 cells, i.e., on SD medium lacking methionine, a transformation efficiency value of null was obtained. These results indicate that TGA2.2 overexpression is toxic to the YRWH2 yeast cells. Adding $1 \mathrm{mM}$ of methionine to the transformation medium repressed TGA2.2 expression and thereby their toxicity, enabling YRWH2 transformants to grow.

In order to familiarize the expected results from the M1YHS screens and in order to test the effect of TGA2.2 on reporter gene expression, TGA2.2 and TGA2.2-VP16 proteins were analyzed for as-1 element binding and auto-activation in YRWH2 strain. For this purpose, TGA2.2 and TGA2.2-VP16 transformants were grown on SD medium lacking tryptophan and histidine, supplemented with $30 \mathrm{mM}$ 3-AT and with or without methionine. The TGA2.2 bait alone did not activate the expression of the HIS3 reporter gene (Figure 6.2, sector 2). The restoration of histidine prototrophy in TGA2.2-VP16 transformants ensures that the TGA2.2 is able to bind to as-1 element (Figure 6.2, sector 4). The TGA2.2-VP16-dependent HIS3 gene activation was dependent on the presence of methionine, verifying that the TGA2.2 overexpression was toxic to the YRWH2 cells. Similar results were obtained using the YRWZ2 strain harboring the lac-Z reporter gene (data not shown). 

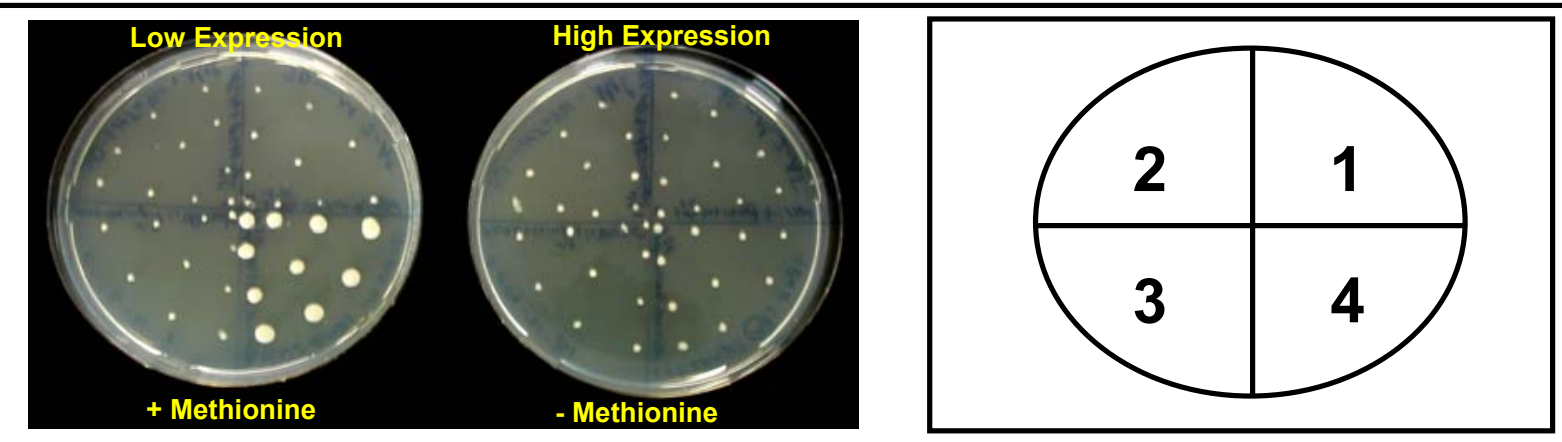

\begin{tabular}{|l|l|c|c|}
\cline { 3 - 4 } \multicolumn{2}{c}{} & \multicolumn{2}{c|}{ Growth on SD lacking histidine } \\
\hline Sector & Bait (TRP1 marker) & - Methionine & + Methionine \\
\hline 1 & pBL & - & - \\
2 & TGA2.2 & - & - \\
3 & pBL & - & - \\
4 & TGA2.2-VP16 & - & +++ \\
\hline
\end{tabular}

Figure 6.2. M1HYS assays of TGA2.2 and TGA2.2-VP16 binding to the as-1 elements in YRWH2.

YRWH2 cells containing pBL (1 and 3), pBL-/TGA2.2 (2) and pBL-/TGA2.2-VP16 (4) plasmids were grown for 4 days at $30{ }^{\circ} \mathrm{C}$ on selective SD medium lacking tryptophan and histidine, supplemented with $30 \mathrm{mM}$ 3-AT and with or without methionine.

The well-studied interactions between NPR1 protein fused to the GAL4AD (GAL4AD-NPR1) and TGA2.2 were tested in the MY1HS as a positive control. The GAL4AD-NPR1 was found to interact with TGA2.2 in the MY1HS (Figure 6.3, sector 2). This result shows the interaction between NPR1 and TGA2.2 at the as-1 element. Intriguingly, the GAL4AD-NPR1 protein partially reduces the toxic effect of TGA2.2 overexpression on the YRWH2 cells; YRWH2 cells containing TGA2.2-VP16 and GAL4AD-NPR1 proteins were able to grow on SD media lacking methionine (Figure 6.3, sector 4). YRWH2 cells expressing the GAL4AD-TGA1a protein were used as a control (Figure 6.3, sector 3). 


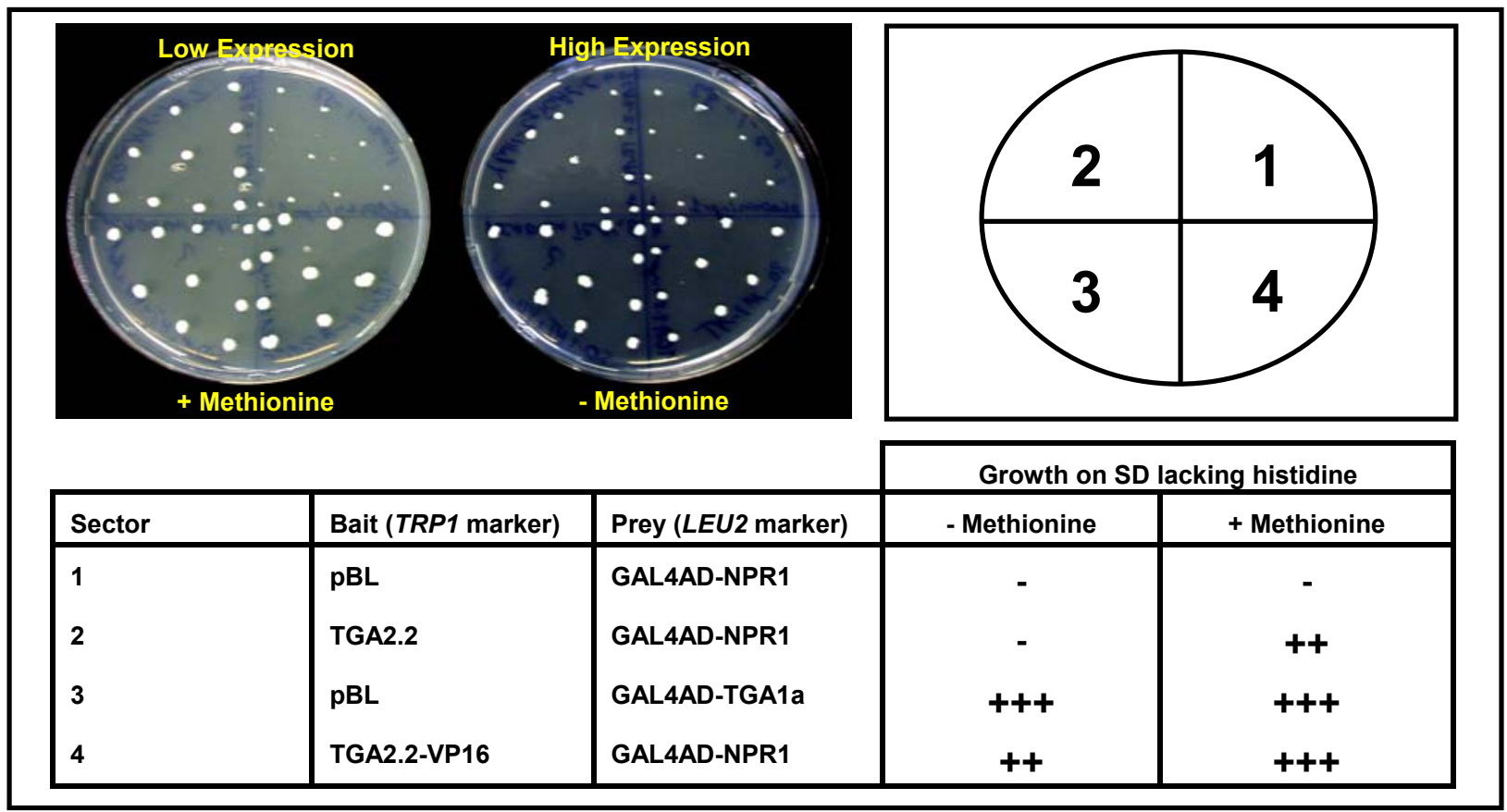

Figure 6.3. M1HYS assays of interactions between NPR1 and TGA2.2 proteins.

YRWH2 cells containing pBL + pGAD424/NPR1 (1), pBL-/TGA2.2 + pGAD424/NPR1 (2), pBL-/TGA2.2-VP16 + pGAD424/NPR1 (3) and $\mathrm{pBL}+\mathrm{pGAD424/TGA1a}$ (4) plasmids were grown for 4 days at $30^{\circ} \mathrm{C}$ on selective SD medium lacking leucine, tryptophan and histidine, supplemented with $30 \mathrm{mM} 3-\mathrm{AT}$ and with or without methionine.

In order to optimize the MY1HS screening conditions, several pre-screen tests were conducted to measure the cDNA library plasmid transformation efficiency, the background growth rate and the optimal methionine and 3-AT concentrations in the media. In addition to that, several miniscreens using different concentrations of NPR1 and TGA1a (as positive controls) were conducted to have a general picture about the MY1HS screens outcome. In conclusion, the MY1HS screening conditions were calibrated so that $\mathrm{YRWH} 2$ yeast cells already containing pBL/TGA2.2 plasmid were used directly for transforming $100 \mu \mathrm{g}$ of cDNA library plasmid and the resulted transformants were plated on SD media lacking tryptophan, leucine and histidine, supplemented with $30 \mathrm{mM}$ 3-AT and $1 \mathrm{mM}$ methionine in order to avoid excessive background growth and to reduce TGA2.2 toxicity, respectively.

The yeast cells were separately transformed with two expression libraries of cDNA fragments of mRNAs prepared from Arabidopsis and tobacco plants. The cDNA fragments from both libraries were fused to the yeast GAL4AD. The Arabidopsis cDNA 
library was cloned into the pGAD10 vector (Weigel et al., 2001), while the tobacco cDNA library was cloned into the pGAD424 vector (Strathmann et al., 2001). The presence of LEU2 as selectable auxotrophic marker in the pGAD10 and pGAD424 plasmids allows the selection of transformed yeast cells on SD medium lacking the amino acid leucine.

\subsection{Isolation of cDNAs Encoding As-1 Binding and TGA2.2- Interacting Proteins Using the MY1HS}

To isolate cDNAs encoding TGA2.2 interacting proteins, the MY1HS screening system was deployed. The YRWH2 cells harboring the TGA2.2 coding sequence were separately transformed with the expression cDNA libraries prepared from Arabidopsis and tobacco plants. Out of $\sim 1 \times 10^{6}$ yeast transformants/screen, several colonies were selected on the basis of histidine prototrophy and 3-AT resistance. These primary positives were further analyzed by growing them successively on SD media lacking tryptophan, leucine and histidine, supplemented with $30 \mathrm{mM} 3-\mathrm{AT}$ and $1 \mathrm{mM}$ methionine. From these primary positives, 45 positive clones (28 and 17 from Arabidopsis and tobacco cDNAs, respectively) were able to continue to grow on the selective media. Restriction enzyme digestion and DNA sequencing analysis of cDNA fragments of the isolated plasmids led to the classification of $45 \mathrm{cDNA}$ clones into four distinct cDNA groups (Table 6.1). Among the four groups, clone 5 from group 4 was the most abundant.

Table 6.1. General characteristics of positive cDNA clones isolated in this work.

\begin{tabular}{lllll}
\hline Group & Clone & Insert size $(\mathbf{b p})$ & Frequency & Source of cDNA library \\
\hline 1 & 13 & 2000 & 12 & Tobacco \\
& 54 & 1300 & 5 & Tobacco \\
2 & 16 & 1000 & 1 & Arabidopsis \\
3 & 44 & 950 & 2 & Arabidopsis \\
& 82 & 1450 & 3 & Arabidopsis \\
4 & 5 & 550 & 22 & Arabidopsis \\
\hline
\end{tabular}


To confirm the interactions with TGA2.2, the recovered prey plasmids were retransformed into YRWH2 cells containing either $\mathrm{pBL}$ or $\mathrm{pBL}-/ \mathrm{TGA} 2.2$ plasmids. The transformants were assayed for histidine prototrophy. Remarkably, the tobacco cDNA library positive clones conferred auto-activation of the HIS3 reporter gene, i.e., they do not need to interact with TGA2.2 to activate reporter gene expression. This result hints at either false positive clones or as-1 binding proteins. Strikingly, sequence analysis revealed that both cDNA inserts represent two closely related genes encoding TGA transcription factors (Table 6.2). Clone 13 contained the full-length sequence of a TGA10 cDNA. The clone 54 contained an open reading frame encoding truncated TGA2.1 protein. As both proteins were extensively analyzed in our group, they were excluded (Niggeweg et al., 2000b; Schiermeyer et al., 2003).

In contrast to tobacco results, the restoration of histidine prototrophy using the Arabidopsis library was dependent on the presence of TGA2.2, indicating that the expression of HIS3 reporter gene driven by the as-1 elements required an interaction between both proteins. Sequence analysis of isolated plasmids revealed that the Arabidopsis cDNA clones encode different polypeptides, identifying four independent genes (Table 6.2). The structural features of the Arabidopsis cDNA clones will be discussed in more details in the next sections.

Table 6.2. Identity of positive cDNA clones isolated in this work.

\begin{tabular}{lllll}
\hline Group & Clone & NCBI Accession Number & Gene Name & Product Description \\
\hline 1 & 13 & & TGA10 & TGA10 bZIP factor \\
& 54 & U90214 & TGA2.1 & Truncated TGA2.1 bZIP factor \\
2 & 16 & NM_116248 & At4g00270 & S. cerevisiae ADR1 like protein \\
3 & 44 & NM_103938 & At1g50570 & Unknown protein \\
& 82 & NM_186999 & At5g55530 & Unknown protein \\
& 5 & NM_102616 & At1g28480 & Putative glutaredoxin \\
\hline
\end{tabular}




\subsection{Functional Analysis of the At4g00270 Isolated cDNA Clone}

\subsubsection{Structural Analysis of At4g00270 cDNA Clone}

To examine the structure of the Arabidopsis cDNA clone 16, the sequenced inserted DNA fragment was analyzed using the vector NTi program and by searching the DNA databases for corresponding genes. The DNA sequence analysis revealed that the clone 16 contains a full-length cDNA, encoding 302 amino acids that represents a putative protein with a predicted molecular mass of $34.05 \mathrm{kDa}$ (Figure 6.4).

The cDNA sequence was identified in the Arabidopsis sequence database and was corresponding to the At4g00270 designated gene (http://arabidopsis.org). The fullcDNA coding sequence of clone 16 was fused in-frame to the GAL4AD of the prey plasmid and contained a translation stop codon, $3^{\prime}$-untranslated region and a poly (A) tail of adenosine residues.

ggtcgtgaagattgggaatcactgctctgcatgcgcctagaatcagcaagtctaaagcaagcaataag

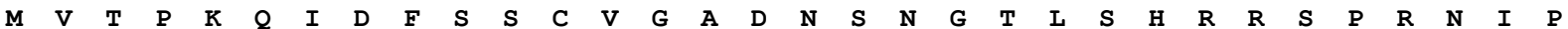
ATGGTGACTCCGAAGCAGATCGATTTCTCTTCCTGTGTTGGTGCTGATAACTCCAACGGTACCСTCTCCCATCGAAGATCTCCACGGAATATTCCT

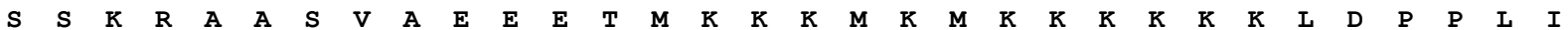
TCCTCAAAGCGTGCTGCTTCCGTCGCAGAAGAAGAGACTATGAAGAAGAAGATGAAGATGAAGAAGAAGAAGAAGAAATTGGATCCGCCGTTGATC

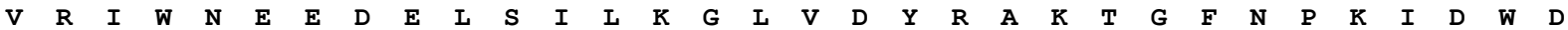
GTCCGGATCTGGAACGAGGAAGATGAGCTCTCTATCTTAAAGGGGTTAGTTGATTACAGAGCTAAGACAGGATTCAATCCCAAAATTGATTGGGAT

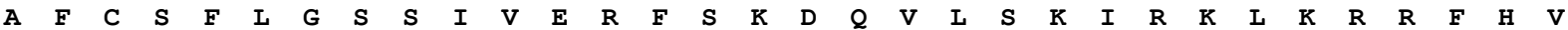
GCGTTTTGTAGTTTCCTCGGAAGTTCTATCGTTGAGAGATTCTCCAAGGATCAGGTTTTGAGTAAAATCAGGAAGTTGAAAAGGAGGTTTCATGTT

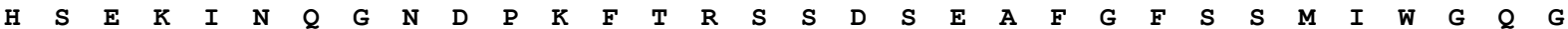
CACTCGGAGAAAATCAATCAAGGGAATGATCCCAAATTTACTAGGTCTAGTGATTCTGAAGCCTTTGGGTTTTCTTCGATGATTTGGGGACAAGGT

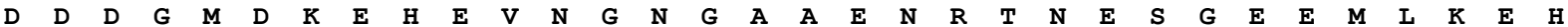
GATGATGATGGTATGGATAAGGAGCACGAGGTAAACGGAAATGGTGCAGCGGAAAACCGGACTAACGAGAGCGGGGAGGAGATGTTGAAGGAGCAC

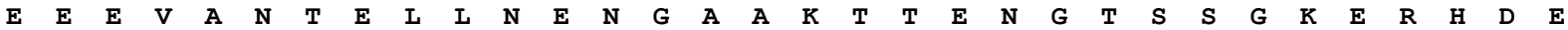
GAGGAGGAAGTGGCTAATACTGAACTTTTAAATGAGAATGGGGCAGCCAAAACAACAGAGAATGGGACTAGTAGTGGAAAAGAGAGACATGATGAG

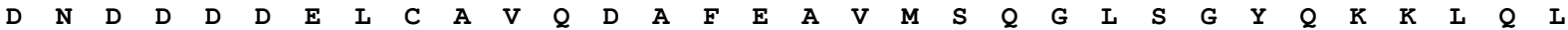
GACAATGATGATGATGATGAGTTATGCGCGGTGCAGGATGCATTTGAGGCGGTGATGTCGCAAGGTTTAAGTGGTTATCAAAAGAAGTTGCAGCTT

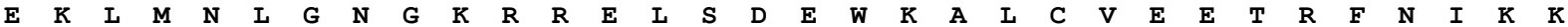
GAGAAGCTGATGAACCTTGGAAATGGTAAAAGAAGAGAGTTGAGTGATGAATGGAAAGCGTTATGTGTTGAGGAAACAAGATTCAATATCAAGAAG $\begin{array}{llllllllllllllllllll}\text { L } & R & F & S & A & K & \text { L } & A & E & A & A & N & D & S & *\end{array}$

СTTAGATTTTCCGCCAAGCTTGCAGAGGCAGCTAATGATAGTTAGatgaaaccaatatgccettgtagcatttggtgttgtttaggttcttagtaagtcataagctctagtctg ttcagtgtatttatctttggatcctgtctttcttctacttgggcaagtgtttgtaagatattccactttttactcaagtatccacaagagccaatgtagtagagtggcttgtgcaagagtctagagtct agggttaataatgtgctttaaggcatgcttgtgtgtgtgcctaagagtgtagtgaagtagtataagtaagagtgtgtgtgtgtcttgtaatattatccaagatattaacaatgtagaagattaaaagaa aaaaaaaa

Figure 6.4. Full-length sequence of At4g00270 cDNA. 
The protein databases analysis predicted that the At4g00270 gene encodes an unknown protein that contains low similarity to the $S$. cerevisiae $A D R 1$ gene and to storekeeper DNA-binding protein (Solanum tuberosum) (Bemis and Denis, 1988; Zourelidou et al., 2002). The complete sequence of At4g00270 gene is found on bacterial artificial chromosome (BAC) clone designated F5I10 (GenBank Accession Number: AF013293).

\subsubsection{At4g00270 Interacts with TGA2.2 in the Y2HS}

To determine whether Arabidopsis At4g00270 protein interacts with the Arabidopsis homologs of TGA2.2 and to verify the observed interaction between TGA2.2 and At4g00270 in the MY1HS, a classical Y2HS assay was conducted. DNA fragments encoding TGA2.2, TGA2 and TGA6 were cloned downstream the GAL4BD domain into the pGBT9 vector. The resulted constructs were cotransformed with the pGAD10/At4g00270 plasmid (encoding GAL4AD-At4g00270) into the Y2HS HF7c strain, carrying the HIS3 reporter gene under the control of UAS ${ }^{G A L 4}$ element, and were then assayed for histidine prototrophy in the presence of $5 \mathrm{mM}$ 3-AT. As observed for MY1HS, TGA2.2 interacts with At4g00270 in the Y2HS (Figure 6.5, sector 3). The interaction affinity between both proteins is similar to that of the NPR1-TGA2.2 interaction (positive control). The At4g00270 protein was also able to interact with the Arabidopsis TGA2 and TGA6 proteins (Figure 6.5, sectors 6 and 8).

In domain swap experiments, in which GAL4BD-At4g00270 and the GAL4ADTGA2.2 coding sequences were cotransformed into HF7c strain and assayed for histidine prototrophy, a loss of TGA2.2-At4g00270 interaction was observed (data not shown). This loss of TGA2.2-At4g00270 interaction could be attributed to changes in interaction affinity between both proteins in the swap orientation, the At4g00270 protein is not well expressed or it does not fold properly in yeast. As the TGA2.2- At4g00270 interaction was lost in the domain swap experiment, the At4g00270 protein was excluded from further analysis. 

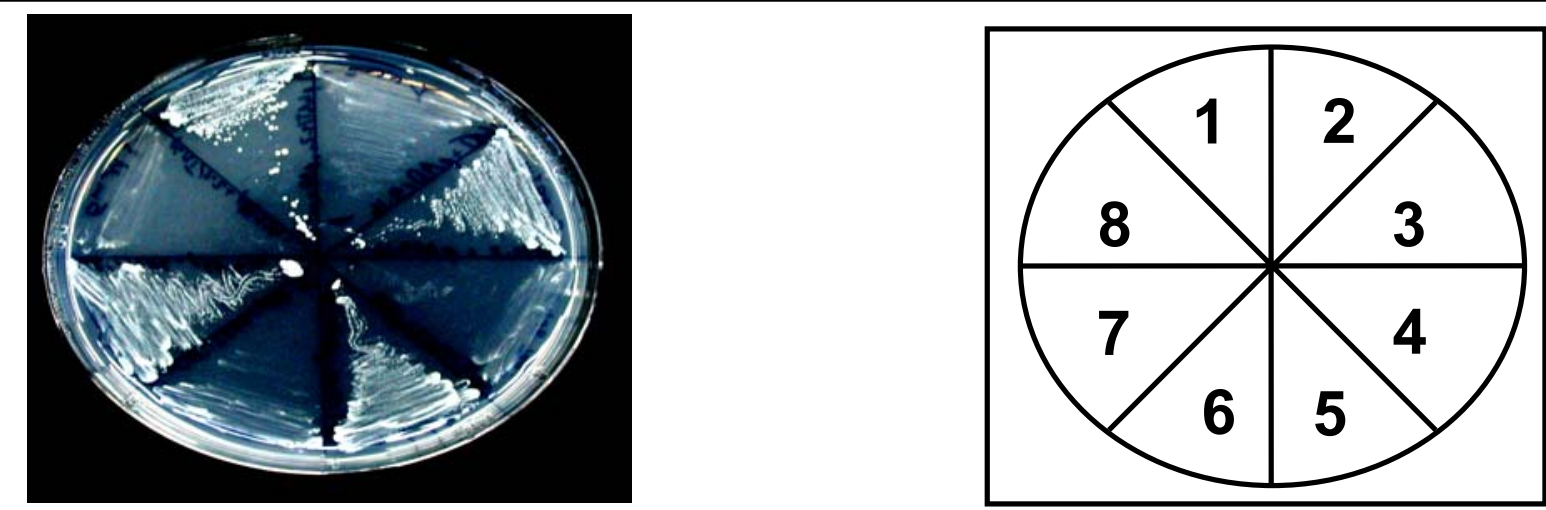

\begin{tabular}{|l|l|l|c|}
\hline Sector & Bait (TRP1 marker) & Prey (LEU2 marker) & Growth on SD lacking histidine \\
\hline 1 & GAL4BD-TGA2.2 & GAL4AD-NPR1 & ++ \\
2 & GAL4BD & GAL4AD-At4g00270 & - \\
3 & GAL4BD-TGA2.2 & GAL4AD-At4g00270 & ++ \\
4 & GAL4BD-TGA2.2 & GAL4AD & - \\
5 & GAL4BD-TGA2 & GAL4AD-At4g00270 & ++ \\
6 & GAL4BD-TGA2 & GAL4AD & + \\
7 & GAL4BD-TGA6 & GAL4AD-At4g00270 & ++ \\
8 & GAL4BD-TGA6 & GAL4AD & \\
\hline
\end{tabular}

Figure 6.5. Y2HS assays of interactions between GAL4AD-At4g00270 and TGA proteins.

HF7c cells containing pGBT9/TGA2.2 + pGAD424/NPR1 (1), pGBT9 + pGAD424/At4g00270 (2), pGBT9/TGA2.2 + pGAD424/At4g00270 (3), pGBT9/TGA2.2 + pGAD424 (4), pGBT9/TGA2 + pGAD424/At4g00270 (5), pGBT9/TGA2 + pGAD424 (6), pGBT9/TGA6 + pGAD424/At4g00270 (7) and pGBT9/TGA6 + pGAD424 (8) plasmids were grown for 3 days at $30^{\circ} \mathrm{C}$ on selective $\mathrm{SD}$ medium lacking leucine, tryptophan and histidine, supplemented with $5 \mathrm{mM} 3-\mathrm{AT}$.

\subsection{Functional Analysis of The At1g50570 and At5g55530 Isolated cDNA Clones}

\subsubsection{Structural Analysis of At1g50570 and At5g55530 cDNA Clones}

DNA sequencing of the cDNA inserts of clone 44 and clone 82 showed that they encode for two homologues proteins. The cDNA sequence of clone 82 contains a partial CDNA coding sequence with an in-frame fusion to the GAL4AD, a translation stop codon, a $3^{\prime}$-untranslated region and a poly (A) tail of adenosine residues. A BLAST search of the Arabidopsis databases showed sequence similarity with the 
At5g55530 gene that encodes a 405 amino acid protein with a predicted molecular mass of $47.97 \mathrm{kDa}$ and shows low similarity to cold-regulated gene SRC2 from soybean (Figure 6.6; Takahashi and Shimosaka 1997). The sequence of the At5g55530 gene was found on the MTE17 BAC clone (GenBank Accession No. AB015479).

At5g55530 protein sequence analysis uncovered a conserved region at residues 40 to 111 that resembles a C2 domain (calcium dependent phospholipid binding domain (Figure 6.6, the red background). The $\mathrm{C} 2$ domain is a region containing approximately 130 residues involved in binding phospholipids in a calcium dependent or independent manner. It is present in a large number of proteins, including protein kinase C, phospholipases and synaptogamin (Reviewed in: Nalefski and Falke, 1996; Rizo and Südhof, 1998). C2 domains have been identified in a growing number of eukaryotic signalling proteins that mediate a broad array of critical intracellular processes, including membrane trafficking, the generation of lipid-second messengers, activation of GTPases, and the control of protein phosphorylation and protein-protein interactions (Nalefski and Falke, 1996). According to Kopka et al., 1998, the C2 domain can be divided into three subdomains, called $A, B$ and $C$; subdomain $A$, generally consisting of DPYVK, is located on the $\mathrm{N}$-terminal side, subdomain $\mathrm{B}$ is a variable polybasic core region, which in most cases contains a KXK(R)-T motif; subdomain $C$, represented by the segment $L N P X W N(X)$-EXFXF, is positioned C-terminus to the basic core region.

Many genes encoding proteins with C2 domains are found in higher plants and as in animal cells these proteins are most likely involved in a variety of signal transduction pathways. For instance, a mutant in the copin gene, which belongs to a class of copin proteins that are characterized by their unique combination of two $\mathrm{C} 2$ domains, exhibits morphological abnormalities, increased resistance to virulent strains of $P$. syringae and Peronospora parasitica, and constitutive expression of $P R$ genes under low-humidity conditions (Jambunathan et al., 2001). 


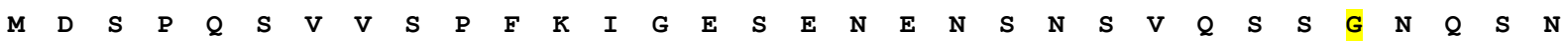
ATGGACTCCCCACAATCTGTTGTTTCACCATTCAAGATTGGTGAGTCAGAGAATGAGAACTCAAATTCTGTGCAGAGTTCTGGAAACCAATCGAAT

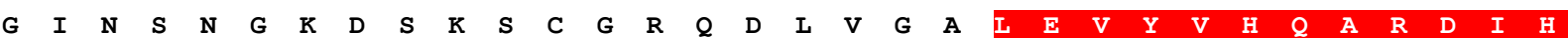
GGCATAAATTCCAATGGGAAAGATTCTAAAAGTTGTGGCCGGCAAGACCTTGTTGGTGCTCTTGAGGTTTATGTCCATCAGGCAAGGGATATCCAT

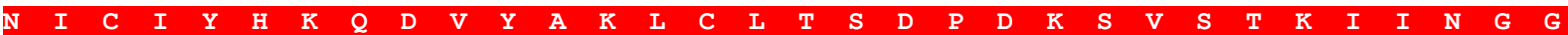
AACATTTGTATATATCACAAGCAAGACGTTTATGCCAAGCTTTGCCTTACAAGTGATCCTGATAAGTCTGTCTCGACCAAAATCATCAATGGCGGT

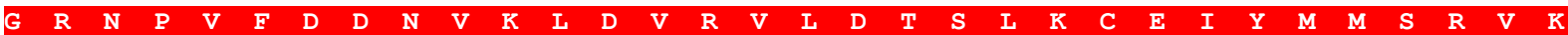
GGGAGGAATCCGGTTTTTATGACAATGTTAAGCTTGATGTCAGGGTTCTGGACACTTCCCTCAAATGTGAGATTTACATGATGAGCAGGGTGAAG

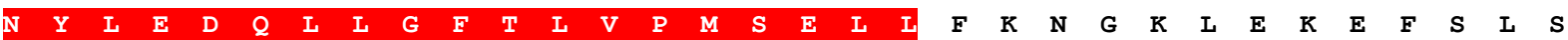
AATTATCTTGAGGACCAGCTGCTTGGTTTTACTCTGGTTCCTATGTCGGAACTGCTCTTCAAGAATGGGAAACTCGAGAAAGAGTTCTCTCTTTCT

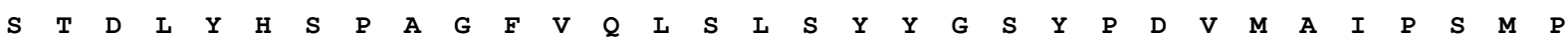
TCCACTGATCTCTACCATTCGCCAGCTGGTTTTGTTCAATTGTCACTCTCCTATTATGGATCCTACCCTGACGTGATGGCTATTCCCTCTATGCCT

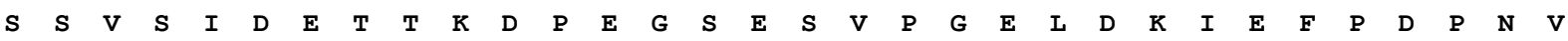
TCGTCTGTTTCTATTGATGAAACTACCAAGGATCCAGAAGGGTCTGAATCAGTTCCGGGTGAGTTGGATAAGATAGAGTTTCCAGATCCTAATGTT

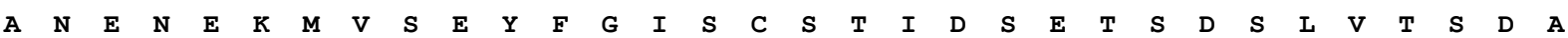
GCTAATGAAAATGAGAAGATGGTTTCCGAGTATTTTGGGATCTCTTGTTCCACTATTGACTCAGAAACTTCTGACAGCTTGGTTACTTCCGATGCT

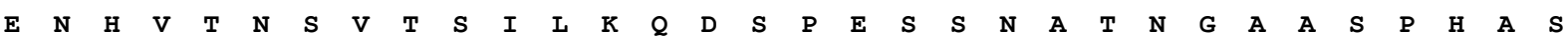
GAGAATCATGTGACTAATTCTGTCACTTCTATACTGAAGCAAGATTCACCTGAGAGCAGCAATGCAACAAATGGAGCTGCTTCTCCTCACGCTTCA

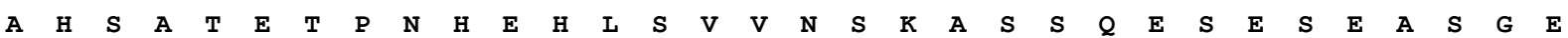
GCTCACTCCGCCACAGAAACACCAAACCATGAACATCTCTCTGTCGTGAACTCCAAAGCGAGTTCCCAGGAGTCAGAGAGCGAGGCTTCTGGTGAG

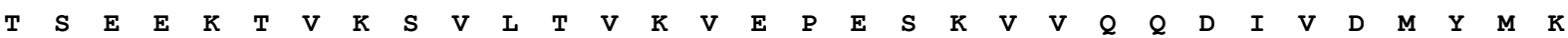
ACATCTGAGGAGAAGACTGTGAAATCCGTCCTCACTGTGAAGGTTGAGCCAGAGTCAAAGGTGGTGCAGCAGGATATAGTCGACATGTACATGAAA

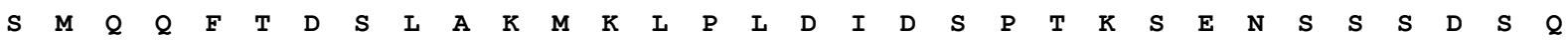
AGCATGCAACAGTTTACAGATTCACTGGCTAAGATGAAGCTTCCTCTGGACATTGACAGCCCAACAAAATCAGAAAATTCAAGCTCTGATTCTCAG $\begin{array}{lllllllllllllllllllllllll}K & L & P & T & P & K & S & N & N & G & S & R & V & F & Y & G & S & R & P & F & F & *\end{array}$ AAGCTGCCAACACCAAAGAGCAACAACGGATCCCGTGTGTTCTATGGGAGCAGGCCTTTCTTCTGAgcatctcttttaccaagttcagagaaagaacgcaggtcacc cttagacttttctaatgaagaagactaatcctaatgatgtaattttataatgtactatttcatgttgtatctcccatctggtcagcttgatgctttagttgatgtgagttattattacgtatcactag cctttactctattagaactatgtacgcattatatgaacttctgctgcctaatcatgtttgtattttctgagttactgcgttttacatccacaagatctttaaagcatagtgataatgcttagattgt

Figure 6.6. Full-length sequence of $A t 5 g 55530$ cDNA.

The red background represents the $\mathrm{C} 2$ domain region and the yellow box points for the beginning of the isolated cDNA clone.

DNA sequence analysis of clone 44 was an eccentric issue. The cDNA sequence of clone 44 contains a partial cDNA coding sequence that is inversely inserted into the pGAD10 prey plasmid, i.e., no in-frame fusion between GAL4AD and the 44 cDNA coding sequence. Astoundingly, the clone 44 did not confer any autoactivation of the HIS3 reporter gene (data not shown), i.e., the presence of the TGA2.2 bait protein was crucial to activate the reporter gene expression in the presence of clone 44. Mining the Arabidopsis databases revealed that the clone 44 represents the Arabidopsis At1g50570 gene that encodes a 388 amino acids protein with a predicted molecular mass of $42.1 \mathrm{kDa}$ (Figure 6.7). The sequence of the At1g50570 gene was found on the F11F12 BAC clone (GenBank accession No.: AC012561). 
actttaccataaaatctcaactttatcccttattcttatctgcaaaattcgttctcgtcccttggattatgggtttttttgttcctcgagaaagttgattgctttcttggaatc atgcgtgccctttctctttgttgttttaaaggatgcgtctgcgttagattgttttagtaactttgtgaattgattaagcacttcttcaccataatcaagtttatagcttttgcttctgatcaggtaaaa ataccaaattttaggagttcttgagctttgtttttaatggcaatatttgattgcagcatcttaaagttctataatttgccagagatctgatttgattcgcttagtaatttctgtttcttgagttagag ttagtgtctcttgtttgttatctgtagaatttgaaccaaactctaaaggtttgtctttattttatttgtattatggatgattccaagtaagagctgctgtcttttttgtttgcagatcctgttggt

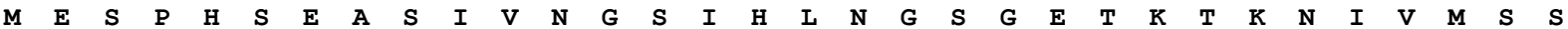
ATGGAATCTCCACATTCTGAGGCATCAATCGTGAATGGTAGTATCCATTTGAATGGCAGTGGTGAAACCAAAACAAAGAATATAGTCATGTCGTCT

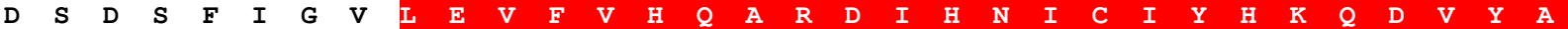
GATTCAGACAGTTTCATCGGTGTGCTTGAGGTTTTTGTTCACCAAGCTAGGGACATCCACAACATCTGTATCTATCATAAGCAAGATGTGTATGCT $\begin{array}{llllllllllllllllllllllllllllllllll}K & \text { L } & C & \text { L } & \text { T } & \text { N } & \text { D } & \text { P } & \text { E } & \text { N } & \text { S } & \text { L } & \text { S } & \text { T } & \text { K } & \text { I } & \text { I } & \text { N } & \text { G } & \text { G } & \text { G } & \text { Q } & \text { N } & \text { P } & \text { V } & \text { F } & \text { D } & \text { D } & \text { T } & \text { L } & Q & \text { F }\end{array}$ AAGCTTTGTCTCACAAATGATCCCGAAAACTCCTTGTCCACAAAGATCATCAATGGTGGAGGGCAAAACCCTGTCTTCGACGATACCCTTCAGTTC $\begin{array}{llllllllllllllllllllllllllllllllll}D & V & K & N & \text { L } & \text { D } & \text { C } & \text { S } & \text { L } & \text { K } & \text { C } & \text { E } & \text { I } & \text { F } & \text { M } & \text { M } & \text { S } & \text { R } & \text { V } & \text { K } & \text { N } & \text { Y } & \text { L } & \text { E } & \text { D } & \text { Q } & \text { L } & \text { L } & G & \text { F } & \text { S } & \text { L }\end{array}$ GACGTTAAGAACCTGGATTGTTCGCTTAAGTGTGAGATATTTATGATGAGCCGCGTGAAGAATTATCTTGAGGATCAGTTACTTGGATTCTCTCTT

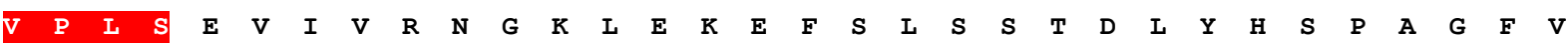
GTACCTTTGTCTGAAGTGATTGTGAGGAATGGGAAATTGGAGAAAGAGTTCTCCСTTTCTTCAACCGATTTGTATCACTCTCCTGCAGGTTTTGTC

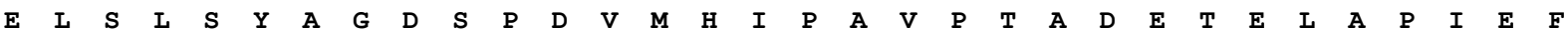
GAGTTGTCTCTCTCGTACGCAGGAGATTCGCCTGACGTGATGCATATTCCTGCGGTTCCAACTGCGGATGAGACCGAGTTGGCTCCTATCGAGTTT

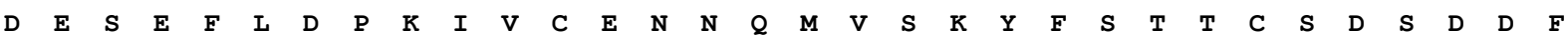
GATGAGAGTGAGTTTTTGGATCCAAAGATTGTCTGTGAAAACAATCAAATGGTGTCTAAGTACTTCTCCACTACGTGTTCTGATTCTGATGATTTT

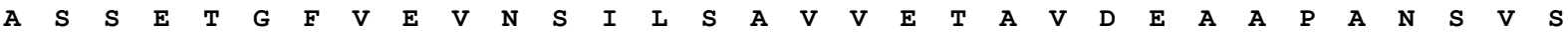
GCAAGCTCTGAAACTGGCTTTGTGGAAGTAAACAGCATCCTGTCTGCAGTTGTTGAAACTGCTGTTGACGAAGCAGCACCGGCCAATTCTGTCTCA

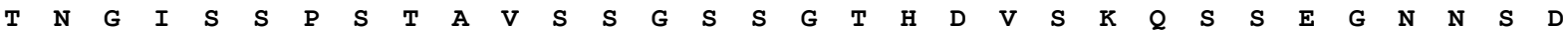
ACAAATGGAATCTCATCTCCATCAACTGCAGTTAGCTCTGGCTCCTCGGGAACTCATGATGTTTCAAAGCAATCTAGTGAAGGAAACAACTCAGAT

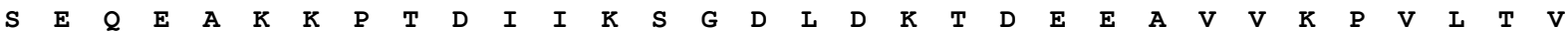
TCAGAACAAGAAGCGAAGAAGCCAACAGATATCATCAAGAGTGGTGATTTAGATAAGACTGATGAAGAAGCAGTTGTGAAACCGGTTCTGACAGTG

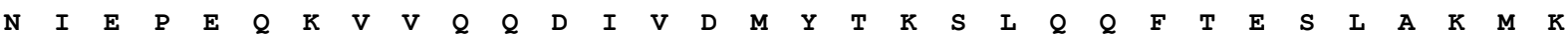
AACATTGAACCAGAGCAAAAGGTAGTGCAACAAGATATTGTTGACATGTACACAAAAAGCTTGCAGCAATTCACTGAGTCACTGGCTAAGATGAAA

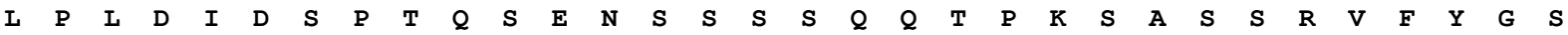
СTTCCTTTGGACATCGATAGCCCAACCCAATCAGAGAACTCAAGCTCCTCCCAGCAGACGCCAAAGAGTGCTAGCTCCCGTGTTTTCTACGGGAGT

R A F $\quad F \quad$ *

AGAGCCTTCTTCTGAagctcagaaatcatctcaagtttggcatcagaagtagcgagcatgtagtgaaagtgtaataagttaaagtagacactatctaaaatgtgtaactatcttcctttgaag cctttagcttttcttgttatctgcaacttttccaatttagtactaaagtttcataatctcttcccttctcatataacagatagacataaagacaagaagtttgtgtttgaagaagaaaacaatacaaag acat a

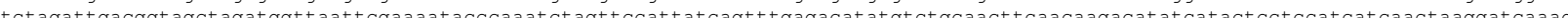
ctag

Figure 6.7. Full-length sequence of At1g50570 cDNA.

The red background represents the $\mathrm{C} 2$ domain region and the yellow box points for the beginning of the isolated cDNA clone.

The striking issue of the At1g50570 protein, as revealed by BLAST searches and sequence alignments, was its sequence homology with the At5g55530 protein. At1g50570 and At5g55530 proteins deduced amino acids showed $54 \%$ identity (Figure 6.8). The deduced amino acid sequences of At1g50570 and At5g55530 showed significant high sequence identity in the $\mathrm{C} 2$ domain. Besides the C2 domain, the two proteins share a conserved region at the C-terminus end. Based on this observation, both clones were considered for further analysis. 


\begin{tabular}{|c|c|c|}
\hline At1g50570 & MESPHSEASIVNGSIHLNGSGETKTKNIVMSSDSDSFIGVLEVF & 44 \\
\hline At5g55530 & MDSPQSVVSPFKIGESENENSNSVQSSGNQSNGINSNGKDSK-----SCGRQDLVGALEVY & 56 \\
\hline $\operatorname{tg} 50570$ & VHQARD IHNICIYHKQDVYAKLCLTNDPENSLSTKI INGGGQNPVFDDTLQFDQLLGFSLV & 129 \\
\hline At5g55530 & VHQARD IHNICIYHKQDVYAKLCLTSDPDKSVSTKIINGGGRNPVFDDNVKLDQLLGFTLV & 141 \\
\hline t1g50570 & PLSEVIVRNGKLEKEFSLSSTDLYHSPAGFVELSLSYAGDSPDVMHIPAVPTA---DET-- & 185 \\
\hline At5g55530 & PMSELLFKNGKLEKEFSLSSTDLYHSPAGFVQLSLSYYGSYPDVMAIPSMPSSVSIDETTK & 202 \\
\hline $\operatorname{tg} 50570$ & -----ELAPIEFDESEFLDPKIVCENNQMVSKYFSTTCSDSDDFASSETGFVEVNSILSAV & 226 \\
\hline At5g55530 & DPEGSESVPGELDKIEFPDPNVANENEKMVSEYFGISCSTIDSETSDSLVTSDAENHVTNS & 263 \\
\hline t1g50570 & VETAVDEAAPANTVSTNGISSP-STAVSSGSSRTHD-VSKQSSEGNNSDSEQEAKKPTDII & 241 \\
\hline At5g55530 & VTSILKQDSPESSNATNGAASPHASAHSATETPNHEHLSVVNSKASSQESESEA------- & 317 \\
\hline At1g50570 & IKSGDLDKTDEEAVVKPVLTVHIEPEQKVVQQDIVDMYTKSLQQFTESLAKMKLPLDIDSP & 360 \\
\hline At5g55530 & --SGE---TSEEKTVKSVLTVKVEPESKVVQQDIVDMYMKSMQQFTDSLAKMKLPLDIDSP & 373 \\
\hline & T---QSENSSSSQQTPKSAS-SRVFYGSRAFF 388 & \\
\hline $5 \mathrm{~g} 5553$ & TKSENSSSDSQKLPTPKSNNGSRVFYGSRPFF 405 & \\
\hline
\end{tabular}

Figure 6.8. Comparison of deduced amino acid sequences of the At1g50570 and At5g55530 proteins.

Red letters represent perfectly conserved amino acid residues, and dashes indicate gaps introduced to maximize alignment. The light blue background represents the $\mathrm{C} 2$ domain amino acids.

\subsubsection{At1g50570 and At5g55530 Interact with TGA2.2 Factor in the Y2HS}

To assess whether TGA2.2 interacts with full lengths At1g50570 and At5g55530 proteins in the classical Y2HS, DNA fragments containing the full-length At1g50570 and At5g55530 genes were amplified and cloned in-frame with the GAL4AD into the pGAD424 plasmid. Interactions between At1g50570 and At5g55530 and TGA2.2 were tested for histidine prototrophy in the HF7c Y2HS strain in the presence of $5 \mathrm{mM} 3-\mathrm{AT}$. As observed for MY1HS, the GAL4BD-TGA2.2 protein interacts with GAL4ADAt1g50570 (Figure 5.9, sector 2) and GALAD-At5g55530 full-length proteins (data not shown). Similar results were observed with the Arabidopsis TGA2, TGA5 and TGA6 proteins (Figure 5.9, sectors 3, 4 and 5). The Y2HS interactions between At1g50570 and TGA class-II factors verified that the YRWH2 histidine prototrophy phenotype is resulted from the At1g50570-TGA2.2 interaction. However, how is the inverted cDNA insert expressed in YRWH2 cells? The answer remains unresolved. 

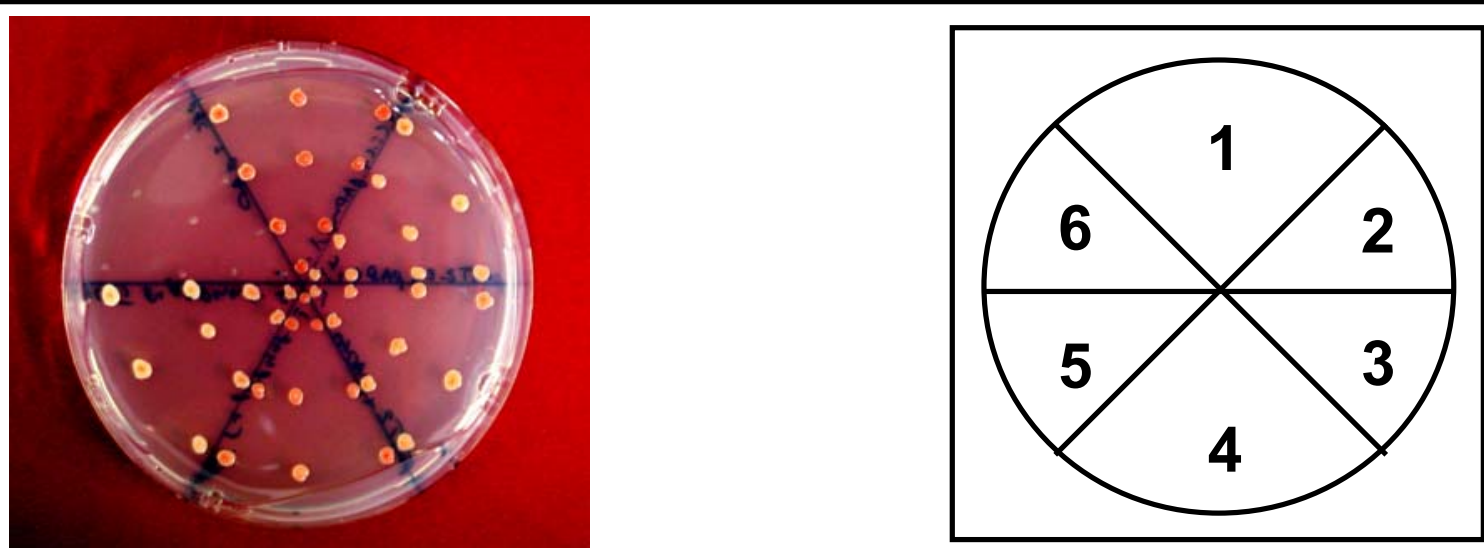

\begin{tabular}{|l|l|l|c|}
\hline Sector & Bait (TRP1 marker) & Prey (LEU2 marker) & Growth on SD lacking histidine \\
\hline 1 & GAL4BD-TGA2.2 & GAL4AD-NPR1 & +++ \\
2 & GAL4BD-TGA2.2 & GAL4AD-At1g50570 & +++ \\
3 & GAL4BD-TGA2 & GAL4AD-At1950570 & +++ \\
4 & GAL4BD-TGA5 & GAL4AD-At1g50570 & +++ \\
5 & GAL4BD-TGA6 & GAL4AD-At1g50570 & +++ \\
6 & GAL4BD & GAL4AD-At1g50570 & - \\
\hline
\end{tabular}

Figure 6.9. Y2HS assays of interactions between At1g50570 and TGA proteins.

HF7c cells containing pGBT9/TGA2.2 + pGAD424/NPR1 (1), pGBT9/TGA2.2 + pGAD424/At1g50570 F (2), pGBT9/TGA2 + pGAD424/At1g50570 F (3), pGBT9/TGA5 + pGAD424/At1g50570 F (4), pGBT9/TGA6 + pGAD424/At1g50570 F (5), pGBT9 + pGAD424/At1g50570 F (6) were grown for 3 days at $30{ }^{\circ} \mathrm{C}$ on selective SD medium lacking leucine, tryptophan and histidine, supplemented with $5 \mathrm{mM} 3-\mathrm{AT}$.

To define the region in TGA2.2 that interacts directly with At1g50570 and At5g55530 proteins, a TGA2.2 gene fragment encoding the carboxyl part, which does not include the bZIP domain, was cloned into the pGBT9 vector. This truncated GAL4BD-TGA2.2 C-terminal protein was coexpressed with GAL4AD-At1g50570 in the HF7c strain and the transformants were assayed for the histidine prototrophy. Similarly to the full-length TGA2.2 results, yeast coexpressing the TGA2.2 C-terminus part (downstream of the bZIP region) and At1g50570 had a histidine prototrophy phenotype (data not shown). This suggests that the C-terminus region of TGA2.2 contributes to the TGA2.2-At1g50570 interaction. It is most likely that the C2 domain is not involved in TGA2.2-At1g50570 interaction. The At1g50570 cDNA isolated (abbreviated as P) in the 
MY1HS, which encodes a truncated protein that lacks 32 amino acids of the $\mathrm{C} 2$ domain still interacts with TGA2.2 in the Y2HS assays.

\subsubsection{At1g50570 Interacts with Class II of Tobacco TGA Factors}

To further determine the specificity of the TGA2.2-At1g50570 interactions, a bait construct containing the GAL4BD-At1g50570 P coding sequence was generated in order to test the interactions with other TGA factors from tobacco using of the Y2HS. First, the GAL4BD-At1g50570 P construct was tested for HIS3 reporter gene autoactivation in the HF7c strain. The bait protein seems to have a low level of transactivation activity (Figure 6.10, sector 1). The GAL4AD-TGA2.2, GAL4AD-TGA2.1, GAL4AD-TGA1a or GAL4AD-TGA10 were cotransformed with GAL4BD-At1g50570 P into HF7c yeast. The histidine prototrophy was monitored in the resulting transformants on media supplemented with $5 \mathrm{mM}$ 3-AT. As observed for TGA2.2, At1g50570 P interacts strongly with TGA2.1 (Figure 6.10, sectors 3 and 4). Surprisingly, the TGA1a and TGA10 transformants showed only background levels of HF7c growth on media lacking histidine, indicating that the At1g50570 did not interact with TGA1a or TGA10 (Figure 6.10, sectors 5 and 6).

The lack of reporter gene expression is not related to poor expression of the TGA1a and TGA10 proteins as previous analysis showed that both proteins interact with GAL4BD-TGA2.2 and this interaction conferred transcriptional activation of the reporter gene in yeast (Niggeweg et al., 2000b; Schiermeyer et al., 2003). In conclusion, the At1g50570 protein interacts specifically with the C-terminus part of tobacco TGA class-II factors. 


\begin{tabular}{|c|c|c|c|}
\hline Sector & Bait (TRP1 marker) & Prey (LEU2 marker) & Growth on SD lacking histidine \\
\hline 1 & GAL4BD-At1g50570 P & GAL4AD & - \\
\hline 2 & GAL4BD & GAL4AD-At1g50570 P & - \\
\hline 3 & GAL4BD-At1g50570 P & GAL4AD-TGA2.1 & ++ \\
\hline 4 & GAL4BD-At1g50570 P & GAL4AD-TGA2.2 & ++ \\
\hline 5 & GAL4BD-At1g50570 P & GAL4AD-TGA1a & - \\
\hline 6 & GAL4BD-At1g50570 P & GAL4AD-TGA10 & - \\
\hline 7 & GAL4BD & GAL4AD & - \\
\hline 8 & GAL4BD-TGA2.2 & GAL4AD-NPR1 & ++ \\
\hline
\end{tabular}

Figure 6.10. Y2HS assays of interactions between At1g50570 P and TGA proteins.

HF7c cells containing pGBT9/At1g50570 P + pGAD424 (1), pGBT9 + pGAD424/At1g50570 P (2), pGBT9/At1g50570 P + pGAD424/TGA2.1 (3), pGBT9/At1g50570 P + pGAD424/TGA2.2 (4), pGBT9/At1g50570 P + pGAD424/TGA1a (5), pGBT9/At1g50570 P + pGAD424/TGA1a (6), pGBT9 + pGAD424 (7) and pGBT9/TGA2.2 + pGAD424/NPR1 (8) plasmids were grown for 3 days at $30^{\circ} \mathrm{C}$ on selective SD medium lacking leucine, tryptophan and histidine, supplemented with $5 \mathrm{mM}$ 3-AT.

\subsubsection{Function of At1g50570 and At5g55530 as Transcription Activators in Yeast}

To test whether At1g50570 and At5g55530 are able to confer autoactivation function in yeast, the At1g50570 and At5g55530 full-length coding sequences were inserted downstream of the GAL4BD in the pGBT9 plasmid. These constructs were introduced into the yeast strain HF7c and assayed for histidine prototrophy. Yeast cells transformed with the GAL4BD-At1g50570 and GAL4BD-At5g55530 constructs were able to grow on media lacking histidine, indicating the activation of the HIS3 reporter gene by the fusion proteins (Figure 6.11, sectors 3 ). 


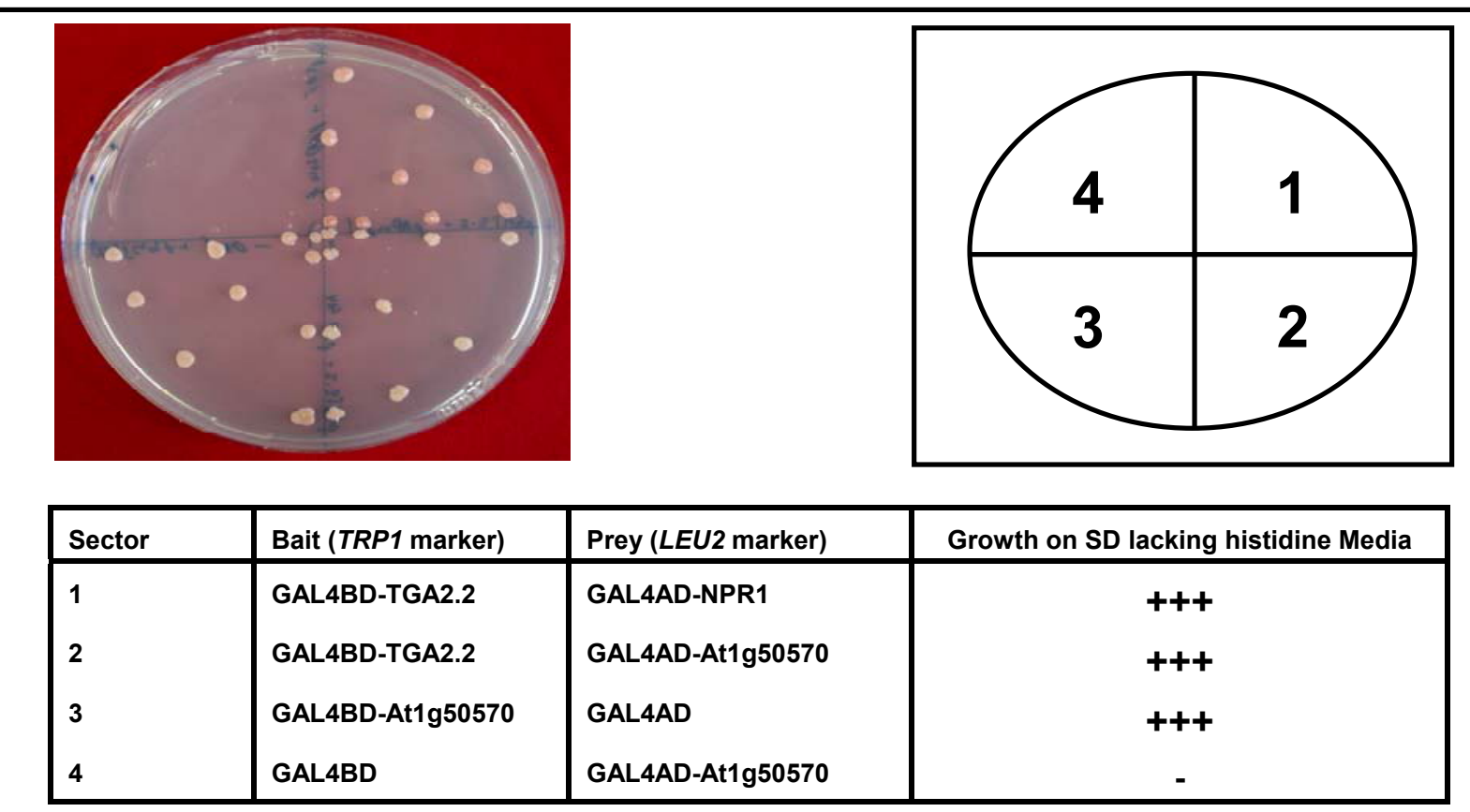

Figure 6.11. Function of At1g50570 as transcription activator in yeast.

HF7c cells containing pGBT9/TGA2.2 + pGAD424/NPR1 (1), pGBT9/TGA2.2 + pGAD424/At1g50570 (2), pGBT9/At1g50570 + pGAD424 (3) and pGBT9 + pGAD424/At1g50570 (4) plasmids were grown for 3 days at $30^{\circ} \mathrm{C}$ on selective SD medium lacking leucine, tryptophan and histidine, supplemented with $5 \mathrm{mM} 3-\mathrm{AT}$.

Additional experiments indicated that conditional expression of the At1g50570 P protein from the Met25 promoter (encoded in pBD-/At1g50570 P) activates expression of the HIS3 reporter gene by the interaction with TGA2.2 expressed from the same promoter (encoded in pLEU/Met25::TGA2.2) in the YRWH2 strain (data not shown). In conclusion, the At1g50570 and At5g55530 proteins can act as transcription activators in yeast.

\subsubsection{At1g50570 Interacts with TGA2.2 In Vitro}

To corroborate the direct physical interactions between TGA2.2 and At1g50570 protein, GST-pull-down (Section 4.5.8), Far Western (Section 4.5.7) and EMSA (Section 4.5.12) in vitro experiments were conducted. For this purpose, the At1g50570 full-length coding sequence was subcloned into the pGEX4T plasmid downstream of the GST cDNA frame. The TGA2.2 coding sequence was subcloned into the pET28a plasmid downstream of a $6 x$ His tag coding sequence. The 6x His-TGA2.2 and GST- 
At1g50570 proteins were expressed in E. coli and purified as described in methods (Section 4.5.3). Purified proteins were analyzed by SDS-PAGE (Figure 6.12)

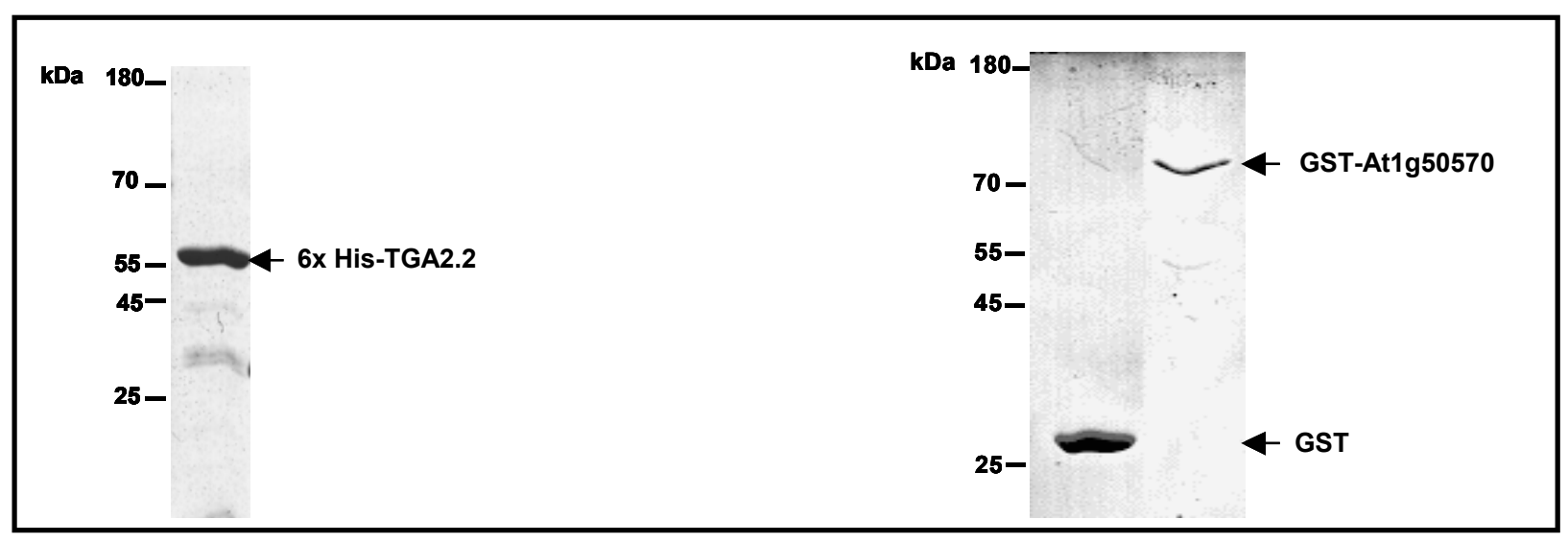

Figure 6.12. SDS-PAGE analysis of purified 6x His-TGA2.2 and GST-At1g50570 proteins.

$10 \mu$ of purified GST, GST-At1g50570 and 6 x His-TGA2.2 proteins were separated on the $12 \%$ gel by SDS-PAGE and subjected to Coomassie Blue staining. Arrows indicates purified proteins positions.

\subsubsection{GST Pull-down Analysis of At1g50570 and TGA2.2 Interaction}

For the GST pull-down assay, $1 \mathrm{ml}$ of $E$. coli lysate expressing the $6 \mathrm{x}$ HisTGA2.2 was mixed with glutathione-sepharose beads loaded with GST or GSTAt1g50570 and the mixtures were then collected by centrifugation. The resulting complexes were analyzed by immunoblotting using antibodies against the $\mathrm{N}$-terminus of TGA2.2. Immunoblot analysis showed that the TGA2.2 protein copurified with At1g50570 (Figure 6.13, lane 2), demonstrating that At1g50570 physically associates with TGA2.2 in vitro.

Figure 6.13. Pull-down assay of GST-At1g50570 binding to 6x His-TGA2.2 protein.

E. coli lysate expressing 6x His-TGA2.2 was incubated with glutathione-sepharose beads loaded with GST-At1g50570 or GST for $1 \mathrm{~h}$ at room temperature. The beads were collected by centrifugation and washed 3 times in $1 \mathrm{x}$ PBS before final collection. $10 \mu \mathrm{l}$ of TGA2.2 cleared lysate (1), GST-pull down At1g50570 (2) and GST (3) Sepharose bound proteins were run on a 12\% SDSpolyacrylamide gel, transferred to a nitrocellulose membrane and then immunoblotted with a TGA2.2 antibody. 


\subsubsection{Far Western Analysis of At1g50570 and TGA2.2 Interaction}

At1g50570 and TGA2.2 interaction was further analyzed by means of the Far Western technique. $1 \mu \mathrm{gg}$ recombinant GST-At1g50570 protein blotted on a nitrocellulose membrane was hybridized with an excess of purified 6x His-TGA2.2 ( 10 $\mu \mathrm{g})$ and the binding of $6 \mathrm{x}$ His-TGA2.2 was revealed with a specific TGA2.2 antibody in an immunoblot analysis. The 6x His-TGA2.2 protein interacts physically with the GSTAt1g5070, whereas no band was detected with the GST protein (Figure 6.14).

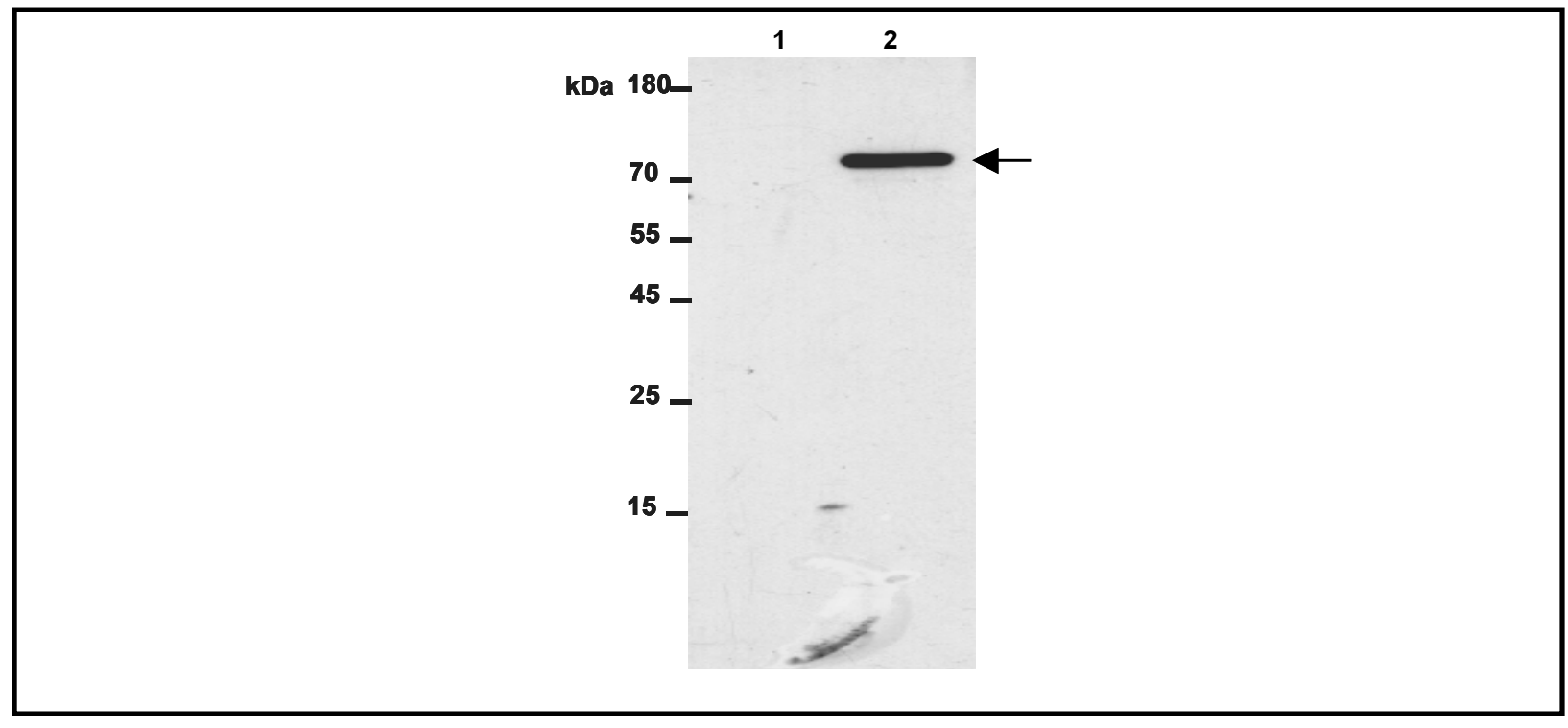

Figure 6.14. Far western analysis of 6X His-TGA2.2 protein binding to GST-At1950570.

$1 \mu \mathrm{g}$ of GST (1) or GST-At1g50570 (2) were run on a 12\% SDS-polyacrylamide gel and then transferred to a nitrocellulose membrane. The membrane was incubated with an excess of 6 x His-TGA2.2 $(\sim 10 \mu \mathrm{g})$ and then immunoblotted with $\alpha$ TGA2.2 antibody.

\subsubsection{At1g50570 Interacts with As-1 Bound TGA2.2}

To determine whether At1g50570 interacts with TGA2.2 at the as-1 element, an EMSA was performed using an in vitro translated TGA2.2 (donated by G. Lyss), purified GST-At1g50570 and a mixture of in vitro translated TGA2.2 and GST-At1g50570 proteins. A super-shift in TGA2.2 mobility was detected in the presence of GSTAt1g50570 protein (Figure 6.15, lane 3). This demonstrates that a complex between GST-At1g50570 and TGA2.2 can form at the as-1 element. By contrast, GST- 
At1g50570 alone did not bind the as-1 element, indicating that the super-shifted TGA2.2 band is a result of TGA2.2-At1g50570 interaction (Figure 6.15, lane 4). To demonstrate that this mobility shift was due to the interaction of At1g50570 with TGA2.2 and not other nonspecific proteins in the preparation, a control reaction was carried out using GST protein. The GST protein alone did not alter the TGA2.2 mobility (data not shown).

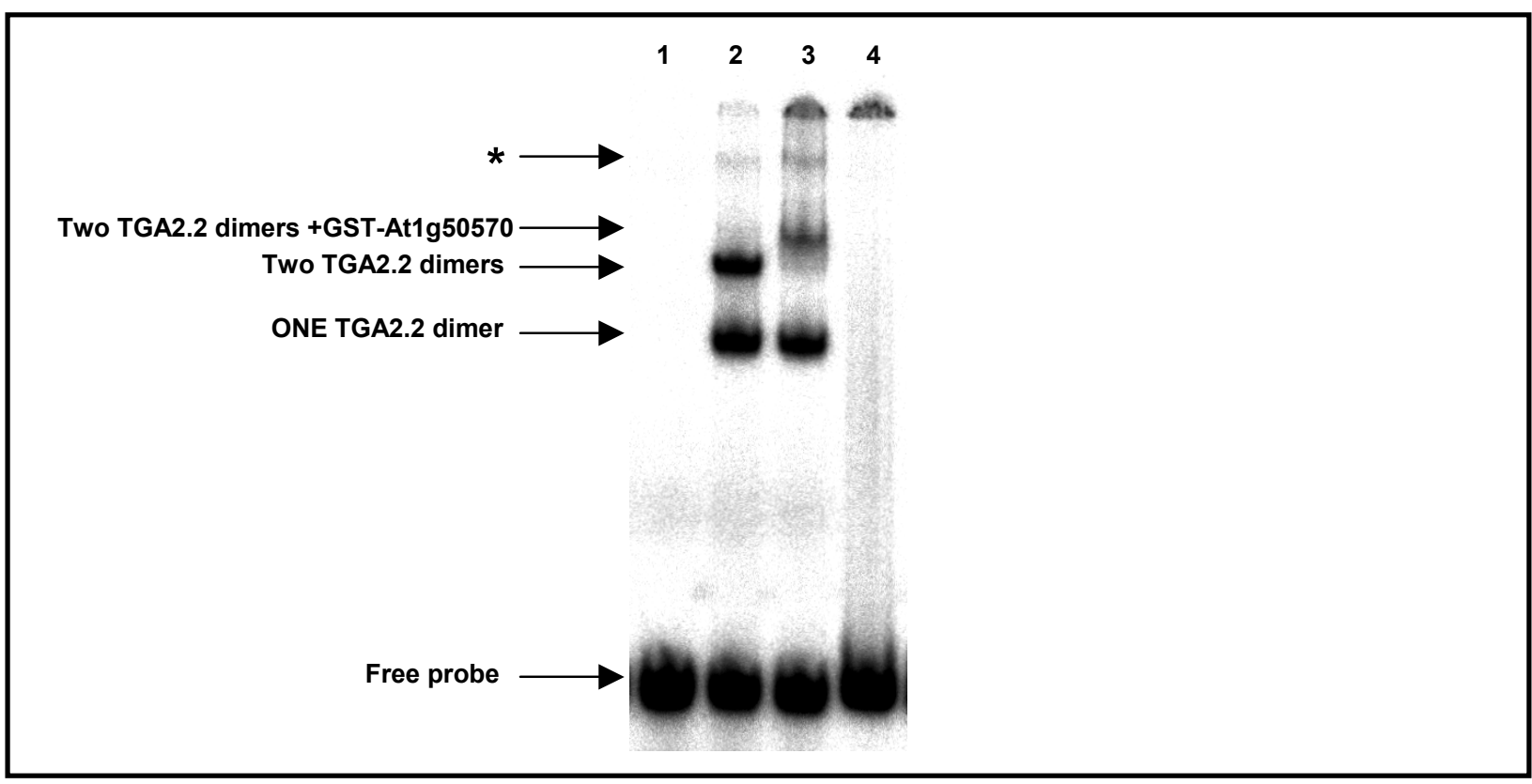

Figure 6.15. EMSA analysis of At1g50570-TGA2.2 interaction.

EMSA was done using as-1 radioactive probes (lane 1), $2 \mu$ of in vitro translated TGA2.2 protein alone (lane 2), a mixture of $2 \mu$ of in vitro translated TGA2.2 with $2 \mu \mathrm{g}$ of GST-At1g50570 protein (lane 3) or GST-At1g50570 alone (lane 4). The mixtures were run on a $5 \%$ native PAGE gel. The protein-DNA complexes were detected by autoradiography. Asterisk indicates non-specific DNA binding activity while arrows indicate specific band shifting.

\subsubsection{Expression Analysis of At1950570 Gene}

To examine the expression patterns of the At1g50570 transcripts in Arabidopsis, RNA gel blot hybridization and RT-PCR experiments were performed. Total RNA samples isolated from roots, leaves, stems, flowers and green siliques were subjected to RT-PCR analysis to investigate the expression pattern of At1950570. After RT-PCR, a specific 1170-bp fragment corresponding to At1g50570 was detected in all tissues analyzed (Figure 6.16). The observed transcripts were consistent with the observation 
that Arabidopsis has 20 At1g50570 ESTs that are isolated from different organs. The expression level of At1g50570 was similar in roots, leaves, stems, flowers and green siliques. The control actin gene was expressed at a similar level in all tissues analyzed (Figure 6.16). To ensure that the observed transcripts are not related to any DNA contaminations, a control actin gene PCR reaction was performed using Arabidopsis genomic DNA (an intron region of about 180 bp exists in the actin gene) and one of the RT-PCR products.

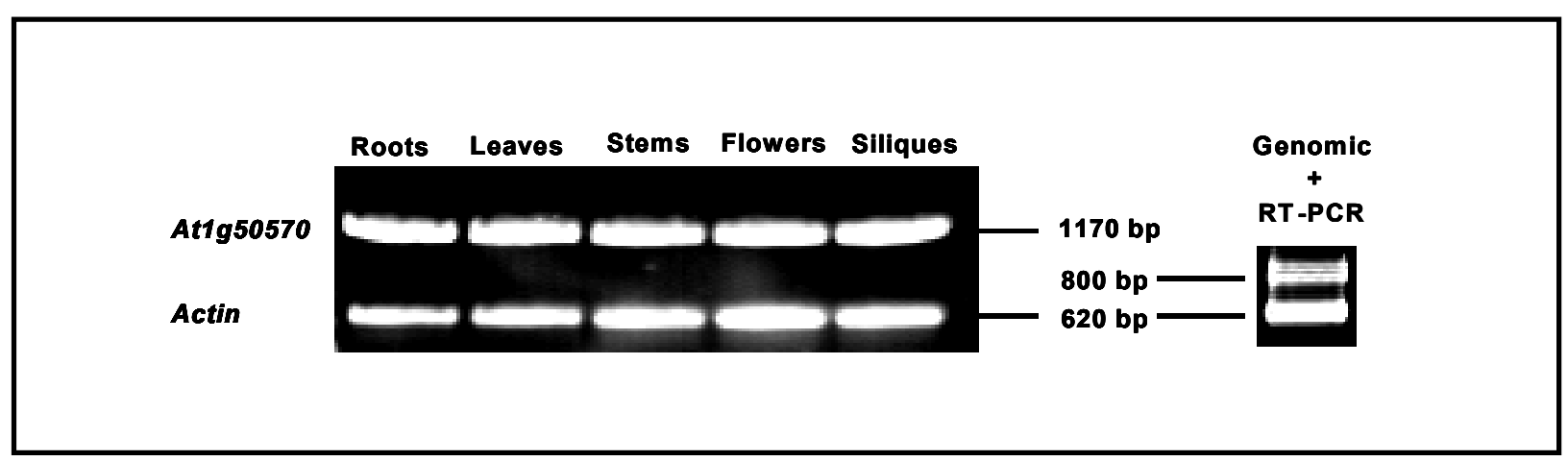

Figure 6.16. Detection of At1g50570 mRNA in different Arabidopsis tissues by RT-PCR.

Total RNA isolated from six weeks old plants parts (roots, leaves, stems, flowers and siliques) were detected for At1g50570 mRNA transcripts using RT-PCR. The actin control is shown at the bottom of the gel. A PCR control reaction for actin using genomic DNA and one of the RT-PCR products is shown on the left.

To characterize the level of accumulation of the At1g50570 transcript in Arabidopsis leaves in response to SAR inducers, total RNA from whole plants sprayed with $1 \mathrm{mM} \mathrm{SA}$ or challenged with $P$. syringae pv. maculicola ES4326 with or without the avrRpt2 $R$ gene at various time points were subjected to RNA gel blot analysis. There was no significant At1g50570 mRNA accumulation within 2 or 24 hours after SA treatment, whereas a moderate accumulation of the At1g50570 mRNA after $24 \mathrm{~h}$ of pathogen challenge was observed (Figure 6.17). In conclusion, the transcription of the At1g50570 gene was not strongly activated by SAR inducers. 


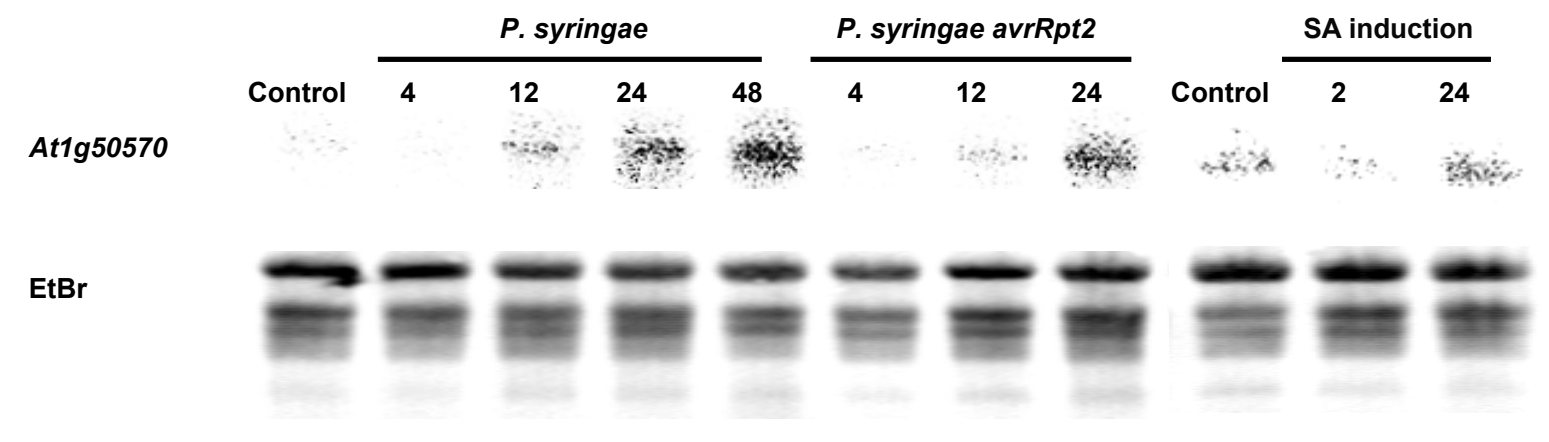

Figure 6.17. RNA gel blots analysis of At1g50570 gene expression after SA or pathogen treatments.

Arabidopsis plants were grown for 4 weeks on soil before spraying with $1 \mathrm{mM} \mathrm{SA}$ or challenged with $P$. syringae pv. maculicola ES4326 with or without the avrRpt2 R gene. Total RNA was isolated from plants at different time points (in hours) and $10 \mu \mathrm{g}$ were separated on denaturing gels in the presence of ethidium bromide $(\mathrm{EtBr})$, photographed to assess equal loading, and examined by Northern blot analysis. A radioactive At1g50570 full-length cDNA probe was hybridized to the membrane, which was then examined by autoradiography.

\subsubsection{Subcellular Localization of At1g50570 Protein}

To examine the subcellular localization of At1g50570, the At1g50570 full-length coding sequence was inserted in-frame upstream of the GFP coding sequence in the HBTL/GFP plasmid (Figure 6.18A). The construct was expressed under the control of the HBT chimeric promoter in BY-2 protoplast. A control plasmid with only the GFP protein was included as a control. Protoplasts transfected with the GFP control construct showed green fluorescence throughout the entire cytoplasm and nucleus (Figure 6.18B). In contrast, the At1g50570-GFP fusion protein was localized mainly to the nuclear envelope and the endoplasmic reticulum (Figure 6.18B). Some residual At1g50570 protein signal in the nucleus appears to be due to the saturation of the nuclear envelope by the overexpressed protein. 


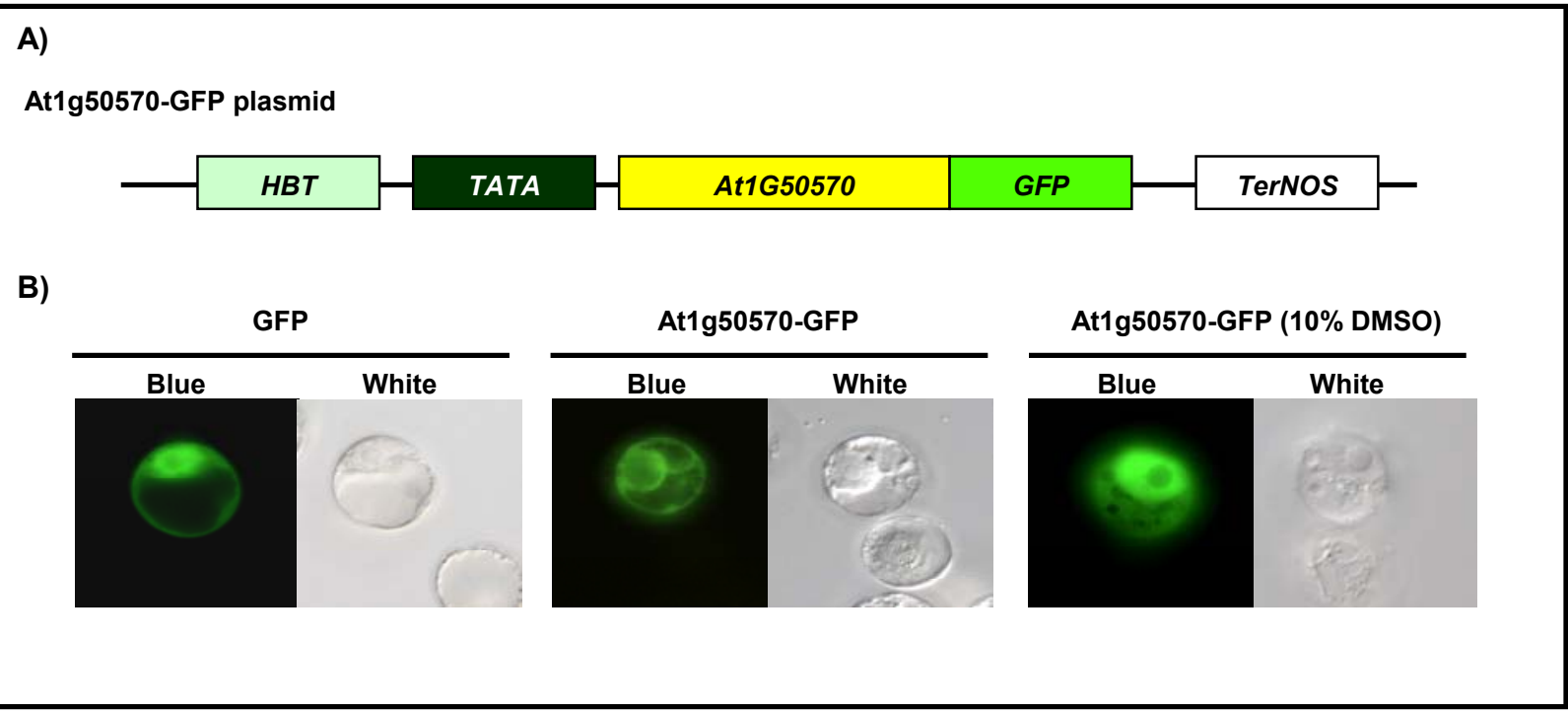

Figure 6.18. Subcellular localization of At1g50570-GFP protein.

A) Schematic diagram of HBTL/At1g50570-GFP plasimd used in subcellular localization experiments.

B) BY-2 protoplasts expressing GFP and At1950570-GFP.

BY-2 protoplasts were transfected with the GFP and At1g50570-GFP constructs, and was visualized using a BX 51 fluorescent microscope using the blue and white light fields.

As described above, At1g50570 protein sequence contains a typical C2 domain. The $\mathrm{C} 2$ domain is responsible for translocation of proteins to the cell membrane compartments in a $\mathrm{Ca}^{2+}$-dependent manner (Nalefski and Falke, 1996). The fact that At1g50570 is localized to the nuclear envelope and the endoplasmic reticulum hints that the $\mathrm{C} 2$ domain might mediate the At1g50570 targeting to those compartments. To examine if the C2 domain mediates the observed localization of At1g50570, the subcellular localization of At1g50570-GFP transfected BY-2 protoplasts was examined after treatments with $10 \mathrm{mM} \mathrm{CaCl}_{2}$ (as a $\mathrm{Ca}^{2+}$ source), $5 \mathrm{mM}$ EGTA (as a $\mathrm{Ca}^{2+}$ chelator). No alteration in the subcellular localization pattern of At1g50570 was observed after $10 \mathrm{mM} \mathrm{CaCl}_{2}$ and $5 \mathrm{mM}$ EGTA treatments (data not shown). In contrast, treatment of At1g50570-GFP transfected protoplast with 10\% DMSO (known for altering membrane fluidity (Trubiani et al., 2003)) prompted protein accumulation in the nucleus, however the protoplast membrane integrity was severely affected (Figure $6.18 \mathrm{~B})$. 


\subsubsection{Function of At1g50570 as Transcription Activators in Protoplasts}

To determine whether the At1g50570 protein is capable of transactivating as-1 element-dependent transcription in plant cells, transactivation experiments using protoplasts prepared from tobacco BY-2 cells were performed. The reporter plasmid consisted of a copy of the as-1 element put upstream of a plant minimal TATAcontaining promoter to control the uidA gene encoding the GUS enzyme (Figure 6.19A). To construct the effector plasmid, the full-length At1g50570 coding sequence was put under the control of the HBT chimeric promoter (a CaMV $35 S$ promoter derivative) (Figure 6.19A).

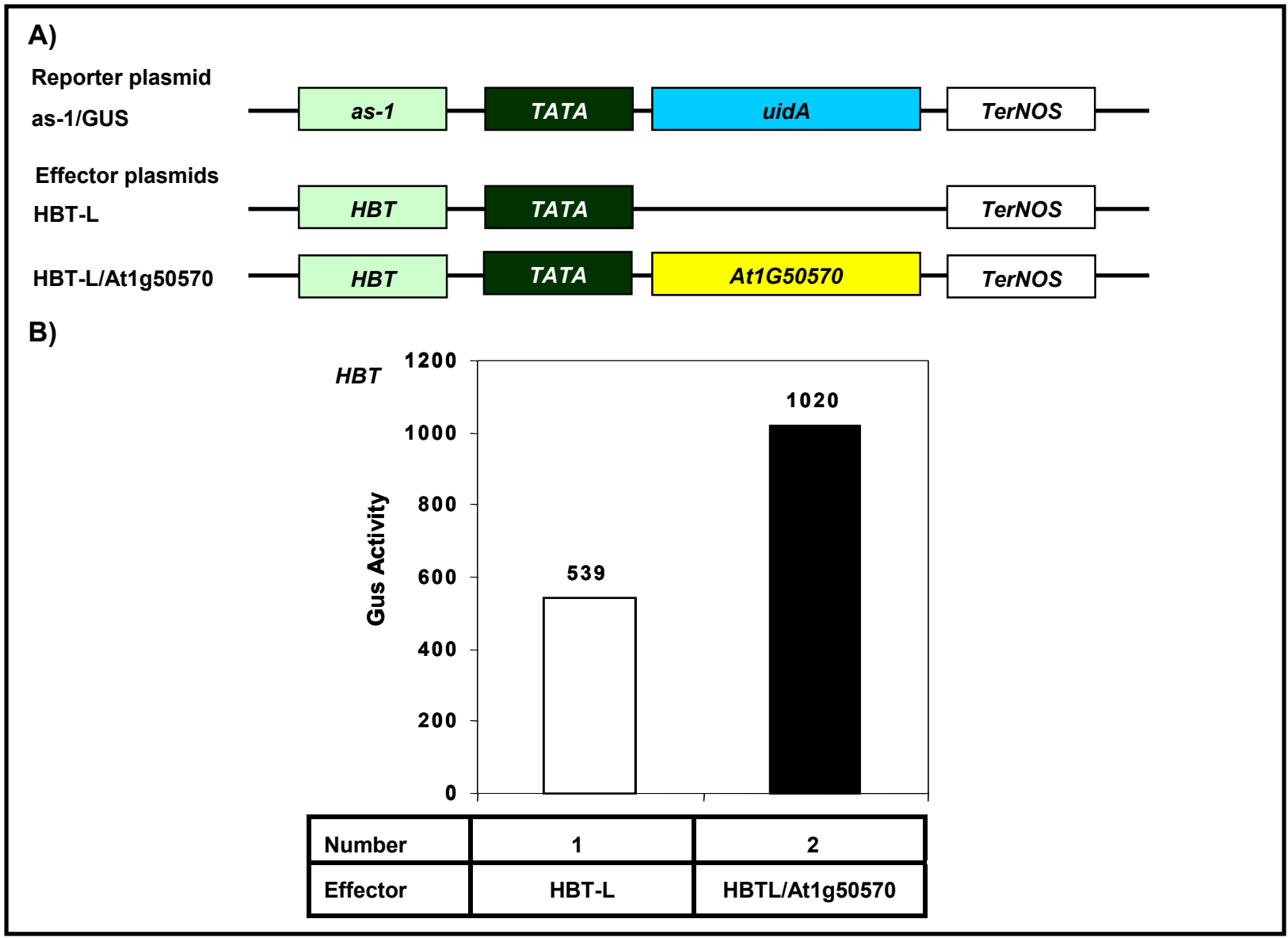

Figure 6.19. Transactivation assay of At1g50570 in BY-2 protoplasts.

A) Schematic diagram of the effector and reporter plasmids used in cotransfection experiments.

B) Transactivation of the as-1::GUS fusion reporter gene by At1g50570 protein.

The reporter gene was cotransfected with $10 \mu \mathrm{g}$ of as-1::GUS reporter and $25 \mu \mathrm{g}$ of At1g50570 effector plasmid or the empty vector as control treatment. GUS Activity was estimated as described in methods. 
The effector plasmid (termed HBTL/At1g50570) and a control effector empty plasmid (HBTL) were cotransfected separately with the reporter plasmid (termed as1::GUS) into tobacco BY-2 protoplasts by electroporation. GUS activities from three independent transfections were measured. At1g50570 protein expressed in protoplasts could activate the uidA reporter gene to about 2 -fold (Figure 6.19B, no. 1 vs. 2). These results would suggest that At1g50570 protein might function as a transcriptional activator that is involved in the as-1 element-dependent responsive gene expression. It is possible that the low nuclear localized At1g50570 levels were responsible for the moderate transactivation activity observed (Figure 6.18B).

To further demonstrate if the At1g50570 protein nuclear localization will lead to transactivate as-1 element-dependent transcription in protoplasts, transactivation experiment was conducted using an At1g50570 protein fused to a NLS (found to be exclusively targeted to nucleus; data not shown). The effector plasmid HBTL/At1g28480 was constructed by inserting the At1g508570 full-length coding sequence in-frame with a NLS sequence of the SV40 large antigen downstream of the $H B T$ chimeric promoter and upstream of GFP coding sequence (Figure 6.20A). The NLS-At1g50570 protein repressed the as-1::GUS reporter transactivity when compared to the HBTL plasmid (Figure 6.20B). These results indicate that the NLS-At1g28480 expression might have a toxic effect on the BY-2 protoplasts. The general toxic effect on BY-2 protoplasts was verified using a $5 x \cup A S^{G A L 4}:$ : uidA reporter gene as a control. 


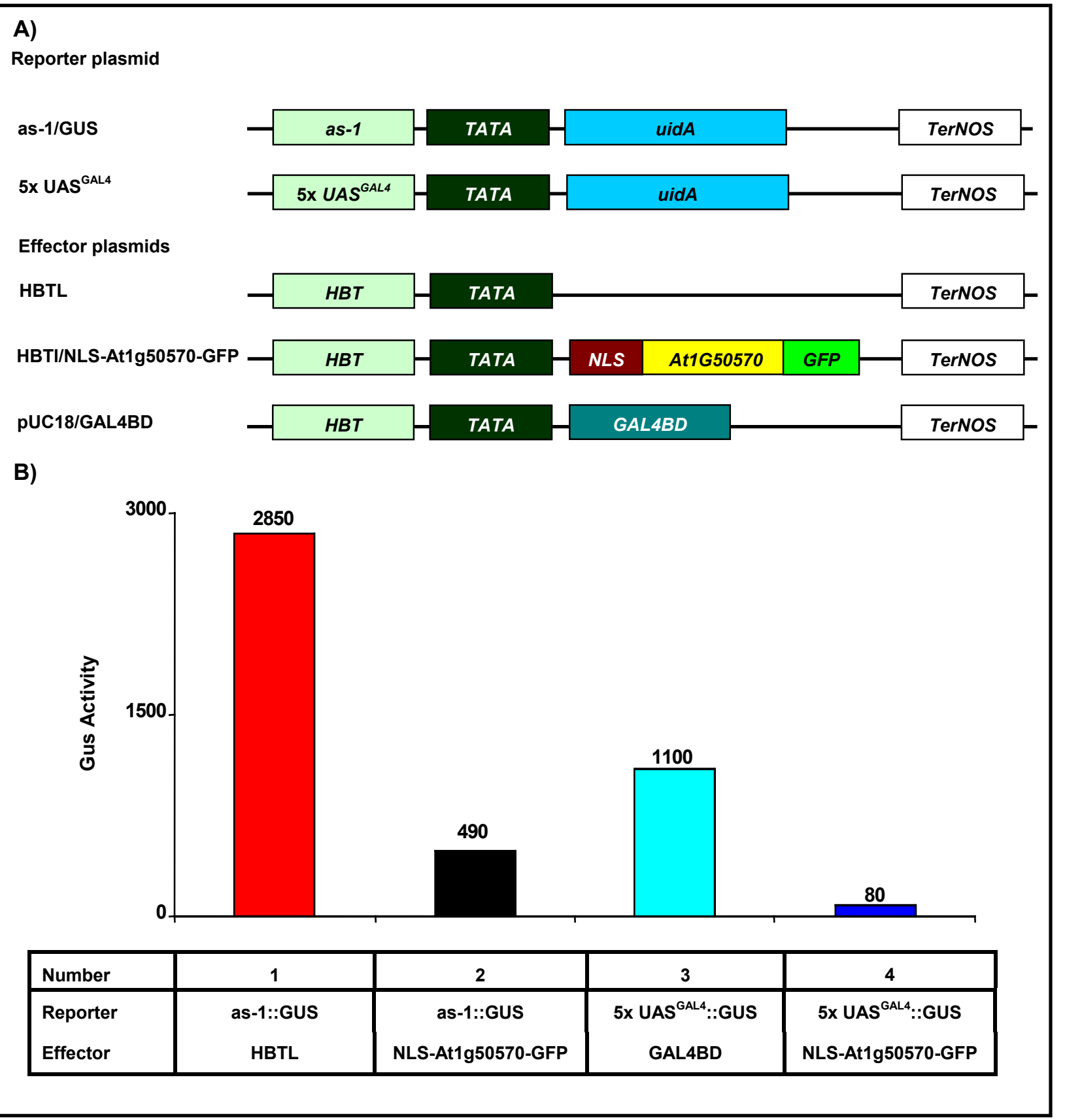

Figure 6.20. Transactivation assay of NLS-At1g50570-GFP in BY-2 protoplasts.

A) Schematic diagram of the effector and reporter plasmids used in cotransfection experiments.

B) Transactivation of the reporter genes by NLS-At1g50570-GFP protein.

The reporter gene was cotransfected with $10 \mu \mathrm{g}$ of as-1::GUS or $5 x$ UAS GAL4::GUS reporter genes and $25 \mu \mathrm{g}$ of NLS-At1g50570GFP effector plasmid or the empty vector as control treatment. GUS Activity was estimated as described in methods. 


\subsubsection{Analysis of the In Vivo Roles of At1g50570 by Generation of At1g50570 Antisense Lines}

To investigate the role of At1g50570 in plants, the full-length coding sequence of At1g50570 was cloned into pFGC5941 vector in the sense and antisense orientations (Figure 6.21A). The pFGC5941/At1g50570 vector contains a CaMV 35S promoter that drives the transcription of a sense and an antisense At1g50570 sequences that are separated by an intron designed so that hairpin RNA structures are formed (Wesley et al., 2001). These double-stranded RNAs are degraded and lead to the production of 21to 23-bp short interfering RNA (siRNA) sequences that will lead to the degradation of the endogenous At1g50570 transcript. The pFGC5941/At1g50570 plasmid was transformed into the Arabidopsis -90-GUS transgenic plants (Redman et al., 2002), which contain a copy of the as-1 element upstream of the uidA gene encoding the GUS enzyme using flower dip method. The transformed plants were selected by BASTA herbicide spraying.

The At1g50570 RNA levels in T2 segregating plants of Basta resistant lines were analyzed using RNA gel blot analysis. In wild-type plants, At1g50570 was expressed constitutively but at a low level, and its transcript level increased slightly after bacterial inoculation (Figure 6.17). Among ten antisense lines tested, the At1g50570 transcripts levels varied compared to control plants. For instance, lines \#1, \#7, \#8, \#9 and \#10 showed normal accumulation of the At1g50570 transcripts, while elevated RNA levels were observed in lines \#2, \#5 and \#6 (Figure 6.21B). Lines \#3 and \#4 had diminished At1g50570 gene expression as compared with the other plants (Figure 6.21B). Based on those observations, the At1g50570 antisense line \#4 was selected for further analysis. 


A)
pFGC5941/At1950570 plasmid
B)

Figure 6.21. Analysis of At1g50570 gene expression in different At1g50570 antisense lines.

A) Schematic diagram of pFGC5941/At1g50570 antisense plasmid used in the generation of antisense plants.

B) RNA gel blots analysis of At1g50570 gene expression in different At1g50570 antisense lines.

Plants were grown for 4 weeks on soil and total RNA was isolated from Arabidopsis -90-GUS plants (control) and Arabidopsis At1g50570 antisense lines. $7.5 \mu \mathrm{g}$ were separated on denaturing gels in the presence of ethidium bromide (EtBr), photographed to assess equal loading, and examined by Northern blot analysis. A radioactive At1g50570 full-length cDNA probe was hybridized to the membrane, which was then examined by autoradiography.

The effect of the At1g50570 repression on the expression of PR-1 gene in response to SA induction was examined. The SA-inducible expression of $P R-1$ gene was not affected in At1g50570 antisense line \#4 as compared to the wild type plant (Figure 6.22). These results indicated that the At1g50570 expression repression did not cause any significant effect on $P R-1$ gene expression. Similar results were obtained when antisense line \#4 was challenged with $P$. syringae pathogen (data not shown).

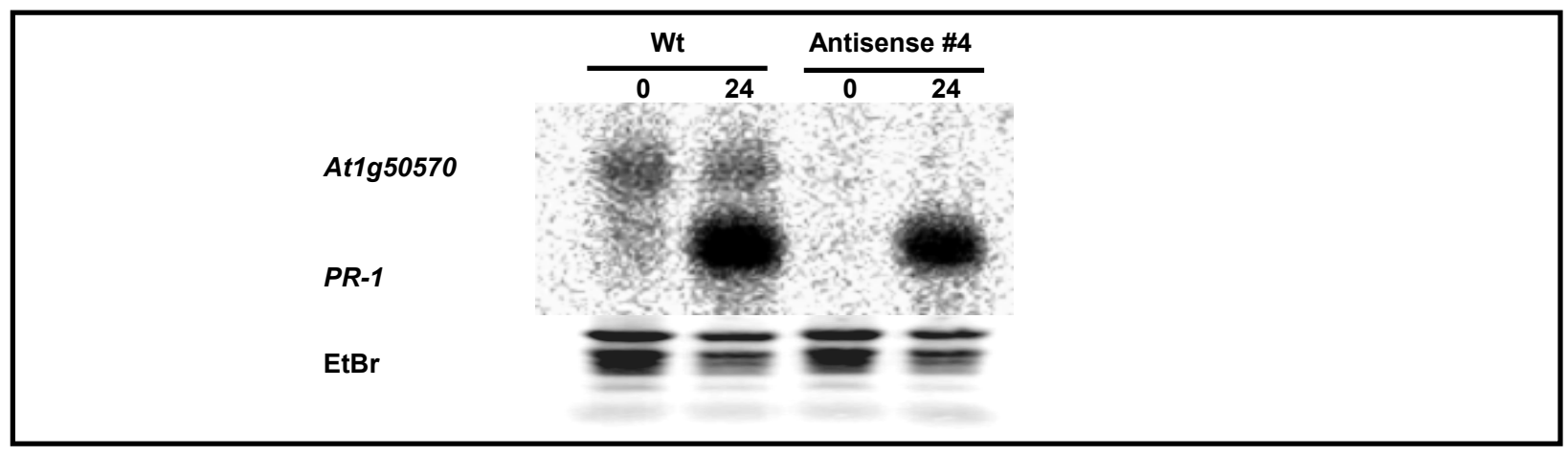

Figure 6.22. RNA gel blots analysis of PR-1 gene expression in At1g50570 antisense line \#4.

Plants were grown for 4 weeks on soil before spraying with $1 \mathrm{mM} \mathrm{SA}$. Total RNA was isolated from plants at different time points (in hours) and $10 \mu \mathrm{g}$ were separated on denaturing gels in the presence of ethidium bromide (EtBr), photographed to assess equal loading, and examined by Northern blot analysis. A radioactive At1g50570 full-length cDNA and PR-1 cDNA probes were hybridized to the membrane, which was then examined by autoradiography. 


\subsubsection{Analysis of the In Vivo Roles of At1g50570 by Generation of At1g50570 Overexpression Lines}

To elucidate the putative function of At1g50570, Arabidopsis overexpression lines were generated. Arabidopsis -90-GUS transgenic plants were transformed with a 3x HA tag fused in-frame to At1g50570 transgene, which is under the control of the strong 2x CaMV 35S promoter (Figure 6.23A). The Alligator2/At1g50570 binary vector, harboring the At1g50570 overexpression cassette, contains a GFP selection marker gene driven by the seed storage protein At2S3 promoter. The GFP selection marker gene allows the selection of At1g50570 overexpression transgenic lines based on their seeds fluorescence level under blue light illumination (Figure 6.23B). The presence of $3 \times \mathrm{HA}$ tag allows protein detection in protein blot analysis using a HA antibody.

T2 plants from seven At1g50570 overexpression lines, showing GFP fluorescence, were examined for the expression of At1g50570 transcripts by using RNA and protein gel blot analysis. RNA gel blot analysis showed that four lines (\#1, \#2, \#3 and \#7) exhibited substantially elevated levels of At1g50570 transcripts (Figure 6.23C). Similarly, protein gel blot and immunoprecipitation analysis confirmed that lines \#1, \#2 and \#3 had significantly increased 3x HA-At1g50570 protein levels compared with the wild type plants (Figure 6.23D and E). Based on the previous analysis, the At1g50570 overexpressor line \#3 transgenic plant was selected for further analysis. 
A)

Alligator2/At1g50570 Plasmid

\begin{tabular}{|l|l|l|l|l|l|l|l|l|l|l|l|l|}
\hline $2 \times 35 S$ & GerNOS & At2S3 \\
\hline
\end{tabular}

B)

C)
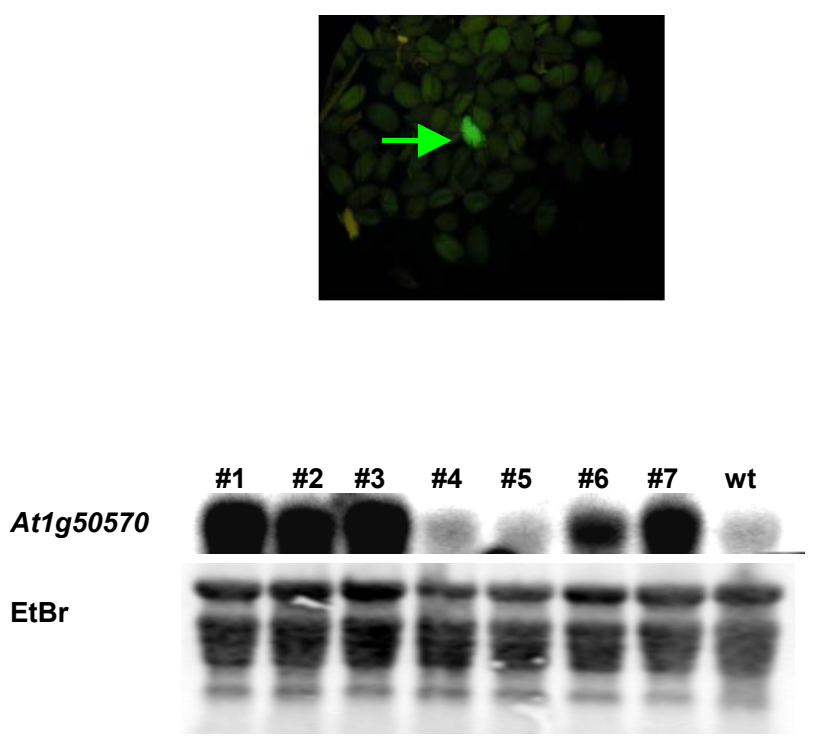

D)

E)

$\mathbf{w t}$

\#2

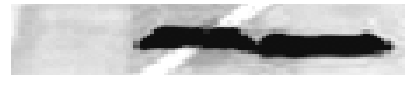

$\begin{array}{llllll}\text { + HA Antibody } & & & \text { - HA Antibody } \\ \text { wt \#1 \#2 \#3 } & & \text { wt \#1 }\end{array}$

Figure 6.23. Analysis of At1g50570 overexpression lines.

A) Schematic diagram of Alligator2/At1g50570 plasmid used in the generation of At1g50570 overexpression plants.

B) Selection of -90-GUS Alligator2/At1g50570 transgenic seeds based on GFP florescence.

C) RNA gel blots analysis of At1g50570 gene expression in different At1g50570 overexpression lines

Total RNA was isolated from -90-GUS plants (control) and -90-GUS Alligator2/At1g50570 transgenic lines. $10 \mu \mathrm{g}$ were separated on denaturing gels in the presence of ethidium bromide (EtBr), photographed to assess equal loading, and examined by Northern blot analysis. A radioactive At1g50570 full-length cDNA probe was hybridized to the membrane, which was examined by autoradiography.

D) Protein gel blot analysis of 3x HA-At1g50570 protein expression levels in At1g50570 overexpression lines \#2 and \#3.

E) Immunoprecipitation analysis for 3x HA-At1g50570 protein detection in At1g50570 overexpression lines \#1, \#2 and \#3. 
To determine the contribution of Atg50570 overexpression to SAR, the expression of PR-1 gene in response to SA induction was examined. At1g50570 overexpression plant did not exhibit any altered $P R-1$ expression in comparison to wild type plant (Figure 6.24). Similar results were observed after $P$. syringae virulent strain infection (data not shown). These results indicated that the At1g50570 overexpression did not have any significant effect on $P R-1$ gene expression.

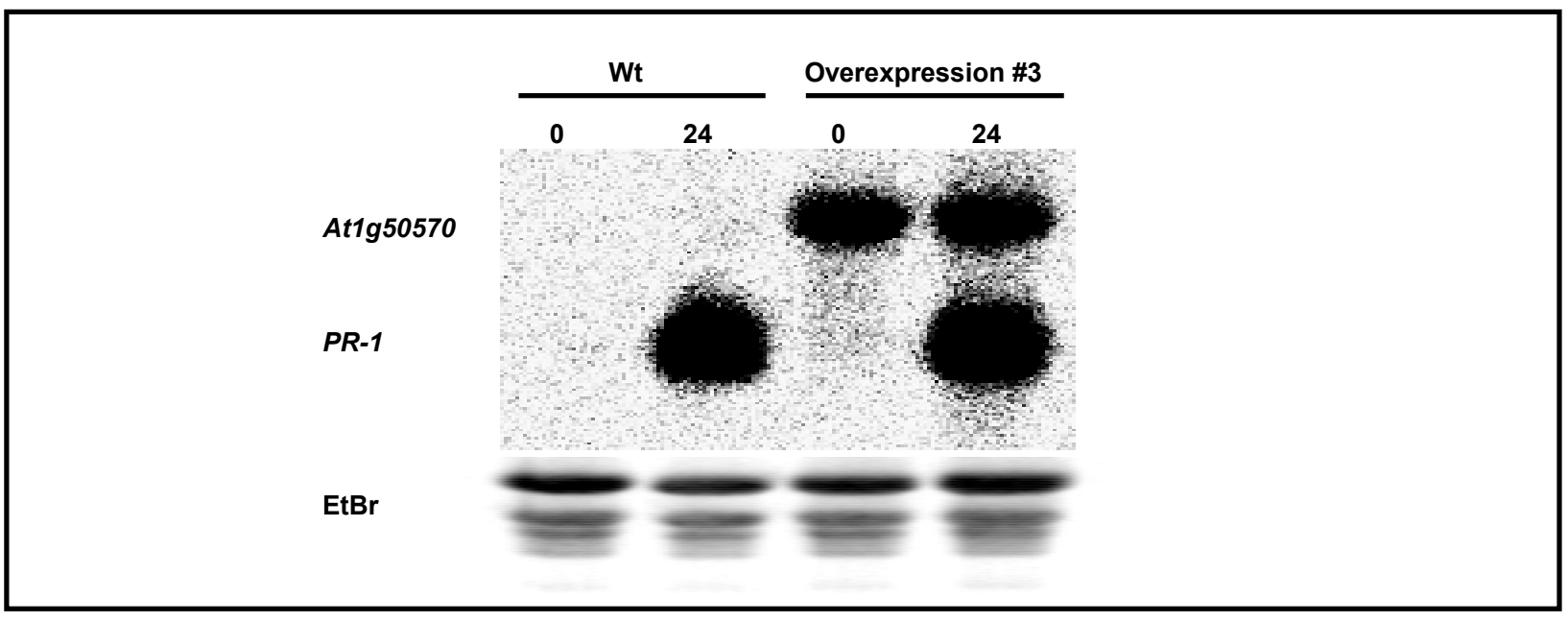

Figure 6.24. RNA gel blots analysis of PR-1 gene expression in At1g50570 overexpression line \#3.

Plants were grown for 4 weeks on soil before spraying with $1 \mathrm{mM} \mathrm{SA}$. Total RNA was isolated from plants at different time points (in hours) and $7.5 \mu \mathrm{g}$ were separated on denaturing gels in the presence of ethidium bromide (EtBr), photographed to assess equal loading, and examined by Northern blot analysis. A radioactive At1g50570 full-length cDNA and PR-1 cDNA probes were hybridized to the membrane, which was examined by autoradiography.

To examine the influence of the At1g50570 overexpression on the GUS reporter gene activity, a histochemical staining assay was performed. Two weeks soil grown 90-GUS and At1g50570 overexpression line \#3 plants were treated with $1 \mathrm{mM} \mathrm{SA}$ or $0.1 \mathrm{mM}$ 2,4-D. The as-1-dependent reporter gene expression was activated after SA and 2,4-D treatments in both transgenic lines (Figure 6.25). However, no constitutive GUS activity was detected in At1g50570 overexpression line \#3. In conclusion, it is clearly demonstrated that the At1g28480 overexpression or repression did not lead to any altered gene expression related to SAR or TGA transcription factors. 


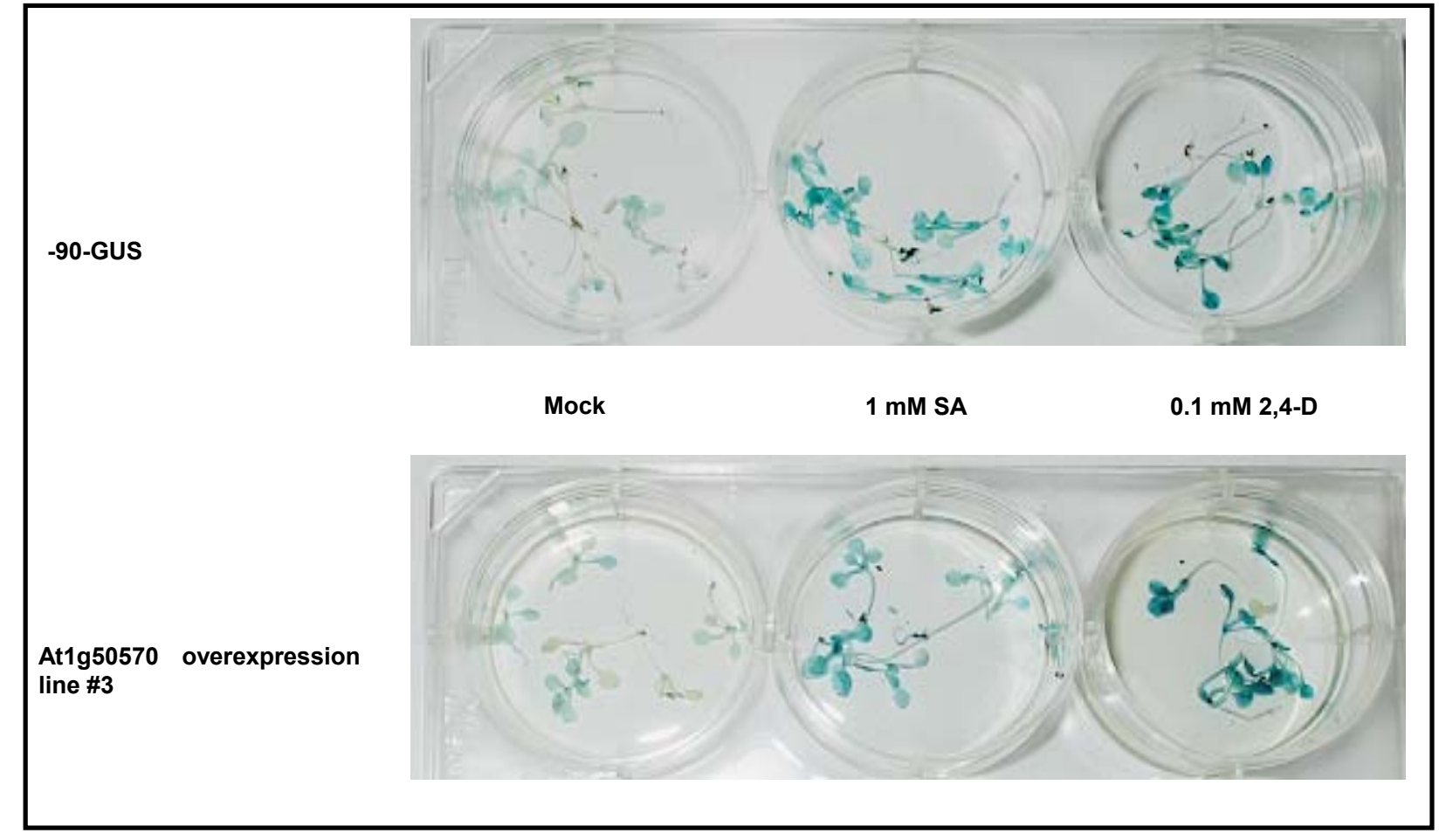

Figure 6.25. Histochemical staining of GUS activities in At1g50570 overexpression line \#3.

Two weeks soil grown -90-GUS transgenic and At1g50570 overexpression line \#3 plants were treated with mock, 1 mM SA or 0.1 $\mathrm{mM}$ 2,4-D for 24 hours and then stained for GUS.

\subsection{Functional Analysis of At1g28480 Isolated cDNA Clone}

\subsubsection{Structural Analysis of At1g28480 Gene}

Among the four groups isolated in the MY1HS screens, clone 5 was the most abundant cDNA insert (Table 6.1, group four). It was isolated twenty-two times using the Arabidopsis cDNA library as a prey. DNA sequence analysis revealed that clone 5 contains a full cDNA coding sequence was fused in-frame to the GAL4AD, a translation stop codon, a $3^{\prime}$-untranslated region and a poly (A) tail of adenosine residues. A BLAST search of the Arabidopsis databases showed sequence identity with the At1g28480 gene that contains an open reading frame of 137 amino acids encodes a putative glutaredoxin protein with a predicted molecular mass of $14.75 \mathrm{kDa}$ (Figure 6.26). The complete sequence of At1g28480 gene was found on the F3M18 BAC clone (GenBank Accession no.: AC010155). 
attaccaaattgttgtatatagtctggtgattccgttttgatggtcgagatcgaaagaagcaagcatccactatgtggtcgtcacatgcgaatatttctaagtatacaaccatct atcgaaagtttcgaaacaacccaaatataatagtaataaattctgagaattctcctattttttattgatatgaaaaagcagtaaatattatgtaaagtagagaggaaccaaaattaaaacgtgcaga tttattaaagaataaagtgggatccaaaaagtcagcgtgaaacatgtgatacgatataacgacacggtcctatgactaagtccactccaatccagtgacgtaaacagcaccatcacccatagcttcct gtgacgcacatccttacgtaaccatcgttgacgctagactttcctctctgatctctctttcttcatgtatatataacaaaccttcctttcctaattggtatctatctttaaaaacatacttgaaaggt

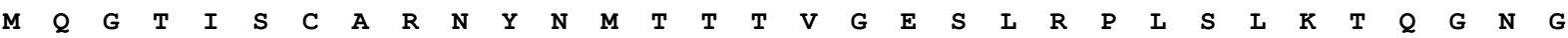
ATGCAAGGAACGATTTCTTGGCAAGAAATTATAACATGACGACAACCGTCGGGGAATCTCTGCGGCCGCTATCGCTTAAAACGCAGGGAAACGGC

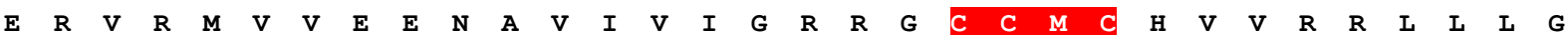
GAGAGAGTTCGGATGGTGGTGGAGGAGAACGCGGTGATTGTGATTGGACGGAGAGGATGTTGCATGTGTCATGTGGTGAGGAGGCTGCTTCTTGGA

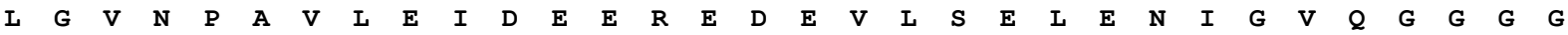
CTTGGAGTGAATCCGGCGGTCCTTGAGATTGATGAGGAGAGGGAAGATGAAGTTTTGAGTGAGTTGGAGAATATTGGAGTTCAAGGCGGCGGAGGT

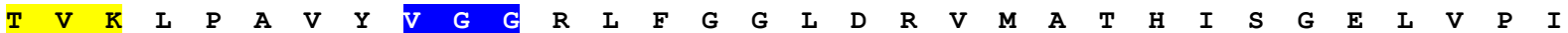
ACGGTGAAGTTACCGGCGGTTATGTAGGAGGGAGGTTGTTTGGAGGGTTAGATAGGGTTATGGCTACTCATATCTCCGGTGAGTTAGTTCCAATT

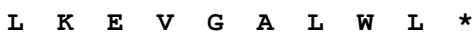

CTTAAGGAAGTTGGGGCTCTGTGGTTGTGAttgtaaattaataatttaaaattatttttttttcttttaattaagaatcttgattggtaattgttgtttacggtttataattgaatcgt ttcatatatatgtatataaagaaa taaa taaaagaaagtctcaagttgaaatttgctagagattgtacccaataattttatagcattcattgtgctctgttttgatagtactcgtttttttttgtcat cagattttatatagattcatttttttttttatggtattcatgttttgatggtactcattgtatcattcgttttaggcatctactcttctaagtgagatagaaattaatggatctgtttgtttaaaagat ttatcaaccttttgtgaaacggaaagaatttattactgtgttagactgttaggtgatagtgatttaaatgtgaccttaatgctcttgtttggggtacgtggtagtttatcagatttgaatattcacaaa tgccaaaatatgagagatccttta

\section{Figure 6.26. Full-length sequence of $A t 1 g 28480$ cDNA.}

The red background represents the redox active center, the yellow background represents a conserved hydrophobic surface, and the blue background points for a putative glutathione binding site.

Glutaredoxins, also known as thioltransferases, are ubiquitous proteins that catalyze reductions of disulfides (protein-S-S) or mixed disulfides formed between proteins and glutathione (protein-S-SG) in a coupled system with glutathione, NADPH, and glutathione reductase. The major function of glutaredoxins is glutathionedependent hydrogen donor for ribonucleotide reductase enzyme (Figure 6.27; Holmgren and Åslund, 1995). Glutaredoxin protein sequence contains three characteristic regions: the dithiol/disulfide active site or redox active center with the sequence YCPYC, a glutathione binding site, and a hydrophobic surface area (Figure 6.26; Lundberg et al., 2001).

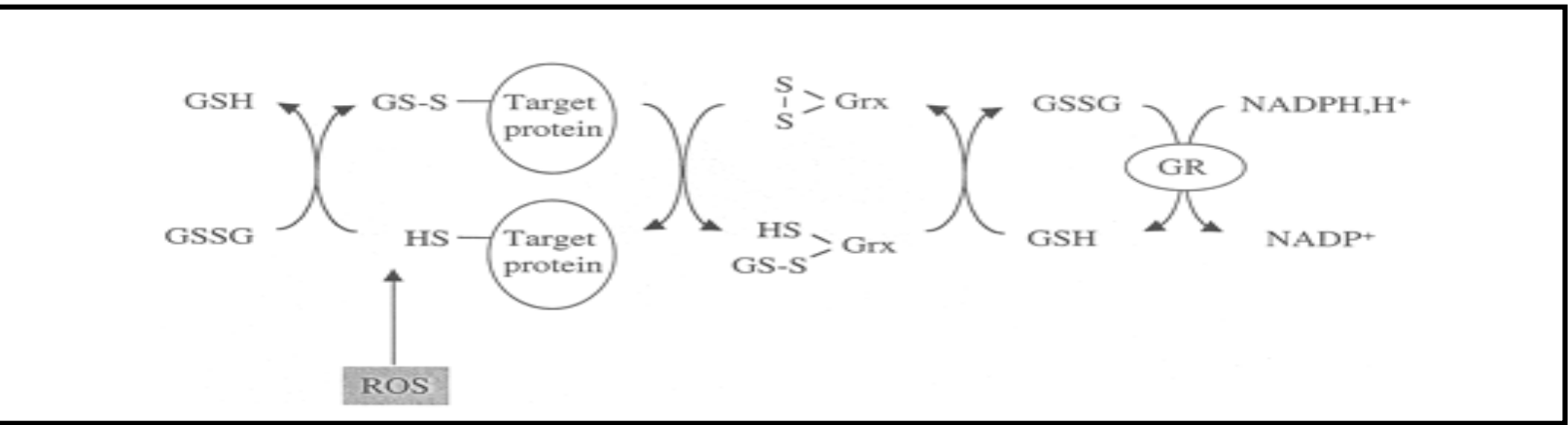

Figure 6.27. Glutaredoxins redox reactions (Lundberg et al., 2001).

Glutathione (GSH or GSSG)-glutaredoxin (Grx) redox reactions of a target protein; ROS: reactive oxygen species. 
The amino-acid sequences of the 24 Arabidopsis glutaredoxins proteins were aligned and a neighbor-joining phylogenetic tree was generated from the protein alignment using the Vector NTi software (Figure 6.28). The At1g28480 protein clustered with the monocysteinic At1g03850 glutaredoxin. Arabidopsis plant has at least 24 genes encoding proteins with homology to glutaredoxin, however, little is known about their function in plant (Meyer et al., 1999). Only two Arabidopsis glutaredoxins have the YCPYC redox active site conserved motif, while the majority of Arabidopsis glutaredoxins are highly variable in their redox active center sequence (Rouhier et al., 2002a).

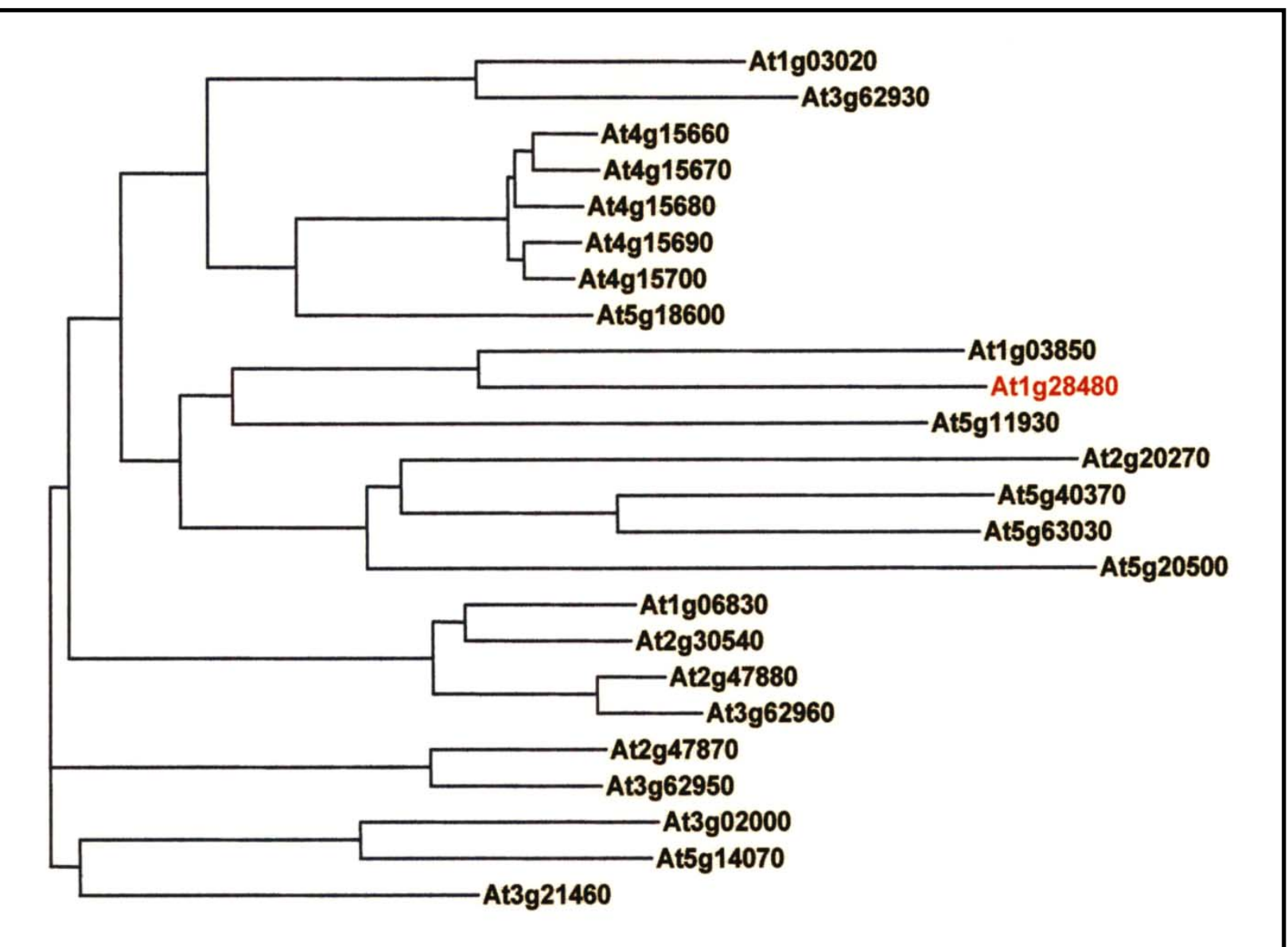

Figure 6.28. Phylogeny of the Arabidopsis glutaredoxin family. At1g28480 is shown in red. 


\subsubsection{TGA2.2 Interacts with At1g28480 in Y2HS}

To verify that Arabidopsis At1g28480 protein interacts with TGA2.2 and to test whether it can interact with Arabidopsis homologs, a classical $\mathrm{Y} 2 \mathrm{HS}$ assay was conducted. The GAL4DB-TGA2.2, GAL4BD-TGA2 and GAL4AD-TGA6 constructs were cotransformed with the pGAD10/At1g28480 into the HF7c strain and the transformants were assayed for histidine prototrophy in the presence of $5 \mathrm{mM} 3-\mathrm{AT}$. In consistence with the MY1HS results, the TGA2.2, TGA2 and TGA6 proteins interacted with At1g28480 in the Y2HS assay (Figure 6.29, sector 3, 5 and 7). These results were further confirmed using a domain swap experiment, in which GAL4BD-At1g28480 the GAL4AD-TGA2.2 transformants were used in similar assays (data not shown).
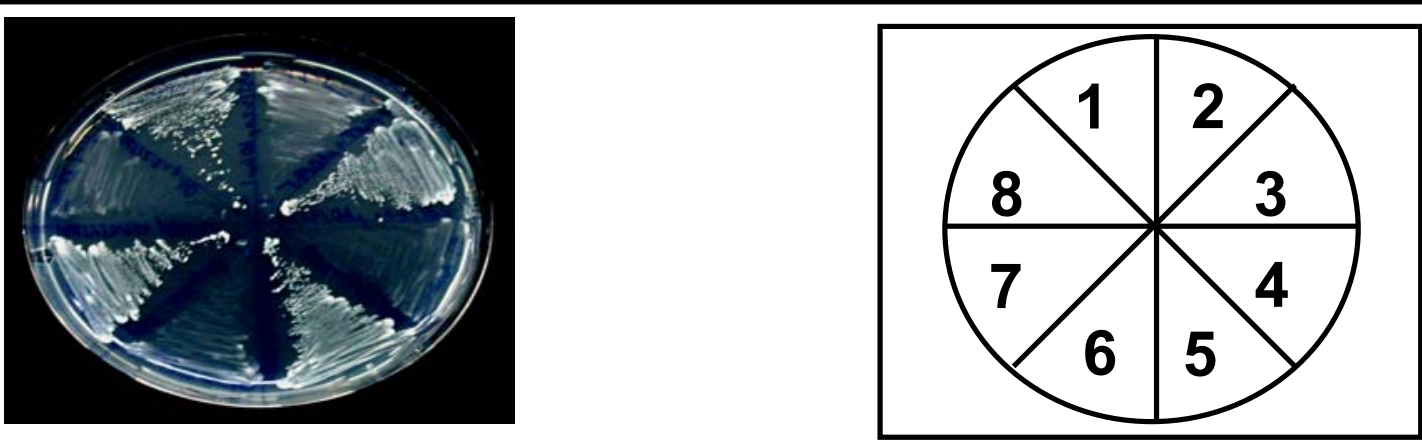

\begin{tabular}{|l|l|l|c|}
\hline Sector & Bait (TRP1 marker) & Prey (LEU2 marker) & Growth on SD lacking histidine \\
\hline 1 & GAL4BD-TGA2.2 & GAL4AD-NPR1 & ++ \\
2 & GAL4BD & GAL4AD-At1g28480 & - \\
3 & GAL4BD-TGA2.2 & GAL4AD-At1g28480 & ++ \\
4 & GAL4BD-TGA2.2 & GAL4AD & - \\
5 & GAL4BD-TGA2 & GAL4AD-At1g28480 & ++ \\
6 & GAL4BD-TGA2 & GAL4AD & - \\
7 & GAL4BD-TGA6 & GAL4AD-At1g28480 & ++ \\
8 & GAL4BD-TGA6 & GAL4AD & - \\
\hline
\end{tabular}

Figure 6.29. Y2HS assays of interactions between At1g28480 and TGA proteins.

HF7c cells containing pGBT9/TGA2.2 + pGAD424/NPR1 (1), pGBT9 + pGAD424/At1g28480 (2), pGBT9/TGA2.2 + pGAD424/At1g28480 (3), pGBT9/TGA2.2 + pGAD424 (4), pGBT9/TGA2 + pGAD424/At1g28480 (5), pGBT9/TGA2 + pGAD424 (6), pGBT9/TGA6 + pGAD424/At1g28480 (7) and pGBT9/TGA6 + pGAD424 (8) plasmids were grown for 3 days at $30^{\circ} \mathrm{C}$ on selective SD medium lacking leucine, tryptophan and histidine, supplemented with $5 \mathrm{mM}$ 3-AT. 


\subsubsection{At1g28480 Interacts with All Identified Members of Tobacco TGA Factors}

The interaction of At1g50570 with other TGA factors from tobacco was analyzed using the Y2HS in the HF7c strain. The bait construct containing the GAL4BDAt1g28480 coding sequence was tested for interactions with other TGA factors from tobacco. The GAL4BD-At1g28480 protein was not able to transactivate the HIS3 reporter gene (Figure 6.30, sector 7). At1g28480 interacts strongly with other identified tobacco TGA factors (Figure 6.30, sectors 3, 5, 9 and 11).
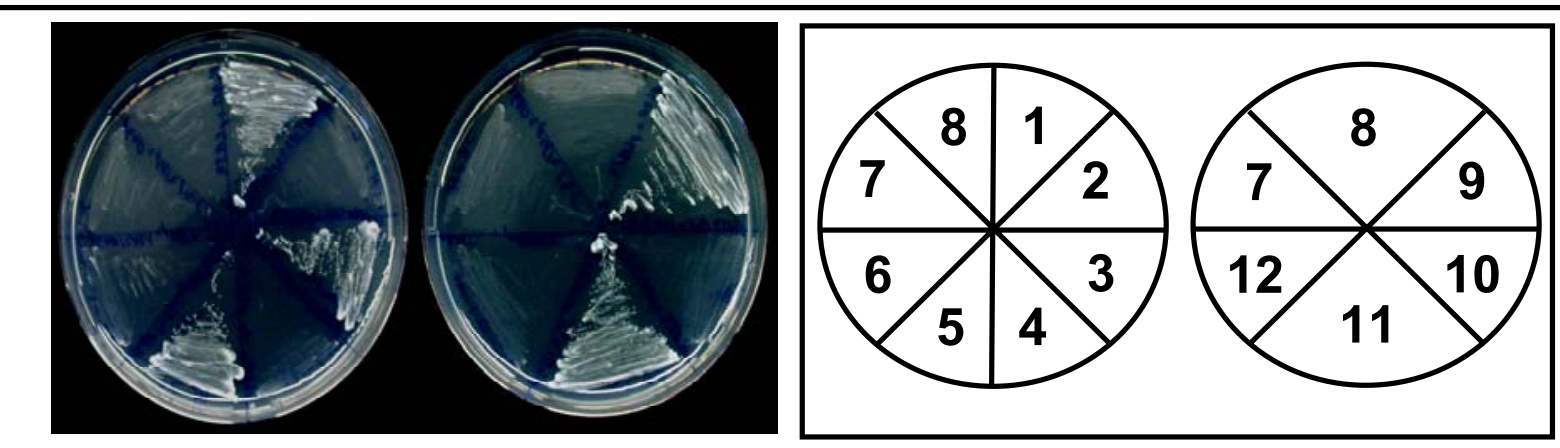

\begin{tabular}{|l|l|l|c|}
\hline Sector & Bait (TRP1 marker) & Prey (LEU2 marker) & Growth on SD lacking histidine \\
\hline 1 & GAL4BD-TGA2.2 & GAL4AD-NPR1 & ++ \\
2 & GAL4BD & GAL4AD-NPR1 & - \\
3 & GAL4BD-At1g28480 & GAL4AD-TGA2.2 & ++ \\
4 & GAL4BD & GAL4AD-TGA2.2 & - \\
5 & GAL4BD-At1g28480 & GAL4AD-TGA2.1 & ++ \\
6 & GAL4BD & GAL4AD-TGA2.1 & - \\
7 & GAL4BD-At1g28480 & GAL4AD & - \\
8 & GAL4BD & GAL4AD & + \\
9 & GAL4BD-At1g28480 & GAL4AD-TGA1a & + \\
10 & GAL4BD & GAL4AD-TGA1a & ++ \\
11 & GAL4BD-At1g28480 & GAL4AD-TGA10 & - \\
\hline
\end{tabular}

Figure 6.30. Y2HS assays of interactions between At1g28480 and TGA proteins.

HF7c cells containing pGBT9/TGA2.2 + pGAD424/NPR1 (1), pGBT9 + pGAD424/NPR1 (2), pGBT9/At1g28480 + pGAD424/TGA2.2 (3), pGBT9 + pGAD424/TGA2.2 (4), pGBT9/At1g28480 + pGAD424/TGA2.1 (5), pGBT9 + pGAD424/TGA2.1 (6), pGBT9/At1g28480 + pGAD424 (7), pGBT9 + pGAD424 (8), pGBT9/At1g28480 + pGAD424/TGA1a (9), pGBT9 + pGAD424/TGA1a (10), pGBT9/At1g28480 + pGAD424/TGA10 (11) and pGBT9 + pGAD424/TGA10 (12) plasmids were grown for 3 days at $30^{\circ} \mathrm{C}$ on selective SD medium lacking leucine, tryptophan and histidine, supplemented with 5 mM 3-AT. 
To define the region in TGA2.2 that interacts directly with At1g28480, the Cterminal domain of TGA2.2 was coexpressed as a GAL4BD fusion with GAL4ADAt1g28480 in the HF7c strain and the transformants were assayed for the histidine prototrophy. The TGA2.2 encoded C-terminus is sufficient to confer interaction with At1g28480 (data not shown). To determine the specificity of the TGA2.2-At1g50570 interaction, Y2HS interaction analysis between TGA2.2 and two other glutaredoxins, At5g20500 and At5g40370, was conducted. Constructs containing the GAL4BDAt5g20500 or GAL4BD-At5g40370 and GAL4AD-TGA2.2 coding sequences were cotransformed into HF7c. The histidine prototrophy assay showed no interaction between TGA2.2 and the At5g20500 and At5g40370 glutaredoxins (data not shown). These results indicate that the interaction between At1g28480 glutaredoxin and TGA2.2 is indeed specific.

\subsubsection{Generation of At1g28480 and TGA2.2 Mutants by Site-directed Mutagenesis}

As described above, glutaredoxin catalyzes reductions of disulfides via its redox active site. To explore if the two-cysteine residues at active site $\left(\mathrm{Cys}^{52}\right.$ and $\mathrm{Cys}^{55}$ ) of At1g28480 plays an important role in the interaction with TGA2.2 site-directed mutagenesis techniques (Section 4.3.12.2) were used to create point mutations in one or both cysteine residues converting them to serine residues (C52S (GSM); C52S/C55S (GDM) (Figure 6.31A). Using this strategy, two glutaredoxin mutants, designated as GSM and GDM, were generated.

If TGA transcription factors undergo redox changes that are modulated by At1g28480 protein, the presence of cysteine residues in their sequences is crucial. Protein sequence analysis of TGA2.2 reveals the presence of a single conserved cysteine residue at the C-terminal part of the protein $\left(\mathrm{Cys}^{181}\right)$. This single conserved cysteine is also found in TGA2.1, TGA2, TGA5, TGA6 and TGA10 that contains other cysteines beside it. The TGA2.2 conserved cysteine residue was point mutated into serine using the site-directed mutagenesis strategy (Section 4.3.12.2). The new

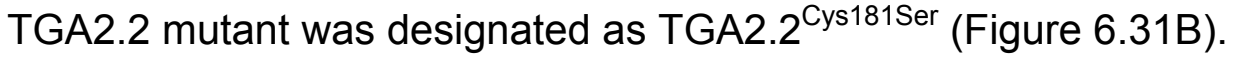




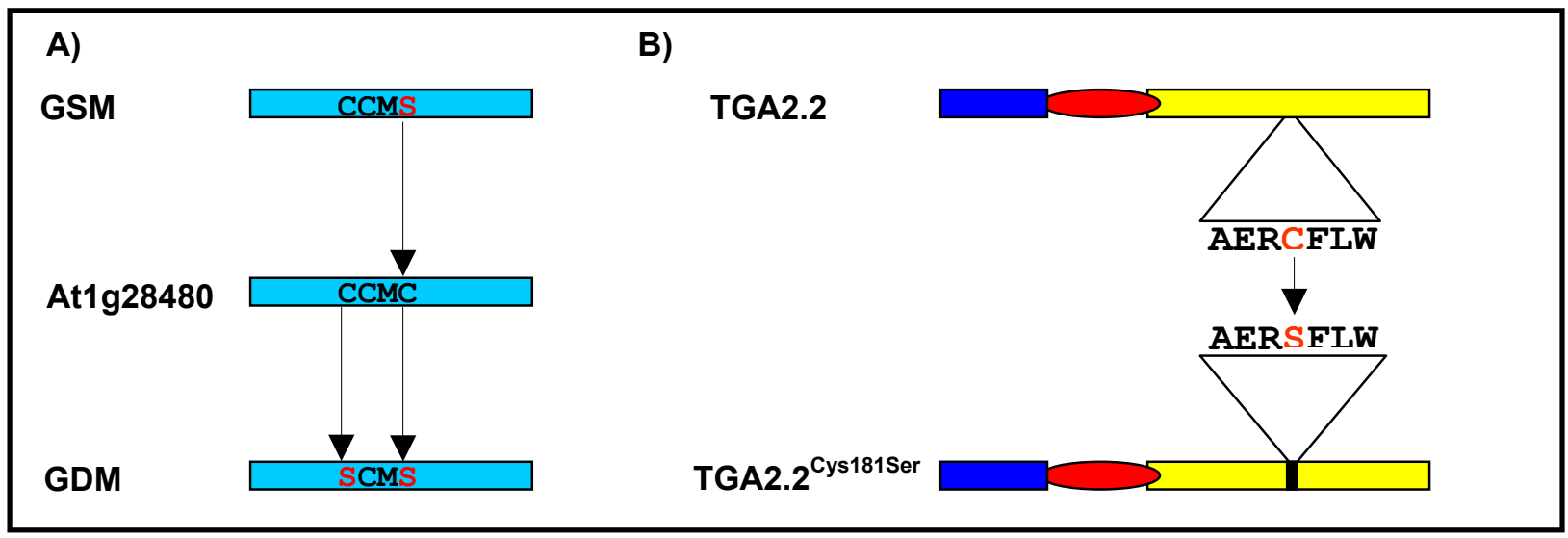

Figure 6.31. TGA2.2 and At1g28480 mutants used in this study.

\subsubsection{Analysis of Disulfide Bridge Formation in TGA2.2}

To determine whether the conserved cysteine in TGA2.2 is involved in the formation of intramolecular or intermolecular disulfide bridges, an immunoblot analysis was performed using the 6x His-TGA2.2 and 6x His-TGA2.2 ${ }^{\text {Cys181Ser }}$ (encoded in $\mathrm{pET} 28 \mathrm{a} / \mathrm{TGA} 2.2^{\mathrm{Cys} 181 \mathrm{Ser}}$ plasmid) proteins under oxidizing or reducing conditions. The 6x His-TGA2.2 ${ }^{\text {Cys181Ser }}$ protein was produced in E. coli and purified as described above. Before subjecting proteins to SDS-PAGE, both proteins were incubated with $1 \mathrm{mM}$ of the oxidizing agent diamide for 15 minutes in order to oxidize them. Putatively oxidized proteins were reduced by incubation with an excess of the reducing agent $B-M E$ or left in its oxidized form. Both oxidized and reduced proteins forms were subjected to SDSPAGE analysis followed by an immunoblot analysis using a TGA2.2 specific antibody.

SDS-PAGE analysis under reducing conditions of the purified 6x His-TGA2.2 and

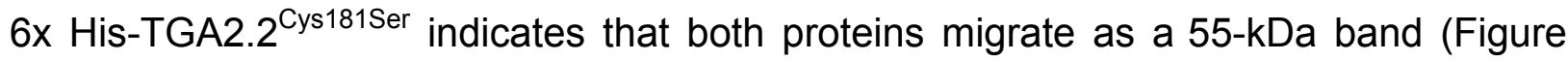
5.30). Under non-reducing conditions, oxidized TGA2.2 produces two bands, a 55-kDa band comprising the majority of the monomeric 6 x His-TGA2.2, and an $\sim 130 \mathrm{kDa}$ band shifted to position of approximately triple the size of the 55-kDa band observed under reducing conditions, suggesting oligomer formation (Figure 6.32, arrow). Under the

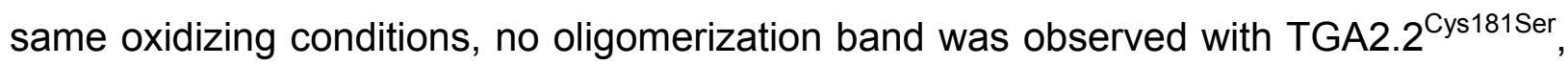
indicating that the TGA2.2 conserved cysteine is responsible for TGA2.2 
oligomerization (Figure 6.32). Although the oligomerization band contains considerably lower amounts of TGA2.2, the results indicate that the TGA2.2 conserved cysteine is involved in the formation of intermolecular disulfide bonds.

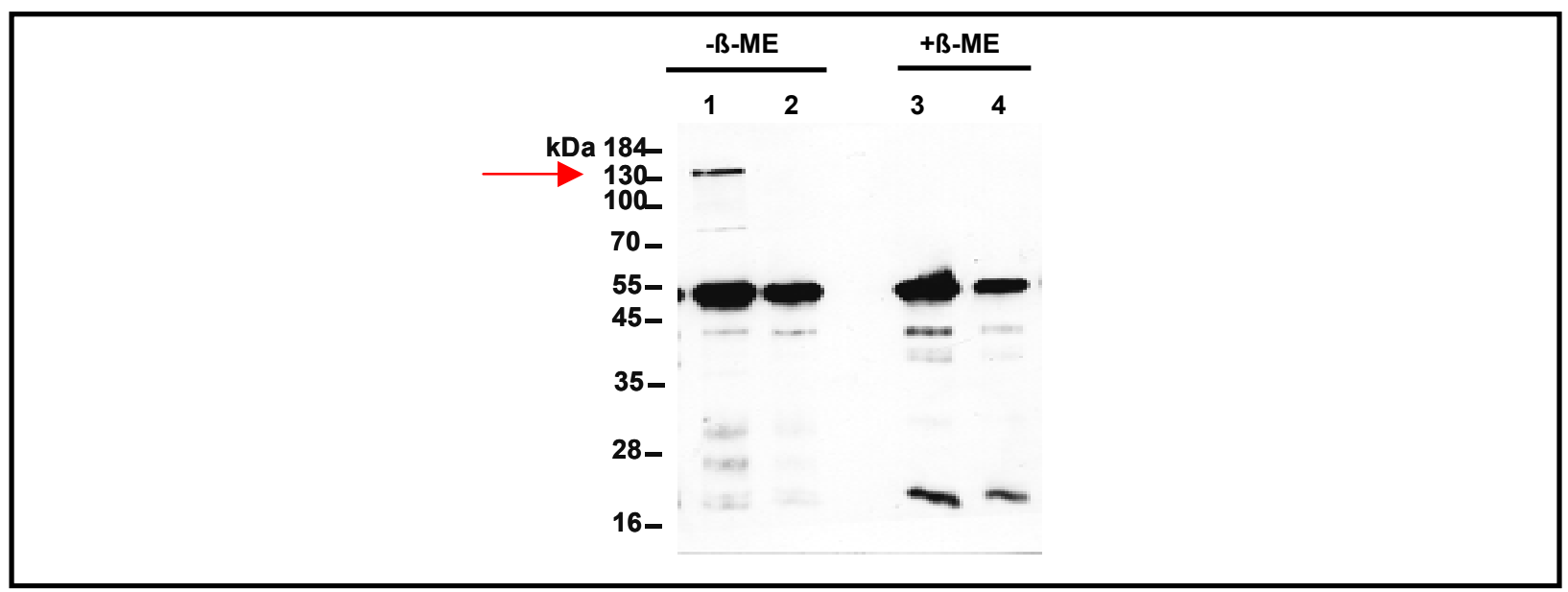

Figure 6.32. Analysis of disulfide bond formation in TGA2.2.

6x His-TGA2.2 (1 and 3) and 6x His-TGA2.2 ${ }^{\text {Cys181Ser }}$ ( 2 and 4) purified proteins were incubated with 1 mM diamide for 30 min then subjected to non-reducing SDS-PAGE and immunoblot analysis was conducted thereafter. The oxidized 6x His-TGA2.2 and 6x HisTGA2. $2^{\text {Cys } 181 \text { Ser }}$ were either reduced with B-ME ( 3 and 4 , respectively) or left in its oxidized form ( 1 and 2 , respectively) before loading for SDS-PAGE. Immunoblot analysis using a TGA2.2 antibody was performed. Arrow indicates the oligomer band.

\subsubsection{The Interactions of TGA2.2 and At1g28480 Mutants in Yeast}

To assess whether the At1g28480 and its generated mutants are still able to interact with TGA2.2 and TGA2.2 ${ }^{\text {Cys181Ser }}$, an interaction assay was conducted in yeast. The full-length coding sequences of GSM and GDM mutants were inserted downstream of the GAL4AD in the pGAD424 plasmid, while the TGA2.2 ${ }^{\text {Cys181Ser }}$ coding sequence was inserted downstream of GAL4BD in the pGBT9 plasmid. The GAL4BD-TGA2.2, GAL4BD-TGA2.2 ${ }^{\text {Cys181Ser }}$ bait proteins were assayed for interactions with GAL4ADAt1g28480, GAL4AD-GSM and GAL4AD-GDM in the HF7c yeast.

Histidine prototrophy assay showed interaction between GAL4BD-TGA2.2 and the GAL4AD-GSM mutant (Table 6.3, no. 5). However, no interaction was observed between GAL4BD-TGA2.2 and GAL4AD-GDM (Table 6.3, no. 7). Therefore, it was assumed that the At1g28480 redox active site is crucial for interaction with TGA2.2, 
suggesting that TGA2.2 might undergo a redox change modulated by Domain swap experiments supported the observation that the interaction was severely reduced, as only a weak interaction was observed as compared with At1g28480-TGA2.2 control interactions (Table 6.3, no. 13). Unfortunately, no protein expression analysis was conducted due to antibody limitations. The GAL4BD-TGA2.2 ${ }^{\text {Cys181Ser }}$ protein interacts with GAL4AD-At1g28480 in yeast (Table 6.3, no. 17).

Table 6.3. Interaction of TGA2.2 and At1g28480 mutants in HF7c yeast strain.

HF7c cells transformed with different bait and prey plasmids combinations (see table) were grown for 3 days at $30^{\circ} \mathrm{C}$ on selective SD medium lacking leucine, tryptophan and histidine, and supplemented with $5 \mathrm{mM}$ 3-AT.

\begin{tabular}{|c|c|c|c|}
\hline Number & Bait (TRP1 marker) & Prey (LEU2 marker) & Growth on SD lacking Histidine Media \\
\hline 1 & GAL4BD-TGA2.2 & GAL4AD-NPR1 & +++ \\
\hline 2 & GAL4BD-TGA2.2 & GAL4AD & - \\
\hline 3 & GAL4BD-TGA2.2 & GAL4AD-At1g28480 & +++ \\
\hline 4 & GAL4BD & GAL4AD-At1g28480 & - \\
\hline 5 & GAL4BD-TGA2.2 & GAL4AD-GSM & +++ \\
\hline 6 & GAL4BD & GAL4AD-GSM & - \\
\hline 7 & GAL4BD-TGA2.2 & GAL4AD-GDM & - \\
\hline 8 & GAL4BD & GAL4AD-GDM & - \\
\hline 9 & GAL4BD-At1g28480 & GAL4AD-TGA2.2 & +++ \\
\hline 10 & GAL4BD-At1g28480 & GAL4AD & - \\
\hline 11 & GAL4BD-GSM & GAL4AD-TGA2.2 & +++ \\
\hline 12 & GAL4BD-GSM & GAL4AD & - \\
\hline 13 & GAL4BD-GDM & GAL4AD-TGA2.2 & + \\
\hline 14 & GAL4BD-GDM & GAL4AD & - \\
\hline 15 & GAL4BD-TGA2.2 $2^{\text {Cys } 181 \mathrm{Ser}}$ & GAL4AD & - \\
\hline 16 & GAL4BD-TGA2.2 ${ }^{\text {Cys181Ser }}$ & GAL4AD-NPR1 & +++ \\
\hline 17 & GAL4BD-TGA2.2 $2^{\text {Cys181Ser }}$ & GAL4AD-At1g28480 & +++ \\
\hline 18 & GAL4BD-TGA2.2 $2^{\text {Cys181Ser }}$ & GAL4AD-GSM & +++ \\
\hline 19 & GAL4BD-TGA2. ${ }^{\mathrm{Cys} 181 \mathrm{Ser}}$ & GAL4AD-GDM & - \\
\hline
\end{tabular}


To determine whether At1g28480 affects TGA2.2 transcriptional activity under oxidative stress, the effect of diamide treatment on the interaction between the two proteins was assayed using the YRWZ2 yeast strain harboring the lac-Z reporter gene under the control of the as-1 elements. The Met25::TGA2.2 and GAL4AD-At1g28480 constructs were cotransformed into YRWZ2 strain and the transformants were assayed for lac-Z reporter gene activity using an ONPG assay. YRWZ2 transformants were grown on $\mathrm{SD}$ medium to an $\mathrm{OD}_{600}$ of 0.6 and then split into two equal aliquots, which were subjected to diamide stress or left untreated for $4 \mathrm{~h}$. In consistence with the histidine prototrophy assay, At1g28480 interacted with TGA2.2 and a transactivation of the TGA2.2-dependent lacZ reporter gene was observed (Figure 6.33, no. 3). YRWZ2 cells subjected to oxidative stress exhibited the same reporter gene activity as the control (Figure 6.33, no. 3 vs. 4). These data establish that the At1g28480-TGA2.2 interaction is not affected by oxidative stress conditions.

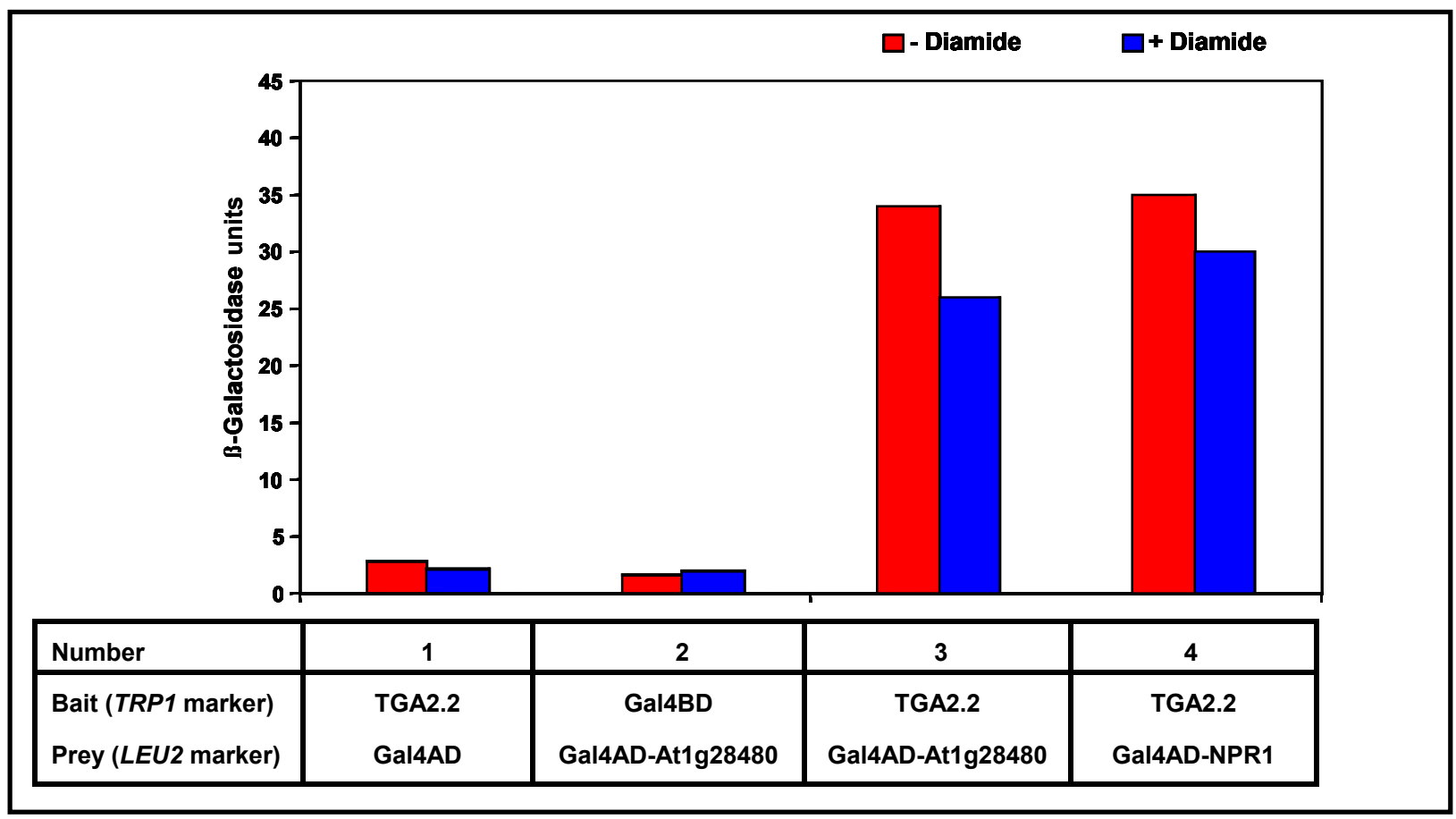

Figure 6.33. Interaction of TGA2.2 and At1g28480 in YRWZ2 yeast strain under oxidative stress.

YRWZ2 cells containing pBL/TGA2.2 + pGAD424 (1), pBL+ pGAD424/At1g28480 (2), pBL/TGA2.2 + pGAD424/At1g28480 (3) and pBL/TGA2.2 + pGAD424/NPR1 (4) plasmids were grown on SD medium lacking tryptophan and leucine to an OD 600 of 0.6 and then split into two equal aliquots, which were subjected to diamide stress or left untreated for $4 \mathrm{~h}$. Cells were then processed and lac- $Z$ activity was measured as described in methods. 


\subsubsection{At1g28480 Enhances TGA2.2 Expression in Yeast}

As described above, the presence of the leucine zipper motif in TGA factors facilitates their dimerization. Previous analysis showed that homodimerization between two TGA2.2 factors is possible and was detectable in EMSAs (Niggeweg et al., 2000b). However, in contrary to the EMSA data, no interaction was observed between two GAL4BD-TGA2.2 and GAL4AD-TGA2.2 hybrid proteins in the Y2HS (C. Thurow, unpublished observations). This TGA2.2 behavior in yeast hints to the possibility that the TGA2.2 factors could undergo a posttranscriptional modification enabling them to dimerize.

To test whether the At1g28480 protein can enhance TGA2.2 dimerization in yeast, the At1g28480 protein was expressed conditionally as a third protein using the Met25::HA-NLS-At1g28480::PGK cassette harbored in the pBD vector. The TGA2.2 coding sequence was inserted in-frame downstream of the GAL4BD cassette in the pBD vector harboring the Met25::HA-NLS-At1g28480::PGK cassette. The newly cloned plasmid, designated pBDTGA2.2/Met25::At1g28480, will allows the expression of two proteins simultaneously in the same yeast cell.

The GAL4AD-TGA2.2 and GAL4BD-TGA2.2 proteins were assayed for their interactions in the presence or absence of HA-NLS-At1g28480 protein in the HF7c Y2HS strain. As anticipated, GAL4BD-TGA2.2 does not interact with GAL4AD-TGA2.2 in yeast (Figure 6.34, sector 2). Also, the solo coexpression of At1g28480 with GAL4BD-TGA2.2 didn't lead to any reporter gene activation (data not shown). Strikingly, the inducible expression of At1g28480 in the presence of GAL4BD-TGA2.2 and GAL4AD-TGA2.2 proteins led to HIS3 reporter gene activation (Figure 6.34, sector 4: -methionine plate). In the contrary, At1g28480 repression abolished the observed activation (Figure 6.34, sector 4; +methionine plate). Similar results were obtained when a HA-NLS-GDM protein was used (data not shown). These results indicate that the At1g28480 protein can facilitate dimer formation between two TGA2.2 factors in yeast. However, it was not clear whether the observed effect is related to ternary complex formation between the three proteins or is due to other unknown mechanisms. 


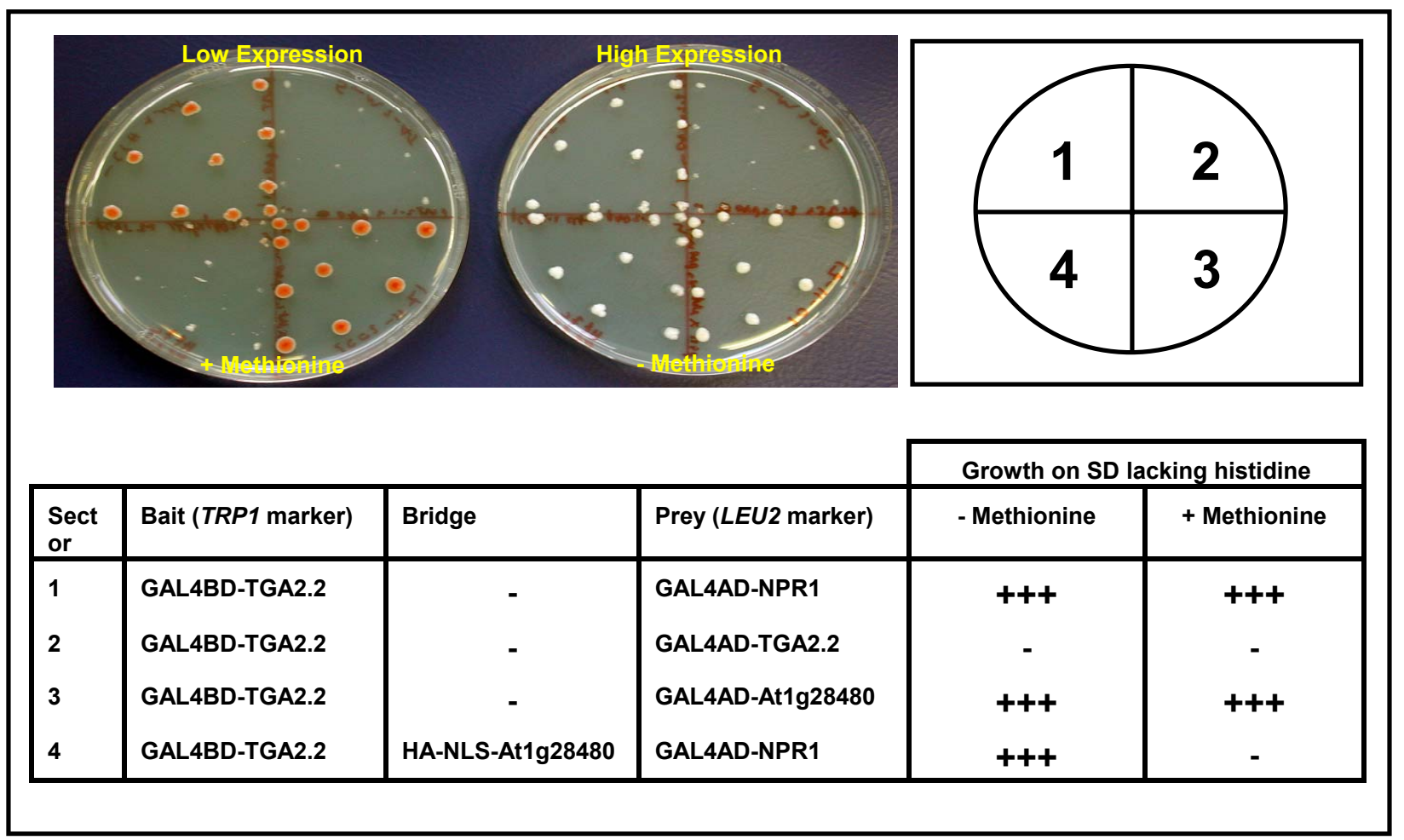

Figure 6.34. Y2HS assays of interactions between At1g28480 and TGA2.2 proteins.

HF7c cells containing pGBT9/TGA2.2 + pGAD424/NPR1 (1), pGBT9/TGA2.2 + pGAD424/TGA2.2 (2), pGBT9/TGA2.2 + pGAD424/At1g28480 (3) and pBDTGA2.2/Met25::At1g28480 + pGAD424/TGA2.2 (4) plasmids, were grown for 3 days at $30{ }^{\circ} \mathrm{C}$ on selective SD medium lacking leucine, tryptophan and histidine supplemented with $5 \mathrm{mM} 3-\mathrm{AT}$.

To understand how At1g28480 affects TGA2.2 interaction, the DNA binding activity of the TGA2.2 protein expressed in yeast was examined. EMSA assay was conducted using native protein extracts made from HF7c yeast cells expressing TGA2.2 alone (encoded in pLEU/Met25::TGA2.2) or coexpressing TGA2.2 and At1g28480 (encoded in pBD/Met25::At1g28480). As expected, a retarded band corresponding to TGA2.2 was present in the binding mixture from both protein extracts (Figure 6.35A). The retarded band is most likely formed by the specific binding of TGA2.2 to the as-1 element as incubation of the as-1 element with a yeast extract expressing At1g28480 alone did not yield any retarded band (data not shown). The coexpression of TGA2.2 and At1g28480 cause a substantial increase in the amount of TGA2.2 complex formed on the as-1 element when compared with yeast cell extract expressing TGA2.2 alone (Figure 6.35A). 
A)

$$
\begin{array}{llll}
1 & 2 & 3 & 4
\end{array}
$$

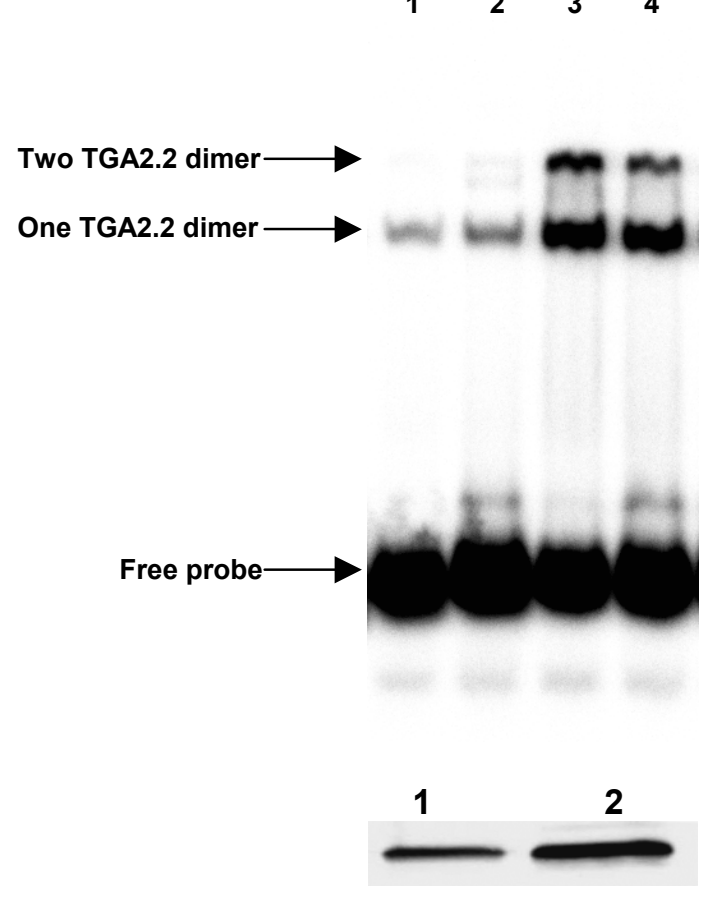

Figure 6.35. At1g28480 enhances indirectly the in vitro binding of TGA2.2 to as-1 element by increasing TGA2.2 expression levels in yeast.

A) EMSA analysis of TGA2.2 binding to as-1 element.

$20 \mu \mathrm{g}$ of yeast native protein extracts expressing TGA2.2 (lanes 1 and 2) or coexpressing TGA2.2 and At1g28480 (lane 3 and 4) were incubated with as-1 radioactive probes, and the mixtures were loaded on native PAGE gel. The protein-DNA complexes were detected by autoradiography.

B) Protein gel analysis of TGA2.2 protein expression levels in HF7c yeast cells.

$20 \mu \mathrm{g}$ of yeast native protein extracts expressing TGA2.2 (lanes 1) or coexpressing TGA2.2 and At1g28480 (lane 2) were analyzed on a $12 \%$ SDS-polyacrylamide transferred to a nitrocellulose membrane, and then immunoblotted with TGA2.2 antibody.

Surprisingly, the protein extracts from yeast cells coexpressing TGA2.2 and At1g28480 showed higher expression levels (about $\sim 3$ fold higher) of the TGA2.2 protein as compared with extracts expressing TGA2.2 alone (Figure 6.35B). These findings indicate that At1g28480, through unknown mechanism, increases TGA2.2 expression levels and thereby leads indirectly to a higher DNA binding activity of the TGA2.2. 


\subsubsection{At1g28480 Interacts via TGA2.2 with NPR1 in Yeast}

In order to investigate possible interactions between At1g28480, TGA2.2 and NPR1, i.e., ternary complex formation, the interaction between the three proteins was examined in Y3HS experiments. The yeast strain HF7c was then transformed with constructs expressing TGA2.2, GAL4BD-At1g28480 and GAL4AD-NPR1. The TGA2.2 protein was expressed conditionally as a third protein using the Met25::TGA2.2::PGK cassette. The Met25::TGA2.2::PGK cassette was cloned into the pGBT9/At1g28480 and pGBT9/GDM plasmid. The newly cloned plasmids were designated pBDAt1g28480/Met25::TGA2.2 and pBDAt1g28480/Met25::TGA2.2, respectively.

As expected, no interaction between GAL4BD-At1g28480 and GAL4AD-NPR1 was observed in yeast (Figure 6.36, sector 2). Also, the coexpression of GAL4BDAt1g28480 with TGA2.2 didn't lead to any reporter gene activation (Figure 6.36, sector 5). When the yeast cells expressed the TGA2.2, GAL4BD-At1g28480 and GAL4AD-NPR1, a robust growth in medium lacking histidine was observed (Figure 6.36, sector 6). Noticeably, low TGA2.2 expression levels have also reinforced the formation of a ternary complex (Figure 6.36, sector 6, + methionine). Also the GAL4BD-GDM protein was able to form ternary complex with NPR1 and TGA2.2 (?, sector 4). These findings would suggest that the At1g28480 is able to interact with NPR1 in the presence of TGA2.2, however it is not clear whether the interaction nature is direct or indirect one.

In order to determine whether other TGA transcription factors involved in ternary complex formation, TGA1 was used instead of TGA2.2 in the described Y3HS. TGA1 was selected because previous studies indicates that it does not interact with NPR1 in the Y2HS (Section 1.9). The coexpression of GAL4BD-At1g28480 with TGA1 alone leads to HIS3 reporter gene activation. Based on this observation it was not feasible to distinguish if there is any ternary complex formed between the three proteins on a histidine prototrophy assay. To overcome this obstacle, An ONPG assay was conducted to quantify the lac-Z reporter gene activity. Cells expressing the TGA1, GAL4BD-At1g28480 and GAL4AD-NPR1 proteins had higher lac-Z reporter gene activity as compared to cells expressing the GAL4BD-At1g28480 and TGA1 proteins 
(Table 6.4, no. 3). These results would suggest that the TGA1 is able to interact with NPR1 via At1g28480. However, in domain swap experiments the interaction between GAL4BD-NPR1, TGA1 and GAL4AD-At1g28480 was lost, adding many question marks on the nature of the TGA1-NPR1 interaction in yeast systems.
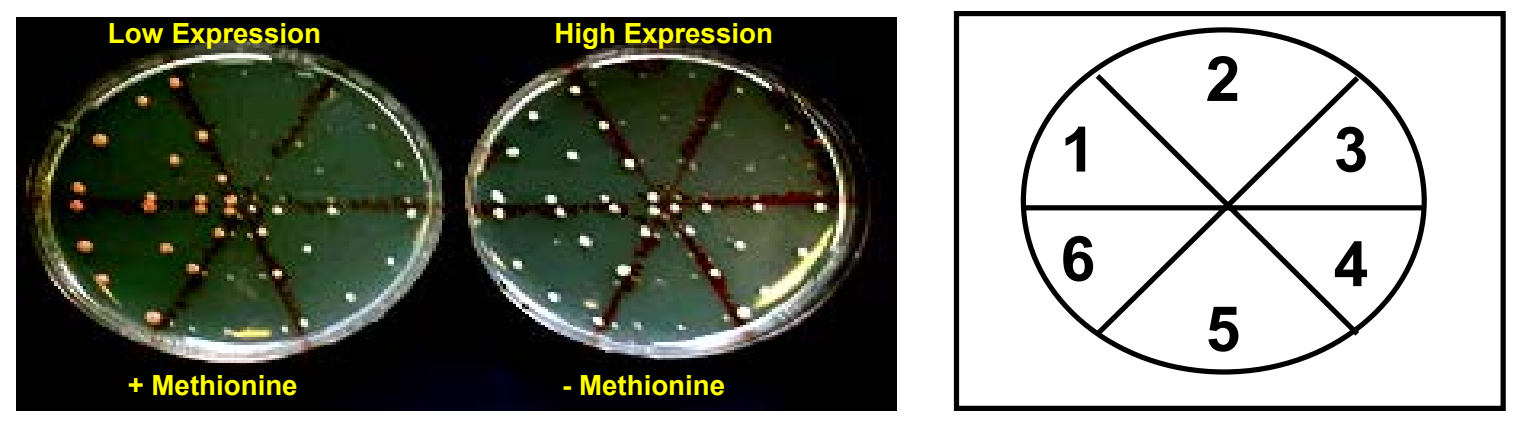

\begin{tabular}{|c|c|c|c|c|c|}
\hline \multirow[b]{2}{*}{ Sector } & \multirow[b]{2}{*}{ Bait (TRP1 marker) } & \multirow[b]{2}{*}{ Bridge } & \multirow[b]{2}{*}{ Prey (LEU2 marker) } & \multicolumn{2}{|c|}{ Growth on SD lacking histidine } \\
\hline & & & & - Methionine & + Methionine \\
\hline 1 & GAL4BD-TGA2.2 & - & GAL4AD-NPR1 & +++ & +++ \\
\hline 2 & GAL4BD-At1g28480 & - & GAL4AD-NPR1 & - & - \\
\hline 3 & GAL4BD-GDM & TGA2.2 & GAL4AD & - & - \\
\hline 4 & GAL4BD-GDM & TGA2.2 & GAL4AD-NPR1 & +++ & ++ \\
\hline 5 & GAL4BD-At1g28480 & TGA2.2 & GAL4AD & - & - \\
\hline 6 & GAL4BD-At1g28480 & TGA2.2 & GAL4AD-NPR1 & +++ & +++ \\
\hline
\end{tabular}

Figure 6.36. At1g28480 interacts with NPR1 via TGA2.2 in HF7c yeast strain.

HF7c cells containing pGBT9/TGA2.2 + pGAD424/NPR1 (1), pGBT9/At1g28480 + pGAD424/NPR1 (2), pBDGDM/Met25::TGA2.2 + pGAD424 (3), pBDGDM/Met25::TGA2.2 + pGAD424/NPR1 (4), pBDAt1g28480/Met25::TGA2.2 + pGAD424 (5) and pBDAt1g28480/Met25::TGA2.2 + pGAD424/NPR1 (6) plasmids, were grown for 3 days at $30{ }^{\circ} \mathrm{C}$ on selective SD medium lacking leucine, tryptophan and histidine, supplemented with $5 \mathrm{mM} 3-\mathrm{AT}$.

Table 6.4. Interaction of TGA1, At1g28480 and NPR1 in HF7c yeast strain.

HF7c cells containing pGBT9/At1g28480 + pGAD424/NPR1 (1), pBDAt1g28480/Met25::TGA1+ pGAD424 (2) and pBDAt1g28480/Met25::TGA1+ pGAD424/NPR1 (3) plasmids were grown on SD medium (lacking methionine) to an OD 600 of 0.6 and were processed and lac- $Z$ activity was measured as described in methods.

\begin{tabular}{|l|l|c|l|c|}
\hline Number & Bait (TRP1 marker) & Bridge & Prey (LEU2 marker) & B -Galactosidase units \\
\hline 1 & GAL4BD-At1g28480 & - & GAL4AD-NPR1 & 0.30 \\
2 & GAL4BD-At1g28480 & TGA1 & GAL4AD & 2.5 \\
3 & GAL4BD-At1g28480 & TGA1 & GAL4AD-NPR1 & 5.5 \\
\hline
\end{tabular}




\subsubsection{At1g28480 Transactivation Assays in Protoplasts}

In order to assess the effect of At1g28480 protein on as-1 element-dependent reporter gene transcription activation, transient assays using BY-2 protoplasts were conducted. The effector plasmid HBTL/At1g28480 was constructed by inserting the At1g28480 full-length coding sequence downstream of the HBT chimeric promoter (Figure 6.37A). The HBTL/At1g28480 and HBTL (control) plasmids were cotransfected separately with the as-1-GUS reporter plasmid into tobacco BY-2 protoplasts. In comparison with the control, the At1g28480 protein had repressed the as-1-GUS reporter gene activity (Figure 6.37B).

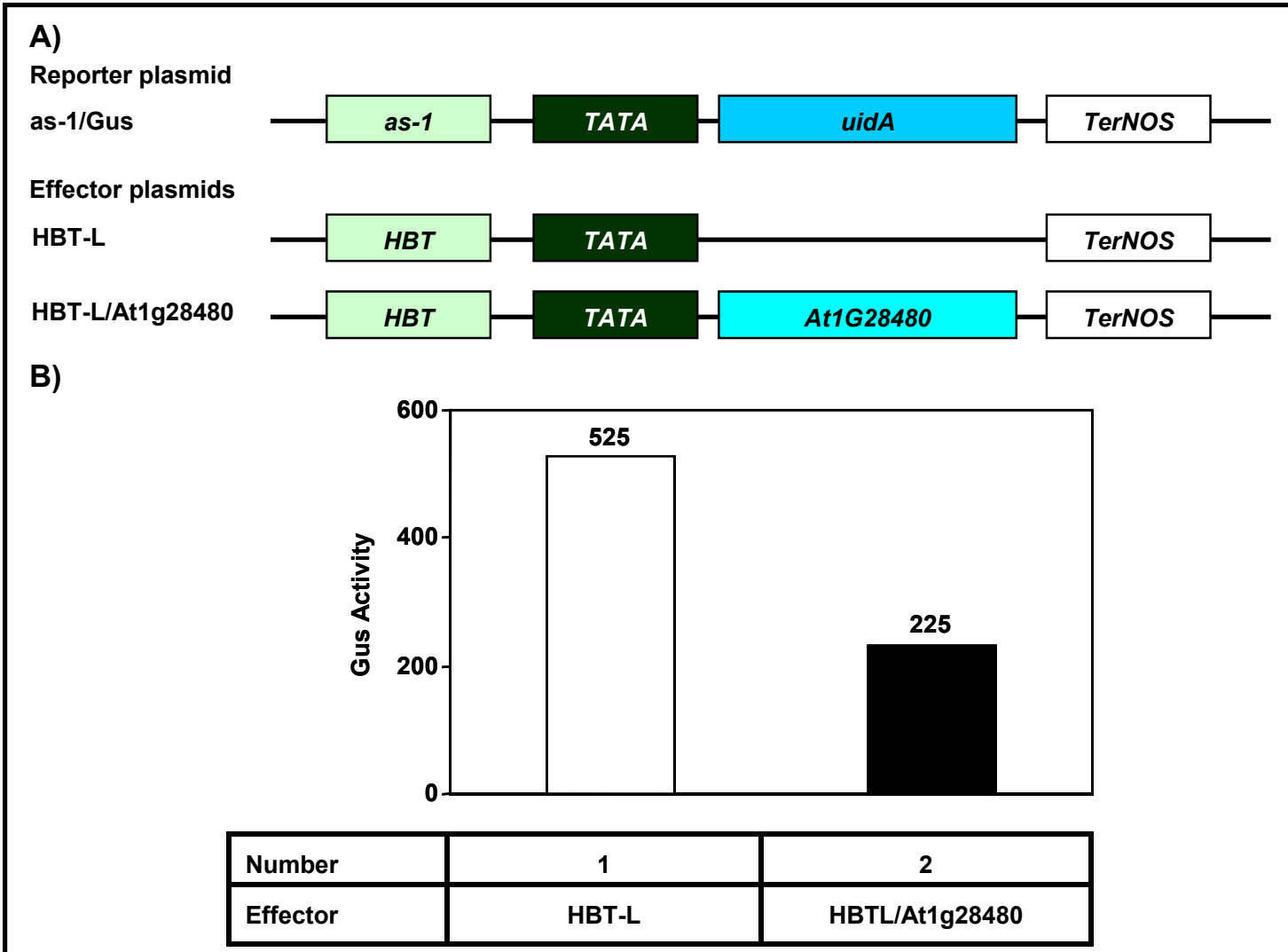

Figure 6.37. Transactivation assay of At $1 \mathrm{~g} 28480$ in BY-2 protoplasts.

A) Schematic diagram of the effector and reporter plasmids used in cotransfection experiments.

B) Transactivation of the as-1::GUS fusion reporter gene by At1g28480 protein.

The reporter gene was cotransfected with $10 \mu \mathrm{g}$ of as-1-GUS reporter and $25 \mu \mathrm{g}$ of At1g28480 effector plasmid or the empty vector as control treatment. GUS Activity was estimated as described in methods. 
The At1g28480 repression effect is most likely due to a toxic effect on the BY-2 protoplast. In consistent with this assumption, transient assay using the $5 x$ $U A S^{G A L 4}::$ uidA reporter gene and its positive control GAL4BD-VP16 effector (strongly activate the $5 x \cup A S^{G A L 4}:$ :uidA reporter gene), a similar repression effect was observed with this control system, indicating a general toxic effect on the BY-2 protoplasts (data not shown).

\subsubsection{Interaction between At1g28480 and TGA2.2 In planta}

To determine whether the direct physical interactions between TGA2.2 and At1g28480 protein could be accomplished by other means rather than yeast hybrid systems, the interaction between both proteins was assessed using a protoplast transient assay similar to the $\mathrm{Y} 2 \mathrm{HS}$. This method was deployed after the failure to detect any TGA2.2 and At1g28480 protein complex using the conventional in vitro assays described above. For this purpose, the At1g50570 full-length coding sequence was ligated in-frame with the GAL4BD coding sequence downstream of the HBT chimeric promoter into the HBT-L plant expression vector. This bait effector plasmid was designated as HBTL/GAL4BD-At1g28480 (Figure 6.38A). The TGA2.2-VP16 coding sequence was cloned downstream of the HBT chimeric promoter into the HBT-L vector, designated as HBT-2.2VPs, was used as an effector prey plasmid (Figure 6.38A; Tharow, 2002).

The described effector plasmids were cotransfected into BY-2 protoplasts, and the At1g28480-TGA2.2 interaction was assayed for the expression of a $5 x$ $U A S^{G A L 4}:$ uidA reporter gene. BY-2 protoplast were also transfected with the reporter gene along with the effector constructs pUC18/GAL4BD, HBTL/GAL4BD-At1g28480 and HBT-2.2VPs separately to serve as internal controls. Protoplasts cotransfected with the reporter plasmids along with GAL4DB-At1g28480 and TGA2.2-VP16 constructs showed a substantial and distinguishable increase of GUS reporter gene activity as compared with other controls (Figure 6.38B, no. 4). These results indicate that TGA2.2 can interact with At1g28480 in planta. 


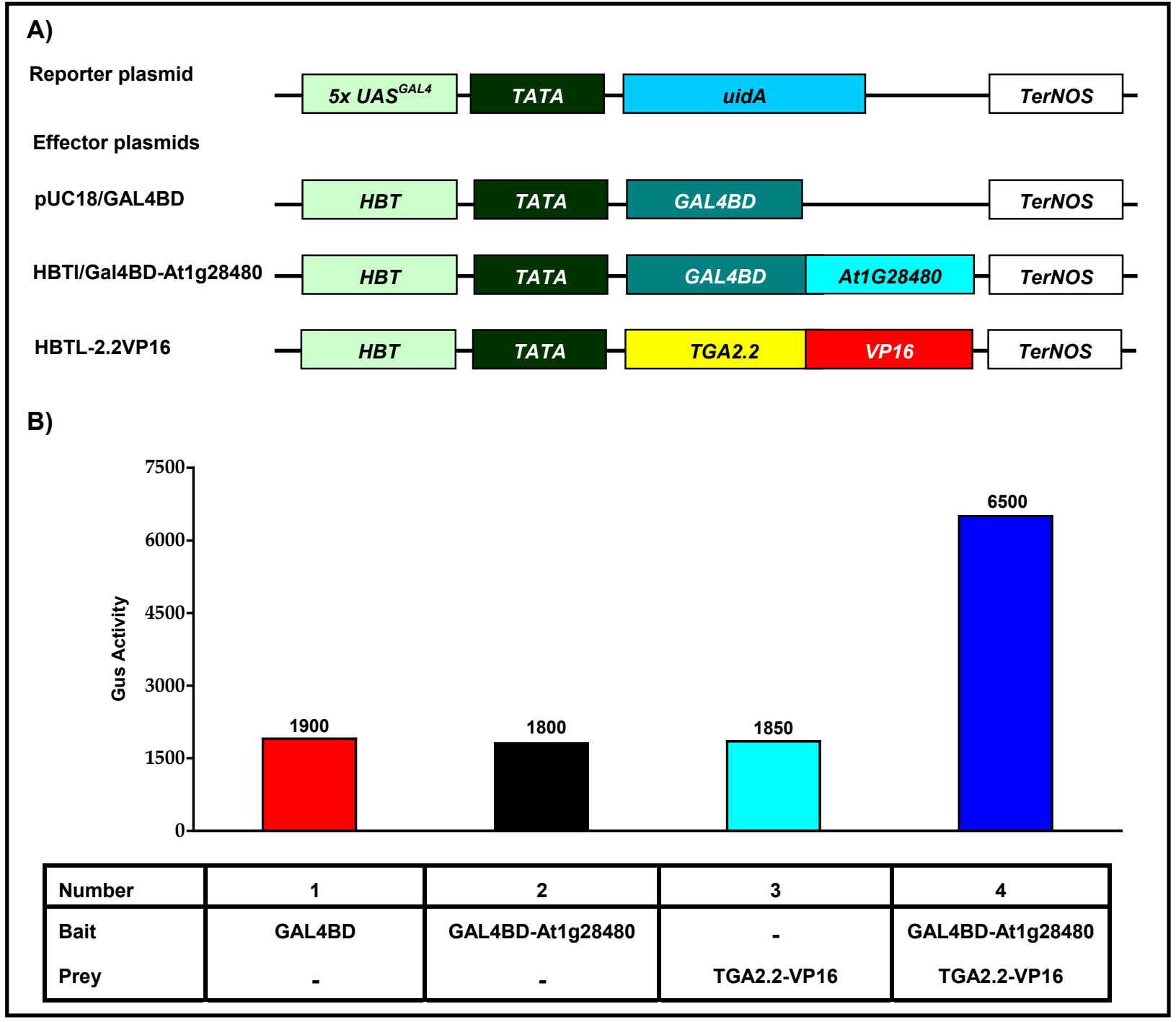

Figure 6.38. At1g28480 interacts with TGA2.2 in BY-2 protoplasts.

$10 \mu \mathrm{g}$ of $5 x \cup A S^{G A L 4}$-uidA reporter gene plasmid were transfected with $25 \mu \mathrm{g}$ pUC18/GAL4BD, $25 \mu \mathrm{g}$ HBTL/GAL4AD-At1g28480 and $25 \mu \mathrm{g}$ HBTL/TGA2.2-VP16 or cotransfected with $12.5 \mu \mathrm{g}$ HBTL/GAL4AD-At1g28480 + $12.5 \mu \mathrm{g}$ HBT-2.2VPs effector plasmids. $\beta$-Glucuronidase Activity estimated as described in methods.

\subsubsection{At1g28480 Subcellular Localization}

The subcellular localization of At1g28480 was assayed in BY-2 protoplasts as described above. The At1g28480 coding region was cloned into HBTL/GFP plasmid, inframe to the $5^{\prime}$ end of a GFP gene (Figure 6.39A). As a positive control, protoplasts were transfected with HBTL/GFP plasmid (Figure 5.39A). The At1g28480-GFP fusion protein was evenly distributed in the cytoplasm and the nucleus (Figure 6.39B). 
A)

At1g50570-GFP plasmid

B)

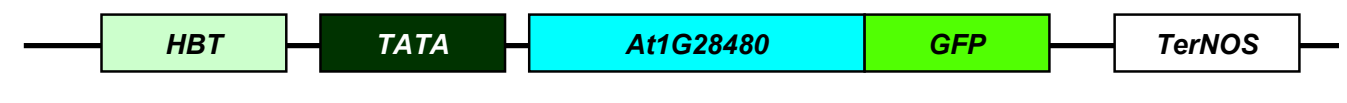

GFP At1g28480-GFP

Blue

White

Blue

White
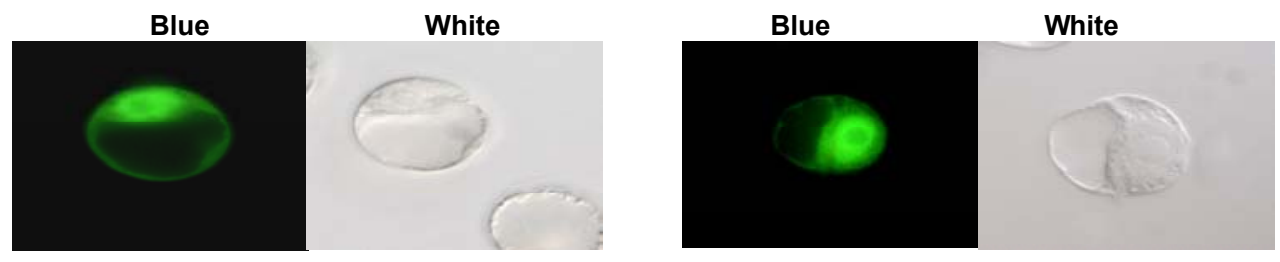

Figure 6.39. Subcellular localization of At1g50570-GFP protein.

A) Schematic diagram of HBTL/At1g28480-GFP plasimd used in subcellular localization experiments.

B) BY-2 protoplasts expressing GFP and At1g28480-GFP.

BY-2 protoplasts were transfected with the GFP and At1g28480-GFP constructs, and was visualized using a BX 51 fluorescent microscope using the blue and white light fields.

\subsubsection{Expression Analysis of At1g28480 Gene}

In order to analysis the At1g28480 tissue-specific expression patterns, gene transcripts from different organs were analyzed using the RT-PCR method. At1g28480 mRNA was detected in flowers, siliques, inflorescence stems, and rosette leaves, and roots, indicating the presence of At1g28480 transcripts in all Arabidopsis plant tissues (Figure 6.40). The actin RT-PCR reactions were used as described above (section 5.4.6).

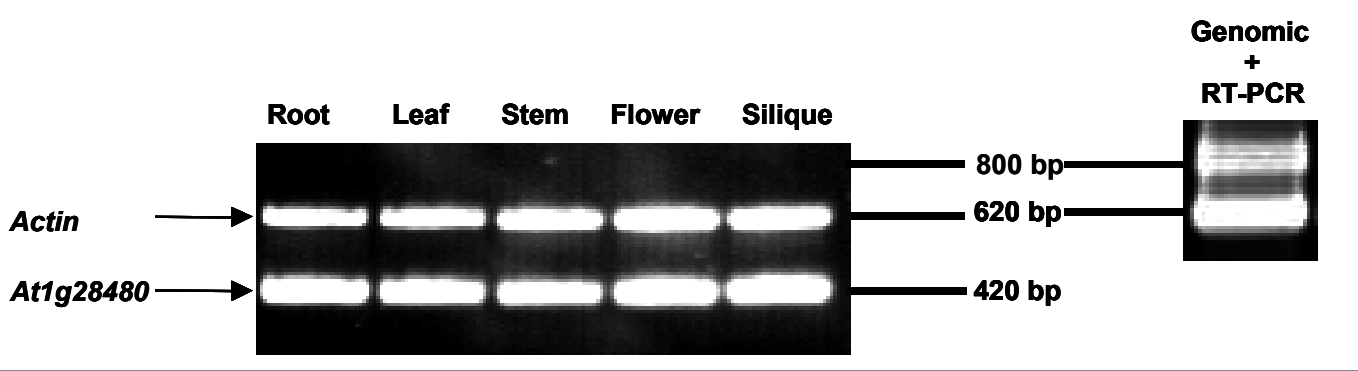

Figure 6.40. Detection of At1g28480 mRNA in different Arabidopsis tissues by RT-PCR.

Total RNA isolated from 4 weeks old plants parts (roots, leaves, stems, flowers and siliques) were detected for At1g28480 mRNA transcripts using RT-PCR. The actin control is shown at the bottom of the gel. A PCR control reaction for actin using genomic DNA and one of the RT-PCR products is shown on the left. 
The expression of At1g28480 in response to SA treatment and P. syringae pv. maculicola ES4326, with or without the avrRpt2 $R$ gene, pathogen challenging was analyzed using RNA blot analysis. Plants sprayed with $1 \mathrm{mM} \mathrm{SA}$ for 2 hours showed significant higher At1g28480 mRNA accumulation compared to untreated plants, whereas after 24 hours of SA treatment At1g50570 mRNA accumulation was simliar as untreated plants (Figure 6.41). Inoculation with the $P$. syringae, virulent or avirulent strain, led to an increase in the expression of At1g28480 starting $12 \mathrm{hr}$ after pathogen inoculation up to $24 \mathrm{hr}$ and then decreasing during the next $48 \mathrm{hr}$ (Figure 6.41). After $P$. syringae, virulent infection, At1g28480 was induced earlier than $P R-1$, whose transcription was maximal after $24 \mathrm{hr}$ (Figure 6.41). These results indicate that the transcription of the At1g28480 gene is strongly activated by SAR inducers.

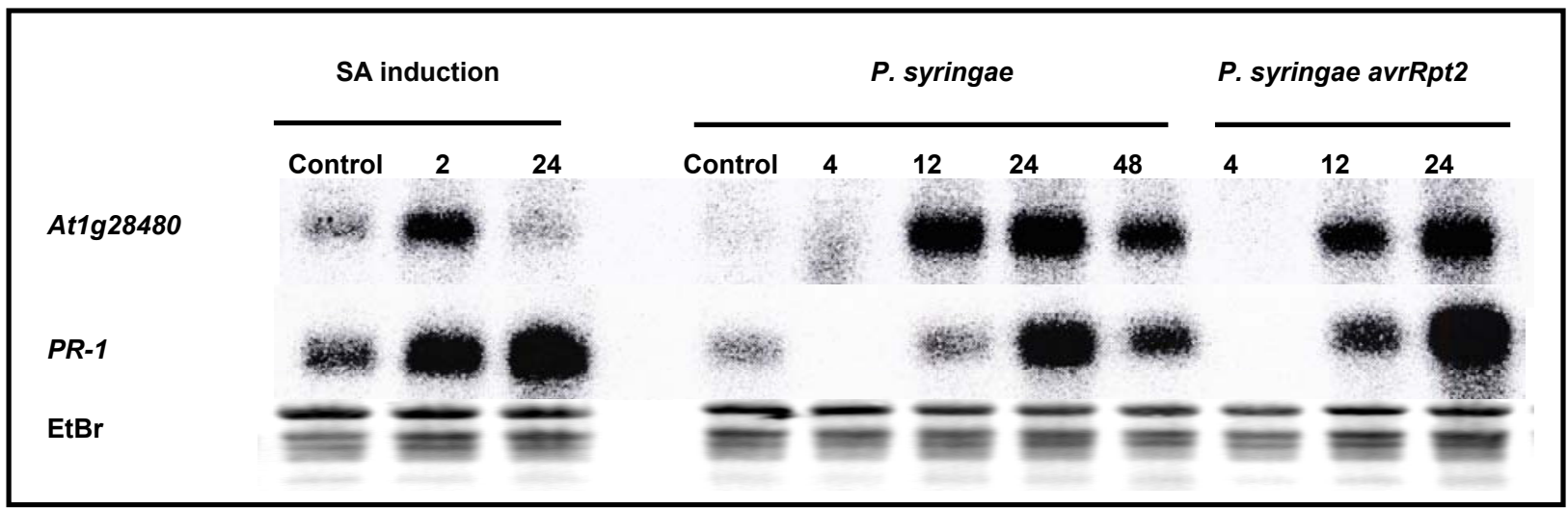

Figure 6.41. RNA gel blots analysis of At1g28480 gene expression after SA or pathogen treatments.

Arabidopsis plants were grown for 4 weeks on soil before spraying with $1 \mathrm{mM} \mathrm{SA}$ or challenged with $P$. syringae pv. maculicola ES4326 with or without the avrRpt2 R gene. Total RNA was isolated from plants at different time points (in hours) and $10 \mu \mathrm{g}$ were separated on denaturing gels in the presence of ethidium bromide $(\mathrm{EtBr})$, photographed to assess equal loading, and examined by Northern blot analysis. A radioactive At1g28480 and PR-1 full-length cDNA probes were hybridized to the membrane, which was then examined by autoradiography.

\subsubsection{Analysis of the In Vivo Roles of At1g28480 by Generation of At1g28480 Antisense Lines}

To determine if At1g28480 has a role in the SA-mediated gene expression signaling, suppression of At1g28480 gene expression in plants via antisense (RNAi) 
approach was conducted. For this purpose, the full-length cDNA fragment of At1g28480 was cloned into the pFGC5941 vector in the sense and antisense orientations (Figure 6.42A). The pFGC5941/At1g28480 vector was transformed into the Arabidopsis -90GUS transgenic plants using the flower dip method. The transformed plants were selected by spraying them with Basta herbicide.

RNA blot analysis was used to analysis the At1g28480 RNA levels in T2 segregating lines after SA treatment for four hours in comparison to the wild type control. In contrary to the At1g28480 RNA transcripts from the control plant that showed a clear band for At1g28480, the antisense lines didn't showed any distinguishable band corresponding to the At1g28480 gene transcripts (Figure 6.42B). The RNA blot analysis was repeated twice with similar At1g28480 transcripts pattern in the antisense lines.

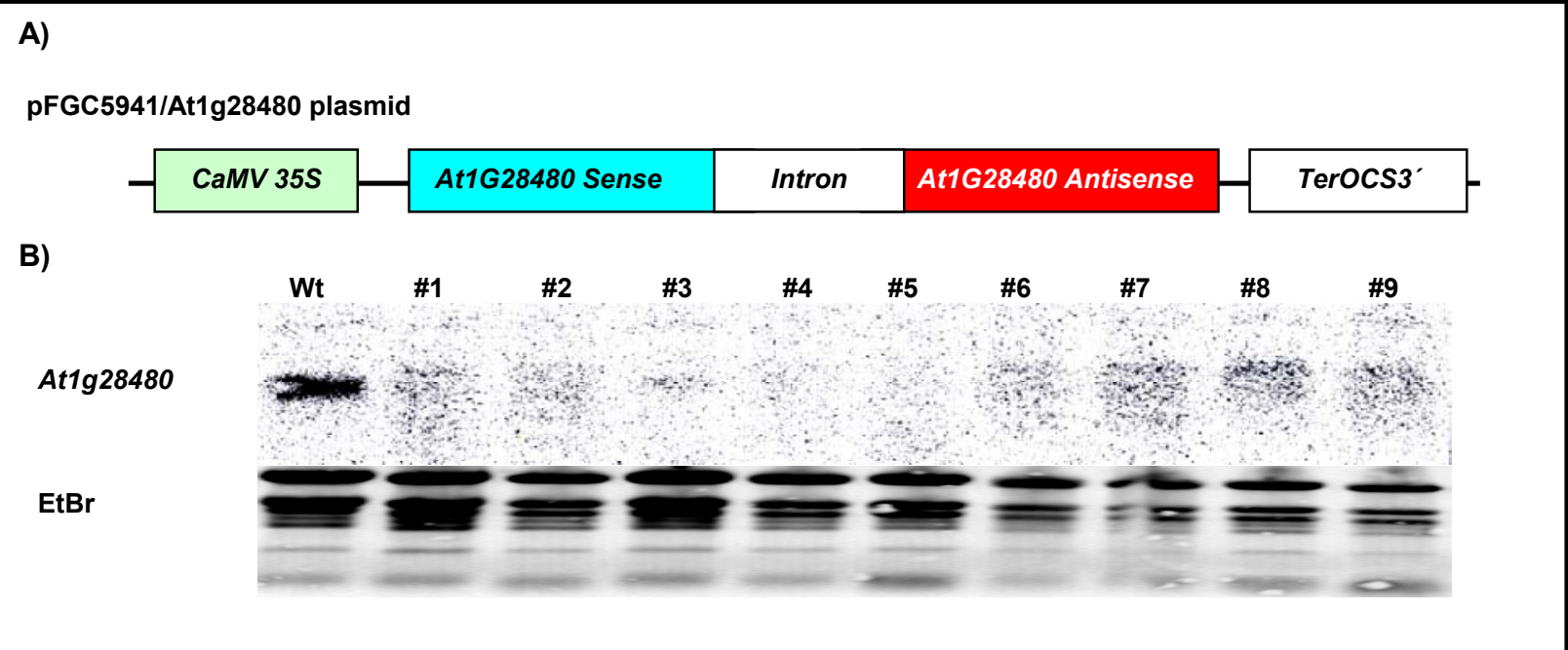

Figure 6.42. Analysis of $A t 1 g 28480$ gene expression in different At1g28480 antisense lines.

A) Schematic diagram of pFGC5941/At1g28480 antisense plasmid used in the generation of antisense plants.

B) RNA gel blots analysis of At1g28480 gene expression in different At1g28480 antisense lines.

Plants were grown for 4 weeks on soil and total RNA was isolated from Arabidopsis -90-GUS plants (control) and Arabidopsis At1g28480 antisense lines. $7.5 \mu \mathrm{g}$ were separated on denaturing gels in the presence of ethidium bromide (EtBr), photographed to assess equal loading, and examined by Northern blot analysis. A radioactive At1g28480 full-length cDNA probe was hybridized to the membrane, which was then examined by autoradiography. 
The expression of $P R-1$ gene in response to SA induction in the At1g28480 antisense lines was examined. The SA-induced $P R-1$ expression after 24 hours was not affected in At1g28480 antisense lines as compared to the wild type plants (Figure 6.43). These results indicated that the At1g28480 transcript suppression didn't have any effect on the $P R-1$ gene expression.

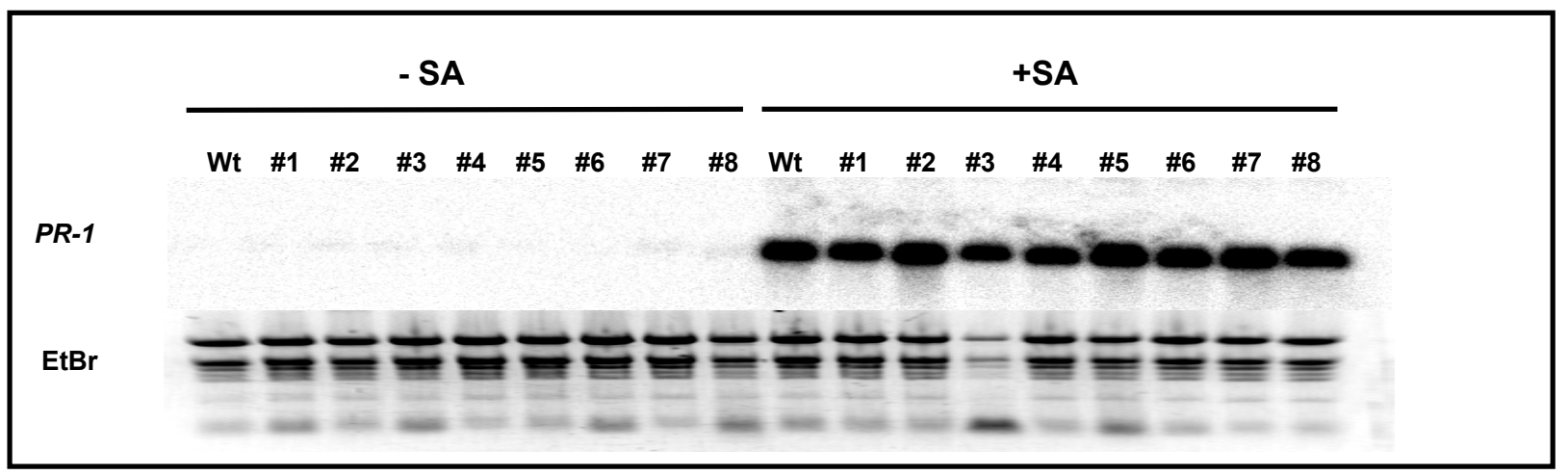

Figure 6.43. RNA gel blots analysis of $P R-1$ gene expression in At1g28480 antisense lines.

Plants were grown for 4 weeks on soil before inducing them with $1 \mathrm{mM} \mathrm{SA}$ for 24 hours. Total RNA was isolated from untreated and SA treated plants and $10 \mu \mathrm{g}$ were separated on denaturing gels in the presence of ethidium bromide (EtBr), photographed to assess equal loading, and examined by Northern blot analysis. A radioactive PR-1 cDNA probe was hybridized to the membrane, which was then examined by autoradiography.

\subsubsection{Analysis of the In Vivo Roles of At1g28480 by Generation of At1g28480 Overexpressor lines}

To examine the effect of At1g28480 overexpression on the SA-dependent gene expression in Arabidopsis plant, -90-GUS transgenic plants were transformed with the Alligator2/At1g28480 binary vector harboring a $3 x H A$ tag sequence fused in-frame to the At1g28480 coding sequence (Figure 6.44A). Protein gel blot analysis of T1 At1g28480 overexpressors lines, showing GFP fluorescent seeds, using a HA specific antibody revealed that lines \#3, \#4 and \#6 accumulates higher protein levels compared with the wild type (Figure 6.44B).

Interestingly, the T1 At1g28480 overexpression line \#7 plant showed a distinguishable phenotype as compared with the -90-GUS transgenic plants (Figure 6.44C). The At1g28480 overexpression line \#7 plant has phenotype of an uneven or 
irregular leaf shape, cotyledon epinasty, late flowering time and crinkled fruits. Examining T2 seeds for the segregation of the T-DNA insertion revealed that the TDNA insertion and the corresponding phenotype segregated together (3:1 ratio). It is possible that this phenotype is related to a T-DNA insertion mutation rather than to At1g28480 overexpression effect. Based on the previous analysis, the At1g28480 overexpressor line \#6 was selected for further analysis.

A)

Alligator2/At1g28480 plasmid

\begin{tabular}{|c|c|c|c|c|c|c|}
\hline $2 \times 35 S$ & $3 \times H A$ & At1G28480 & TerNOS & Ter35S & GFP & At2S3 \\
\hline
\end{tabular}

B)

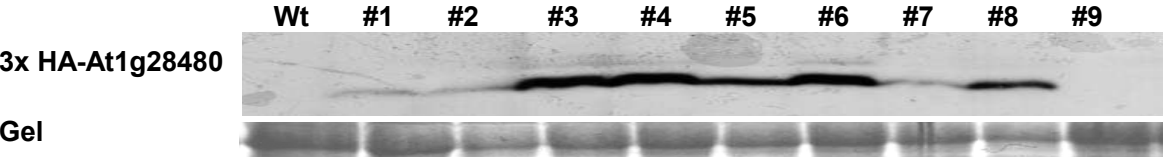

C)

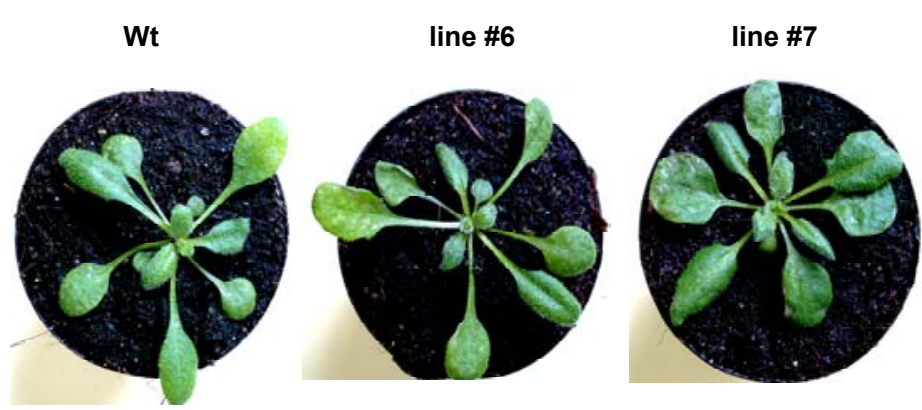

Figure 6.44. Analysis of At1g50570 overexpression lines.

A) Schematic diagram of Alligator2/At1g28480 plasmid used in the generation ofAt1g28480 overexpressor lines.

B) Protein gel blot analysis using aHA antibody of 3x HA-At1g28480 levels in Alligator2/At1g28480 transgenic lines. Coomassie stained gel serve as loading control

C) Alligator2/At1g28480 transgenic lines phenotypes.

The effect of the At1g28480 overexpression on the expression of genes induced by SA was examined. The expression patterns of GST6 and PR-1 after SA treatment were examined in the At1g28480 overexpressor line \#6 plants and were then compared 
to those of wild type plants. At1g28480 overexpression didn't have any significant effect on the SA-inducible gene expression (Figure 6.45A and B).

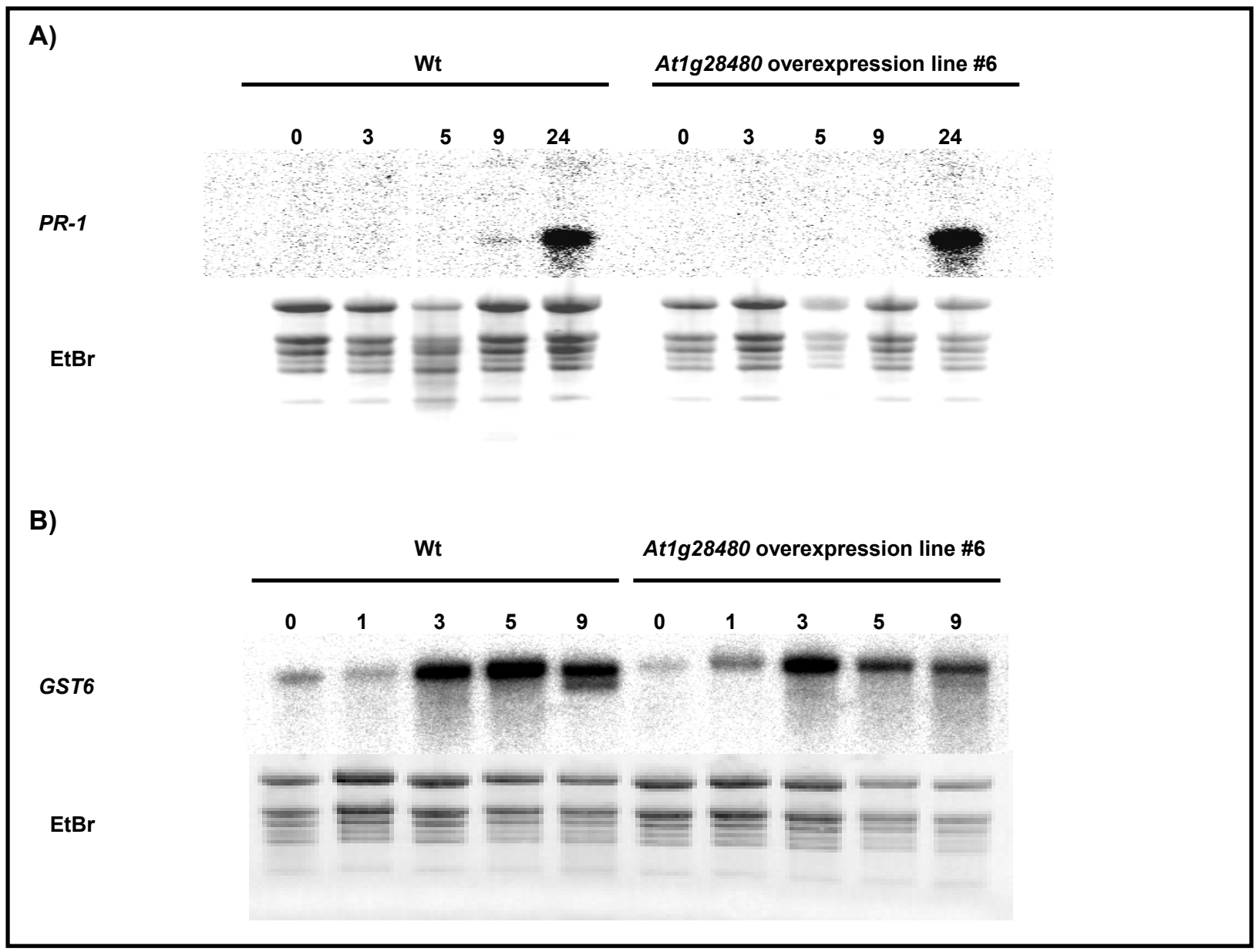

Figure 6.45. RNA gel blots analysis of PR-1 and GST6 expression in At1g28480 overexpressor line \#6.

Plants were grown for 4 weeks on soil before spraying with $1 \mathrm{mM} \mathrm{SA}$. Total RNA was isolated from plants at different time points (in hours) and $10 \mu \mathrm{g}$ were separated on denaturing gels in the presence of ethidium bromide (EtBr), photographed to assess equal loading, and examined by Northern blot analysis. A radioactive PR-1 (A) and GST6 (B) cDNA probes were hybridized to the membrane, which was examined by autoradiography.

The expression pattern of the GUS reporter gene was analyzed using histochemical GUS staining in At1g28480 overexpressor lines and in the wild-type background after 2,4-D treatment. As expected, the as-1-dependent reporter gene expression was activated after 2,4-D treatments in the wild type background (Figure 
6.46). However, the 2,4-D inducible expression pattern of as-1::GUS in At1g28480 overexpressor line \#3 was severely repressed when compared with that of -90-GUS plants. In conclusion, it is seems that the At1g28480 overexpression had led to repress auxin-dependent gene expression.

-90-GUS

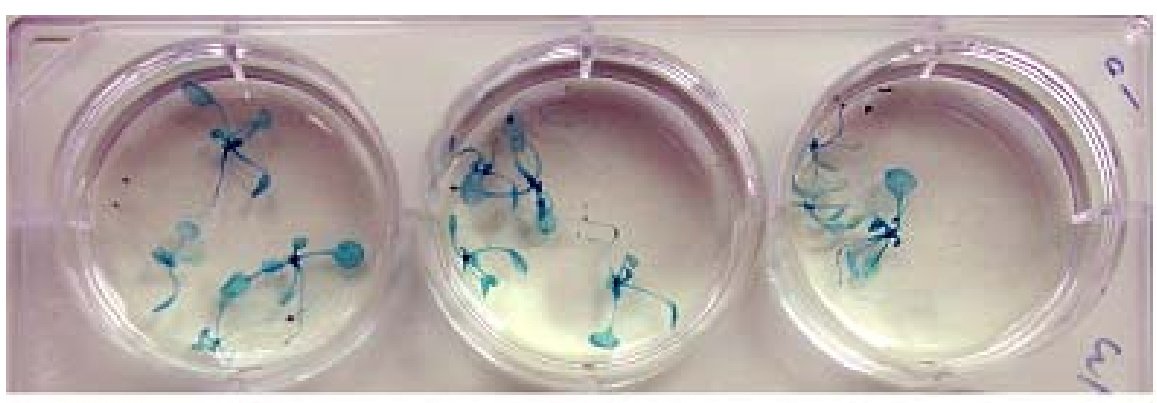

$0.1 \mathrm{mM} 2,4-\mathrm{D}$

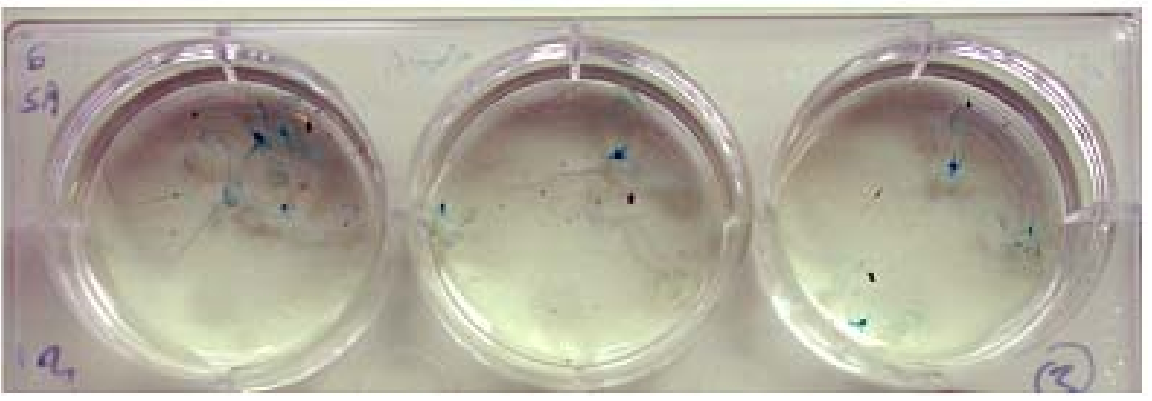

Figure 6.46. Histochemical staining of GUS activities in At1g28480 overexpression line \#3.

Two weeks soil grown -90-GUS transgenic and At1g28480 overexpression line \#3 plants were treated with 0.1 mM 2,4-D for 24 hours and then stained for GUS. 


\section{Discussion}

\subsection{The MY1HS as a Method to Isolate TGA2.2 Partners}

TGA2.2 is a transcription factor that mediates SA- and auxin- regulated gene expression. Being expressed constitutively, the activity of TGA2.2 must be regulated by either post-transcriptional modification or protein-protein interactions. Based on evidence for the later mechanism (Jupin and Chua, 1996; Stange et al., 1997), we tried to identify regulatory proteins that can interact with TGA2.2. A MY1HS strategy was established and employed using a TGA2.2 bait protein bound to an as-1 element found upstream of a HIS3 reporter gene, to screen a cDNA expression library from Arabidopsis and tobacco vegetative tissues for interacting proteins.

Recently, several different yeast hybrid screens were conducted in our group to isolate TGA interacting partners. For instance, Thurow (2002) was successful in isolating a tobacco NPR1 homolog using TGA2.1-GAL4BD as a bait in a classical Y2HS approach. In another approach, utilizing TGA2.1 in a split-protein sensor system that is based on the reconstitution of ubiquitin-mediated cleavage of a reporter protein, a DEAD box RNA-helicase and an E2 ligase were identified as TGA2.1-interacting partners (Krawczyk, 2003). Siemsen (2002) identified a scarecrow-like transcription factor that acts as a putative TGA2 coactivator protein using a MY1HS that utlized TGA2 from Arabidopsis as a bait protein and an Arabidopsis cDNA library, which was not fused to any activation domain.

In order to identify TGA2.2-interacting proteins, a MY1HS that utilizes TGA2.2 bound to the as-1 element was deployed (Figure 6.1). This novel screening method should identify prey proteins that are able to interact with TGA2.2 bait protein to assemble an as-1 bound activation complex, which will lead to the activation of a reporter gene. Similar approaches, termed as the one-and-a-half hybrid system (Serebriiskii et al., 2001), were described previously in a number of instances, such as 
the identification of regulatory proteins that are involved in activation of ftz-dependent promoters (Yu et al., 1999).

The MY1HS screening conditions were optimized to work with established positive controls. Bait protein expression is considered to be a limiting criterion before performing any yeast hybrid screen (Toby and Golemis, 2001). The TGA2.2 bait protein was under the control of the Met25 promoter cassette that can regulate the transcription of the TGA2.2 coding sequence upon adding or omitting methionine in the culture medium, i.e., an "on" or "off" switch system for the expression of the TGA2.2 bait protein. TGA2.2 overexpression was toxic to the YRWH2 screening strain. The problem was resolved by lowering TGA2.2 expression levels in YRWH2 through methionine application to the screening media. The toxic effect of TGA2.2 on the YRWH2 cells might be due to TGA2.2 binding to other cis-elments found in yeast promoter regions. The quality of a cDNA library is critical to the success of any yeast hybrid screen. In the current study, the cDNA inserts (from the Arabidopsis and tobacco cDNA library plasmids) were driven by a truncated $A D H 1$ promoter. The weak expression of cDNA inserts is considered as a serious pitfall for any yeast hybrid screen (Agatep et al., 1998). The detection of protein expressed from the truncated $A D H 1$ promoter using an immunoblot analysis was not applicable.

The MY1HS screens were successful in identifying several TGA2.2-interacting proteins (Table 6.1 and Table 6.1). In this regard, it might be significant to mention that two types of cDNA clones were expected to activate reporter gene expression: those that bind directly to the as-1 element and those that interact directly with TGA2.2 but do not bind to the as-1 elements. In the MY1HS screens using the tobacco cDNA library, two TGA transcription factor-related cDNAs, TGA2.1 and TGA10 were isolated (Table 6.2). The observation that a TGA10 cDNA clone was isolated in the MY1HS using a cDNA library prepared from tobacco leaves suggests that the TGA10 mRNA might be expressed in vegetative tissues. However, RT-PCR and protein immunoblot expression analysis demonstrated that TGA10 is a root specific TGA transcription factor 
(Schiermeyer et al., 2003). Even though, it is necessary to conduct an independent expression analysis to confirm these results.

The MY1HS screens had identified other candidates that can interact with TGA2.2 without binding to the as-1 element. A screen with an Arabidopsis cDNA library yielded four putative TGA2.2-interacting candidates (Table 6.1). However, there were distinct and overlapping interaction patterns among the four putative candidates with the TGA transcription factors. For instance, the Y2HS experiments revealed that the isolated At4g00270 cDNA clone did not interacted with TGA2.2 prey protein when it was fused to the GAL4BD domain (data not shown). Among the isolated TGA2.2 interacting proteins, the focus was concentrated on the characterizing of two cDNA groups, groups 3 and 4, respectively (Table 6.1 and Table 6.1).

Group 3 cDNA inserts, encoding the At1g50570 and At5g55530 proteins, respectively, were selected for multiple reasons. First, both cDNA inserts encode for two homologous proteins. Second, the presence of the conserved C2 domain, which is involved in a variety of signal transduction pathways. Finally, the group interacts exclusively with the class-II of TGA factors. The group 4 cDNA insert, encoding the At1g28480 protein, was selected because of its ability to interact with all identified TGA factors, sequence similarity to glutaredoxins and its potential ability to mediate changes of the redox state of TGA factors.

\subsection{Functional Analysis of At1g50570 and At5g55530 Proteins}

Both the At1g50570 and At5g55530 proteins contain a typical C2 domain (Figure 6.8), which was originally identified in protein kinase $C$ and has been described in more than 60 proteins (Nalefski and Falke, 1996; Rizo and Südhof, 1998). Numerous genes encoding proteins with $\mathrm{C} 2$ domains are expressed in plants and are speculated to be involved in a variety of signal transduction pathways (Kopka et al., 1998).

Recently, Arabidopsis C2 domain containing proteins have been identified and their role as signalling proteins was confirmed (Jambunathan et al., 2001; Qin and 
Wang, 2002). For instance, a humidity-sensitive Arabidopsis mutant, which encodes a copin protein that contains two $\mathrm{C} 2$ domains, had an increased resistance to virulent bacterial and oomyceteous pathogens (Jambunathan et al., 2001). The amino acid sequences comparison of At1g50570 and At5g55530 with other sequences of different plant species such as tomato, potato, soybean, rice, maize and corn (http://tigr.org) revealed that the At1g50570 and At5g55530 amino acid sequences are conserved within the plant kingdom. In Arabidopsis, the amino acid sequences of At1g50570 and At1g55530 showed consensus amino acids similarity ( 38\%) to a third protein, known as At5g12300. The At5g12300 interaction with TGA2.2 was not studied, however, it might be possible that the three proteins have redundant functions.

Although the role of $\mathrm{C} 2$ domain in mediating protein-protein interactions is well documented (Rickman and Davletov, 2003; Zhang, 2003A), it is most likely that it is not involved in the At1g50570 and At5g55530 interactions with TGA2.2 because the At1g50570 cDNA isolated in the MY1HS, encodes a truncated protein that lacks 32 amino acids of the C2 domain. Probably, the interaction region is defined to the conserved regions that are found downstream of the $\mathrm{C} 2$ domain (Figure 6.8).

Transient expression of At1g50570-GFP protein in BY-2 protoplast revealed that the At1g50570-GFP was targeted to the nuclear envelope and to the endoplasmic reticulum (Figure 6.18). As TGA-factors are staidly localized to the nucleus, it has to be postulated that an interaction can only occur upon a stimulus that changes the localization of At1g50570. Indeed, the membrane binding activity of C2-domain containing phospholipid binding proteins can be changed in response to calcium. Usually, the $\mathrm{C} 2$ domain binds $\mathrm{Ca}^{2+}$ and mediates $\mathrm{Ca}^{2+}$-dependent membrane targeting of proteins, i.e., the $\mathrm{C} 2$ domain containing proteins under resting state (low $\mathrm{Ca}^{2+}$ levels) are dispersed in the cytoplasm and the nucleus (Cho, 2001). The activation of 5lipoxygenase protein involves its calcium-dependent translocation from the cytoplasm and the nucleus to the nuclear envelope via a C2-like domain (Kulkarni et al., 2002). In addition, there are $\mathrm{C} 2$ domains whose binding to membranes does not require calcium. Das et al., 2003, showed that C2 domain of PTEN, a tumor suppressor protein, was 
necessary and sufficient for the $\mathrm{Ca}^{2+}$-independent targeting of PTEN from cytoplasm and the nucleus to the plasma membrane. Intuitively, one can assume the presence of $\mathrm{C} 2$ domain-inducing conditions (high $\mathrm{Ca}^{2+}$ levels) for the BY-2 protoplasts that mediate the constitutive targeting of At1g50570-GFP to membranes. Experiments designed to observe a difference in At1g50570 localization upon addition of SA or auxin were unsuccessful. However, as protoplast represent de-differentiated cell with putatively notactive signal transduction pathways, experiments have to be repeated with onion epidermal cells, using particle bombardment technique.

The mRNA accumulation analysis suggests that At1g50570 transcripts are expressed constitutively in Arabidopsis plants (Figure 6.16 and Figure 6.17). The observed At1g50570 expression profile is in congruence with the presence of over 20 ESTs that show complete sequence identity with the At1g50570 gene and were isolated from different organs and challenged plants (http://arabidopsis.org). Time course experiments showed that the transcription of At1g50570 was not influenced by SA treatment (Figure 6.17). However, At1g50570 expression did increase moderately, when Arabidopsis plants were challenged with $P$. syringae (Figure 6.17). The At1g50570 response was late, appeared after 24 and 48 hours post pathogen infection, which resembles the induction kinetics of other SAR marker genes such as $P R-1$ gene (Figure 6.17 vs. Figure 6.41). Interestingly, in plants challenged with $P$. syringae virulent strain, the $P R-1$ transcripts accumulated transiently (start increasing after 12 hours, reached maximum after 24 and then decreased after 48 hours), whereas the At1g50570 mRNA continued to increase steadily after 12 hours from pathogen infection (Figure 6.17 vs. Figure 6.41). These observations might indicate that the At1g50570 is not involved in mediating the $P R-1$ gene accumulation in response to treatments that induce SAR signalling. However, it is possible that the observed At1g50570 transcript accumulation after pathogen challenge is mediating other resistance responses against pathogen rather than SAR.

The At1g50570 and At5g55530 proteins were demonstrated to function as transcriptional activators in yeast cells (Figure 5.11). These results strongly suggest 
that both proteins can mediate as-1-dependent gene activation by interaction with TGA2.2, i.e., once bound to the TGA2.2, At1g50570 and At5g55530 can act as coactivator that might be recruited to the general transcription machinery. The sequence analysis of the At1g50570 isolated cDNA insert revealed the absence of inframe fusion with the GAL4AD, indicating that the truncated At1g50570 protein was able to interact with TGA2.2 and to transactivate the reporter gene expression. This behavior of the At 1 g50570 truncated protein mimics the strategy used by Siemsen (2002), where a cDNA library that is not fused to any AD was used to identify TGA2 coactivator proteins. Surprisingly, GAL4BD-At1g50570 truncated protein (encoded in the At1g50570 isolated cDNA) showed low transactivation activity levels in yeast when compared with the GAL4BD-At1g50570 full-length protein (Figure 6.10 vs. Figure 6.11). It is most likely that length of At1g50570 protein is crucial to achieve its full activation potential, however, this low transactivation activity of the GAL4BD-At1g50570 truncated protein could be attributed to the yeast hybrid system itself. For instance, Zhang et al., 1999, reported that the N-terminal region of NPR1 has low levels of reporter gene transcriptional activity when compared with the full-length protein, which didn't activate the expression of reporter gene at all. The nature of the transactivation domain is not clear, however, it is most likely located downstream of the C2 domain, as the comparison of deduced amino acids sequence of the At1g50570 and At5g55530 upstream of the $\mathrm{C} 2$ domain showed no significant sequence identity (Figure 6.8).

The results showed that At1g50570 protein could function as transcription activator of an as-1-reporter gene when transfected into protoplasts as effector plasmids (Figure 6.19). The At1g50570 transactivation levels were considerably moderate ( 2 fold-induction) when compared with the basal transactivation levels of the as-1-reporter gene alone. These moderate levels of as-1-dependent reporter gene transactivation could be attributed to the presence of trace levels of At1g50570 protein in the nucleus (Figure 6.18B). In order to test whether At1g50570 nuclear targeting can enhance as-1-dependent reporter gene transactivation, as-1-GUS reporter 
transactivation assays were conducted using 10\% DMSO, which was shown to induced higher At1g50570-GFP protein accumulation in the nucleus. Unfortunately, the high DMSO treatment was extremely toxic for BY-2 protoplasts, thus it was unfeasible to test the effect of DMSO-dependent At1g50570 nuclear localization on the as-1-dependent transcriptional activity. Additionally, the as-1-reporter gene transcriptional activity was tested using an At1g50570 protein fused to an NLS (exclusively targeted to nucleus (data not shown). The NLS-At1g50570-GFP protein had repressed the as-1-GUS and the 5x UAS GAL4::uidA (used as a control) reporter genes activities, indicating the presence of a general toxic effect on the BY-2 protoplasts (Figure 6.20). In conclusion, the yeast and protoplasts transactivation experiments indicate that At1g50570 can act as a coactivator protein in vivo. The open question still is: what are the mechanisms that regulate the At1g50570 targeting to nucleus where it can function as a transcriptional activator. The At1g50570 lethal effect might suggest a potential function in HR establishment.

In Y2HS, both the At1g50570 and At5g55530 interacted strongly with class-II of tobacco and Arabidopsis TGA transcription factors, whereas, no interactions with tobacco TGA1a and TGA10 factors were detected (Figure 6.10). This result suggests that the interactions between At1g50570 and the class-II of tobacco TGA factors may be highly specific. Interestingly, the At1g50570 interaction with TGA factors behaves similar to the NPR1 protein. The Arabidopsis NPR1 protein didn't interact with the tobacco TGA1a and TGA10 factors in the Y2HS (Thurow, 2002). NPR1 was found to interact with Arabidopsis TGA2, TGA3, TGA5, TGA6, and TGA7 factors in yeast, whereas no interaction with TGA1 and TGA4 was observed (Després et al., 2000). Similarly to the NPR1 protein, the specificity of the interaction is defined to the Cterminal part of TGA2.2 downstream of the bZIP region (data not shown). In conclusion, the At1g50570 interaction with TGA2.2 mimics that of NPR1. One can assume that the interaction between At1g50570 and the TGA1 factor requires the redox control of TGA1 (Després et al., 2003). To interact with NPR1, two critical cysteine residues within the TGA1 should be reduced. The formation of a TGA1 intramolecular disulfide bridge 
inhibits the interaction with NPR1. It might be possible that At1g50570 needs to interact with a reduced form of TGA1 or TGA1a.

The interaction between TGA2.2 and At1g50570 was further confirmed in GST pull-down, Far Western and EMSA experiments (Figure 6.13, Figure 6.14 and Figure 6.15). GST-At1g50570 protein interacts with two TGA2.2 dimers bound to the as-1 element palindromes in an EMSA. These results suggest that the interaction between At1g50570 and the class-II of TGA factors has a high value of specificity (Figure 5.15). Krawczyk et al. (2002) have shown that the conserved spacing between the two centers of the palindromes of the as-1 element is essential for conferring full transcriptional activity in vivo. In this regard, the presence of a coactivator that associates only with two correctly spaced TGA dimers was postulated. To further confirm these observations, the interaction between TGA2.2 and At1g50570 was tested in a MY1HS using YTSH2 strain, which carries a HIS3 reporter gene downstream of three-times tandemly repeated as-1-2 elements (the as-1 lacked two bp between the two palindromes) (Siemsen, 2002). However, At1g50570 does interact with TGA2.2 in the YTSH2 strain, indicating that the conserved spacing in the as-1 element was not crucial for the interaction to take place (data not shown).

As observed above, several lines of evidence suggest that At1g50570 and At5g55530 proteins might activate expression of as-1 responsive genes by interacting with TGA class-II transcription factors. However, does the At1g50570 protein act as a positive regulator of TGA-responsive genes in plants? To answer this question, At1g50570 antisense and overexpression transgenic lines were generated and analyzed. Although At1g50570 antisense approach was successful, no increase or decreases in the basal levels of $P R-1$ gene expression were observed (Figure 6.21 and Figure 6.22). At1g50570 and At5g55530 are highly homologous and exhibit similar TGA2.2 interaction patterns, thus it might be possible that both proteins are functionally redundant.

The overexpression of At1g50570 failed to produce any phenotype related to gene expression under non-induced conditions (Figure 6.24 and Figure 6.25). It might 
be possible that the At1g50570 protein is not able to interact with TGA factors under these conditions. At1g50570 might undergo some kind of relocalization, which might be mediated by SA or auxin treatments, that will enable it to interact with TGA factors. Overexpression of NPR1, which interacts with TGA factors, did not lead to any constitutive $P R$ gene expression under non-inducing conditions but the $P R$ gene induction after pathogen infection was stronger, but not quicker, when compared to wild type plants (Cao et al., 1998). These observations suggested that SAR inducers modulate an NPR1 activation step. Mou et al. (2003) showed that INA, a SAR inducer, activates NPR1 by converting it from an oligomeric form (oxidized), which is arrested in cytoplasm, to a monomeric form (reduced) that is localized to the nuclear. For At1g50570, it is tempting to speculate that the mechanism of At1g50570 activation requires its nuclear localization. A logical assumption is that under non-inducing conditions, At1g50570 is localized to cellular membranes rather than the nucleus. The presence of C2 domain in At1g50570 strengthens this assumption (Figure 6.18). As described above, At1g50570 might respond to a certain stimulus that will lead eventually to its release from the cellular membranes and make it available to interact with TGA factors in the nucleus.

In summary, two novel proteins, At1g50570 and At5g55530, were found to interact strongly with the TGA2.2 transcription factor in yeast hybrid systems and in vitro. In future experiments, the At1g50570 and TGA2.2 interactions should be verified in vivo using the tandem affinity purification tag system that allows rapid purification of native protein complexes (Rigaut et al., 1999). The redundant or overlapping function that might exist between the two homologous proteins might be resolved by the generation of a double knockout mutant. Also, it might be interesting to demonstrate the in vivo function of At1g50570 by generating NLS-At1g50570 overexpression transgenic lines or by regulating the subcellular localization of At1g50570 by generating a fusion with the rat glucocorticoid receptor HBD in a double knockout mutant background (Picard et al., 1988). The rat glucocorticoid receptor HBD system was used to control the nuclear transport of various transcriptional regulators in Arabidopsis (Kinkema et 
al., 2000; Wagner et al., 1999). The outputs of these experiments might give a conclusive evidence for the roles of these proteins in regulating TGA factors activity.

\subsection{Functional Analysis of At1g28480 Protein}

The identification of At1g28480, a glutaredoxin protein, as a TGA2.2 interacting protein emerged when several recent reports demonstrated the importance of redox regulation in SAR establishment. There is a growing body of evidence that indicates that an altered redox state of the cell can activate different signaling pathways in plants. For instance, the generation of ROS, e.g., $\mathrm{H}_{2} \mathrm{O}_{2}$, during the oxidative burst is one of the earliest cellular responses to pathogens (Apel and Hirt, 2004; Lamb and Dixon, 1997). Increasing evidences suggest that $\mathrm{H}_{2} \mathrm{O}_{2}$, which is generated during the oxidative burst, functions as a signaling molecule in the plant immune system. For instance, $\mathrm{H}_{2} \mathrm{O}_{2}$ induces the expression of defense-related genes such as the Arabidopsis GSTs and PR-1 (Chen and Singh, 1999; Klessig et al., 2000). Microarray analysis of $\mathrm{H}_{2} \mathrm{O}_{2}$-induced gene expression in Arabidopsis revealed that the as-1 promoter element is a potential $\mathrm{H}_{2} \mathrm{O}_{2}$-responsive cis-element (Desikan et al., 2001). In the contrary, Garreton et al. (2002) reported that binding of the TGA transcription factors to as-1 element is responsive to oxidative species other than $\mathrm{H}_{2} \mathrm{O}_{2}$. In consistence with these observations, the TGA1 and NPR1 transcriptional regulators were found to undergo some kind of redox modifications (Després et al., 2003, and Mou et al., 2003). What is the molecular basis of the redox signal that mediates the modification of both proteins? Both authors speculate the involvement of thioredoxins, glutaredoxins and Ref-1, an apurinic/apyrimidinic endonuclease that is known to mediate the redox regulation of many eukaryotic transcription factors. The identification of the At1g28480 glutaredoxin appeared as the missing link that could regulate TGA factors by redox processes.

Glutaredoxins, also known as thioltransferases, are small disulfide reducing enzymes that have been shown to catalyze the reactivation of many oxidatively modified proteins (Holmgren, 1989). Glutaredoxins are part of the thioredoxin superfamily of proteins that includes thioredoxin, GST and glutathione peroxidases (Åslund and Beckwith, 1999). Usually, gluatredoxin has a conserved active site 
consensus sequence of "YCPYC" that is involved in the reversible oxidation by the formation of a disulfide bond between the two active site cysteine residues (Figure 6.26; Berardi and Bushweller, 1999). The glutaredoxin reactivity with glutathione is mediated by a glutathione-binding site (Bushweller et al., 1994). The glutathione-binding site mediates the formation of glutathione-containing mixed disulfides bridge, implying that glutaredoxin has a role in glutathionylation and deglutathionylation of target proteins. Beside its essential function for the glutathione-dependent reduction of ribonucleotides to deoxyribonucleotides by the ribonucleotide reductase enzyme (Holmgren, 1979), glutaredoxin has been shown to be a molecule that operates in the redox-regulation of gene expression via modulation of transcription factors. For instance, the activation OxyR transcriptional factor of $E$. coli is reversed by cellular disulfide-reducing machinery that involves a glutaredoxin (Zheng et al., 1998). Several studies have demonstrated that the glutaredoxin can modulate the DNA binding and transcriptional activities of several transcription factors, e.g., NFkB, AP-1 and NFI (Bandyopadhyay, et al., 1998, Hirota, et al., 2000).

Glutaredoxins have been isolated and characterized from different organisms such as E. coli (Åslund et al., 1996), yeast (Grant, 2001) and humans (Lundberg et al., 2001). However, studies about plant glutaredoxin enzymatic properties, structure and characteristics are scarce (Meyer et al., 1999). Minakuchi et al. (1994) had characterized the first plant glutaredoxin cDNA from rice, while Morell et al. (1994) had identified and localized the first glutaredoxin in spinach leaves. The first hint about glutaredoxin function in plants came after the detection of glutaredoxin in phloem sap of different plant species (Szederkenyi et al., 1997). Since this discovery, only little information on glutaredoxin function in plants has emerged. Furthermore, the target proteins of glutaredoxins in plants are not known. For instance, a poplar phloem peroxiredoxin, which was isolated from a xylem/phloem cDNA library and known for its role in regulating intracellular levels of $\mathrm{H}_{2} \mathrm{O}_{2}$, was found to accept protons from a poplar glutaredoxin (Rouhier et al., 2002b). In the genome of Arabidopsis, there are at least 24 glutaredoxins or glutaredoxin-like proteins (Meyer et al., 1999). Only two Arabidopsis 
glutaredoxins, At5g20500 and At5g40370, showed the conserved active site consensus sequence of "YCPYC". The information about Arabidopsis glutaredoxins is scarce.

In the present study, At1g28480 clone accounted for 24 of 45 positives clones identified in the YM1HS, although its low expression does not imply an overrepresentation of the clone in the cDNA library (Table 6.1). The interaction between the At1g28480 glutaredoxin and all identified members of the tobacco TGA transcription factors was demonstrated using the Y2HS (Figure 6.30). Interestingly, the At1g28480 glutaredoxin was able to interact strongly with class-I of tobacco TGA transcription factors, which does not interact with NPR1 and At1g50570 proteins in yeast. This result might suggest that At1g28480 could modulate the redox state of class-I TGA transcription factors by reducing the previously described conserved cysteine residues in their amino acid sequences (Després et al., 2003). The specificity of the interaction between TGA2.2 and At1g28480 glutaredoxin was demonstrated by testing the interaction with two other glutaredoxins, At5g20500 and At5g40370. Both classical glutaredoxins failed to interact with TGA2.2 in Y2HS, indicating that the interaction between TGA2.2 and At1g28480 is indeed specific. The At5g20500 and At5g40370 glutaredoxins showed amino acids similarity to At1g28480 of $48 \%$ and $52 \%$, respectively, indicating that their sequence similarities with At1g28480 are considerably low. The highest sequence similarity with At1g28480 (45\% identity, 60\% similarity) was found with monocysteinic At1g03850 glutaredoxin (Figure 5.26). At1g03850 is predicted to be a chloroplastic-targeted protein. Therefore the interaction between At1g03850 with TGA2.2 was not studied. The amino acid sequences comparison of At1g28480 with other sequences of different plant species revealed that the its amino acid sequence is conserved within plant kingdom (http://tigr.org).

In TGA2.2, the C-terminal part downstream of the bZIP region was defined as the interaction region with At1g28480 (data not shown). Interestingly, sequence analysis of the tobacco and Arabidopsis class-II TGA transcription factors revealed that they contain a single conserved cysteine in their putative interaction region. Therefore, the nature of the interaction between TGA2.2 and At1g28480 was analyzed further by 
using different At1g28480 and TGA2.2 cysteine point mutations (Figure 6.31). A small percentage of TGA2.2 protein was able to form an oligomer under oxidizing conditions when compared with the TGA2. $2^{\text {Cys } 181 \text { Ser }}$ mutant protein (Figure 6.32). These results indicate that the TGA2.2 single conserved cysteine might be involved in disulfide formation and it could be sensitive to redox changes. Interestingly, Lenk (2001) had identified a similar band in his immunoblot analysis using protein extracts prepared from SNN tobacco plants overexpressing a TGA2.1 deleted form (lacking 29 amino acids from the TGA2.1 N-terminal region). Lenk (2001) speculated that a heterodimer between TGA2.2 and TGA2.1, which might be mediated by the conserved cysteine residue, is responsible for the corresponding band.

The TGA2.2 ${ }^{\text {Cys181Ser }}$ mutant protein was found to interact with the At1g28480 glutaredoxin, indicating that the single conserved cysteine of TGA2.2 is not involved in the interaction with the At1g28480 protein. Several previous reports had shown that mutations in cysteine residues of many proteins, which had shown in vitro redox sensitivity, did not show redox-regulated functions in vivo. For instance, Ordway et al. (2003) found that a mutation in cysteine 64 of mouse Ref-1, which was previously implicated in reduction of oxidized cysteine residues within the DNA binding domains of several transcription factors in vitro, didn't have any influence on the in vivo AP-1 transcription factor DNA binding activity.

An At1g28480 cysteine single mutant (GSM; CCMS; C55S), which retains only cysteine 52 in its redox active site, displays the same binding specificity for TGA2.2 as At1g28480 (Table 6.3). These observations indicate that active site cysteine 55 is not required for At1g28480-TGA2.2 interaction. When two point mutations in both At1g28480 glutaredoxin active site cysteine residues (GDM; SCMS; C52S and C55S) were introduced, an alteration in the TGA2.2-At1g28480 interaction affinities was observed (Table 6.3). This suggests that the At1g28480 glutaredoxin redox active center might be involved in modulating the interaction with TGA2.2. Intriguingly, the GAL4AD-GDM was not able to interact with TGA2.2, while GAL4BD interacted weakly when compared with GAL4AD- and GAL4BD-At1g28480, respectively (Table 6.3). It 
could be possible that the TGA2.2-GDM loss of interaction is related to weak expression levels of GDM in yeast. Unlike classical glutaredoxins that have a conserved active site sequence of "YCPYC", At1g28480 glutaredoxin contains an additional conserved cysteine residue at position 53 (Figure 6.26). The presence of CCMC sequence as the redox active site might suggest that cysteine 53 might substitute the cysteine 52 if mutated. Data supporting such assumptions are still lacking.

The confirmation of the interaction between TGA2.2 and At1g50570 by in vitro means and the analysis of At1g28480 glutaredoxin activity in a redox assay were not feasible. At1g28480 production in E. coli expression systems yielded very low amounts of At1g28480 protein (data not shown). Rouhier et al. (2002c) had reported low expression of a poplar glutaredoxin in $E$. coli and they proposed a strategy used to optimize it production in $E$. coli through the manipulation of its cDNA sequence. However, the interaction between At1g28480 and TGA2.2 was confirmed by a protoplast two-hybrid system (Figure 6.38). At1g28480 was detected in cytoplasm and nucleus (Figure 6.39). These findings demonstrated that both proteins could interact in plant cells.

To better understand the function of At1g28480 in regulating TGA2.2, several experiments were conducted in yeast to analyze the putative function of At1g28480. The effect of At1g28480 or GDM overexpression on the interaction between TGA2.2 monomers was studied using Y3HS. The results clearly showed that At1g28480 enhanced indirectly in vivo TGA2.2 interaction and in vitro binding to the as-1 element by increasing TGA2.2 protein levels in yeast cells (Figure 6.34 and Figure 6.35). Similar results were obtained using the GDM protein (data not shown). It is most likely that At1g28480 acts like a chaperone, i.e., provides a suitable microenvironment where TGA2.2 is more stable or free to interact. Molecular chaperones are a class of polypeptide-binding proteins that are implicated in protein folding, protein targeting to membranes, protein renaturation or degradation after stress and the control of proteinprotein interactions (reviewed in Hartl and Hayer-Hartl, 2002). Several glutaredoxin or 
glutaredoxin like proteins have been shown to display a chaperone-like activity (Kern el al., 2003; Lundström-Ljung and Holmgren, 1995). However, the mode of action of the At1g28480 glutaredoxin protein in increasing the TGA2.2 protein levels in yeast is unknown.

A property of signalling proteins in general is that treatments that activate them often enhance expression of their genes. At1g28480 expression levels respond markedly to pathogen infection and SA treatment (Figure 6.41). The onset of expression of At1g28480 after virulent pathogen infection was earlier than the onset of the PR-1 gene. Similarly, At1g28480 transcript appeared after two hours after SA treatment. Somehow, the increase in At1g28480 transcription is correlated to subsequent PR-1 transcript accumulation (Figure 6.41). These induction patterns suggest that the accumulation of the At1g28480 transcript might be involved functionally in the regulation of plant defense or SA-mediated responses through At1g28480 interaction with TGA factors. The overall picture of such speculated events are still unclear and should be investigated in the future. Interestingly, the observation that At1g28480 can form a ternary complex with TGA factors and NPR1 in yeast might link the function of At1g28480 to the NPR1, which is the key regulator of $P R$ genes expression. The ternary complex formation might be responsible for the modulation of DNA-binding specificity and/or transcriptional activity of TGA transcription factors in plants. As described above, At1g28480 glutaredoxin might function as a chaperone, thus it might be possible that At1g28480 stabilizes the interaction between NPR1 and TGA2.2 or it might increase the interaction affinity between both proteins. However, the significance of the At1g28480-TGA2.2-NPR1 ternary complex still unclear and further characterization should be carried out.

To test the above hypothesis, transgenic plants that overexpress or repress expression of At1g28480 were analyzed. The At1g28480 encoding mRNA was severely reduced in the RNAi lines, while At1g28480 protein levels significantly accumulated in the overexpressor lines (Figure 6.42 and Figure 6.44). One At1g28480 overexpressor line revealed a distinguishable phenotype under normal conditions (Figure 6.44). The 
At1g28480 overexpression line \#7 plant phenotypes of irregular leaf shape, cotyledon epinasty, late flowering time and crinkled fruits mimic those of JAW locus, which produces a microRNA that can guide messenger RNA cleavage of several TCP genes, which encode transcription factors, that control leaf development (Palatnik et al., 2003). It might be interesting to characterize this transgenic line and to verify if it is corresponding to At1g28480 overexpression or not. Similarly to At1g50570, the overexpression or repression of At1g28480 failed to produce any phenotypes related to SA-inducible gene expression (Figure 6.43 and Figure 6.45). These observations should be interrupted carefully as the selected gene promoters contain, in addition to as-1 element, both positive and negative regulatory elements (Lebel et al., 1998). Therefore, regulation of these promoters is certainly more complicated than what is thought. It might be possible that other promoter elements besides as-1, or other transcription factors in addition to TGA transcription factors, are important for enhancing or repressing the expression of the selected marker genes and as a subsequence they will mask the function of At1g28480 or At1g50570. As discussed above, the TGA factors can function as both positive and negative regulators of SA-dependent gene expression, which make it difficult to define the function of any specific factor. In contrast, At1g28480 overexpressor transgenic lines revealed weak GUS expression after 2,4-D induction. TGA transcription factors regulate several auxin-induced genes such as GNT35 and Nt103, which are involved in plant defense against xenobiotic stresses (Johnson et al., 2001b; Niggeweg et al., 2000; Pascuzzi et al., 1998). One likely mechanism suggested here, which involves At1g28480, is the preventing of DNA binding of TGA transcription factor to the as-1 element. It might be possible that the At1g28480 glutaredoxin activity quenches an oxidative stress signal that leads to the activation of TGA transcription factors (Garreton et al., 2002). Further analysis should be conducted to determine the role and the mechanism by which At1g28480 represses the auxin inducible gene expression.

In summary, the At1g28480 protein seems to interact with TGA2.2 as a chaperone in yeast hybrid systems. In future experiments, the At1g28480 and TGA2.2 interactions should be verified by in vitro and in vivo (TAP-tag) methods. The redox 
properties of At1g28480 should be demonstrated using purified proteins or through complementation assay in E. coli as described previously (Bick et al., 1998; Rouhier et al., 2003). The influence of At1g28480 on auxin-dependent gene expression should be further analyzed using transgenic plants that overexpress the GDM mutant, which might help into better understand the mechanism by which the At1g28480 influence the auxin inducible gene expression. The DNA microarray analysis could be powerful approach for the elucidation of At1g28480 function and its regulatory networks (Schenk et al., 2000). 


\section{$8 \quad$ Literature Cited}

Abel, K., and Hirt H. (2004). Reactive Oxygen Species: Metabolism, Oxidative Stress, and Signal Transduction. Annu. Rev. Plant Biol., 55: 373-99.

Agatep, R., Kirkpatrick, R. D., Parchaliuk, D. L., Woods, R. A. and Gietz, R. D. (1998). Transformation of Saccharomyces cerevisiae by the Lithium Acetate SingleStranded Carrier DNA/Polyethylene Glycol (LiAc/ss-DNA/PEG) Protocol. Tech. Tips Online, 1: 51:P01525.

Anderson, M.D., Zhixiang, C. T. and Klessig, D. F. (1998). Possible Involvement of Lipid Peroxidation In Salicylic Acid-Mediated Induction of PR-1 Gene Expression. Photochemistry, 47: 555-566.

Asai, T., Tena, G., Plotnikova, J., Willmann, M. R., Chiu, W., Gomez-Gomez, L., Boller, T., Ausubel, F. M. and Sheen, J. (2002). MAP Kinase Signalling Cascade in Arabidopsis Innate Immunity. Nature, 415: 977-983.

Åslund, F. and Beckwith, J. (1999). The Thioredoxin Superfamily: Redundancy, Specificity, and Gray-Area Genomics. J. Bact., 181: 1375-1379.

Åslund, F., Nordstrand, K., Berndt, K.D., Nikkola, M., Bergman, T., Ponstingl, H., Jornvall, H., Otting, G. and Holmgren, A. (1996). Glutaredoxin-3 from Escherichia coli. Amino acid sequence, 1H AND 15N NMR assignments, and structural analysis. J. Biol. Chem., 271: 6736-6745.

Ausubel, F.M., Brent, R., Kingston, R.E., Moore, D.D., Seidman, J.G. and Struhl, K. (1988). Current Protocols in Molecular Biology. John Wiley \& Sons, New York 10022, USA.

Bandyopadhyay, S., Starke, D.W., Mieyal, J.J. and Gronostajski, R.M. (1998). Thioltransferase (Glutaredoxin) Reactivates the DNA-Binding Activity of OxidationInactivated Nuclear Factor I. J. Biol. Chem., 273: 392-397. 
Bartel, P.L., Chien, C.T., Sternglanz, R. and Fields, S. (1993). Elimination of False Positives that Arise in Using the Two-Hybrid System. Biotechniques, 14: 920-924.

Bemis LT, Denis CL Identification of Functional Regions in the Yeast Transcriptional Activator ADR1. Mol Cell Biol., 8: 2125-2131.

Bent, A. F. (1996). Plant Disease Resistance Genes: Function Meets Structure. Plant Cell, 8: 1757-1771.

Berardi, M.J. and Bushweller, J.H. (1999) Binding Specificity and Mechanistic Insight into Glutaredoxin-Catalyzed Protein Disulfide Reduction. J. Mol. Biol., 292: 151161.

Berrocal-Lobo, M., Molina, A. and Solano, R. (2002). Constitutive Expression of ETHYLENE-RESPONSE-FACTOR1 in Arabidopsis Confers Resistance to Several Necrotrophic Fungi. Plant J., 29: 23-32.

Bick J.A., Åslund, F., Chen, Y. and Leustek, T. (1998). Glutaredoxin Function for the carboxyl-Terminal Domain of the Plant-Type 5'-Adenylylsulfate Reductase. Proc. Natl. Acad. Sci. USA, 95: 8404-8409.

Bonas, U. and van den Ackerveken, G. (1999). Gene-for-gene Interactions: Bacterial Avirulence Proteins Specify Plant Disease Resistance. Curr. Opin. Microbiol., 2: 94-98.

Bowling, S.A., Guo, A., Cao, H., Gordon, A.S., Klessig, D.F. and Dong, X. (1994). A Mutation in Arabidopsis that Leads to Constitutive Expression of Systemic Acquired Resistance. Plant Cell, 6: 1845-1857.

Brachmann, R.K. and Boeke, J.D. (1997). Tag Games in Yeast: the Two-Hybrid System and beyond. Curr. Opin. Biotechnol., 8: 561-568.

Brenner, W. (2002). I. Construction of an Inducible Suicide System to Identify Mutants of The Salicylic Acid Dependent Signal Transduction Chain; II. Expression of 
Animal Signal Transduction Components in Tobacco to Produce an Inducible Expression System (In German), Ph.D. Thesis, Georg-August University Göttingen, Germany.

Brent, R. and Ptashne, M. (1981). Mechanisms of Action of the lexA Gene Product. Proc. Natl. Acad. Sci. USA, 78: 4204-4208.

Bullock, W.O., Fernandez, J.M. and Short, J.M. (1987). XL1-Blue: A High Efficiency Plasmid Transforming RecA-Escherichia coli Strain with B-Galactosidase Selection. Biotechniques, 5: 376-379.

Bushweller, J., Billeter, M., Holmgren, A. and Wüthrich, K. (1994). The NMR Solution Structure of the Mixed Disulfide between E. coli Glutaredoxin (C14S) and Glutathione. J. Mol. Biol., 235: 1585-1597.

Cao, H., Bowling, S.A., Gordon, S., and Dong, X. (1994). Characterization of an Arabidopsis Mutant that is Non-Responsive to Inducers of Systemic Acquired Resistance. Plant Cell, 6: 1583-1592.

Cao, H., Glazebrook, J., Clarke, J.D., Volko, S. and Dong, X. (1997). The Arabidopsis NPR1 Gene that Controls Systemic Acquired Resistance Encodes a Novel Protein Containing Ankyrin Repeats. Cell, 88: 57-63.

Cao, H., Li. X. and Dong, X. (1998). Generation of Broad-Spectrum Disease Resistance by Overexpression of an Essential Regulatory Gene in Systemic Acquired Resistance. Proc. Natl. Acad. Sci. USA, 95: 6531-6536.

Chamnongpol, S., Willekens, H., Moeder, W., Langebartels, C., Sandermann, H. Jr., van Montagu, M., Inzé, D. and Van Camp, W. (1998). Defense Activation and Enhanced Pathogen Tolerance Induced by $\mathrm{H}_{2} \mathrm{O}_{2}$ in Transgenic Tobacco. Proc. Natl. Acad. Sci. USA, 95: 5818-5823. 
Chandok, M.R., Ytterberg, A.J., van Wijk, K.J. and Klessig, D.F. (2003). The PathogenInducible Nitric Oxide Synthase (iNOS) in Plants is a Variant of the P Protein of the Glycine Decarboxylase Complex. Cell, 113: 469-82.

Chen, W. and Singh, K.B. (1999) The auxin, hydrogen peroxide and salicylic acid induced expression of the Arabidopsis GST6 promoter is mediated in part by an ocs element. Plant J., 19: 667-677.

Chen, W., Provart, N.J., Glazebrook, J., Katagiri, F., Chang, H.S., Eulgem, T., Mauch, F., Luan, S., Zou, G., Whitham, S.A., Budworth, P.R., Tao, Y., Xie, Z., Chen, X., Lam, S., Kreps, J.A., Harper, J.F., Si-Ammour, A., Mauch-Mani, B., Heinlein, M., Kobayashi, K., Hohn, T., Dangl, J.L., Wang, X. and Zhu, T. (2002). Expression Profile Matrix of Arabidopsis Transcription Factor Genes Suggests Their Putative Functions in Response to Environmental Stresses. Plant Cell, 14: 559-574.

Chen, Z., Ricigliano, J.W. and Klessig, D.F. (1993). Purification and Characterization of a Soluble Salicylic Acid-Binding Protein from Tobacco. Proc. Natl. Acad. Sci. USA, 90: 9533-9537.

Cheong, Y.H., Moon, B.C., Kim, J.K., Kim, C.Y., Kim, M.C., Kim, I.H., Park, C.Y., Kim, J.C., Park, B.O., Koo, S.C., Yoon, H.W., Chung, W.S., Lim, C.O., Lee, S.Y. and Cho, M.J. (2003). BWMK1, a Rice Mitogen-Activated Protein Kinase, Locates in the Nucleus and Mediates Pathogenesis-Related Gene Expression by Activation of a Transcription Factor. Plant Physiol., 132: 1961-1972.

Chern, M.S., Fitzgerald, H.A., Yadav, R.C., Canlas, P.E., Dong, X. and Ronald, P.C. (2001). Evidence for a Disease-Resistance Pathway in Rice Similar to the NPR1Mediated Signaling Pathway in Arabidopsis. Plant J. ,27: 101-113.

Cho, W. (2001). Membrane Targeting by C1 and C2 Domains. J. Biol. Chem., 276: 32407-32410. 
Clarke, J.D., Aarts, N., Feys, B.J., Dong, X. and Parker, J.E. (2001). Constitutive Disease Resistance Requires EDS1 in the Arabidopsis Mutants cpr1 and cpr6 and is Partially EDS1-Dependent in cpr5. Plant J., 26: 409-420.

Clarke, J.D., Liu, Y., Klessig, D.F. and Dong, X. (1998). Uncoupling PR Gene Expression from NPR1 and Bacterial Resistance: Characterization of the Dominant Arabidopsis cpr6-1 Mutant. Plant Cell, 10: 557-569.

Clarke, J.D., Volko, S.M., Ledford, H., Ausubel, F.M. and Dong, X. (2000). Roles of Salicylic Acid, Jasmonic Acid, and Ethylene in cpr-Induced Resistance in Arabidopsis. Plant Cell, 12: 2175-2190.

Clough, S.J. and Bent, A.F. (1998). Floral Dip: a Simplified Method for AgrobacteriumMediated Transformation of Arabidopsis thaliana. Plant J., 16: 735-743.

Clough, S.J., Fengler, K.A., Yu, I.C., Lippok, B., Smith, R.K.Jr. and Bent, A.F. (2000). The Arabidopsis dnd1 "defense, no death" Gene Encodes a Mutated Cyclic Nucleotide-Gated Ion Channel. Proc. Natl. Acad. Sci., USA. 97:9323-9328.

Coates, P.J. and Hall, P.A. (2003). The Yeast Two-Hybrid System for Identifying Protein-Protein Interactions. J. Pathol., 199: 4-7.

Cohn, J., Sessa, G. and Martin, G.B. (2001). Innate Immunity in Plants. Curr. Opin. Immuno., 13: 55-62.

Dangl, J.L. and Jones, J.D. (2001). Plant Pathogens and Integrated Defense Responses to Infection. Nature, 411: 826-833.

Das, S., Dixon, J.E. and Cho, W. (2003). Membrane-Binding and Activation Mechanism of PTEN. Proc. Natl. Acad. Sci. USA, 100: 7491-7496.

De Leon, I.P., Sanz, A., Hamberg, M. and Castresana, C. (2002). Involvement of the Arabidopsis Alpha-DOX1 Fatty Acid Dioxygenase in Protection Against Oxidative Stress And Cell Death. Plant J., 29(1): 61-72. 
Delaney, T.P., Friedrich, L. and Ryals, J.A. (1995). Arabidopsis Signal Transduction Mutant Defective in Chemically and Biologically Induced Disease Resistance. Proc. Natl. Acad. Sci. USA, 92: 602-6606.

Delaney, T.P., Uknes, S., Vernooij, B., Friedrich, L., Weymann, K., Negrotto, D., Gaffney, T., Gutrella, M., Kessmann, H., Ward, E. and Ryals, J. (1994). A Central Role of Salicylic-Acid in Plant-Disease Resistance. Science, 266: 1247-1250.

Delledonne, M., Xia, Y., Dixon, R.A. and Lamb, C. (1998). Nitric Oxide Functions as a Signal in Plant Disease Resistance. Nature, 394: 585-588.

Desikan, R., A.H., Mackerness, S., Hancock, J.T. and Neill, S.J. (2001). Regulation of the Arabidopsis Transcriptome by Oxidative Stress. Plant Physiol., 127:159-172.

Després, C., Chubakc, C., Rochona, A., Clarkb, R., Bethuneb, T., Desveauxd, D. and Fobert, P.F. (2003). The Arabidopsis NPR1 Disease Resistance Protein is a Novel Cofactor that Confers Redox Regulation of DNA Binding Activity to the Basic Domain/Leucine Zipper Transcription Factor TGA1. Plant Cell, 15: 2181-2191.

Després, C., DeLong, C., Glaze, S., Liu, E. and Fobert, P.R. (2000). The Arabidopsis NPR1/NIM1 Protein Enhances the DNA Binding Activity of a Subgroup of the TGA Family of bZIP Transcription Factors. Plant Cell, 12: 279-290.

Desveaux, D., Subramaniam, R., Despres, C., Mess, J.N., Levesque, C., Fobert, P.R., Dangl, J.L. and Brisson, N. (2004). A "Whirly" Transcription Factor is Required for Salicylic Acid-Dependent Disease Resistance in Arabidopsis. Dev. Cell, 6: 229240.

Dewdney, J., Reuber, T.L., Wildermuth, M.C., Devoto, A., Cui, J., Stutius, L.M., Drummond. E.P. and Ausubel, F.M. (2000). Three Unique Mutants of Arabidopsis Identify eds Loci Required for Limiting Growth of a Biotrophic Fungal Pathogen. Plant J., 24: 205-218. 
Dohmen, R.J., Strasser, A.W., Honer, C.B., Hollenberg, C.P. (1991). An Efficient Transformation Procedure Enabling Long-Term Storage of Competent Cells of Various Yeast Genera. Yeast, 7: 691-692.

Dong, X. (2001). Genetic Dissection of Systemic Acquired Resistance. Curr. Opin. Plant Biol., 4:309-314.

Dower, W.J., Miller, J.F. and Ragsdale, C.W. (1988). High Efficiency Transformation of E. coli by High Voltage Electroporation. Nucleic Acids res., 16: 6127-6145.

Drees, B.L. (1999). Progress and Variations in Two-Hybrid and Three-Hybrid Technologies. Curr. Opin. Chem. Biol., 3: 64-70.

Du, H. and Klessig, D. F. (1997). Identification of a Soluble, High-Affinity Salicylic AcidBinding Protein in Tobacco. Plant Physiol., 113: 1319-1327.

Durner, J. and Klessig, D.F. (1998). Inhibition of Ascorbate Peroxidase by Salicylic Acid and 2,6-Dichloroisonicotinic Acid, Two Inducers of Plant Defense Responses. Proc. Natl. Acad. Sci. USA, 92: 11312-11316.

Durrant, W.E. and Dong, X. (2004). Systemic Acquired Resistance. Annu. Rev. Pyhtopathol., 42: 185-209.

Eulgem, T., Rushton, P.J., Robatzek, S. and Somssich, I.E. (2000). The WRKY Superfamily of Plant Transcription Factors. Trends Plant Sci., 5: 199-206.

Falk, A., Feys, B.J., Frost, L.N., Jones, J.D., Daniels, M.J. and Parker, J.E. (1999). EDS1, an Essential Component of $R$ Gene-Mediated Disease Resistance in Arabidopsis Has Homology to Eukaryotic Lipases. Proc. Natl. Acad. Sci. USA, 96: 3292-3297.

Fan, W. and Dong, X. (2002). In Vivo Interaction between NPR1 and Transcription Factor TGA2 Leads to Salicylic Acid-Mediated Gene Activation in Arabidopsis. Plant Cell, 14: 1377-1389. 
Feinberg, A.P. and Vogelstein, B. (1983). A Technique for Radiolabeling of DNA Restriction Endonuclease Fragments to High Specific Activity. Anal. Biochem., 132: 6-13.

Feys, B.J., Moisan, L.J., Newman, M.A. and Parker, J.E. (2001). Direct Interaction between the Arabidopsis Disease Resistance Signaling Proteins, EDS1 and PAD4. EMBO J., 20: 5400-5411.

Fields, S. and Song, O. (1989). A Novel Genetic System to Detect Protein-Protein Interactions. Nature, 340: 245-246.

Fields, S. and Sternglanz, R. (1994). The Two-Hybrid System: an Assay for ProteinProtein Interactions. Trends Genet., 10: 286-92.

Flor, H.H. (1971). Current Status of Gene-for-Gene Concept. Annu. Rev. Phytopathol., 9, 275.

Friedrich, L., Lawton, K., Dincher, S., Winter, A., Staub, T., Uknes, S., Kessmann, H. and Ryals, J. (1996). Benzothiadiazole Induces Systemic Acquired Resistance in Tobacco. Plant J., 10: 61-70.

Friedrich, L., Lawton, K., Dietrich, R, Willits, M., Cade, R. and Ryals, J. (2001). NIM1 overexpression in Arabidopsis Potentiates Plant Disease Resistance and Results in Enhanced Effectiveness of Fungicides. Mol. Plant. Microbe. Interact., 14: 1114-24.

Frye, C.A., Tang, D. and Innes, R.W. (1998). An Arabidopsis Mutant with Enhanced Resistance to Powdery Mildew. Plant Cell, 10: 947-956.

Frye, C.A., Tang, D. and Innes, R.W. (2001). Negative Regulation of Defense Responses in Plants by a Conserved MAPKK Kinase. Proc. Natl. Acad. Sci. USA, 98: 373-378. 
Gaffney. T., Friedrich, I., Vernooij, B., Negrotto, D., Nye, G., Uknes, S., Ward, E., Kessmann, H. and Ryals, J. (1993). Requirement of Salicylic-Acid for the Induction of Systemic Acquired-Resistance. Science, 261: 754-756.

Garreton V, Carpinelli J, Jordana X, Holuigue L. (2002). The As-1 Promoter Element is an Oxidative Stress-Responsive Element and Salicylic Acid Activates it via Oxidative Species. Plant Physiol. 130: 1516-1526.

Gietz, R.D. and Woods, R.A. (2002). Transformation of Yeast by the Liac/Ss Carrier DNA/PEG Method. Methods Enzymol., 350: 87-96.

Glazebrook, J. (2001). Genes Controlling Expression of Defense Responses in Arabidopsis-2001 Status. Curr. Opin. Plant Biol., 2001, 4: 301-308.

Glazebrook, J. Rogers, E.E. and Ausubel, F.M. (1997a). Use of Arabidopsis for Genetic Dissection of Plant Defense Responses. Annu. Rev. Genet. 31: 547-69.

Glazebrook, J., Zook, M., Mert, F., Kagan, I., Rogers, E.E., Crute, I.R. Holub, E.B., Hammerschmidt, R. and Ausubel, F.M. (1997b). Phytoalexin-Deficient Mutants of Arabidopsis Reveal That PAD4 Encodes a Regulatory Factor and That Four PAD Genes Contribute to Downy Mildew Resistance. Genetics, 146: 381-392.

Grant, C.M. (2001). Role of the Glutathione/Glutaredoxin and Thioredoxin Systems in Yeast Growth and Response to Stress Conditions. Mol. Micro., 39(3), 533-541.

Gupta, V., Willits, M.G. and Glazebrook, J. (2000). Arabidopsis thaliana EDS4 Contributes to Salicylic Acid (SA)-Dependent Expression of Defense Responses: Evidence for Inhibition of Jasmonic Acid Signaling by SA. Mol. Plant Microbe. Interact., 13: 503-511.

Hammond-Kosack, K.E. and Jones, J.D.G. (1997). Plant Disease Resistance Genes. Annu. Rev. Plant Physiol. Plant Mol. Biol., 48: 575-607. 
Hammond-Kosack, K.E. and Jones, J.D.G. (1996). Resistance Gene-Dependent Plant Defense Responses. Plant Cell, 8: 1773-1791.

Hanahan, D. (1983). Studies on Transformation of Escherichia coli with Plasmids. J. Mol. Biol., 166: 557-580.

Hartl, F.U. and Hayer-Hartl, M. (2002). Molecular Chaperones in the Cytosol: from Nascent Chain to Folded Protein. Science, 295: 1852-1858.

Heath, M.C. (2000). Hypersensitive Response-Related Death. Plant Mol. Biol., 44: 321334.

Heck, S., Grau, T., Buchala, A., Metraux, J.P. and Nawrath, C. (2003). Genetic Evidence that Expression of NahG Modifies Defense Pathways Independent of Salicylic Acid Biosynthesis in the Arabidopsis-Pseudomonas syringae pv. tomato Interaction. Plant J., 36: 342-352.

Hidalgo, P., Garretón, V., Berríos, C.G., Ojeda, H., Jordana, X. and Holuigue, L. (2001). A Nuclear Casein Kinase 2 Activity is Involved in Early Events of Transcriptional Activation Induced by Salicylic Acid in Tobacco. Plant Physiol., 125: 396-405.

Hirota, K., Matsui, M., Murata, M., Takashima, Y., Cheng, F.S., Itoh, T., Fukuda, K. and Yodoi, J. (2000). Nucleoredoxin, Glutaredoxin, And Thioredoxin Differentially Regulate NF-Kappab, AP-1, And CREB Activation In HEK293 Cells. Biochem. Biophys. Res. Commun., 274: 177-182.

Ho, S.N., Hunt, H.D., Horton, R.M., Pullen, J.K. and Pease, L.R. (1989). Site-Directed Mutagenesis by Overlap Extension Using the Polymerase Chain Reaction. Gene, 77: 51-9.

Holmgren, A. (1979). Glutathione-Dependent Synthesis of Deoxyribonucleotides. Purification and Characterization of Glutaredoxin from Escherichia coli. J. Biol. Chem., 254:3664-3671. 
Holmgren, A. (1989). Thioredoxin and Glutaredoxin Systems. J. Biol. Chem., 264: 13963-13966.

Holmgren, A. and Aslund, F. (1995). Glutaredoxin. Methods Enzymol., 252: 283-292.

Hunt, M.D., Delaney, T.P., Dietrich, R.A., Weymann, K.B., Dangl, J.L. and Ryals, J.A. (1997). Salicylate-Independent Lesion Formation in Arabidopsis Isd Mutants. Mol. Plant Microbe Interact., 10: 531-536.

Innes, R.W. (2001). Mapping out the Roles of MAP Kinases in Plant Defense. Trends Plant Sci., 6: 392-394.

Jakoby, M., Weisshaar, B., Droge-Laser, W., Vicente-Carbajosa, J., Tiedemann, J., Kroj, T. and Parcy, F. (2002). bZIP Transcription Factors in Arabidopsis. Trends Plant Sci., 7: 106-111.

Jambunathan, N., Siani, J.M. and McNellis, T.W. (2001). A Humidity-Sensitive Arabidopsis copine mutant Exhibits Precocious Cell Death and Increased Disease Resistance. Plant Cell,13: 2225-2240.

Jefferson, R.A., Kavanagh, T.A. and Bevan, M.W. (1987). GUS fusions: $\beta-$ Glucuronidase as a Sensitive and Versatile Gene Fusion Marker in Higher Plants. EMBO J., 6: 3901-3907.

Jirage, D., Tootle, T.L., Reuber, T.L., Frost, L.N., Feys, B.J., Parker, J.E., Ausubel, F.M. and Glazebrook, J. (1999). Arabidopsis thaliana PAD4 Encodes a Lipase-like Gene that is Important for Salicylic Acid Signaling. Proc. Natl. Acad. Sci. USA, 96: 1358313588.

Jirage, D., Zhou, N., Cooper, B., Clarke, J.D., Dong, X. and Glazebrook, J. (2001). Constitutive Salicylic Acid-Dependent Signaling in cpr1 and cpr6 Mutants Requires PAD4. Plant J., 26: 395-407. 
Johnson, C., Bodena, E. and Arias, J. (2003). Salicylic Acid and NPR1 Induce the Recruitment of trans-Activating TGA Factors to a Defense Gene Promoter in Arabidopsis. Plant Cell, 15: 1846-1858.

Johnson, C., Boden, E., Desai, M., Pascuzzi, P. and Arias, J. (2001a). In Vivo Target Promoter-Binding Activities of a Xenobiotic Stress-Activated TGA Factor. Plant J., 28: $237-243$.

Johnson, C., Glover, G. and Arias, J. (2001b). Regulation of DNA Binding and Transactivation by a Xenobiotic Stress-Activated Plant Transcription Factor. J. Biol. Chem., 276, 172-178.

Jupin, I. and Chua, N.H. (1996). Activation of the CaMV As-1 Cis-element by Salicylic Acid: Differential DNA-Binding of a Factor Related to TGA1a. EMBO J., 15: 56795689 .

Kachroo, P., Shanklin, J., Shah, J., Whittle, E.J. and Klessig, D.F. (2001). A Fatty Acid Desaturase Modulates the Activation of Defense Signaling Pathways in Plants. Proc. Natl. Acad. Sci. USA, 98: 9448-9453.

Kachroo, P., Yoshioka, K., Shah, J., Dooner, H.K. and Klessig, D.F. (2000). Resistance to Turnip Crinkle Virus in Arabidopsis is Regulated by Two Host Genes and is Salicylic Acid Dependent but NPR1, Ethylene, and Jasmonate Independent. Plant Cell, 12: 677-690.

Katagiri, F., Lam, E. and Chua, N.H. (1989). Two Tobacco DNA-Binding Proteins with Homology to the Nuclear Factor CREB. Nature, 340: 727-730.

Katagiri, F., Seipel, K. and Chua, N.H. (1992). Identification of a Novel Dimer Stabilization Region in a Plant bZIP Transcription Activator. Mol. Cell Biol. 12: 4809-4816. 
Kern, R., Malki, A., Holmgren, A. and Richarme, G. (2003). Chaperone Properties of Escherichia coli Thioredoxin and Thioredoxin Reductase. Biochem. J. 371: 965972.

Kim, H.S. and Delaney, T.P. (2002). Overexpression of TGA5, which Encodes a bZIP Transcription Factor that Interacts with NIM1/NPR1, Confers SAR-Independent Resistance in Arabidopsis thaliana to Peronospora parasitica. Plant J., 32: 151-163.

Kinkema, M., Fan, W. and Dong, X. (2000). Nuclear Localization of NPR1 is Required for Activation of $P R$ Gene Expression. Plant Cell, 12: 2339-2350.

Klessig, D.F., Durner, J., Noad, R., Navarre, D.A., Wendehenne, D., Kumar, D., Zhou, J.M., Shah, J., Zhang, S., Kachroo, P., Trifa, Y., Pontier, D., Lam, E. and Silva, H. (2000). Nitric Oxide and Salicylic Acid Signaling in Plant Defense. Proc. Natl. Acad. Sci. USA, 97: 8849-8855.

Koncz, C. and Schell, J. (1986): The Promoter of TL-DNA Gene 5 Controls the Tissue Specific Expression of Chimeric Genes Carried by a Novel Type of Agrobacterium Binary Vector. Mol. Gen. Genet., 204: 383-396.

Kopka, J., Pical, C., Hetherington, A.M. and Muller-Rober, B. (1998). $\mathrm{Ca}^{2+} /$ Phospholipid-Binding (C2) Domain in Multiple Plant Proteins: Novel Components of the Calcium-Sensing Apparatus. Plant Mol. Biol., 36: 627-637.

Krawczyk, S., Thurow, C., Niggeweg, R. and Gatz, C. (2002). Analysis of the Spacing between the Two Palindromes of Activation Sequence-1 with Respect to Binding to Different TGA Factors and Transcriptional Activation Potential. Nucleic. Acids Res., 30: 775-781.

Krawczyk, S. (2003). Functional Analysis of the bZIP Transcription Factor TGA2.1 in Nicotiana tabacum: Identification of Interacting Partners and Characterization of 
Plants with Reduced Amounts of TGA2.1 (in German). Ph.D. thesis, Georg-August University - Goettingen, Germany.

Kulkarni, S., Das, S., Funk, C.D., Murray, D. and Cho, W. (2002). Molecular Basis of the Specific Subcellular Localization of the C2-like Domain of 5-Lipoxygenase. J. Biol. Chem., 277: 13167-13174.

Kumar, D. and Klessig, D.F. (2003). High-Affinity Salicylic Acid-Binding Protein 2 is Required for Plant Innate Immunity and Has Salicylic Acid-Stimulated Lipase Activity. Proc. Natl. Acad. Sci. USA, 100: 16101-16106.

Laemmli, U.K. (1970): Cleavage of Structural Proteins during the Assembly of the Head of Bacteriophage T4. Nature, 227: 680-685.

Lam, E. and Lam, K.P. (1995). Binding Site Requirements and Differential Representation of TGA Factors in Nuclear ASF-1 Activity. Nucl. Acids Res. 23: 3778-3785.

Lam, E., Benfey, P.N., Gilmartin, P.M., Fang, R.X. and Chua, N.H. (1989). Site-Specific Mutations Alter in vitro Factor Binding and Change Promoter Expression Pattern in Transgenic Plants. Proc. Natl. Acad. Sci. USA, 86: 7890-7894.

Lam, E., Kato, N. and Lawton, M. (2001). Programmed Cell Death, Mitochondria and the Plant Hypersensitive Response. Nature, 411: 848-853.

Lamb, C. and Dixon R.A. (1997). The Oxidative Burst in Plant Disease Resistance. Annu. Rev. Plant Physiol. Plant Mol. Biol., 48: 251-275.

Le Gouill, C., Parent, J.L., Rola-Pleszczynski, M. and Stankova, J. (1994). Analysis of Recombinant Plasmids by a Modified Alkaline Lysis Method. Anal. Biochem., 219: 164. 
Lebel, E., Heifetz, P., Thorne, L., Uknes, S., Ryals, J. and Ward, E. (1998). Functional Analysis of Regulatory Sequences Controlling $P R-1$ Gene Expression in Arabidopsis. Plant J., 16: 223-233.

Lee, H., Leon, J. and Raskin, I. (1995). Biosynthesis and Metabolism of Salicylic Acid. Proc. Natl. Acad. Sci. USA, 92: 4076-4079.

Lenk, I. (2001). Analysis of the in Vivo Function of Transcription Factors TGA2.1 and TGA2.2 from Tobacco as Fusions with a Constitutive Activation Domain (in German). Ph.D thesis, Georg-August University - Goettingen, Germany.

Li, J., Brader, G. and Tapio Palva, E. (2004). The WRKY70 Transcription Factor: A Node of Convergence for Jasmonate-Mediated and Salicylate-Mediated Signals in Plant Defense. Plant Cell, 16: 319-331.

Li, X., Zhang, Y.L., Clarke, J.D., Li, Y. and Dong, X.N. (1999). Identification and Cloning of a Negative Regulator of Systemic Acquired Resistance, SNI1, through a Screen for Suppressors of npr1-1. Cell, 98: 329-339.

Liu, X.J. and Lam, E. (1994). Two Binding Sites for the Plant Transcription Factor ASF1 Can Respond co Auxin Treatments in Transgenic Tobacco. J. Biol. Chem., 269: 668-675.

Liu, Y., Jin, H., Yang, K.Y., Kim, C.Y., Baker, B. and Zhang, S. (2003). Interaction between Two Mitogen-Activated Protein Kinases during Tobacco Defense Signaling. Plant J., 34: 149 -160.

Lorrain, S., Vailleau, F., Balague, C. and Roby, D. (2003). Lesion Mimic Mutants: Keys for Deciphering Cell Death and Defense Pathways in Plants? Trends Plant Sci., 8: 263-271.

Luderer, R., and Joosten, M.H. (2001). Avirulence Proteins of Plant Pathogens: Determinants of Victory and Defeat. Mol. Plant Pathol., 2: 355-364. 
Lundberg, M., Johansson, C., Chandra, J., Enoksson, M., Jacobsson, G., Ljung, J., Johansson, M. and Holmgren, A. (2001). Cloning and Expression of a Novel Human Glutaredoxin (Grx2) with Mitochondrial and Nuclear Isoforms. J. Biol. Chem., 276: 26269-26275.

Lundstrom-Ljung J. and Holmgren A. (1995). Glutaredoxin Accelerates GlutathioneDependent Folding of Reduced Ribonuclease a Together with Protein DisulfideIsomerase. J. Biol. Chem., 270: 7822-7828.

Malamy, J., Carr, J.P., Klessig, D.F. and Raskin, I. (1990). Salicylic acid: A Likely Endogenous Signal in the Resistance Response of Tobacco to Viral Infection. Science, 250: 1002-1005.

Maldonado A.M., Doerner, P., Dixon, R.A., Lamb, C.J. and Cameron, R.K. (2002). A Putative Lipid Transfer Protein Involved in Systemic Resistance Signalling in Arabidopsis. Nature, 419:399-403.

Maleck, K., Levine, A., Eulgem, T., Morgan, A., Schmid, J., Lawton, K.A., Dangl, J.L. und Dietrich, R.A. (2000). The Transcriptome of Arabidopsis thaliana during Systemic Acquired Resistance. Nat. Genet., 26: 403-410.

Martin, G.B. (1999). Functional Analysis of Plant Disease Resistance Genes and their Downstream Effectors. Curr. Opnion Plant Sci., 2: 273-279.

Martin, G.B., Bogdanove, A.J. and Sessa, G. (2003). Understanding the Functions of Plant Disease Resistance Proteins. Annu. Rev. Plant Physiol. Plant Mol. Biol., 54:23-61.

Mauch, F., Mauch-Mani, B., Gaille, C., Kull, B., Haas, D. and Reimmann, C. (2001). Manipulation of Salicylate Content in Arabidopsis thaliana by the Expression of an Engineered Bacterial Salicylate Synthase. Plant J., 25: 67-77. 
Mayda, E., Mauch-Mani, B. and Vera, P. (2000). Arabidopsis dth9 Mutation Identifies a Gene Involved in Regulating Disease Susceptibility without Affecting Salicylic AcidDependent Responses. Plant Cell, 12: 2119-2128.

McDowell, J.M. and Woffenden, B.J. (2003). Plant Disease Resistance Genes: Recent Insights and Potential Applications. Trends Biotechnol., 21: 178-183.

Meshi, T., Moda, I., Minami, M., Okanami, M., Iwabuchi, M. (1998). Conserved Ser Residues in the Basic Region of the bZIP-Type Transcription Factor HBP-1a(17): Importance in DNA Binding and Possible Targets for Phosphorylation. Plant Mol. Biol., 36: 125-136.

Métraux, J.P., Signer, H., Ryals, J., Ward, E., Wyss-Benz, M., Gaudin, J., Raschdorf, K., Schmid, E., Blum, W. and Inverardi, B. (1990). Increase in Salicylic Acid at the Onset of Systemic Acquired Resistance in Cucumber. Science, 250: 1004.

Meyer, Y., Verdoucq, L. and Vignols, F. (1999). Plant Thioredoxins and Glutaredoxins: Identity and Putative roles. Trends Plant Sci., 4: 388-394.

Meyerowitz, E.M. (1987) Arabidopsis thaliana. Annu Rev Genet., 21: 93-111.

Minakuchi, K., Yabushita, T., Masumura, T., Ichihara, K. and Tanaka K. (1994). Cloning and Sequence Analysis of a cDNA Encoding Rice Glutaredoxin. FEBS Lett., 337: 157-160.

Mölders, W., Buchala, A. and Métraux, J.P. (1996). Transport of Salicylic Acid in Tobacco Necrosis Virus-Infected Cucumber Plants. Plant Physiol., 112: 787-792.

Morell, S., Follmann, H. and Haberlein, I. (1995). Identification and Localization of the First Glutaredoxin in Leaves of a Higher Plant. FEBS Lett., 369: 149-152.

Mou, Z., Fan, W. and Dong, X. (2003). Inducers of Plant Systemic Acquired Resistance Regulate NPR1 Function through Redox Changes. Cell, 113: 935-944. 
Mullis, K.B. and Faloona, F.A. (1987). Specific Synthesis of DNA in vitro via a Polymerase Catalyzed Chain Reaction. Methods Enzymol., 155: 335-350.

Nalefski, E.A. and Falke, J.J. (1996). The C2 Domain Calcium-Binding Motif: Structural and Functional Diversity. Protein Sci., 5: 2375-90.

Nandi, A., Krothapalli, K., Buseman, C.M., Li, M., Welti, R., Enyedi, A. and Shah, J. (2003b). Arabidopsis sfd Mutants Affect Plastidic Lipid Composition and Suppress Dwarfing, Cell Death, and the Enhanced Disease Resistance Phenotypes Resulting from the Deficiency of a Fatty Acid Desaturase. Plant Cell, 15: 23832398.

Nawrath, C. and Metraux, J.P. (1999). Salicylic Acid Induction-Deficient Mutants of Arabidopsis Express $P R-2$ and $P R-5$ and Accumulate High Levels of Camalexin after Pathogen Inoculation. Plant Cell, 11: 1393-404.

Nawrath, C., Heck, S., Parinthawong, N. and Métraux J.P. (2002). EDS5, an Essential Component of Salicylic Acid-Dependent Signaling for Disease Resistance in Arabidopsis, Is a Member of the MATE Transporter Family. Plant Cell, 14: 275-286.

Neuenschwander, U., Vernooij, B., Friedrich, L., Uknes, S., Kessmann, H. and Ryals, J. (1995). Is Hydrogen Peroxide a Second Messenger of Salicylic Acid in Systemic Acquired Resistance? Plant J., 8: 227-233.

Neuhaus, G., Neuhaus-Url, G., Katagiri, F., Seipel, K. and Chua, N.H. (1994). TissueSpecific Expression of As-1 in Transgenic Tobacco. Plant Cell, 6: 827-834.

Nickolov, K. (2003). Subcellular Localization of Nicotiana tabacum TGA Transcription Factors. PhD thesis, Georg-August University - Goettingen, Germany.

Niggeweg, R., Thurow, C., Kegler, C. and Gatz, C. (2000a). Tobacco Transcription Factor TGA2.2 is the Main Component of As-1-Binding Factor ASF-1 and is 
Involved in Salicylic Acid- and Auxin-Inducible Expression of As-1-Containing Target Promoters. J. Biol. Chem., 275: 19897-19905.

Niggeweg, R., Thurow, C., Weigel, R., Pfitzner, U. and Gatz, C. (2000b). Tobacco TGA Factors Differ with Respect to Interaction with NPR1, Activation Potential and DNABinding Properties. Plant Mol. Biol., 42: 775-788.

Nimchuk, Z., Eulgem, T., Holt, B.F.3rd. and Dangl, J.L. (2003). Recognition and Response in the Plant Immune System. Annu. Rev. Genet., 37: 579-609.

Ohta, M., Matsui, K., Hiratsu, K., Shinshi, H. and Ohme-Takagi, M. (2001). Repression Domains of Class II ERF Transcriptional Repressors Share an Essential Motif for Active Repression. Plant Cell, 13: 1959-1968.

Ordway, J.M., Eberhart, D. and Curran, T. (2003). Cysteine 64 of Ref-1 is not Essential for Redox Regulation of AP-1 DNA binding. Mol. Cell Biol., 23: 4257-4266.

Palatnik JF, Allen E, Wu X, Schommer C, Schwab R, Carrington JC, Weigel D. (2003). Control of Leaf Morphogenesis by MicroRNAs. Nature, 425: 257-263.

Pascuzzi, P., Hamilton, D., Bodily, K. and Arias, J. (1998). Auxin-Induced Stress Potentiates Trans-activation by a Conserved Plant Basic/Leucine-Zipper Factor. J. Biol. Chem., 273: 26631-26637.

Penninckx, I.A., Eggermont, K., Terras, F.R., Thomma, B.P., De Samblanx, G.W., Buchala, A., Métraux, J.P., Manners, J.M. and Broekaert, W.F. (1996). PathogenInduced Systemic Activation of a Plant Defensin Gene in Arabidopsis Follows a Salicylic Acid-Independent Pathway. Plant Cell, 8: 2309-2323.

Penninckx, I,A,, Thomma, B,P., Buchala, A., Métraux, J.P. and Broekaert W.F. (1998). Concomitant Activation of Jasmonate and Ethylene Response Pathways Is Required for Induction of a Plant Defensin Gene in Arabidopsis. Plant Cell, 10: 2103-2114. 
Peterson, M., Brodersen, P., H., N., Andreasson, E., Lindhart, U., Johanssen, B., Nielsen, H.B., Lacy, M., Austin, M.J., Parker, J.E., Sharma, S.B., Klessig, D.F., Martienssen, R., Mattson, O., Jensen, A.B. and Mundy, J. (2000). Arabidopsis MAP Kinase 4 Negatively Regulates Systemic Acquired Resistance. Cell, 103: 11111120.

Picard, D., Salser, S.J. and Yamamoto, K.R. (1988). A Movable and Regulable Inactivation Function within the Steroid Binding Domain of the Glucocorticoid Receptor. Cell, 54: 1073-1080.

Pieterse, C.M.J., van Wees, S.C.M., Ton, J., van Pelt, J.A., and Van Loon, L.C. (2002). Signalling in Rhizobacteria-Induced Systemic Resistance in Arabidopsis thaliana. Plant Biol. 4: 535-544.

Pieterse, C.M.J., van Wees, S.C.M., van Pelt, J.A., Knoester, M., Laan, R., Gerrits, N., Weisbeek, P.J. and van Loon, L.C. (1998). A Novel Signaling Pathway Controlling Induced Systemic Resistance in Arabidopsis. Plant Cell, 10: 1571-1580.

Pontier, D., Miao, Z.H. and Lam, E. (2001). Trans-Dominant Suppression of Plant TGA Factors Reveals their Negative and Positive Roles in Plant Defense Responses. Plant J., 27: 529-238.

Pontier, D., Privat, I., Trifa, Y., Zhou, J.M., Klessig, D.F. and Lam, E. (2002). Differential Regulation of TGA Transcription Factors by Post-Transcriptional Control. Plant J., 32: 641-653.

Qin, X.F., Holuigue, L., Horvath, D.M. und Chua, N.H. (1994). Immediate Early Transcription Activation by Salicylic Acid via the Cauliflower Mosaic Virus as-1 Element. Plant Cell, 6: 863-874.

Qin, C. and Wang, X. (2002). The Arabidopsis Phospholipase D Family. Characterization of a Calcium-Independent and Phosphatidylcholine-Selective PLD 11 with Distinct Regulatory Domains. Plant Physiol. 128: 1057-1068. 
Redman, J., Whitcraft, J., Gulam, H., and Arias, J. (2002). Abiotic and Biotic Stress Differentially Stimulate As-1 Element Activity in Arabidopsis. Plant Cell Rep., 21:180-185.

Rickman C, Davletov B. (2003). Mechanism of Calcium-Independent Synaptotagmin Binding to Target SNAREs. J. Biol. Chem., 278:5501-5504.

Riechmann, J.L., Heard, J., Martin, G., Reuber, L., Jiang, C., Keddie, J., Adam, L., Pineda, O., Ratcliffe, O.J., Samaha, R.R., Creelman, R., Pilgrim, M., Broun, P., Zhang, J.Z., Ghandehari, D., Sherman, B.K. and Yu G. (2000). Arabidopsis Transcription Factors: Genome-Wide Comparative Analysis Among Eukaryotes. Science, 290: 2105-2110.

Rigaut, G., Shevchenko, A., Rutz, B., Wilm, M., Mann, M. and Séraphin, B. (1999). A Generic Purification Method for Protein Complex Characterization and Proteome Exploration. Nat. Biotechnol., 17: 1030-1032.

Rizo, J. and Südhof T.C. (1998). C2-domains, Structure and Function of a Universal $\mathrm{Ca}^{2+}$-Binding Domain. J. Biol. Chem, 273: 15879-15882.

Rogers, E.E. and Ausubel, F.M. (1997). Arabidopsis Enhanced Disease Susceptibility Mutants Exhibit Enhanced Susceptibility to Several Bacterial Pathogens and Alterations in PR-1 Gene Expression. Plant Cell, 9: 305-316.

Ross, A.F. (1961). Systemic Acquired Resistance Induced by Localized Virus Infections in Plants. Virology, 14: 340-358.

Rouhier N., Gelhaye E, Jacquot J.P. (2002a). Exploring the Active Site of Plant Glutaredoxin by Site-Directed Mutagenesis. FEBS Lett., 511: 145-149.

Rouhier, N., Gelhaye, E. and Jacquot, J.P. (2002b). Glutaredoxin-dependent Peroxiredoxin from Poplar. J. Biol. Chem, 277: 13609-13614. 
Rouhier, N., Gelhaye, E., Sautie're, P.E. and Jacquot, J.P. (2002c). Enhancement of Poplar Glutaredoxin Expression by Optimization of the cDNA Sequence. Protein Expr. Purif., 24: 234-241.

Rouhier, N., Vlamis-Gardikas, A., Lillig, C.H., Berndt, C., Schwenn, J.D., Holmgren, A. and Jacquot, J.P. (2003). Characterization of the Redox Properties of Poplar Glutaredoxin. Antioxid. Redox Signal., 5: 15-22.

Rusterucci, C., Montillet, J.L., Agnel, J.P., Battesti, C., Alonso, B., Knoll, A., Bessoule, J.J., Etienne. P., Suty, L., Blein, J.P. and Triantaphylides, C. (1999). Involvement of Lipoxygenase-Dependent Production of Fatty Acid Hydroperoxides in the Development of the Hypersensitive Cell Death induced by Cryptogein on Tobacco Leaves. J. Biol. Chem., 274: 36446-36455.

Ryals, J.A., Neuenschwander, U.H., Willits, M.G., Molina, A., Steiner, H.Y. and Hunt, M.D. (1996). Systemic Acquired Resistance. Plant Cell, 8: 1809-1819.

Ryals, J., Weymann, K., Lawton, K., Friedrich, L., Ellis, D., Steiner, H.Y., Johnson, J., Delaney, T.P., Jesse, T., Vos, P., and Uknes, S. (1997). The Arabidopsis NIM1 Protein Shows Homology to the Mammalian Transcription Factor Inhibitor IKB. Plant Cell, 9: 425-439.

Sanger, F., Nicklen, S. and Coulson, A.R. (1977). DNA Sequencing with ChainTerminating Inhibitors. Proc. Natl. Acad. Sci. USA, 74: 5463-5467.

Schenk, P.M., Kazan, K., Wilson, I., Anderson, J.P., Richmond, T., Somerville, S.C. and Manners, J.M. (2000). Coordinated Plant Defense Responses in Arabidopsis revealed by Microarray Analysis. Proc. Natl. Acad. Sci. USA, 97: 11655-11660.

Schiermeyer, A., Thurow, C. and Gatz, C. (2003). Tobacco bZIP Factor TGA10 is a Novel Member of the TGA Family of Transcription Factors. Plant Mol. Biol., 51: 817-829. 
Serebriiskii, I.G., Khazak, V. and Golemis, E.A. (2001). Redefinition of the Yeast TwoHybrid System in Dialogue with Changing Priorities in Biological Research. Biotechniques, 30: 634-640.

Serino, L., Reimmann, C., Baur, H., Beyeler, M., Visca, P. and Haas, D. (1995). Structural Genes for Salicylate Biosynthesis from Chorismate in Pseudomonas aeruginosa. Mol. Gen. Genet., 249:217-228.

Shah, J. (2003). The Salicylic Acid Loop in Plant Defense. Curr. Opin. Plant Biol., 6:365-371.

Shah, J., Kachroo, P., Nandi, A. and Klessig, D.F. (2001). A Recessive Mutation in the Arabidopsis SS/2 Gene Confers SA- and NPR1-Independent Expression of PR Genes and Resistance against Bacterial and Oomycete Pathogens. Plant J., 25: 563-574.

Shulaev, V., Leon, J. and Raskin, I. (1995). Is Salicylic Acid a Transported Signal of Systemic Acquired Resistance in Tobacco? Plant Cell, 7: 1691-1701.

Siemsen, T. (2002). Identification of of Proteins Interacting with the TGA2 bZIP Transcription Factor Using a Modified Yeast-One Hybrid System. Diploma Thesis, Georg-August University - Goettingen, Germany

Singh, K.B., Foley, R.C. and Onate-Sanchez, L. (2002). Transcription Factors in Plant Defense and Stress Responses. Curr. Opin. Plant Biol., 5: 430-436.

Slaymaker, D.H., Navarre, D.A., Clark, D., del Pozo, O., Martin, G.B. and Klessig, D.F. (2002). The Tobacco Salicylic Acid-Binding Protein 3 (SABP3) is the Chloroplast Carbonic Anhydrase, which Exhibits Antioxidant Activity and Plays a Role in the Hypersensitive Defense. Proc. Natl. Acad. Sci. USA, 99: 11640-11645. 
Stange, C., Ramirez, I., Gomez, I., Jordana, X. and Holuigue, L. (1997). Phosphorylation of Nuclear Proteins Directs Binding to Salicylic Acid-Responsive Elements. Plant J., 11: 1315-1324.

Sticher, L., Mauch-Mani, B. and Métraux, J.P. (1997). Systemic Acquired Resistance. Annu. Rev. Plant Pathol. 35: 235-270.

Strathmann, A., Kuhlmann, M., Heinekamp, T. and Droge-Laser, W. (2002). BZI-1 Specifically Heterodimerises with the Tobacco bZIP Transcription Factors BZI-2, BZI-3/TBZF and BZI-4, and is Functionally Involved in Flower Development. Plant J., 28:397-408.

Studier, F.W. and Moffat, B.A. (1986). Use of Bacteriophage T7 RNA Polymerase to Direct Selective High-Level Expression of Cloned Genes. J. Mol. Biol., 189: 113130.

Subramaniam, R., Desveaux, D., Spickler, C., Michnick, S.W. and Brisson, N. (2001). Direct Visualization of Protein Interactions in Plant Cells. Nat. Biotechnol., 19: 769772.

Szederkenyi, J., Komor, E. and Schobert, C. (1997). Cloning of the cDNA for Glutaredoxin, an Abundant Sieve-Tube Exudate Protein from Ricinus communis L. and Characterisation of the Glutathione-Dependent Thiol-Reduction System in Sieve Tubes. Planta, 202: 349-356.

Takahashi, A., Casais, C., Ichimura, K. and Shirasu, K. (2003). HSP90 Interacts with RAR1 and SGT1 and is Essential for RPS2-Mediated Disease Resistance in Arabidopsis. . Proc. Natl. Acad. Sci. USA, 100: 11777-11782.

Tao, Y., Xie, Z., Chen, W., Glazebrook, J., Chang, H.S., Han, B., Zhu, T., Zou, G. and Katagiri F. (2003). Quantitative Nature of Arabidopsis Responses during Compatible and Incompatible Interactions with the bacterial Pathogen Pseudomonas syringae. Plant Cell, 15:317-330. 
Thurow, C. (2001). Biochemical Purification, Functional Analysis and Identification of Interacting Partners of the SARP Complex from Tobacco, Involved in Salicylic Acid -Inducible Gene Expression (in German). Ph.D. thesis, Georg-August University Goettingen, Germany.

Tirode, F., Malaguti, C., Romero, F., Attar, R., Camonis, J. and Egly, J.M. (1997). A Conditionally Expressed Third Partner Stabilizes or Prevents the Formation of a Transcriptional Activator in a Three-Hybrid System. J. Biol. Chem., 272: 2299522999.

Toby, G.G. and Golemis, E.A. (2001). Using the Yeast Interaction Trap and Other TwoHybrid- Based Approaches to Study Protein-Protein Interactions. Methods, 24, 201-217.

Tokuhisa, J.G., Singh, K., Dennis, E.S., and Peacock, W.J. (1990). A DNA-Binding Protein Factor Recognizes Two Binding Domains within the Octopine Synthase Enhancer Element. Plant Cell, 2: 215-224.

Trubiani, O., Salvolini, E., Staffolani, R., Di Primio, R. and Mazzanti, L. (2003). DMSO Modifies Structural and Functional Properties of RPMI-8402 Cells by Promoting Programmed Cell Death. Int. J. Immunopatholi Pharmacol., 16: 253-259.

Uquillas, C., Letelier, I., Blanco, F., Jordana, X. and Holuigue, L. (2004). NPR1Independent Activation of Immediate Early Salicylic Acid-Responsive Genes in Arabidopsis. Mol. Plant Microbe. Interact., 17: 34-42.

Van Loon, L.C. (1983). The Induction of Pathogenesis-Related Proteins by Pathogens and Specific Chemicals. Neth. J. Plant. Pathol., 89: 265-273

Van Loon, L.C., van Kammen A. 1970. Polyacrylamide Disc Electrophoresis of the Soluble Leaf Proteins from Nicotiana tabacum var. 'Samsun' and 'Samsun NN' II. Changes in Protein Constitution after Infection with Tobacco Mosaic Virus. Virology, 40: 199-211. 
Van Loon, L.C. and Van Strien, E.A. 1999. The Families of Pathogenesis-Related Proteins, their Activities, and Comparative Analysis of PR-1 Type Proteins. Physiol. Mol. Plant Pathol. 55: 85-97.

Van Wees, S.C. and Glazebrook J. (2003). Loss of Non-Host Resistance of Arabidopsis NahG to Pseudomonas syringae pv. phaseolicola is Due to Degradation Products of Salicylic Acid. Plant J., 33: 733-742.

Verberne, M.C., Verpoorte, R., Bol, J.F., Mercado-Blanco, J. and Linthorst, H.J. (2000). Overproduction of Salicylic Acid in Plants by Bacterial Transgenes Enhances Pathogen Resistance. Nat. Biotechnol., 18: 779-783.

Vernooij, B., Friedrich, L., Morse, A., Reist, R., Kolditz-Jawhar, R., Ward, E., Uknes, S., Kessmann, H. and Ryals, J. (1994). Salicylic Acid Is Not the Translocated Signal Responsible for Inducing Systemic Acquired Resistance but Is Required in Signal Transduction. Plant Cell, 6: 959-965.

Vernooij, B., Friedrich, L., Ahl-Goy, P., Staub, T., Kessmann, H. and Ryals, J. (1995). 2,6-Dichloroisonicotinic Acid-Induced Resistance to Pathogens Does Not Require the Accumulation of Salicylic Acid. Mol. Plant Microbe. Interact. 8: 228-234.

Wagner, D., Sablowski, R.W.M. and Meyerowitz, E.M. (1999). Transcriptional Activation of APETALA1 by LEAFY. Science, 285:582-584.

Ward, E.R., Uknes, S.J., Williams, S.C., Dicher, S.S., Wiederhold, D.L., Alexander, D.C., Ahl-Goy, P., Metraux. J.P. and Ryals J.A. (1991). Coordinate Gene Activity in Response to Agents that Induce Systemic Acquired Resistance. Plant Cell, 3: 1085-1094.

Weigel, R.R., Bäuscher, C., Pfitzner, A.J.P. and Pfitzner, U.M. (2001). NIMIN-1, NIMIN2 and NIMIN-3, Members of a Novel Family of Proteins from Arabidopsis that Interact with NPR1/NIM1, a Key Regulator of Systemic Acquired Resistance in plants. Plant Mol. Biol., 46: 143-160. 
Wesley, S.V., Helliwell, C.A., Smith, N.A., Wang, M.B., Rouse, D.T., Liu, Q., Gooding, P.S., Singh, S.P., Abbott, D., Stoutjesdijk, P.A., Robinson, S.P., Gleave, A.P., Green, A.G. and Waterhouse, P.M. (2001). Construct Design for Efficient, Effective and High-Throughput Gene Silencing in Plants. Plant J., 27:581-590.

Weymann, K., Hunt, M., Uknes, S., Neuenschwander, U., Lawton, K., Steiner, H.Y. and Ryals, J. (1995). Suppression and Restoration of Lesion Formation in Arabidopsis Isd Mutants. Plant Cell, 7: 2013-2022.

Whalen, M.C., Innes, R.W., Bent, A.F. and Staskawicz, B.J. (1991). Identification of Pseudomonas syringae Pathogens of Arabidopsis and a Bacterial Locus Determining Avirulence on both Arabidopsis and Soybean. Plant Cell, 3: 49-59.

White, R.F. (1979). Acetylsalicylic Acid (aspirin) Induces Resistance to Tobacco Mosaic Virus in Tobacco. Virology, 99: 410-412.

Wildermuth, M.C., Dewdney, J., Wu, G. and Ausubel, F.M. (2001). Ischorismate Synthase is Required to Synthesize Salicylic Acid for Plant Defense. Nature, 414: 562-565.

Xia, Y., Suzuki, H., Borevitz, J., Blount, J., Guo, Z., Patel, K., Dixon, R.A. and Lamb, C. (2004). An Extracellular Aspartic Protease Functions in Arabidopsis Disease Resistance Signaling. EMBO J., 23: 980-988.

Xu, Y., Chang, P.F., Liu, D., Narasimhan, M.L., Raghothama, K.G., Hasegawa, P.M. and Bressan, R.A. (1994). Plant Defense Genes are Synergically Induced by Ethylene and Methyl Jasmonate. Plant Cell, 6: 1077-1085.

Yoshioka, K., Kachroo, P., Tsui, F., Sharma, S.B., Shah, J. and Klessig, D.F. (2001). Environmentally Sensitive, SA-Dependent Defense Responses in the cpr22 Mutant of Arabidopsis. Plant J., 26: 447-459. 
Yu, D., Chen, C., Chen, Z. (2001). Evidence for an Important Role of WRKY DNA Binding Proteins in the Regulation of NPR1 Gene Expression. Plant Cell, 13: 15271540.

Yu, I.C., Parker, J. and Bent, A.F. (1998). Gene-for-Gene Disease Resistance without the Hypersensitive Response in Arabidopsis dnd1 mutant. Proc. Natl. Acad. Sci. USA, 95: 7819-7824.

Yu, Y., Yussa, M., Song, J., Hirsch, J. and Pick, L. (1999). A Double Interaction Screen Identifies Positive and Negative ftz Gene Regulators and ftz-Interacting Proteins. Mech. Dev. 83: 95-105.

Zhang, R., He, X., Liu, W., Lu, M., Hsieh, J.T. and Min, W. (2003a). AIP1 Mediates TNF-Alpha-Induced ASK1 Activation by Facilitating Dissociation of ASK1 from its Inhibitor 14-3-3. J. Clin. Invest., 111: 1933-1943.

Zhang, Y., Tessaro, M.J., Lassner, M. and Li, X. (2003b). Knockout Analysis of Arabidopsis Transcription Factors TGA2, TGA5, and TGA6 Reveals their Redundant and Essential Roles in Systemic Acquired Resistance. Plant Cell, 15: 2647-2653.

Zhang, S.Q. und Klessig, D.F. (1998): The Tobacco Wounding-Activated MitogenActivated Protein Kinase is Encoded by SIPK. Proc. Natl. Acad. Sci. USA, 95, 7225-7230.

Zhang, S.Q. and Klessig, D.F. (2001). MAPK Cascades in Plant Defense Signaling. Trends Plant Sci., 6: 520-527.

Zhang, B., Chen, W., Foley, R.C., Buttner, M. and Singh, K.B. (1995). Interactions between Distinct Types of DNA Binding Proteins Enhance Binding to Ocs Element Promoter Sequences. Plant Cell, 7: 2241-2252. 
Zhang, Y.L., Fan, W.H., Kinkema, M., Li, X. and Dong, X.N. (1999). Interaction of NPR1 with Basic Leucine Zipper Protein Transcription Factors that Bind Sequences Required for Salicylic Acid Induction of the PR-1 Gene. Proc. Natl. Acad. Sci. USA, 96: 6523-6528.

Zheng, M., Aslund, F. and Storz, G. (1998). Activation of the OxyR Transcription Factor by Reversible Disulfide Bond Formation. Science, 279: 1718-1721.

Zhou, N., Tootle T.L., Tsui, F., Klessig, D.F. and Glazebrook, J. (1998). PAD4 Functions Upstream from Salicylic Acid to Control Defense Responses in Arabidopsis. Plant Cell, 10: 1021-1030

Zhou, J.M., Trifa, Y., Silva, H., Pontier, D., Lam, E., Shah, J. and Klessig, D.F. (2000). NPR1 Differentially Interacts with Members of the TGA/OBF Family of Transcription Factors that Bind an Element of the PR-1 Gene Required for Induction by Salicylic Acid. Mol. Plant-Microbe Interact., 13: 191-202.

Zourelidou, M., de Torres-Zabala, M., Smith, C. and Bevan, M.W. (2002) Storekeeper Defines a New Class of Plant-Specific DNA-Binding Proteins and is a Putative Regulator of Patatin Expression. Plant J., 30: 489-497. 


\section{$9 \quad$ Appendix}

\subsection{Sequences}

\subsubsection{Arabidopsis Isolated cDNA inserts}

\subsubsection{1 pGAD10/At4g00270}

Rest sequence: pGAD10

$\begin{array}{lllllllllllllllllllllllllllll}\text { I } & S & R & G & S & E & F & A & A & A & S & T & \text { L } & G & \text { N } & \text { H } & \text { C } & \text { S } & A & C & A & \text { L } & E & S & A & S\end{array}$ ADH1-Promoter-GAL4ADAGATCTCTCGAGGATCCGAATTCGCGGCCGCGTCGACCTTAGGGAATCACTGCTCTGCATGCGCCCTAGAATCAGCA BgIII ECORI SalI

$S \quad I \quad K \quad Q \quad A \quad I \quad S \quad M \quad---\cdots-->$ *

AGTCTAAAGCAAGCAATAAGCATG-At1g00248-TGAAACCAATATGCCCTTGTAGCATTTGGTGTTGTTTAGGTTCTTAGTAAGTCATAAGCTCT AGTCTGTTCAGTGTATTTATCTTTGGATCCTGTCTTTCTTCTACTTGGGCAAGTGTTTGTAAGATATTCCACTTTTTACTCAAGTATCCACAAGAGC CNATGTAGTAGAGTGGCTTGTGCAAGAGTCTAGAGTCTAGGGTTAATAATGTGCTTTAAGGCATGCTTGTGTGTGTGCCTAAGAGTGTAGTGAAGTA GTATAAGTAAGAGTGTGTGTGTGTCTTGTAATATTATCNCACAGATATTAACAATGTAGAAGATCTAAAAAAAAAAAAAAAAAAAAAAGTCGACGCG GCCGCGAATTCAGATCT

ECORI BgIII

\subsubsection{2 pGAD10/At1g28480}

Rest sequence: pGAD10

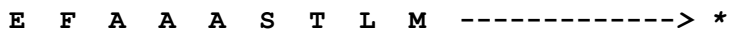

ADH1-Promoter-GAL4AD-AGATCTCTCGAGGATCCGAATTCGCGGCCGGTCGACCTTAATG-At1g28480 CDS-TGATTGTAAATTAATAA BgIII $\quad \overline{E C O R I}$

TTTAAAATTATTTTTTTTCTTTTAATTAAGAATCTTGATTGGTAATTGTTGTTTACGGTTTATAATTGAATCGTTTCATATATATGTATATAAAGA AATAAATAAAAGAAAAGTCTCAAGTTAAAAAAAAAAAAAAAAAAAAAAAAAGTCGACGCGGCCGCGAATTCAGATCT

\subsubsection{3 pGAD10/At1g50570}

Rest sequence: pGAD10 ADH1-Promoter-GAL 4AD-AGATCTCTCGAGGATCCGAATTCGCGGCCGCGTCGACTTTTTTTTTTTTTTTTTTTTTTCATTATGAAACTTTAGT

ACTAAATTGGAAAAGTTGCAGATAACAAGAAAAGCTAANGGCTTCAAAGGAAGATAGTTACACATTTTAGATAGTGTCTACTTTTAACTTATTACAC TTTCACTACATGCTCGCTACTTCTGATGCCGAAACTTGGAGATGATTTCTGAGCTTCTCA-At1g50570 partial CDS-ATCGTCGACGCGGC

CGCGAATTCAGATCT

*

ECORI BgIII

\subsubsection{4 pGAD10/At5g55530}

Rest sequence: pGAD10

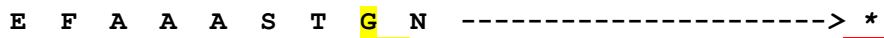

ADH1-Promoter-GAL4AD-AGATCTCTCGAGGATCCGAATTCGCGGCCGCGTCGACCGGAAAC-At1g55530 partial CDS-TGAGCATCT BgIII ECORI SalI

TCTTTTACCAAGTTCAGAGAAAGAACGCAGGTCACCCTTAGACTTTTCTAATGAAGAAAGACTAATCCTAATGATGTAATTTTATAATGTACTATTT CATGTTGTATCTCCCATCTGGTCAGCTTGATGCTTTAGTTGATGTGAGTTATTATTACGTATCACTAGCCTTTACTCTATTAGAACTATGTACGCAT TATATGAACTTCTGCTGCCTAATCATGTTTGTATTTTCTGAGTTACTGCGTTTTACATCCACAAGAATCTTTAAAGCATAGTGATAAATGCTTAGAT TGCAAAAAAAAAAAAAAAAAAGTCGACGCGGCCGCGAATTCAGATCT 


\subsubsection{At1g28480 and TGA2.2 mutants}

\subsubsection{GDM}

$\begin{array}{lllllllllllllllllllllllllllllllllll}M & Q & G & T & I & S & C & A & R & N & Y & N & M & T & T & T & V & G & E & S & L & R & P & L & S & L & K & T & Q & G & N & G\end{array}$ ATGCAAGGAACGATTTCTTGTGCAAGAAATTATAACATGACGACAACCGTCGGGGAATCTCTGCGGCCGCTATCGCTTAAAACGCAGGGAAACGGC

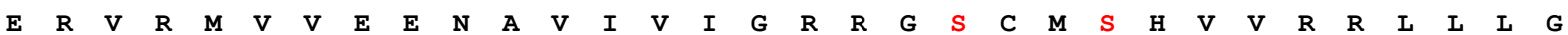
GAGAGAGTTCGGATGGTGGTGGAGGAGAACGCGGTGATTGTGATTGGACGGAGAGGATCTTGCATGTCTCATGTGGTGAGGAGGCTGCTTCTTGGA $\begin{array}{llllllllllllllllllllllllllllllllllll}\text { L } & G & \text { V } & \text { N } & \text { P } & \text { A } & \text { V } & \text { L } & \text { E } & \text { I } & \text { D } & \text { E } & \text { E } & \text { R } & \text { E } & \text { D } & \text { E } & \text { V } & \text { L } & \text { S } & \text { E } & \text { L } & \text { E } & \text { N } & \text { I } & G & \text { V } & Q & G & G & G & G\end{array}$ CTTGGAGTGAATCCGGCGGTCCTTGAGATTGATGAGGAGAGGGAAGATGAAGTTTTGAGTGAGTTGGAGAATATTGGAGTTCAAGGCGGCGGAGGT $\begin{array}{llllllllllllllllllllllllllllllllllll}T & \text { V } & \text { K } & \text { L } & \text { P } & \text { A } & \text { V } & \text { Y } & \text { V } & \text { G } & G & \text { R } & \text { L } & \text { F } & G & G & \text { L } & \text { D } & \text { R } & \text { V } & \text { M } & \text { A } & \text { T } & \text { H } & \text { I } & \text { S } & G & E & \text { L } & \text { V } & \text { P } & \text { I }\end{array}$ ACGGTGAAGTTACCGGCGGTTTATGTAGGAGGGAGGTTGTTTGGAGGGTTAGATAGGGTTATGGCTACTCATATCTCCGGTGAGTTAGTTCCAATT

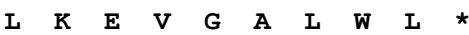

CTTAAGGAAGTTGGGGCTCTGTGGTTGTGA

\subsubsection{GSM}

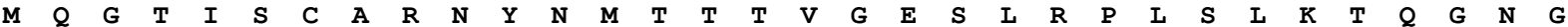
ATGCAAGGAACGATTTCTTGTGCAAGAAATTATAACATGACGACAACCGTCGGGGAATCTCTGCGGCCGCTATCGCTTAAAACGCAGGGAAACGGC

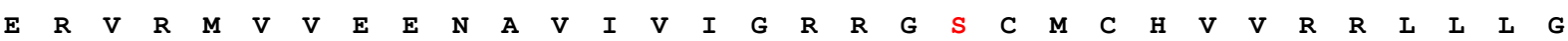
GAGAGAGTTCGGATGGTGGTGGAGGAGAACGCGGTGATTGTGATTGGACGGAGAGGATCTTGCATGTGTCATGTGGTGAGGAGGCTGCTTCTTGGA

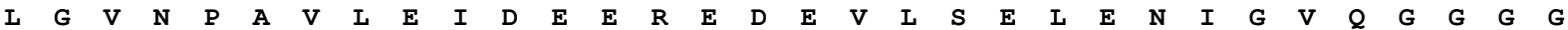
CTTGGAGTGAATCCGGCGGTCCTTGAGATTGATGAGGAGAGGGAAGATGAAGTTTTGAGTGAGTTGGAGAATATTGGAGTTCAAGGCGGCGGAGGT

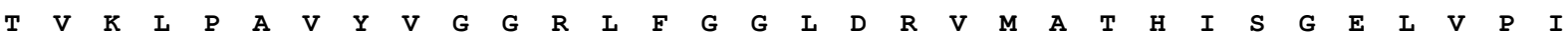
ACGGTGAAGTTACCGGCGGTTATGTAGGAGGGAGGTTGTTTGGAGGGTTAGATAGGGTTATGGCTACTCATATCTCCGGTGAGTTAGTTCCAATT

I $\quad K \quad E \quad V \quad G \quad A \quad I \quad W \quad I \quad$ *

CTTAAGGAAGTTGGGGCTCTGTGGTTGTGA

\subsubsection{TGA2.2 $2^{\text {Cys } 181 \text { Ser }}$}

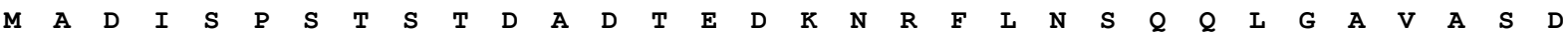
ATGGCTGATATCAGTCCTAGTACATCAACAGATGCCGATACGGAAGATAAGAACAGGTTCCTAAATTCTCAACAACTGGGTGCGGTAGCTTCTGAT

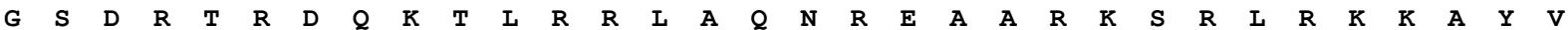
GGAAGTGACAGGACAAGAGATCAGAAGACACTTCGTAGACTTGCCCAAAATCGTGAAGCAGCTCGAAAAAGTCGTCTAAGGAAAAAGGCATATGTT

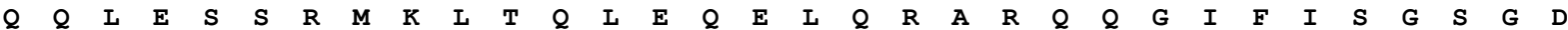
CAACAGTTAGAGAGCAGCCGGATGAAGCTGACACAACTAGAGCAGGAACTTCAACGAGCTCGACAACAGGGCATATTTATTTCAGGTTCAGGAGAT

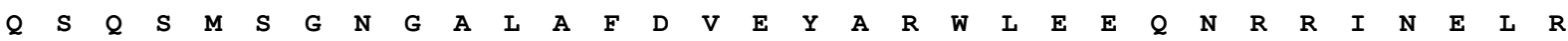
CAATCACAGTCGATGAGCGGAAATGGAGCTTTGGCATTTGATGTAGAATATGCCCGGTGGTTGGAGGAGCAGAACCGACGAATTAATGAGCTAAGG

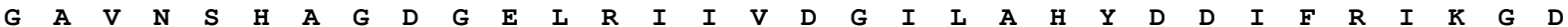
GGAGCTGTAAATTCTCATGCTGGTGATGGTGAACTTCGCATAATTGTCGACGGTATCTTAGCACACTATGATGACATATTCAGGATAAAAGGGGAT

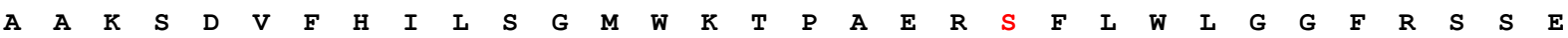
GCTGCAAAGTCCGACGTTTTTCACATATTGTCGGGCATGTGGAAAACTCCAGCAGAGAGATCCTTCTTGTGGCTTGGTGGATTCCGTTCGTCTGAA

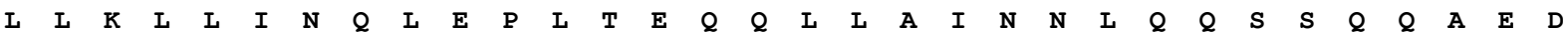
СTССTCAAGCTCCTCATTAACCAGTTGGAGCCTTTAACCGAACAACAATTATTGGCAATCAACAACTTGCAACAGTCATCCCAACAGGCTGAAGAT $\begin{array}{lllllllllllllllllllllllllllllllllllllllll}A & I & S & O & G & M & E & A & I & O & O & S & I & A & E & T & I & A & G & S & I & G & P & S & S & S & S & G & N & V & A & N\end{array}$ GCTTTATCCCAAGGAATGGAGGCACTGCAGCAGTCTTTGGCTGAGACTCTGGCGGGGTCCCTTGGACCTTCAAGTTCCTCAGGGAATGTTGCCAAT

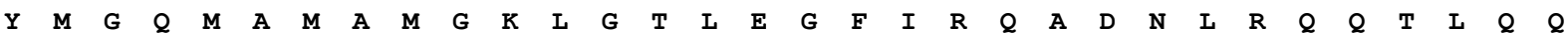
TATATGGGTCAAATGGCCATGGCAATGGGGAAGCTCGGAACTCTCGAGGGCTTCATACGACAGGCTGATAACCTTCGGCAACAAACATTGCAGCAA

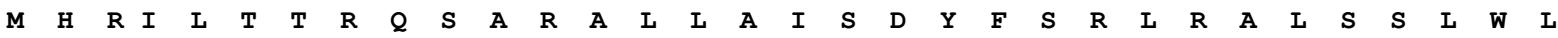
ATGCATCGTATATTGACAACTCGCCAATCAGCTCGTGCTCTTCTTGCGATCAGTGATTATTTCTCTCGGCTTCGAGCACTGAGCTCTCTCTGGCTT

A $\quad R \quad P \quad R \quad E \quad$ *

GCTCGCCCCCGGGAATAA 


\subsection{List of Figures}

Figure 2.1. A classic HR from tobacco in response to tobacco music virus infection (Lam et al., 2001).....4

Figure 2.2. Proposed SA biosynthetic pathways in plants (Shah 2003) . .........................................

Figure 2.3. Nuclear localization of NPR1-GFP in response to INA induction (Kinkema et al., 2000) ........15

Figure 2.4. Three-dimensional structure of the bZIP domain bound to DNA (Jakoby et al., 2002)..........19

Figure 2.5. Sequence of as-1 element from the CaMV promoter. .....................................................19

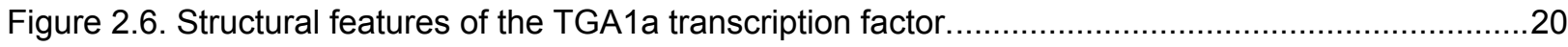

Figure 2.7. Model of PR-1 transcriptional regulation (Durrant and Dong 2004)..................................26

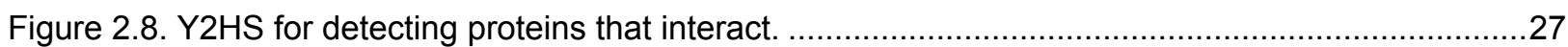

Figure 5.1. Schematic diagram of site directed mutagenesis by overlap extension .............................61

Figure 6.1. Strategy for the isolation of TGA2.2-interacting proteins by selection in yeast......................83

Figure 6.2. M1HYS assays of TGA2.2 and TGA2.2-VP16 binding to the as-1 elements in YRWH2 .......86

Figure 6.3. M1HYS assays of interactions between NPR1 and TGA2.2 proteins. .................................87

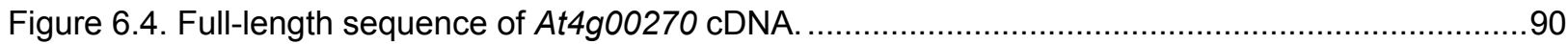

Figure 6.5. Y2HS assays of interactions between GAL4AD-At4g00270 and TGA proteins...................92

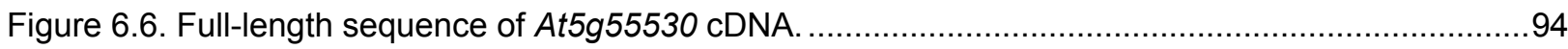

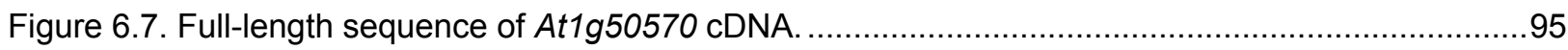

Figure 6.8. Comparison of deduced amino acid sequences of the At1g50570 and At5g55530 proteins. .96

Figure 6.9. Y2HS assays of interactions between At1g50570 and TGA proteins.................................97

Figure 6.10. Y2HS assays of interactions between At1g50570 P and TGA proteins. ...........................99

Figure 6.11. Function of At1g50570 as transcription activator in yeast. ............................................100

Figure 6.12. SDS-PAGE analysis of purified 6x His-TGA2.2 and GST-At1g50570 proteins.................101

Figure 6.13. Pull-down assay of GST-At1g50570 binding to 6x His-TGA2.2 protein. .........................101

Figure 6.14. Far western analysis of 6 X His-TGA2.2 protein binding to GST-At1g50570 ..................102

Figure 6.15. EMSA analysis of At1g50570-TGA2.2 interaction. .................................................103

Figure 6.16. Detection of At1g50570 mRNA in different Arabidopsis tissues by RT-PCR. ..................104

Figure 6.17. RNA gel blots analysis of At1g50570 gene expression after SA or pathogen treatments...105

Figure 6.18. Subcellular localization of At1g50570-GFP protein. ..................................................106

Figure 6.19. Transactivation assay of At1g50570 in BY-2 protoplasts. ..........................................107

Figure 6.20. Transactivation assay of NLS-At1g50570-GFP in BY-2 protoplasts. .............................109

Figure 6.21. Analysis of At1g50570 gene expression in different At1g50570 antisense lines...............111

Figure 6.22. RNA gel blots analysis of $P R-1$ gene expression in At1g50570 antisense line \#4 ............111

Figure 6.23. Analysis of At1g50570 overexpression lines...........................................................113

Figure 6.24. RNA gel blots analysis of $P R-1$ gene expression in At1g50570 overexpression line \#3.....114

Figure 6.25. Histochemical staining of GUS activities in At1g50570 overexpression line \#3................115 


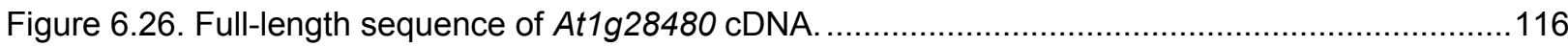

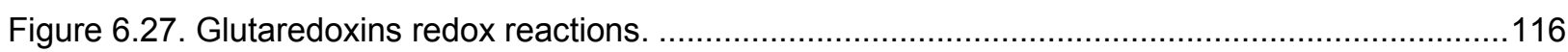

Figure 6.28. Phylogeny of the Arabidopsis glutaredoxin family. At1g28480 is shown in red.................117

Figure 6.29. Y2HS assays of interactions between At1g28480 and TGA proteins.............................118

Figure 6.30. Y2HS assays of interactions between At1g28480 and TGA proteins.............................119

Figure 6.31. TGA2.2 and At1g28480 mutants used in this study...................................................121

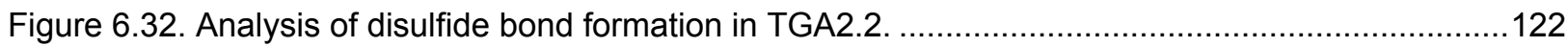

Figure 6.33. Interaction of TGA2.2 and At1g28480 in YRWZ2 yeast strain under oxidative stress. .......124

Figure 6.34. Y2HS assays of interactions between At1g28480 and TGA2.2 proteins........................126

Figure 6.35. At1g28480 enhances indirectly the in vitro binding of TGA2.2 to as-1 element by increasing

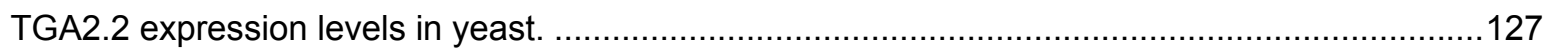

Figure 6.36. At1g28480 interacts with NPR1 via TGA2.2 in HF7c yeast strain. ...............................129

Figure 6.37. Transactivation assay of At1g28480 in BY-2 protoplasts. ..........................................130

Figure 6.38. At1g28480 interacts with TGA2.2 in BY-2 protoplasts...............................................132

Figure 6.39. Subcellular localization of At1g50570-GFP protein. .................................................133

Figure 6.40. Detection of At1g28480 mRNA in different Arabidopsis tissues by RT-PCR. ..................133

Figure 6.41. RNA gel blots analysis of At1g28480 gene expression after SA or pathogen treatments...134

Figure 6.42. Analysis of At1g28480 gene expression in different At1g28480 antisense lines................135

Figure 6.43. RNA gel blots analysis of $P R-1$ gene expression in At1g28480 antisense lines...............136

Figure 6.44. Analysis of At1g50570 overexpression lines........................................................137

Figure 6.45. RNA gel blots analysis of PR-1 and GST6 expression in At1g28480 overexpressor lines 139

Figure 6.46. Histochemical staining of GUS activities in At1g28480 overexpression line \#3................139

\subsection{List of Tables}

Table 2.1. Types of plant and pathogen genetic interactions in the gene for gene resistance.................. 3

Table 6.1. General characteristics of positive cDNA clones isolated in this work...................................88

Table 6.2. Identity of positive cDNA clones isolated in this work. ...................................................... 89

Table 6.3. Interaction of TGA2.2 and At1g28480 mutants in HF7c yeast strain................................123

Table 6.4. Interaction of TGA1, At1g28480 and NPR1 in HF7c yeast strain. ....................................129 


\subsection{Acknowledgments}

First and foremost, I am greatly indebted to PROF. DR. C. GATZ, my Ph.D. advisor, who gave me an opportunity to learn and practice science in her lab. Her endless enthusiasm for experiments and to research has always been inspirational. There was never a time when she did not have time for me nor was I left short on resources. Besides all these, the fact that she believed in me gave me the strength I needed during difficult times.

Dr. R. Weigel, I sincerely thank you for your assistance in directing my research and also for your exceptional advice on several occasions. Appreciation is also extended to Dr. G. Kriete, Dr. G. Lyß, Dr. C. Thurow and R. Scholz, for your valuable advices and suggestions during my Ph.D. study.

One of the greatest experiences of any graduate study is enjoying the lab "atmosphere". I was happy to have incredible lab-mates who made my stay a thoroughly enjoyable one, thank you very much for all the great things. I am also grateful to my colleagues in lab 338: Andreas, Anna, Ivan, Guido and Thomas.

My special thanks and gratitude go to the German Academic Exchange Service (Deutscher Akademischer Austausch Dienst - DAAD) for the financial support.

Finally, I would like to thank those who mean a lot to me personally. My wonderful parents whose sacrifice and unconditional love through all these years have helped me achieve one of my dreams. My brothers, sisters and family, thank you for all the support and encouragement. My best friend, A. Al-Ammouri, you was always there when I needed, thank you. 


\subsection{Curriculum vitae}

Name:

Place and date of birth:

Marital status:

Nationality:

Address:

E-mail

Education:

School

Elementary and Preparatory

Secondary

University

B.Sc.

M.Sc.

Ph.D
Ayed Mrief Ayed Al Abdallat

Amman, December $1^{\text {st }}, 1974$

Single

Jordanian

Untere Karspüle 2,

D-37073 Göttingen,

Germany,

amalabdallat@hotmail.com

(1980-1992)

North Marka (1980-1989).

Al-Hussein collage for secondary education (1990-1992).

General secondary education certificate/ scientific stream Average: $85.5 \%$, rating: very good.

(1993-2004)

University of Jordan, Amman, Jordan (1993-1997).

B.Sc. degree in plant production.

Ranked the first: Average: 3.64 out of 4, rating: very good.

University of Jordan, Amman, Jordan (1997-1999).

M.Sc. degree in Horticulture and plant protection.

Ranked the first: Average: 3.94 out of 4, rating: Excellent.

George August University, Göttingen, Germany (2000-2004).

Present Ph.D. study: Isolation and Characterization of Proteins Interacting with Tobacco Transcription Factor TGA2.2. 